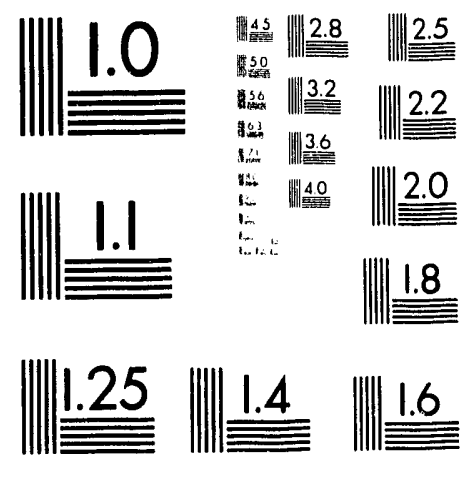



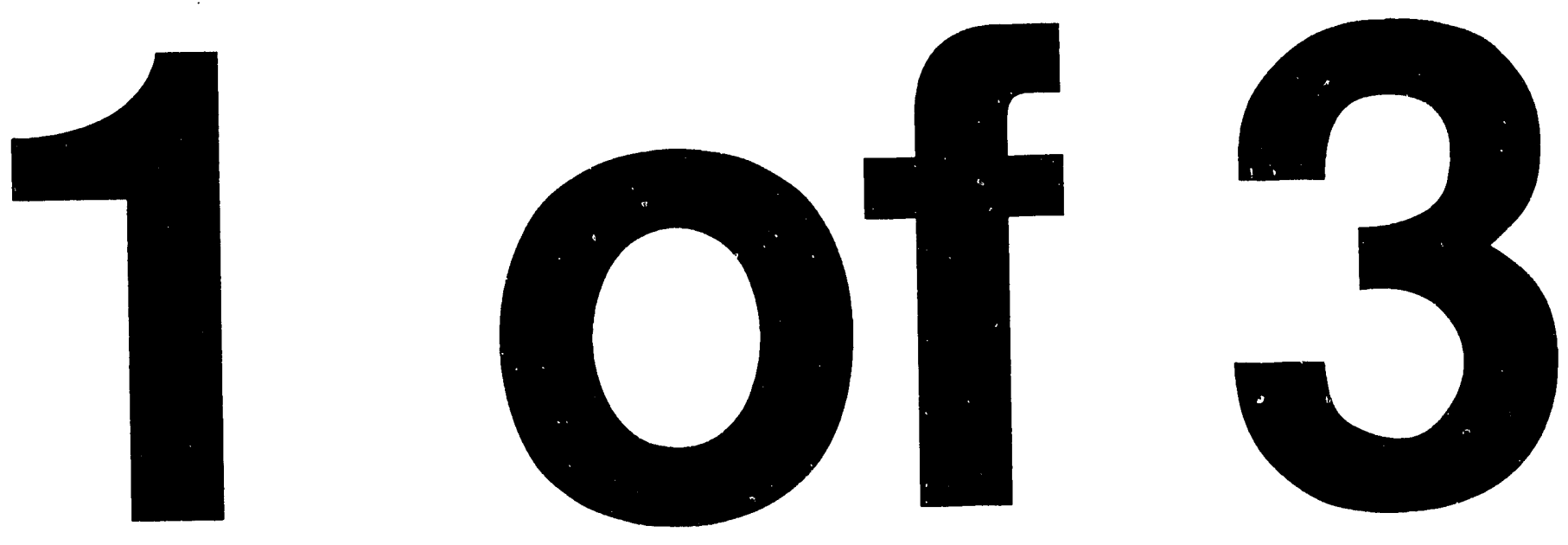
SAND93-0827

Unlimited Release

Printed September 1993

\title{
Global Positioning System Receiver Evaluation Results
}

\author{
Raymond H. Byrne \\ Advanced Vehicle Development Department \\ Sandia National Laboratories \\ Albuquerque, NM 87185, U.S.A.
}

\begin{abstract}
A Sandia project currently uses an outdated Magnavox 6400 Global Positioning System (GPS) receiver as the core of its navigation system. The goal of this study was to analyze the performance of the current GPS receiver compared to newer, less expensive models and to make recommendations on how to improve the performance of the overall navigation system. This paper discusses the test methodology used to experimentally analyze the performance of different GPS receivers, the test results, and recommendations on how an upgrade should proceed. Appendices contain detailed information regarding the raw data, test hardware, and test software.
\end{abstract}

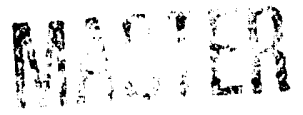




\section{ACKNOWLEDGMENTS}

The author wishes to recognize the technical reviews of this report by Billy Caskey (9616), Kevin Malone (9615), and J. Bryan Pletta (9616) of Sandia National Laboratories. The author also wishes to recognize the efforts of Molly Minahan (editing), Leona C. Tartaglia and Sandra Winter (word processing), and Hawaii Olmstead (illustration), Tech Reps. Inc., during the production of this report. 


\section{PREFACE}

The intent of this study was to compare the performance of a particular two-channel, sequencing global positioning system (GPS) receiver to that of the newer five- and six-channel parallel receivers. The parallel channel receivers used in this study were selected based upon availability, cost, size, and receiver specifications. Unfortunately, due to budget and time constraints, the entire spectrum of parallel channel receivers could not be included in this study. Also, a variety of comparable GPS receivers have been introduced since this study was begun. The appropriate choice of a receiver is dictated, of course, by the application. 


\section{CONTENTS}

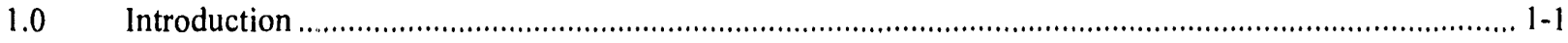

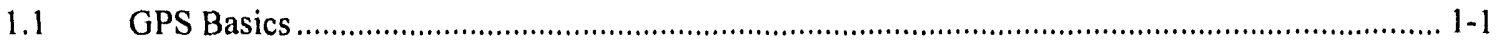

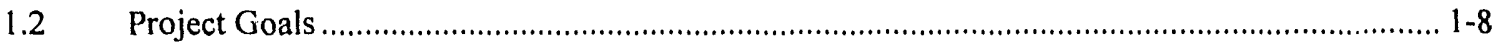

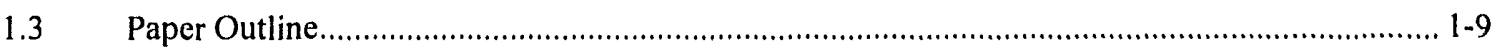

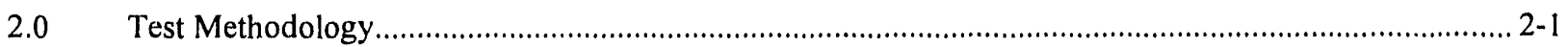

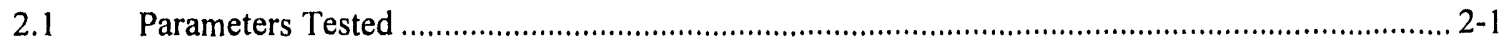

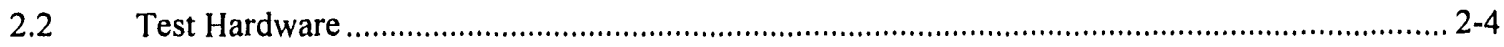

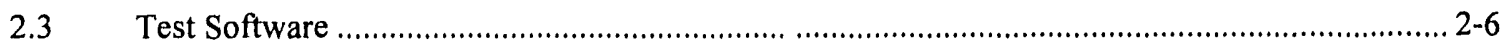

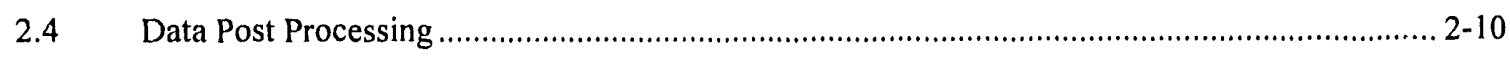

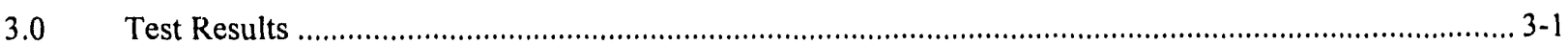

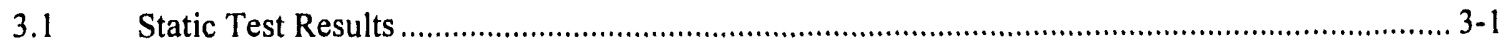

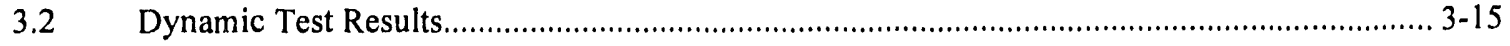

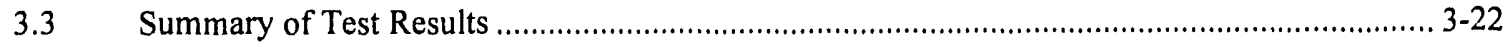

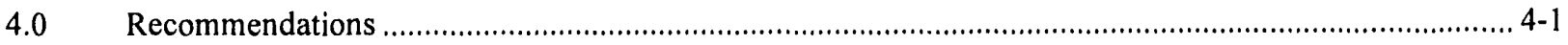

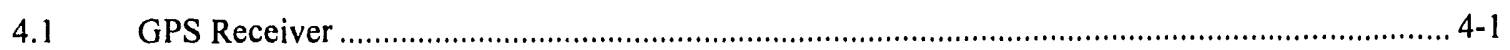

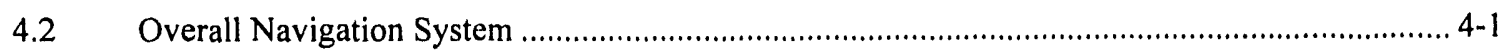

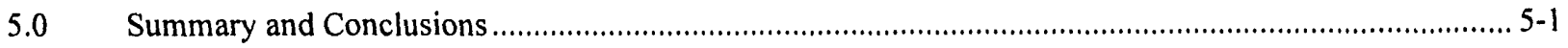

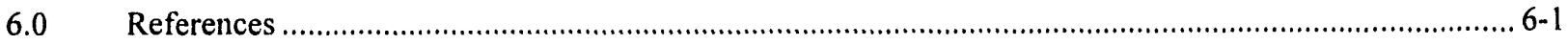

Appendix A: Test Fixture Hardware - Cable Pinouts ............................................................................... A-1

Appendix B.1: Serial Data Formats - Magellan OEM Module ……............................................................. B. $1-1$

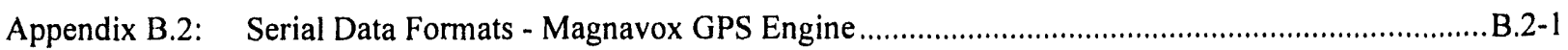

Appendix B.3: Serial Data Formats - Rockwell NavCore V ……..................................................................3.1

Appendix B.4: Serial Data Formats - Magnavox 6400 ….............................................................................

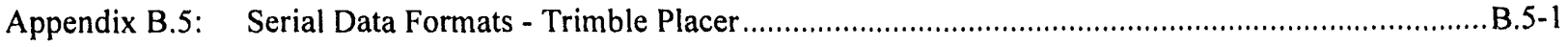

Appendix C.1: Software Listing - GPS Conversion Program …............................................................... $1-1$

Appendix C.2: Software Listing - GPS Data Acquisition Program ........................................................... $2-1$

Appendix C.3: Software Listing - ASCII to Binary Conversion Program ……….............................................. $3-1$

Appendix C.4: Software Listing - Description of Ziatech Software Routines ..................................................4-1

Appendix D.1: GPS Data - Maps Made During Dynamic Testing .......................................................... D. $1-1$

Appendix D.2: GPS Data - Static Test Navigation Mode as a Function of Time .......................................... D.2-1

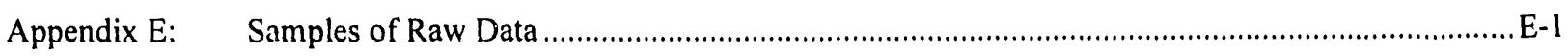

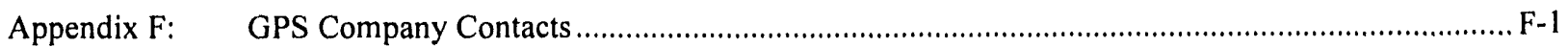




\section{Figures}

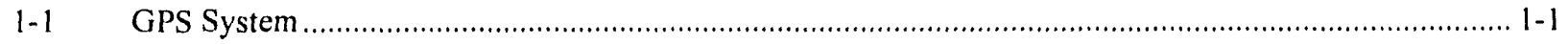

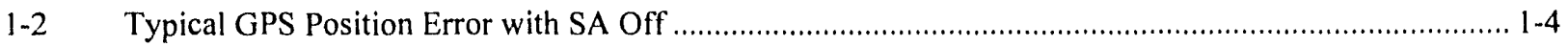

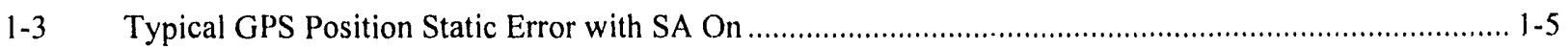

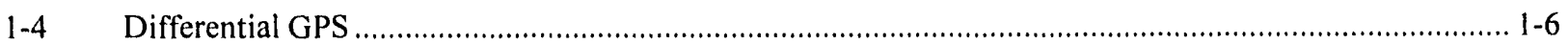

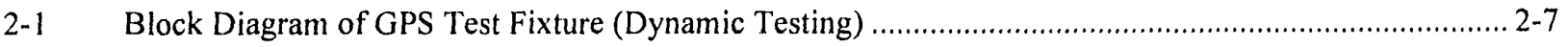

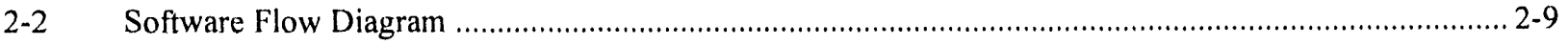

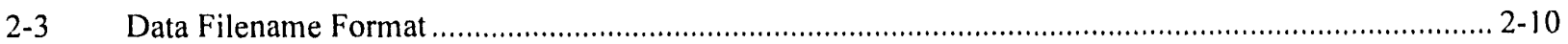

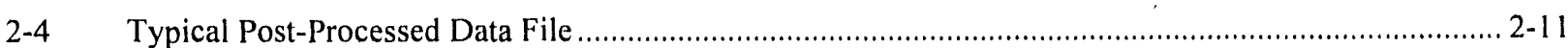

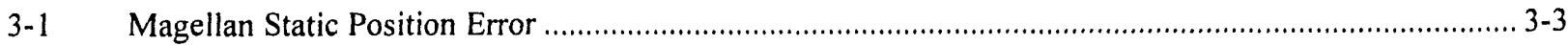

3-2 Magnavox GPS Engine Static Position Error .................................................................................. 3-4

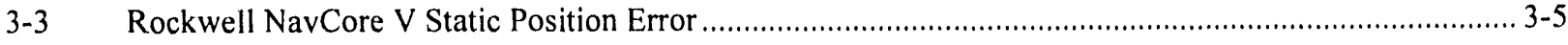

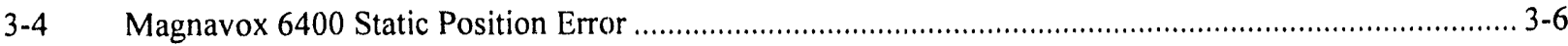

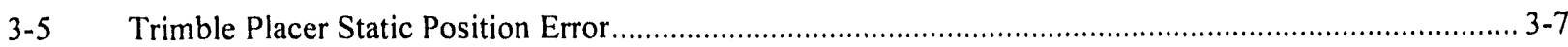

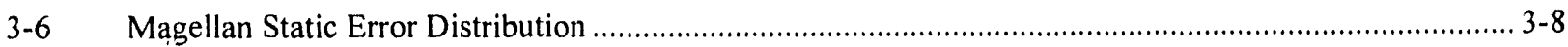

3-7 Magnavox GPS Engine Static Error Distribution............................................................................... 3-9

3-8 Rockwell NavCore V Static Error Distribution .......................................................................... 3-10

3-9 Magnavox 6400 Static Error Distribution ................................................................................ 3-11

3-10 Trimble Placer Static Error Distribution ...................................................................................... 3-12

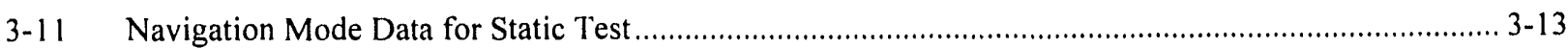

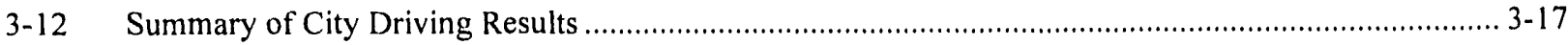

3-13 Summary of Mountain Driving Results........................................................................................ 3-18

3-14 Summary of Canyon Driving Results....................................................................................... 3-19

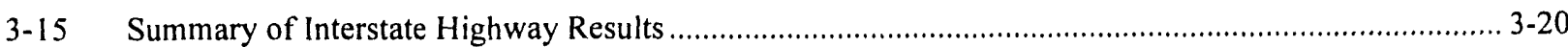

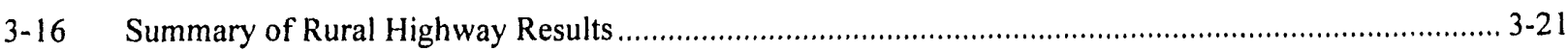

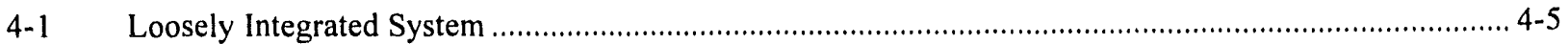

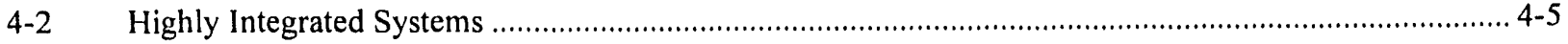

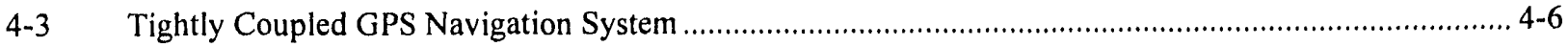




\section{Tables}

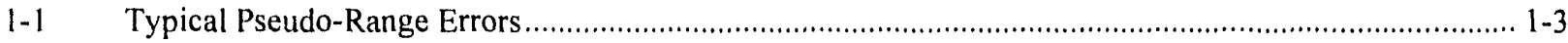

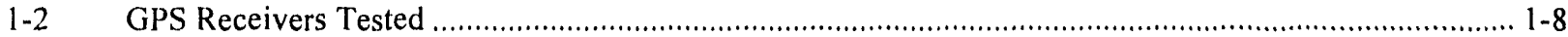

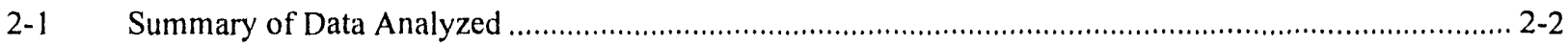

2-2 Summary of Parameters Measured and Performance Areas Evaluated ................................................ 2-3

2-3 Comparison of RS-232 and RS-422 Serial Communications............................................................ 2-4

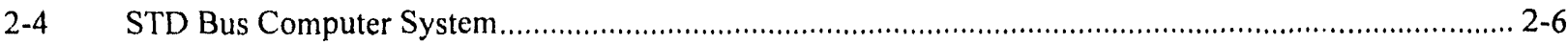

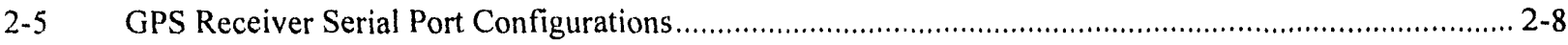

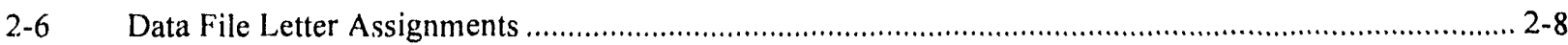

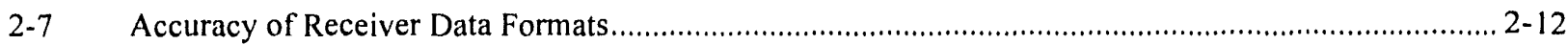

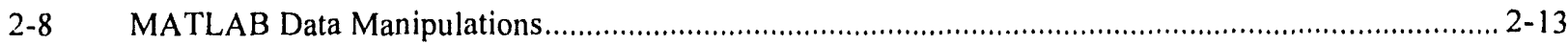

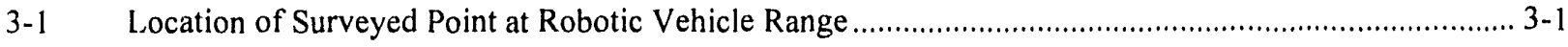

3-2 Summary of Static Position Error Mean and Variance for Different Receivers....................................... 3-2

3-3 Summary of Navigation Mode Data for Static Test ......................................................................... 3-13

3-4 Summary of DOP - Navigation Mode Switching Criterions ........................................................ 3-14

3-5 Summary of Terrain Used for Dynamic Testing ......................................................................... 3-15

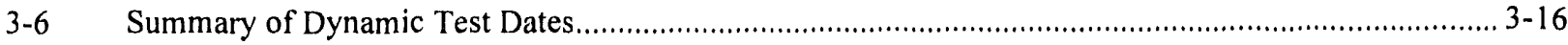

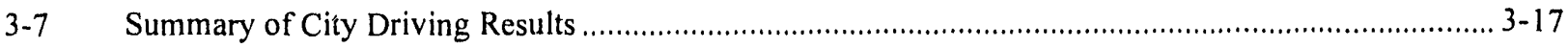

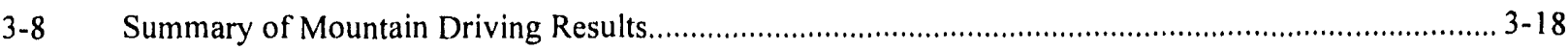

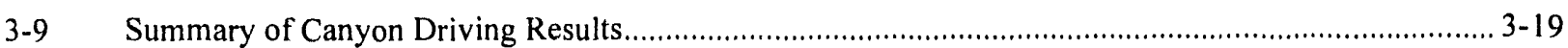

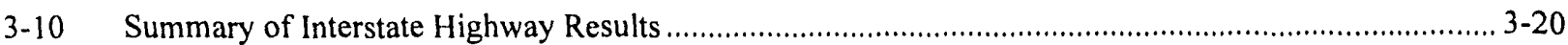

3-11 Summary of Rural Highway Results …................................................................................... 3-21

4-1 Summary of Problems Encountered with GFS Receivers Tested ....................................................... 4-2

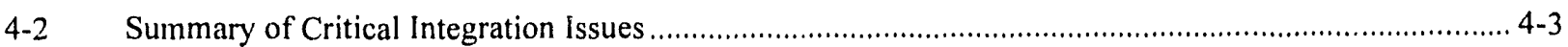

4-3 Purchasing a Highly Integrated Navigation System vs. Performing the System Integration In-House ...... 4-7

4-4 Summary of Pricing for Different Navigation Systems ............................................................... 4-8

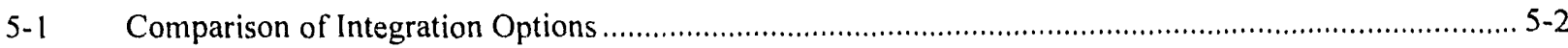


viil 


\section{ACRONYMS}

$\begin{array}{ll}\text { ASCII } & \text { American Standard Code for Information Interchange } \\ \text { LUP } & \text { dilution of precision } \\ \text { FM } & \text { frequency modulation } \\ \text { GDOP } & \text { geometric dilution of precision } \\ \text { GPS } & \text { Global Positioning System } \\ \text { HDOP } & \text { horizontal dilution of precision } \\ \text { IC } & \text { integrated circuit } \\ \text { IVHS } & \text { Intelligent Vehicle Highway Systems } \\ \text { LANL } & \text { Los Alamos National Laboratory } \\ \text { LCD } & \text { liquid crystal display } \\ \text { MATLAB } & \text { Math Library } \\ \text { OEM } & \text { original equipment manufacturer } \\ \text { PC } & \text { personal computer } \\ \text { PDOP } & \text { position dilution of precision } \\ \text { RAM } & \text { random access memory } \\ \text { RF } & \text { radio frequency } \\ \text { SA } & \text { selective availability } \\ \text { SNR } & \text { signal-to-noise ratio } \\ \text { STD } & \text { standard } \\ \text { SV } & \text { satellite vehicle } \\ \text { TDOP } & \text { time dilution of precision } \\ \text { 3D } & \text { three dimensional } \\ \text { 2D } & \text { two dimensional } \\ \text { TTL } & \text { transistor-transistor-logic } \\ \text { VDOP } & \text { vertical dilution of precision } \\ & \\ \text { SD } & \end{array}$




\subsection{INTRODUCTION}

A Sandia project currently uses an outdated Magnavox 6400 Global Positioning System (GPS) receiver as the core of its navigation system. The goal of this paper is to analyze the performance of the current GPS receiver compared to newer, less expensive models and to make recommendations on how to improve the performance of the overall navigation system.

\subsection{GPS Basics}

This section describes the basic operation of the GPS system for those not familiar with the technology. Those already familiar with GPS might want to skip this section and move on to Section 1.2.

The GPS system was devcloped by the United States Air Force to allow accurate position location anywhere in the world. GPS uses the principle of triangulation to estimate position. Triangulation involves measuring the distance to threc known landmarks to determine position. For the GPS system, these landmarks are satellites orbiting the earth at a height of about 10,900 nautical miles; the satellites, sometimes referred to as Satellite Vehicles (SVs), are depicted in Figure 1-1. The full constellation of satellites will contain 21 active satellites and 3 spares for a total of 24 . As of November 1, 1992, there are 19 satellites functioning in orbit. The full constellation should be operational by early 1993 .

The range from each satellite is determined by measuring the time of flight of a radio signal transmitted by each satellite and received by the receiver. Distance is calculated using the simple equation shown below:

$$
\text { distance }=\text { time }^{*} \text { speed }
$$
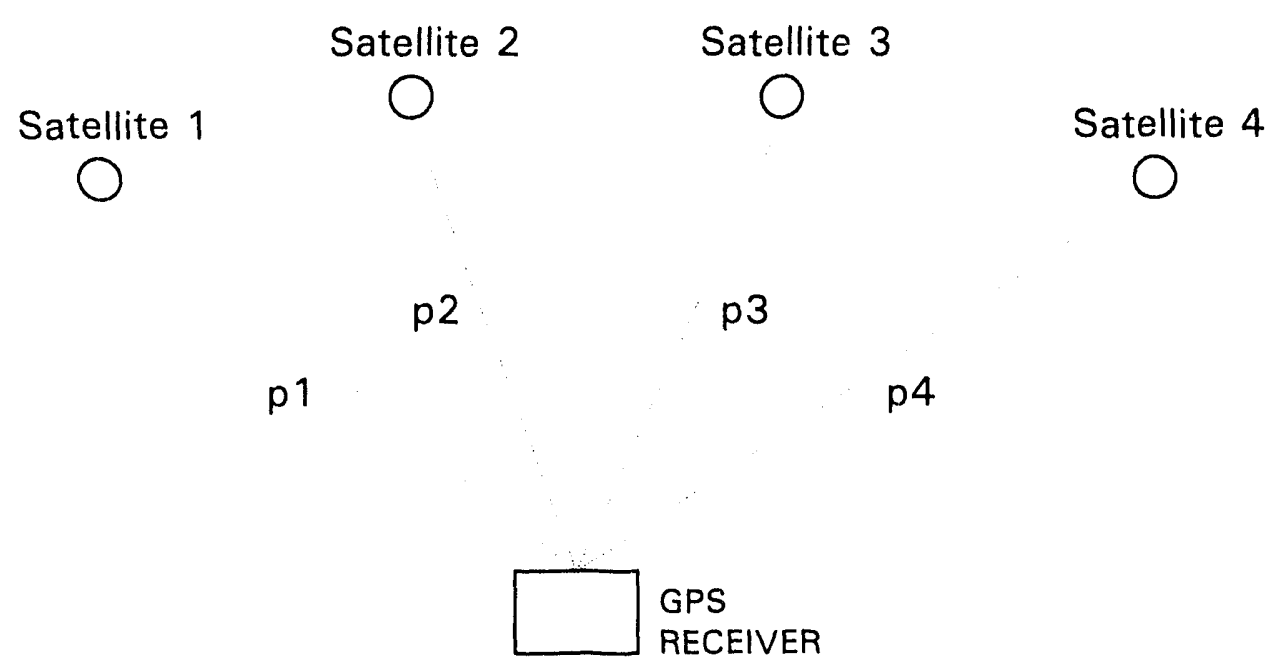

AVD-9616-1-1

Figure 1-1. GPS System. 
A radio signal travels at the speed of light, which is 186,000 miles/second. Because radio signals travel very quickly, very accurate timing is required to measure distance accurately. In one nanosecond (10 ${ }^{-9}$ sccond), a radio signal travels 0.982 fect. Therefore, GPS receivers have very accurate clocks capable of nanosecond resolution. The distance to a satellite is referred to as a pscudo-range because it is an estimate of the range.

In order to measure the time it takes a message to travel from a satcllite to the receiver, the start time of the message must be known. This is accomplished by synchronizing the clock on the receiver with the clock on the satellite. All the satellites use expensive atomic clocks to ensure that all of the satellite clocks are synchronized. Atomic clocks use the vibration period of a particular atom (cesium is a popular onc) to kecp timc. All satellites have scveral atomic clocks to ensure that one is always functioning.

Each satellite broadcasts a pseudo-random code, or sequence of numbers, that repeat periodically. Every satellite has a unique but known pseudo-random code. By generating the same pseudo-random code in the receiver, the time of flight of the radio signal can be estimated by looking at the difference in start times between the received code and the generated code. Because of the nature of the pscudo-random codes, the start of the code doesn't have to be compared, a unique unambiguous section of the code anywhere in the message will suffice. In more technical terms, the time of flight is determined by sliding the generated code over the incoming signal until a peak in the autocorrelation is achieved.

Two different codes are broadcast by each satellite on two different frequencies. The "C/A" code is broadcast on the first frequency, $\mathrm{Ll}$, at approximately $1.575 \mathrm{GHz}$. This is the code intended for civil applications and is available to all users. The military code, or " $\mathrm{P}$ " code, is transmitted on the $\mathrm{L} 1$ frequency as well as the $\mathrm{L} 2$ frequency $(1.227 \mathrm{GHz})$. Once the full GPS constellation is operational, the Air Force intends to encrypt the " $p$ " code into " $Y$ " code and its use will be limited to authorized military users.

Once the distance to three satellites is measured, theoretically one can rbtain a position fix. The orbits of the satellites are known very precisely, and the Air Force constantly measures the actual orbit so that the satellites can determine their actual position very accurately. This orbital information, known as the ephemeris, is broadcast to the GPS receiver so that the exact location of the satellite vehicles is known at all times.

If the clock on the GPS receiver was synchronized to the atomic clocks on the satellites, then the distance to three satellites would be sufficient for determining the location of the receiver. However, the clocks on GPS receivers have to be small and inexpensive so they are not as accurate as the satellite clocks. This introduces a time offset error to the measurements. The GPS receiver clock is cither ahead or behind the time kept by the atomic clocks by an unknown amount. By measuring the distance to a fourth satellite, this timing crror can be climinated. Measuring the range to four satellites with a clock offset $\Delta \mathrm{T}$ yiclds four equations with four unknowns. It is then easy to solve for the local clock offset as well as the $x, y, z$ position of the GPS receiver. If a two- 
dimensional locition is required (altitude is already known, for cxample, sea level), then only three satellites are necded.

Many factors exist that influence the accuracy of the GPS receiver's position estimate. The radio signal is refracted as it travels through the carth's atmosphere and therefore docs not travel in a straight line. Small variations in the satellite's orbits also affect the accuracy of the GPS fix. Most significantly, the Air Force intentionally sends incorrect clock and ephemeris information on the C/A code to degrade the position accuracy to about 100 meters. This degradation is known as Sclective Availability (SA). This intentional degradation is intended to kecp unfriendly countrics from developing precision guided munitions with GPS. A list of several factors which degrade GPS accuracy appear in Table 1-1 (Brown and Hwang, 1992). The crrors in Table 1-1 describe pscudo-range errors that combine with satellite geometry to determine the magnitude of the position crror. The particular satellite geometry contributes an error multiplicr to the pscudo-range crror that will be discussed latcr.

As secn in Table 1-1, the largest error source is sclective availability (SA). The pscudo-range crrors caused by SA degrade the position accuracy of GPS to about 100) meters. The effects of SA are illustrated in Figures $1-2$ and 1-3. SA was turned off in October for a bricf period while the Air Force was conducting tests. The data in Figure 1-2 was taken during this period and shows GPS crror as a function of time with SA off. Figure 1-3 shows GPS crror as a function of time with SA on. The slowly varying crror in Figure 1-3 is caused by SA. Both plots represent data taken as part of this project.

Table 1-1. Typical Pscudo-Range Errors (Brown and Hwang, 1992)

\begin{tabular}{lc}
\hline \multicolumn{1}{c}{ Error Component } & $\begin{array}{c}\text { Pscudo-range Error } \\
\text { Standard Deviation (metcrs) }\end{array}$ \\
\hline Satcllite Position & 3 \\
\cline { 2 - 2 } Ionospherc refraction with correction & 5 \\
Troposphere refraction with correction & 2 \\
Multipath (reflections of RF signal) & 5 \\
Sclectivc Availability (SA) & 30 \\
\hline
\end{tabular}




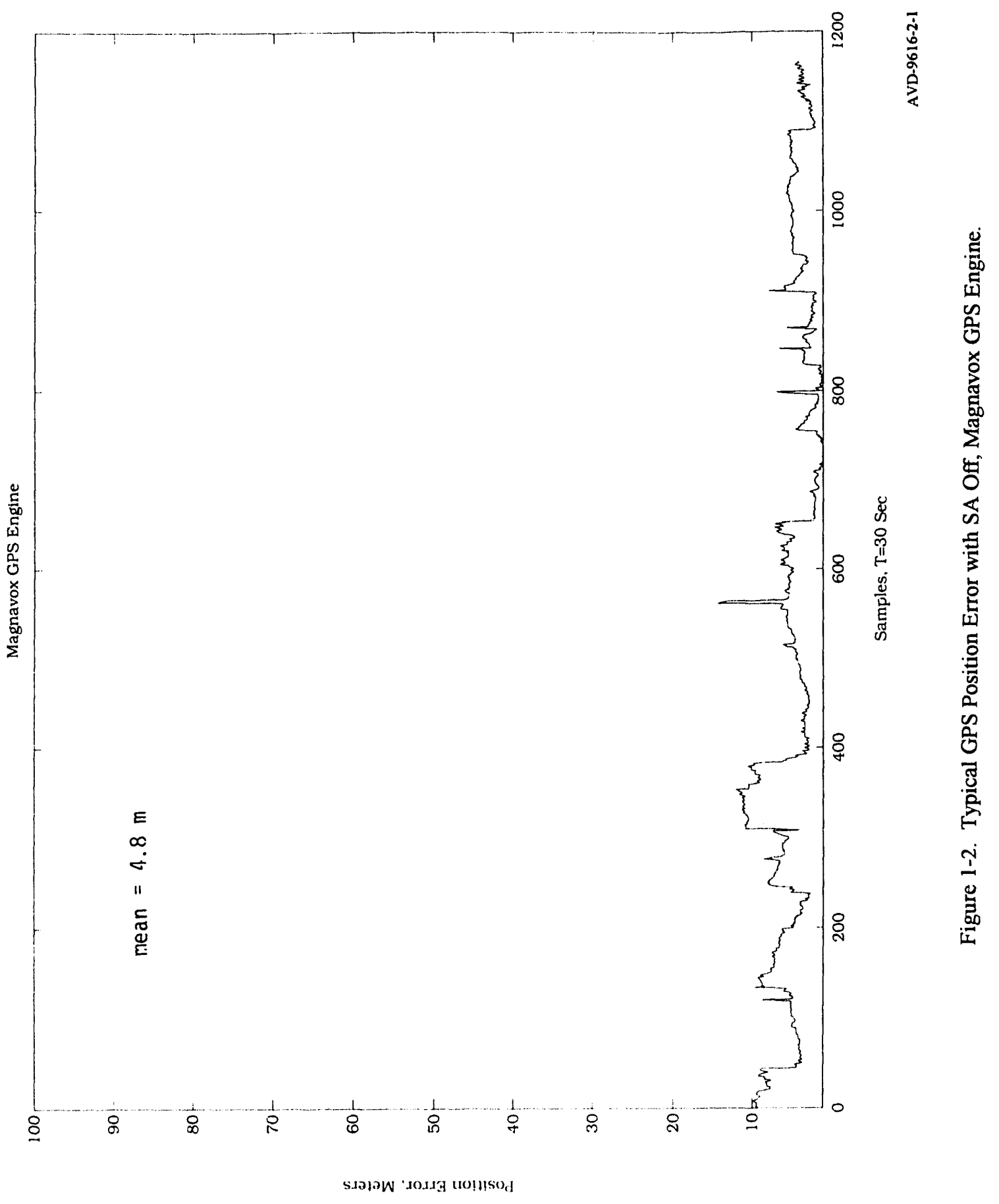




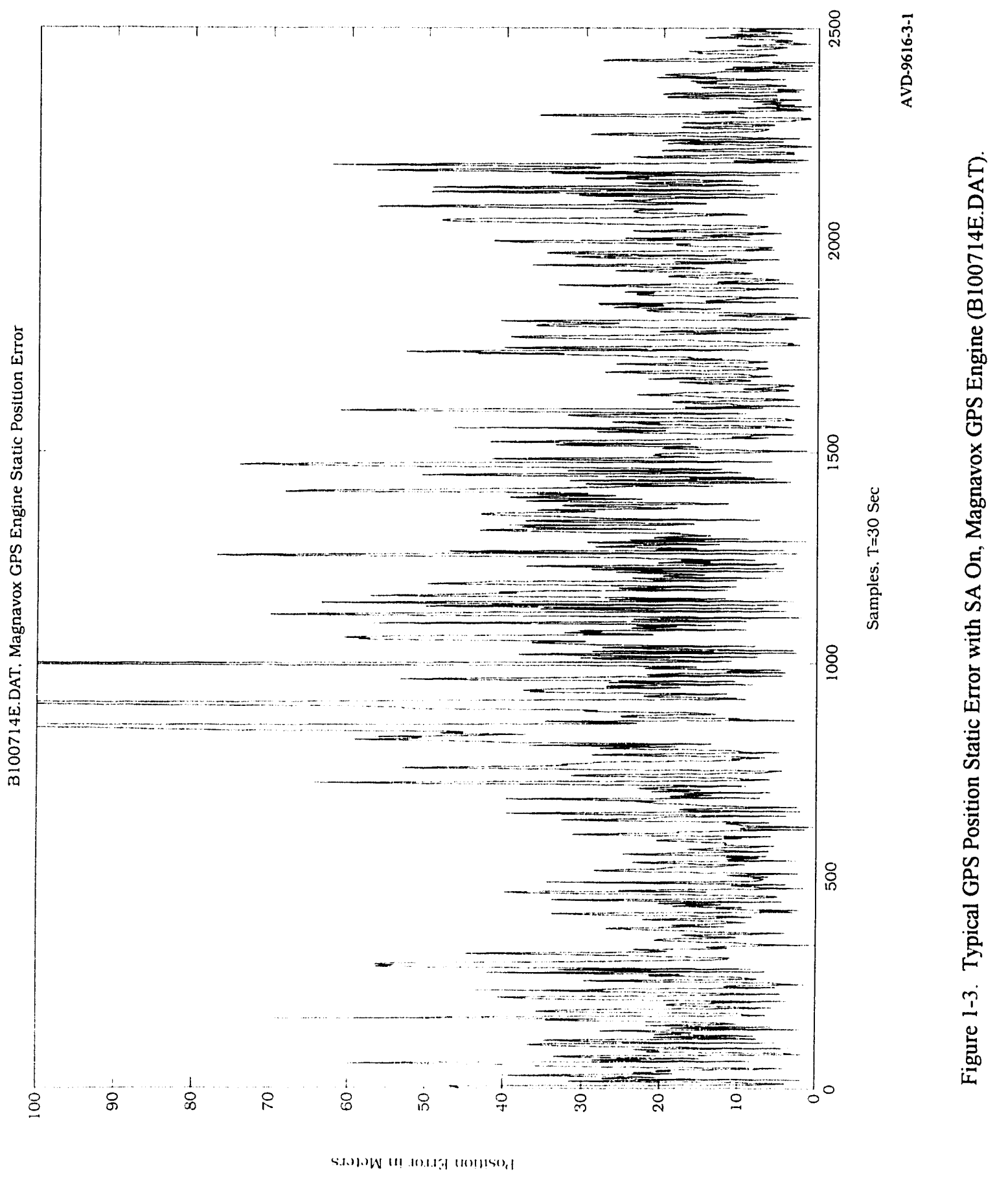


The particular geometry of the satellites relative to the receiver also affects the position accuracy. Some geometrics are more favorable than others. Terms used to describe the strength of the position fix based on the geometry include: Dilution of Precision (DOl'), Horizontal Dilution of Precision (HDOP), Geometric Dilution of Precision (GDOP), Position Dilution of Precision (PDOP), Time Dilution of Precision (TDOP), and Vertical Dilution of Precision (VDOP). The various DOPs are crror multiplicrs that indicate the accuracy of a particular type of position fix based on a certain pscudo-range error. For instance, if the pscudo-range measurements are accurate to 10 meters and the HDOP is equal to 3.5 , the horizontal position accuracy would be 35 meters (10* 3.5). A PDOP of 2 or 3 is fairly good, while a PDOP of 10 is not so good. Certain geometrics can cause the DOP to become very large (infinite). Two uscful DOP identities are shown in Equations (1-2) and (1-3).

$$
\begin{aligned}
& \mathrm{PDOP}^{2}=\mathrm{VDOP}^{2}+\mathrm{HDOP}^{2} \\
& \mathrm{GDOP}^{2}=\mathrm{PDOP}^{2}+\mathrm{TDOP}^{2}
\end{aligned}
$$

One way to improve GPS accuracy is by taking differential measurements, often referred to as differential GPS (DGPS). This is shown in Figure 1-4.

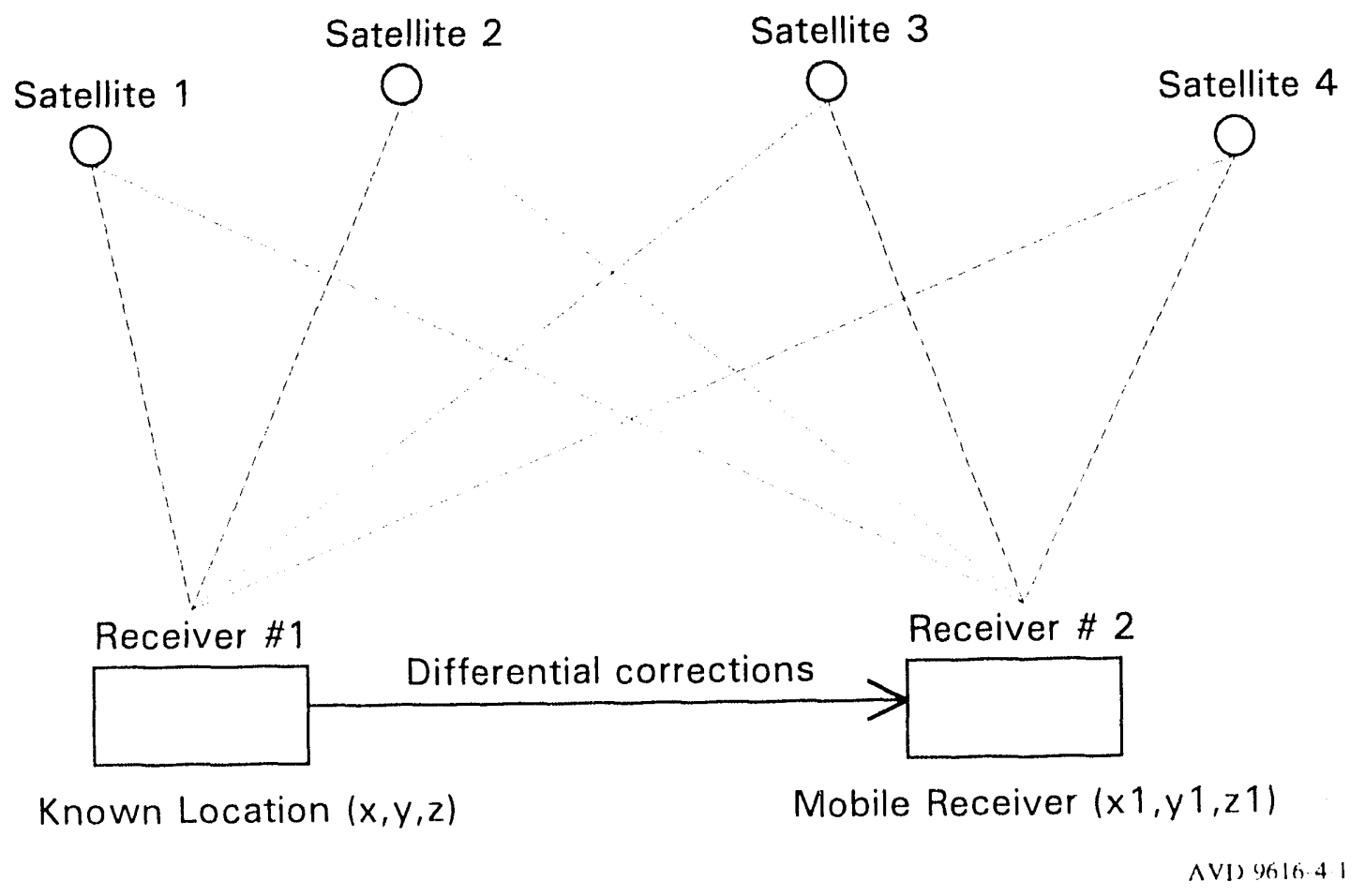

Figure 1-4. Differential GPS. 
By placing one GPS receiver in the differential system at a surveyed, known location, the errors from SA, ephemeris, and atmospheric effects can be practically eliminated from the mobile receiver. If the two receivers are not very far apart, they will be using the same satellites as well as the same region of the atmosphere and will be subjected to essentially the same error sources. In practice, it is desirable to keep the receivers within 10 kilometers of each other. The sum of all the error terms can be calculated for the receiver at the known location and then corrections can be sent to other receivers in the area. Differential GPS can easily reduce the position error to less than 10 meters. Other, more complicated methods of obtaining increased accuracy include using differential GPS with carrier phase measurements.

The Coast Guard plans to implement a differential GPS system around the coastal waters of the United States, including the Great Lakes, Hawaii, and Puerto Rico. This system will aide in maritime navigation and will offer a great improvement in positional accuracy over Loran C. Magnavox and CUE Network Corporation also plan to market a nationwide subscriber network that allows users to receive differential corrections over an FM radio link (GPS Report, 1992). Surveyor's currently use differential GPS to obtain positional accuracies of centimeters, but these measurement require post processing of the data and assume a stationary GPS receiver.

GPS receivers are often compared based on the number of channels they have for tracking satellites. As mentioned in the previous section, a GPS receiver must track at least four satellites to perform three-dimensional navigation. Early receivers had only one or two channels for tracking satellites, so they had to sequence from one satellite to another to obtain a position fix. These types of receivers are known as sequencing receivers because they have to switch quickly from one satellite to another to obtain the four necessary pseudo-ranges. More modern receivers have dedicated channels for each satellite being tracked. The number of channels can range from 4 to 12 or more, depending on the cost and accuracy of the receiver. Receivers with 5 or more channels have the advantage of being able to track more than the four necessary satellites simultaneously. This allows incorporating more pseudo-ranges in the position fix for increased accuracy and also lets the receiver continue to navigate if one of the satellites is temporarily obstructed.

In summary, this section has presented an introduction to the basic operation of GPS. GPS uses the concept of triangulation to determine the location of a receiver. The known landmarks from which distances are measured are the GPS satellites orbiting the Earth. The time-of-flight of a pseudo-random code sent synchronously from each satellite is measured at the receiver to determine the distance to each satellite. Ideally, only three satellites would be needed to determine the location of the receiver. However, because of receiver clock errors, a fourth satellite is needed to synchronize the receiver clock with the atomic clocks on the satellites. The largest source of ciPS position error is Selective $\Lambda$ vailability (SA). Most of the position error can be eliminated by using a differential GPS system. 


\subsection{Project Goals}

The current navigation system uses dead reckoning (compass and odometry), updated with position fixes from either GPS or TRANSIT as its position location system. The GPS receiver, a Magnavox 6400 unit, is a 2-channel sequencing receiver that is based on technology more than 10 years old. Newer GPS receivers are less expensive, typically have five or six channels, and offer improved performance. In addition, maintenance and repair of the Magnavox receiver is becoming more expensive as the receiver becomes more obsolete. Therefore, upgrading the current navigation system is a high priority. One goal of this study was to compare the current GPS system with several inexpensive, commercially available systems to quantify the performance improvements gained by switchin, to a newer receiver. The receivers tested are listed in Table 1-2. The "briginal equipment manufacturer (OEM) type" receivers are single board GPS receivers that are meant to be integrated into a system or product. The Trimble and Magnavox 6400 receivers are "integrated" commercial products.

Table 1-2. GPS Reccivers Tested

\begin{tabular}{|c|c|}
\hline Recciver & Description \\
\hline Magnavox 6400 & $\begin{array}{l}\text { 2-Channel, sequencing receiver, receiver in } \\
\text { current system, Integrated System }\end{array}$ \\
\hline Magcllan OEM GPS Module & 5-Channel GPS Recciver, OEM type \\
\hline Magnavox GPS Enginc & 6- Channel GPS Receiver, OEM type \\
\hline Rockwell NavCore V & 5- Channel GPS Receiver, OEM type \\
\hline Trimble Placer & 6-Channel Receiver, Integrated System \\
\hline
\end{tabular}

The current navigation system also uses a fluxgate magnetometer (electronic compass) to detcrmine vehicle heading as part of the dead-reckoning system. A fluxgate magnetometer senses the Earth's magnetic ficld to determine the direction of magnetic North (the direction a compass would point). The large mass of stecl present in the current application interferes with the performance of the magnetometer because the stecl (a ferrous matcrial) warps the Earth's magnetic field around the sensor. In general, magnetometers are more accurate when they are not near any induced magnetic fields caused by elcetric currents or ferrous materials. Therefore, the deadreckoning performance is degraded because the fluxgate magnetometer heading is not always accurate. Another goal of this study was to suggest methods of improving the dead-reckoning system's performance.

The performance of the current GPS receiver was tested along with four commercially available receivers. Testing included static testing as well as dynamic testing. The results of the testing are outlined in this report. 
Recommendations on how to improve the performance of the dead-reckoning system are based on experience with fluxgate magnetometers at Sandia's Robotic Vehicle Range (RVR). This report documents the GPS receiver testing, test results, and recommendations on how to improve the current navigation system.

\subsection{Paper Outline}

As mentioned in the previous section, the goal of this study was to analyze the performance of several commercial receivers compared to the current GPS system and to make recommendations on how to improve the overall navigation system. This report documents the test methodology used to gather GPS data, the test results, as well as recommendations on how to improve the current navigation system. The test methodology is described in Section 2.0. The parameters tested are discussed in Section 2.1; the test hardware is documented in Section 2.2; and the test software is described in Section 2.3. The test results are discussed in Section 3.0. The static results are presented in Section 3.1, while the dynamic results are described in Section 3.2. Section 3.3 provides a summary of the test results. The recommendations for improving the current navigation system are outlined in Section 4.0. Section 4.1 discusses the selection of an upgraded GPS receiver, while Section 4.2 addresses overall navigation issues. Section 5.0 contains a summary of the report.

Appendices are used to document areas with greater detail than would be suitable for the report. Appendix A contains a detailed description of the test hardware. Appendix B contains descriptions of the serial data communication protocols used by the GPS receivers tested. Appendix $\mathrm{C}$ contains a listing of the software used for the GPS receiver testing. This includes the data acquisition software as well as the data post processing software. Appendix D contains raw GPS data. This includes maps made while taking dynamic data and navigation mode as a function of time. Appendix $\mathrm{E}$ contains examples of the raw GPS data. Appendix $\mathrm{F}$ lists the individual contacts who provided technical support and pricing information for the GPS receivers tested. 


\subsection{TEST METHODOLOGY}

The project goal of this study was to compare the performance of the current GPS system to commercially available GPS receivers, and then to make overall recommendations on how to improve the current navigation system. Many possible parameters exist that may be measured when comparing GPS receivers. These include position error, number of satellites tracked, signal-to-noise ratios, and time-to-first-fix. Section 2.1 discusses the parameters that were chosen to compare the performance of the current GPS receiver to several commercial offthe-shelf units. Section 2.2 describes the text fixture hardware developed to gather GPS data from the five different receivers and Section 2.3 describes the software used to gather the data. Post processing the gathered data is discussed in Section 2.4 .

\subsection{Parameters Tested}

Many parameters exist that may be tested when comparing different GPS receivers. These parameters include receiver sensitivity, static accuracy, dynamic accuracy, number of satellites tracked, and time-to-first-fix. The tests performed to evaluate the five different GPS receivers consisted of both static and dynamic testing. This section discusses the parameters tested and the rationalization for choosing these parameters.

For this navigation application, time-to-first-fix is an important parameter. The current GPS receiver can take up to 30 minutes to initialize and lock onto the satellite signals before it starts navigating. However, all of the newer receivers advertise fast position fixes, usually under one minute, if the receiver knows its position to within several hundred miles. This is often referred to as a "warm start." The difference between a 30-second first fix and a 2-minute first fix is not that important for this application. However, 1-2 minutes is a great improvement over 30 minutes. Although this parameter was not explicitly measured, attention was paid to time-to-first-fix to confirm that the newer receivers were meeting the quoted specification.

The number of satellites tracked and receiver sensitivity are important parameters for this application. The more satellites tracked, the less likely an obstruction of one or more satellites will result in a loss of navigation. Also, a more sensitive receiver is less likely to be affected by foliage and other obstructions that reduce signal strengths. The receiver sensitivity is affected by the type of antenna used and the type of cabling. Some antennas have higher gains than others, different cables have different attenuation characteristics, and the longer the cable the greater the signal attenuation. The navigation mode, two-dimensional (2-D) or threc-dimensional (3-D), is affected by the number of satellites visible. Provided that the geometry results in an acceptable DOP, a minimum of four satcllites are necessary for 3-D navigation. Additional satellites may be used to achicve a more robust position fix. If four satellites are in vicw, but the DOP is higher than a certain threshold, many reccivers will switch to 2-D navigation. 
2. Test Methodology

Ideally, measuring the signal-to-noise ratio (SNR) in the receiver and the number of satellites being tracked would yield the most insight into receiver performance. However, this information is usually buried in several different data packets for any given receiver. For some receivers, this information is not always available (the Trimble Placer does not output SNRs or the number of satellites tracked for example). Thereforc, a compromise was made and packets were requested that contained the position fix as well as the navigation mode or number of satellites tracked. Usually this data was contained in the same data packet. This reduced the amount of data stored and simplified the data analysis. The information gathered from each receiver is listed in Table 2-1.

Table 2-1. Summary of Data Analyzed

\begin{tabular}{|c|c|}
\hline Recciver & Data Gathered \\
\hline Magellan & $\begin{array}{l}\text { Latitude, Longitude } \\
\text { Number of satcllites used - implies navigation } \\
\text { mode (nonc, 2-D, or 3-D) }\end{array}$ \\
\hline Magnavox GPS Engine & $\begin{array}{l}\text { Latitude, Longitude } \\
\text { Navigation Modc (nonc, 2-D, or 3-D) }\end{array}$ \\
\hline Rockwell NavCore V & $\begin{array}{l}\text { Latitude, Longitude } \\
\text { Navigation Mode (none, } 2-\mathrm{D} \text {, or } 3-\mathrm{D} \text { ) } \\
\text { Notc: Number of satcllites tracked also available } \\
\text { from raw data }\end{array}$ \\
\hline Magnavox 6400 & $\begin{array}{l}\text { Latitude, Longitude } \\
\text { Number of satcllites tracked }\end{array}$ \\
\hline Trimble Placer & $\begin{array}{l}\text { Latitude, Longitude } \\
\text { Navigation Mode (none, 2-D, or 3-D) }\end{array}$ \\
\hline
\end{tabular}

Differences in navigation modes can be caused by several factors; these include differences in number of satellites being tracked, differences in the DOP value that cause a switch from 3-D to 2-D navigation, and differences in satellite mask angles and receiver/antenna sensitivity. The DOP settings and mask angles are known for each receiver, so the navigation mode data will allow comparing the number of satellites tracked and receiver/antenna sensitivity as one performance criterion. Although the navigation mode data lumps scveral factors together, it does give a comparison of overall receiver/antenna performance.

As mentioned in the previous section, the antenna and cable choice affects the performance of the GPS receiver. The antennas used for the GPS testing were supplied with the receiver or OEM cvaluation kit. The cabling was also supplied with the exception of the Magnavox GPS Engine. Therefore, the performance of the 
antenna and cabling was lumped together with the overall GPS system because cach manufacturer recommends (or provides) antennas and cabling.

Other performance factors include the amount of filtering in a GPS receiver. Excessive filtering reduces the amount of variance in the position and velocity data, but also slows the response of the receiver. Excessive filtering will cause a receiver to output incorrect positions when starting, stopping, or turning sharply. This type of crror is not very important for this application because the position data is sent over a radio frequency (RF) link to a command center. The delay and sampling introduced by the communication link will probably be much greater than the delay introduced by filtering in the receiver. Additional parameters that were not analyzed are velocity and heading acc'iracy. Accurate velocity information is alrcady available from odometry, and heading information that would be required for dead reckoning is not needed while GPS is functional (GPS is more accurate than dead reckoning over long periods of time).

Another easy-to-measure performance critcrion is static position accuracy. This parameter was measured by placing the GPS receivers at a surveyed location and taking data for approximately 24 hours. Although in this application, the receivers will be moving most of the time, the static accuracy does give a good idea of the receivers' position accuracy capabilities.

The parameters measured and the performance insights gained from these measurements are summarized in Table 2-2.

Table 2-2. Summary of Parameters Mcasured and Performance Arcas Evaluated

\begin{tabular}{ll}
\hline \multicolumn{1}{c}{ Parameter Measured } & \multicolumn{1}{c}{ Performance it Evaluates } \\
\hline Time-to-first-fix & $\begin{array}{l}\text { How quickly a receiver starts navigating. Not } \\
\text { cxplicitly measured, but qualitatively considered. }\end{array}$ \\
Static Position Accuracy & Static accuracy and insight into overall accuracy. \\
Static Navigation Mode - Number of & $\begin{array}{l}\text { Taking into account DOP switching, gives insight into } \\
\text { recciver/antenna sensitivity. }\end{array}$ \\
Dynamic Position Plots & $\begin{array}{l}\text { Some accuracy information is obtained by comparing } \\
\text { different data plots taken while driving down the same } \\
\text { section of road. Most of this analysis is qualitative } \\
\text { though becausc there is no ground-truth data for } \\
\text { comparison. }\end{array}$ \\
Dynamic Navigation Mode & $\begin{array}{l}\text { Taking DOP switching into account gives insight into } \\
\text { the sensitivity of the recciver/antenna and the rate with } \\
\text { which the receiver recovers from obstructions. }\end{array}$ \\
\hline
\end{tabular}


In summary, the GPS testing performed for this project consisted of storing position and navigation mode data from five different GPS receivers for both static and dynamic tests. The static testing provides information about the static position accuracy as well as the sensitivity of the receiver and antenna if DOP switching is taken into account. The dynamic testing mostly provides information about the receiver/antenna sensitivity and the receiver's ability to recover from temporary obstructions (taking into account DOP switching). The dynamic testing also provides some qualitative information about position accuracy by comparing plots of the data points from the various receivers.

\subsection{Test Hardware}

This section describes the test fixture developed to gather GPS data from the five different GPS receivers tested. A more detailed description of the test fixture hardware appears in Appendix A.

The GPS receivers tested use a serial interface for communicating position information. The Magnavox 6400 receiver communicates using RS-422 scrial communications, while the other four receivers use the RS-232 communications standard. The RS-422 and RS-2.32 standards for data transmission are described and compared in morc detail in Table 2-3.

Table 2-3. Comparison of RS-232 and RS-422 Scrial Communications

\begin{tabular}{|c|c|}
\hline RS-232 Communications & RS-422 Communications \\
\hline Single-cnded data transmission & Differential data transmissions \\
\hline $\begin{array}{l}\text { Relatively slow data rates (usually }<20 \mathrm{~K} \text { baud), } \\
\text { short distances up to } 50 \text { fect, most widely used. }\end{array}$ & $\begin{array}{l}\text { Very high data rates (up to } 10 \mathrm{M} \text { baud), long } \\
\text { distances (up to } 4000 \text { fect at } 100 \mathrm{~K} \text { baud), good } \\
\text { noise immunity. }\end{array}$ \\
\hline
\end{tabular}

For the short distances involved in transmitting GPS data from the receiver to a computer, the type of serial communications is not important. In fact, even though RS-232 communications are inferior in some ways to RS422 , RS-2.32 is easicr to work with because it is a more common standard (especially for PC-type computers).

The GPS receivers tested use scrial communications to send information to another computer as well as to receive configuration commands. Typically, the GPS receivers output a position update at a fixed rate, once per second for cxample. With live GPS reccivers "alking" at their own fixed ratc, a data acquisition system was needed that could gather serial data from five scrial ports simultancously, without losing information. Scrial ports may be monitored in two ways, cither in polled or interrupt operation. In polled operation, software periodically "looks" at the serial port to determine if a new character, or byte, has been received. If the software is too slow in 
checking the port, some data may be lost. However, under interrupt operation, an interrupt is generated whenever a new character is received, allowing the software to be doing something else when there are no new characters to process.

For this application, interrupt operation was necessary to be able to quickly gather scrial data from five ports without losing information if all of the receivers happened to talk at the same time. A PC typically has two interrupt capable scrial ports. Additional scrial ports may be added via an expansion card, but these additional serial ports can usually only epcrate in a polled mode. A PC expansion card would not work for the data rates and number of ports that could potentially be talking simultancously in this application. Therefore, a Standard (STD) Bus computer was selected as the data acquisition system. PC-compatible STD Bus computers are readily available, and scrial cards are also available that support interrupt operation. PC compatibility simplifics softwarc development and data transfer. Also, STD Bus computers are well suited for portable data acquisition because of their small form factor and low power consumption.

The STD Bus data acquisition hardware used to gather GPS data is outlined in Table 2-4. The overall system is best described as an embedded PC because all of the functional features of a PC are available in a reduced form factor. A 286-compatible processor allowed software development using Borland's Turbo C. An interrupt-driven serial card yielded a total of six interrupt-driven scrial channels. A hard disk was used for data storage, while a 3.5-inch drive was used to transfer data between a PC and the data acquisition computer. A video/kcyboard card was necessary to interface to a video monitor and standard IBM XT keyboard. A small, low power liquid crystal display (LCD) was used for the dynamic testing where low power consumption was critical.

A block diagram of the overall GPS test system is shown in Figure 2-1. Figure 2-1 depicts the system used for dynamic testing where power was supplied from a 12-volt battery. For the static testing, AC power was available with an extension cord. Therefore, the computer supply was connected directly to AC, while the +12 volts for the GPS receivers was generated using a Hewlett Packard supply for the static test.

The Magnavox GPS Engine requires interface circuitry to convert from transistor-transistor-logic (TTL) levels $(0,5$ volts) to RS-232 levels $(-12,+12$ volts). The Magnavox GPS Engine and the Magcllan OEM modulc also required an external battery for the battery-backed random access memory (RAM). In addition, the Magnavox GPS Engine requires regulated power at +5 volts and +7 volts. These voltages were generated using linear regulator integrated circuits (ICs) and the raw battery supply.

The GPS test fixture was set up in a Chevrolet van with an extended rear for additional room. The GPS antennas were mounted on aluminum plates that where attached to the van with magnets. The Rockwell antenna came with a magnetic mount so it was attached directly to the roof. The five antennas were within one meter of each other near the rear of the van and mounted at the same height so that no antenna obstructed the others. 
2. Test Methodology

Table 2-4. STD Bus Computer System

\begin{tabular}{|c|c|}
\hline STD Bus Card or Peripheral & Description \\
\hline ZT 8901 (Ziatech Corp.) & $\begin{array}{l}\text { Low power CMOS, } 286 \text { compatible processor, } 3 \\
\text { serial ports, } 640 \mathrm{~K} \text { RAM, } 380 \mathrm{~K} \text { battery-backed } \\
\text { RAM disk, } 48 \text { parallel } 1 / 0 \text { lines }\end{array}$ \\
\hline ZT 88CT41 (Ziatech Corp.) & $\begin{array}{l}\text { Quad serial card, low power CMOS, supports } \\
\text { interrupt operation, RS- } 232 \text { or RS- } 422 \text { operation }\end{array}$ \\
\hline ZT-8980/ZT-1030 (Ziatech Corp.) & Video/Keyboard Support, Driver for LCD Display \\
\hline ZT-8950 (Ziatech Corp.) & 3.5-Inch Disk Drive \\
\hline ZT-8952-40 (Ziatech Corp.) & 40 MByte Hard Disk \\
\hline IBM XT Keyboard & Keyboard \\
\hline
\end{tabular}

For the dynamic testing, power was supplied from a $60 \mathrm{Amp}$-Hour lead acid battery. The battery was used to power the AC-DC inverter as well as the five receivers. The van's electrical system was tried at first, but noise caused the computer to lock up occasionally. Using an isolated battery solved this problem. An AC-powered computer monitor was used for the static testing because AC power was available. For the dynamic testing, the low power LCD display was used.

A more detailed description of the test fixture hardware appears in Appendix A. This includes interface circuit schematics as well as serial cable pinouts.

\subsection{Test Software}

This section describes the software developed to gather the GPS data from the five different GPS receivers.

As mentioned in the previous section, the five GPS receivers tested use serial communications to communicate with another computer. Serial communications require a defined protocol, so that both computers know the allowed commands and data formats. The serial communications protocols for the different GPS receivers are listed in Appendix B. The description in Appendix B is limited to the packets used.

The baud rates and serial port configurations of the different GPS receivers are listed in Table 2-5. 


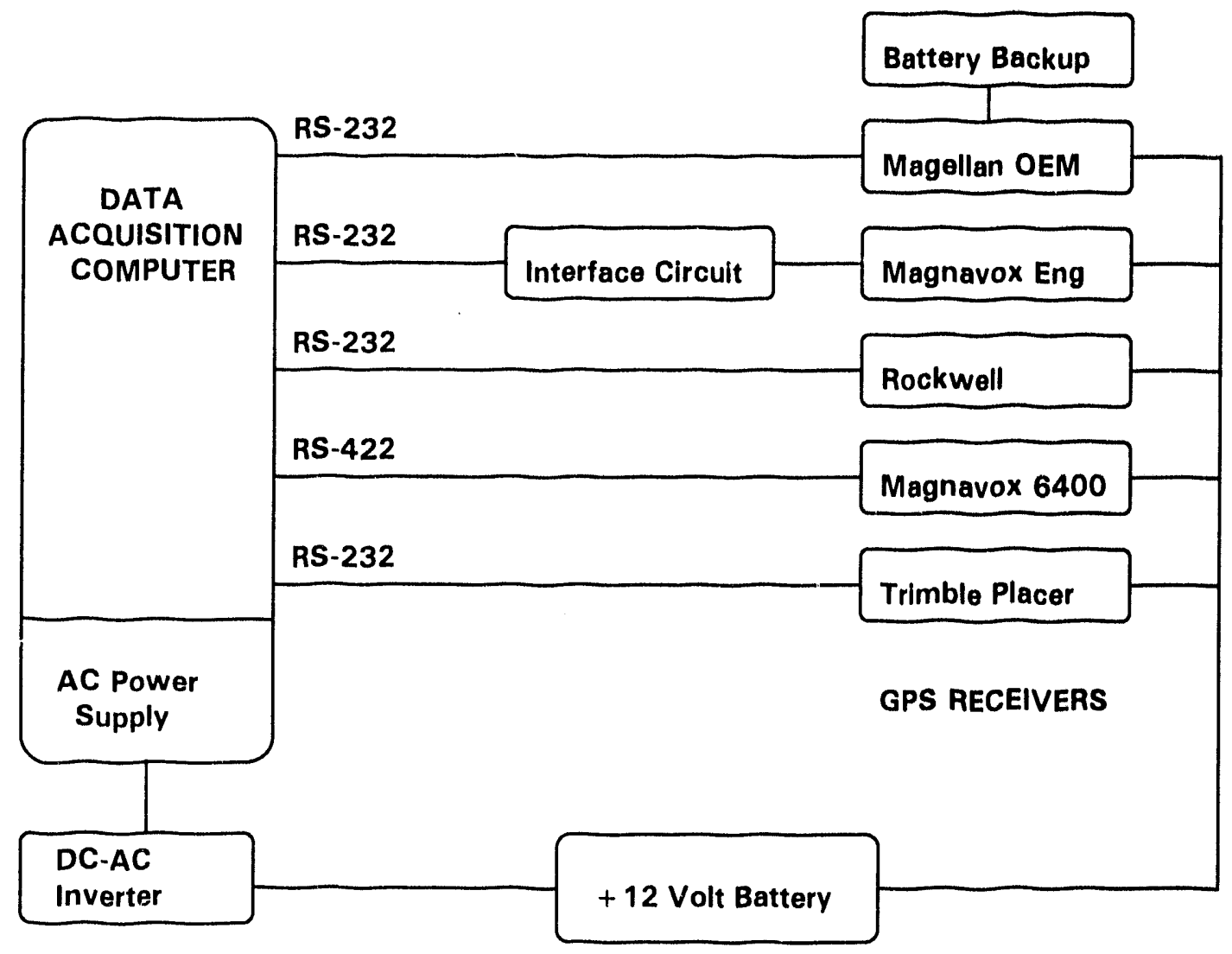

AVID-9616-5.1

Figure 2-1. Block Diagram of GPS Test Fixture (Dynamic Testing). 
Table 2-5. GPS Receiver Serial Port Configurations

\begin{tabular}{ll}
\hline \multicolumn{1}{c}{ Receiver } & Serial Port Configuration \\
\hline Magellan & 9600 baud, 8 bit, 1 stop, no parity \\
Magnavox GPS Engine & 4800 baud, 8 bit, 1 stop, no parity \\
Rockwell NavCore V & 9600 baud, 8 bit, 1 stop, odd parity \\
Magnavox 6400 & 2400 baud, 7 bit, 1 stop, odd parity \\
Trimble Placer & 9600 baud, 8 bit, I stop, odd parity \\
\hline
\end{tabular}

The data acquisition software is outlined in Figure 2-2. The data acquisition program first reads the clock to determine the time and date. Then, it creates and opens a data file for each of the GPS receivers. The filename created for each receiver is unique and contains information about the GPS receiver as well as the date and time of the test. The filename format is shown in Figure 2-3.

The letter at the beginning of the data filename corresponds to one of the five GPS receivers. This relationship is outlined in Table 2-6.

Table 2-6. Data File Letter Assignments

\begin{tabular}{lc}
\hline \multicolumn{1}{c}{ Receiver } & File Letter \\
Magellan OEM Module & A \\
Magnavox GPS Engine & B \\
Rockwell NavCore V & C \\
Magnavox 6400 & D \\
Trimble Placer & F \\
\hline
\end{tabular}

After creating and opening the data files for storing the serial GPS data, the software then initializes the interrupt controllers on the processor card and the serial card. Then the serial ports are initialized and configured for the correct baud rate. Once the serial ports are configured. the software initializes the Magellan, Magnavox GPS Engine. and Trimble Placer to output data every 30 seconds. This reduces the amount of data stored and allows taking data over a longer period of time. The Magnavox 6400 outputs data at once per second, and this is 


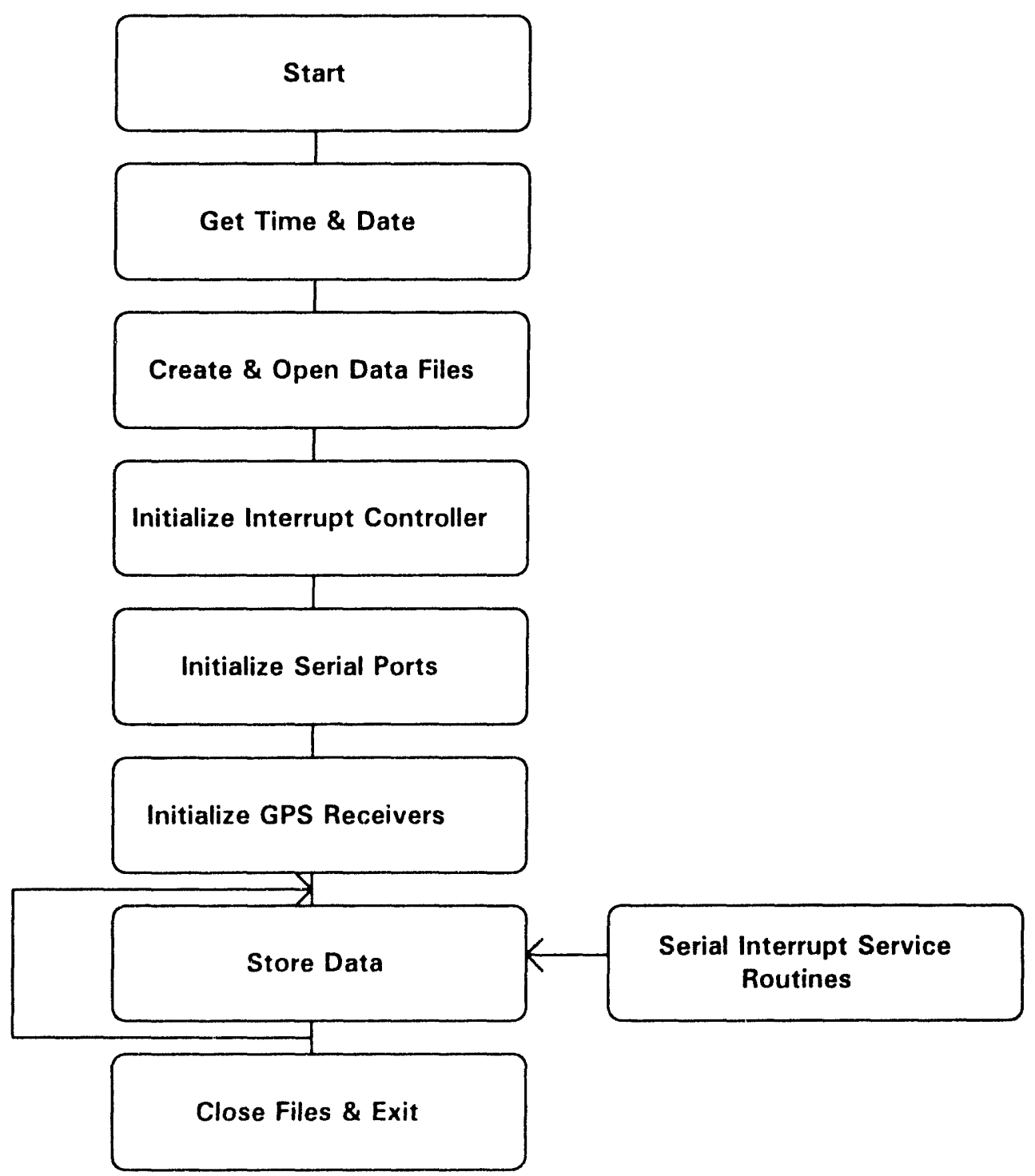

AV1).9616-6.1

Figure 2-2. Software Flow Diagram. 


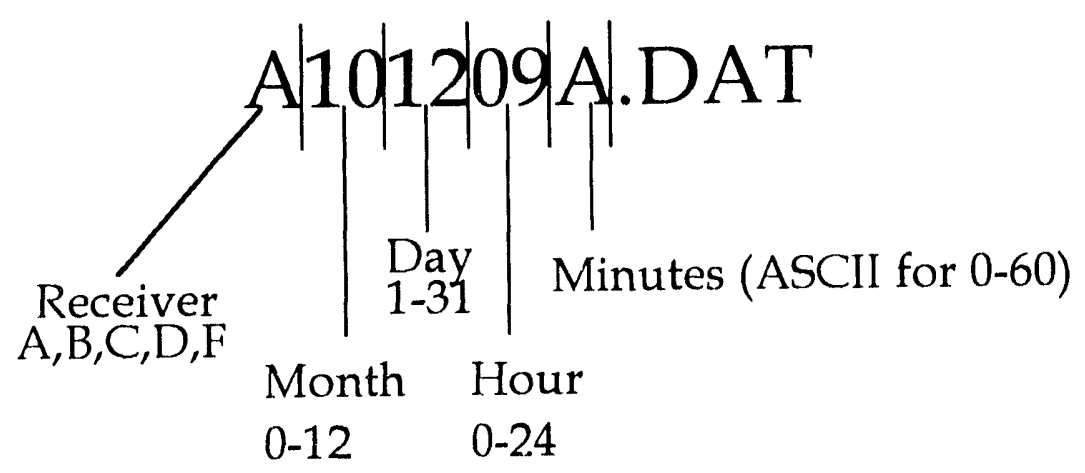

AV1).9616-7.1

Figure 2-3. Data Filename Format.

not casily changed. Therefore, all of the 6400 data was stored. The Rockwell receiver also outputs data once per sccond, and is not configurable for other data rates. Therefore, the software only logged every $30^{\text {th }}$ message. This yiclds an effective data rate of once every 31 seconds ( a slight bug in the softwarc ).

Once everything is initialized, the data acquisition software uses interrupt service routines to place incoming scrial data into buffers. The main loop of the program emptics these buffers into the appropriate data filcs as time permits. Because all of the data acquisition is done in fast interrupt service routines, no serial data is lost even if all of the reccivers "talk" at the same time. The program is exited by hitting the <enter> key on the keyboard. This closes all of the data files, turns off the interrupt service routines, and exits the program. Some crror checking is used in the program to display communications crrors, like overflow and parity errors, to the screen should they occur. These crrors were never seen during normal operation.

Some software routines were provided by Ziatech Corporation for the scrial card. These routines initialize the scrial ports and interrupt controller, and also contain the interrupt service routines for putting the scrial data into a buffer. These routines greatly simplified the software development. A description of these routines appears in Apperidix C.4.

\subsection{Data Post Processing}

As mentioned in the previous section, the GPS data was stored in raw form and post processed to extract position and navigation data. This was done so that the raw data could be analyzed again if there were any questions with the results. Also, storing the data as it came in from the scrial ports receuired less computational effort and reduced the chance of overloading the data acquisition computer. This section describes the software used to post process the data. 
The GPS serial data from each receiver was stored in an ASCII file on the hard disk of the data acquisition computer. After laking data. the ASCII files were transferred to a PC using the BACKUP and RESTORE DOS commands and 3.5 -inch floppy disks. A 5()$-\mathrm{MH} / 486$ computer was used to post process and analyze the GPS data. The raw data files were converted into new files with latitude. longitude, and navigation mode columns The file conversion software is listed in Appendix C.1. A typical post processed filc is shown in Figure 2-4

The latitude and longitude are represented in decimal degrecs. For the navigation mode, 4 corresponds to 3-D navigation, 3 corresponds to 2-D navigation, and -1 corresponds to not navigating. This columnar format was chosen because the data can be casily loaded into MATLAB for processing. MATLAB is a software package for analyzing and processing matrices and vector data. Therefore, it is well suitcd for analyzing vectors of position data.

The number of significant figures of valid data is a function of the data format of the different GPS receivers. The data formats for latitude and longitude are outlined in Table 2-7.

Looking at Table 2-7, the minimum resolution of the different GPS receivers varies greatly. However, the resolution of all of the receivers is still orders of magnitude less than the typical position error of up to 100 meters. Therefore, this parameter will not be an issuc in the data analysis.

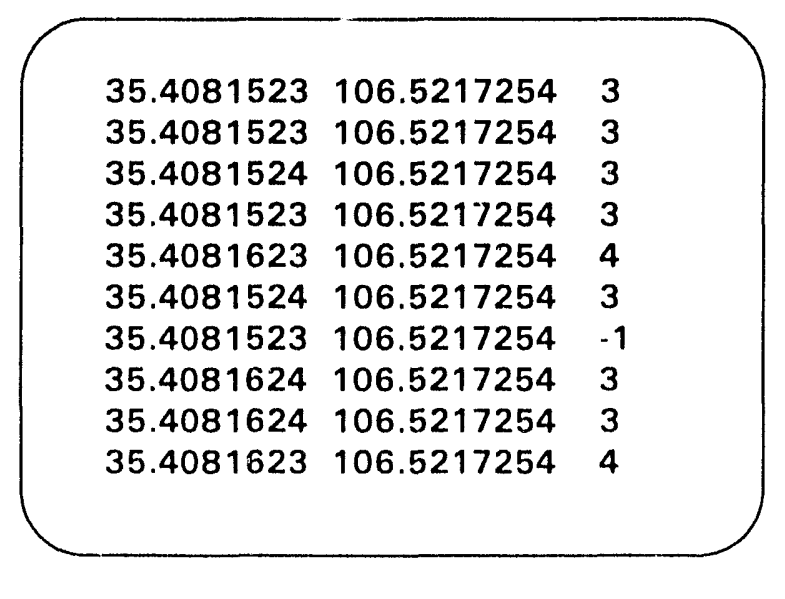

AVI)

Figure 2-t Typical post-processed dalta lile showing latitude. longitude. and Nar mode 
Table 2-7. Accuracy of Receiver Data Formats

\begin{tabular}{|c|c|c|}
\hline Receiver & Data Format Resolution & Minimum Resolution (mcters) \\
\hline Magcllan & $10^{-7}$ degrecs & 0.011 \\
\hline Magnavox GPS Engine & $1.7 \times 10^{-6}$ degrecs & 0.19 \\
\hline Rockwcll NavCore V & $\begin{array}{l}10^{-11} \text { radians }\left(5.73 \times 1()^{-10}\right. \\
\text { degrecs) }\end{array}$ & $6.36 \times 10^{-5}$ \\
\hline Magnavox 6400 & $10^{-8}$ radians $\left(5.73 \times 10^{-7}\right.$ degrecs $)$ & $6.36 \times 10^{-2}$ \\
\hline Trimble Placer & $10^{-5}$ degrees & 1.11 \\
\hline
\end{tabular}

Once the raw data was converted to files with latitude, longitude, and navigation mode in columnar form, the data was loaded into MATLAB and analyaed. Simplificd cxamples of the different manipulations performed on the data are summarized in Table 2-8. Other MATLAB features including axis labeling, axis sizing, and histogram bin definition were used to make the appropriate plots for this paper.

Degrees of latitude and longitude were converted to meters using the conversion factors listed below. The conversion factors are from the survey performed by Santiago Romero, Jr., al registered professional surveyor in the state of New Mexico (sec Section 3.1 of this report)

$$
\begin{array}{ll}
\text { Lattude Conversion Factor } & 11.0988 \times 10^{4} \mathrm{~meter} / \mathrm{degrec} \text { latitude } \\
\text { Longitude Conversion Factor } & 9.126 \times 10^{4} \mathrm{~meter} / \mathrm{degrec} \text { longitude }
\end{array}
$$

In summary, the data post processing consisted of massaging the raw data to obtain latitude. longitude. and the navigation mode into a form suitable for entry into MATL.AB. Then, MATl.AB was used to analyze the data. Data mantipulations included obtaining the position cror from a surveyed location, generating histograms of position error and navigation mode. and plotting dynamic position data. The meatl and variance of the position errors were also obtained 
Table 2-8. MA'TLAB Data Manipulations

\begin{tabular}{|c|c|}
\hline Data Manipulation & MATLAB Commands \\
\hline Load data filc & 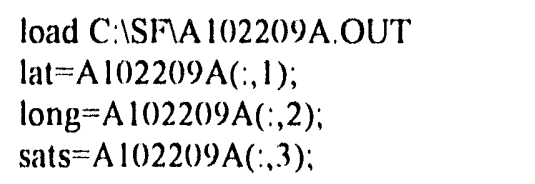 \\
\hline Determine position crror as a function of time & $\begin{array}{l}\text { lat=(lat-RVR_lat)*11.0988c4; } \\
\text { long=(long-RVR_long)*9.126c4; } \\
\mathrm{c}=\text { sqrt(lat.*lat + long. }{ }^{*} \text { long); } \\
\text { plot(c) }\end{array}$ \\
\hline Gencratc histogram of position crror & hist(c) \\
\hline Detcrmine mean and variance of position crror & $\begin{array}{l}\operatorname{mcan}(\mathrm{c}) \\
\operatorname{cov}(\mathrm{c})\end{array}$ \\
\hline Plot navigation mode as a function of time & plot(sats) \\
\hline Gencratc histogram of navigation mode & hist(sats) \\
\hline
\end{tabular}




\subsection{TEST RESULTS}

Sections 3.1 and 3.2 discuss the test results for the static and dynamic tests. The results of the static and dynamic tests provide different information about the overall performance of the GPS receivers. The static test compares the accuracy of the different receivers as they navigate at a surveyed location. The static test also provides some information about the receiver/antenna sensitivity by comparing navigation modes (2D, 3D, or not navigating) of the different receivers over the same time period. Differences in navigation mode may be causcd by scveral factors. One is that the receiver/antenna opcrating in 2D may not be able to track a satellite close to the horizon. This reflects receiver/antenna sensitivity. Another reason is that different receivers have different DOP !imits that cause them to switch to 2-D navigation when four satcllites are in view but the DOP becomes too high. This mercly reflects the designcr's preference in setting DOP switching masks that are somewhat arbitrary.

Dynamic testing was used to compare relative receiver/antenna sensitivity and to determine the amount of time that navigation was not possible because of obstructions. By driving over different types of terrain, ranging from normal city driving to decp canyons, the relative sensitivity of the different receivers was observed. The navigation mode (2D, 3D, or not navigating) was used to compare the relative performance of the receivers. In addition, plots of the data taken give some insight into the accuracy by qualitatively observing the scatter of the data. Because of the qualitative nature of this observation, this data is found in Appendix D and is not analyzed in detail in this report.

The static and dynamic testing results are summarized in Section 3.3.

\subsection{Static Test Results}

Static testing was conducted at a surveyed location at Sandia National Laboratories' Robotic Vehicle Range (RVR). The position of the surveyed location is described in Table 3-1. The survey was performed by Santiago Romero. Jr. a registered professional surveyor in the State of New Mexico.

Table 3-1. Location of Surveyed Point at Robotic Velicle Range

\begin{tabular}{cc}
\hline \multicolumn{1}{c}{ Surveyed Latilude } & \multicolumn{1}{c}{ Surveyed longitude } \\
\hline $350227.716(6) 7$ (deg min sec) & $1063116.1+169)($ deg min sec) \\
$35(0410322(\mathrm{deg})$ & $106.5211 .505(\mathrm{deg})$ \\
\hline
\end{tabular}


The data taken for this final report was gathered on October 7-8, 1992, from 2:21 p.m. 10 2:(1) p.m. Although this is the only static data analyzed in this report, a significant amount of additional data was gathered when all of the receivers were not functioning simultancously. This previously gathered data supported the trends found in the October 7.8 test.

The plots of the static position crror for cach receiver are shown in Figures 3-1 to 3-5. A summary of the mean and standard deviation ( $\sigma)$ of the position crror for the different receivers appears in Table 3-2.

Table 3-2. Summary of Static Position Error Mcan and Variance for Different Reccivers

\begin{tabular}{|c|c|c|}
\hline Receiver & $\begin{array}{c}\text { Mcan Position Error } \\
\text { (mcters) }\end{array}$ & $\begin{array}{l}\text { Position Error STD Deviation } \\
\text { (metcrs) }\end{array}$ \\
\hline Magellan & 33.48 & 2.3 .17 \\
\hline Magnavox GPS Engine & 22.0() & 16.06 \\
\hline Rockwell NavCore V & 3() .09 & 20.27 \\
\hline Magnavox 6400 & 28.01 & 19.76 \\
\hline Trimble Placer & 29.97 & 23.58 \\
\hline
\end{tabular}

As cvidenced in Table 3-2, the Magnavox GPS lingine was noticably more accurate when comparing static position error. The Magellan, Rockwell, Magnavox 64(0), and 'Trimble Placer all cxhibit comparable, but larger. average position errors. This trend was also observed when $\mathrm{SA}$ was lurned off. However, a functioning Rockwell receiver was not available for this test so the data will not be presented. It is imteresting to note that the Magnavox 64()() unit compares well with the newer receivers when looking at static accuracy 'This is expecled Because the receiver only has two channcls, il will take longer to reacefuire salfellites after blockages and will also have more difficulty with dynamic siluations. Howerer, in a static test, the weaknesses of a sefulnefing, receiver are not noticed.

The crror distributions for the data taken during the static test are shown in ligures 3-6 to 3-10. 1,ooking at the error distributions, the Magnavox (SPS lingine has the most dala points within 20 meters of the surveyed position. This corresponds with the smallest mean position error exhibited by the Magnavox receiver. 'The error distributions for the other four receivers are fairly similar. The Magnavox (of(1) unit has slighlly more data points in the 10-20 meter error bin, but otherwise there are no unique feattures. The Magnavox (iPS fingine is lhe only receiver of the five tested that had a noticeably superior static position error distribution. 


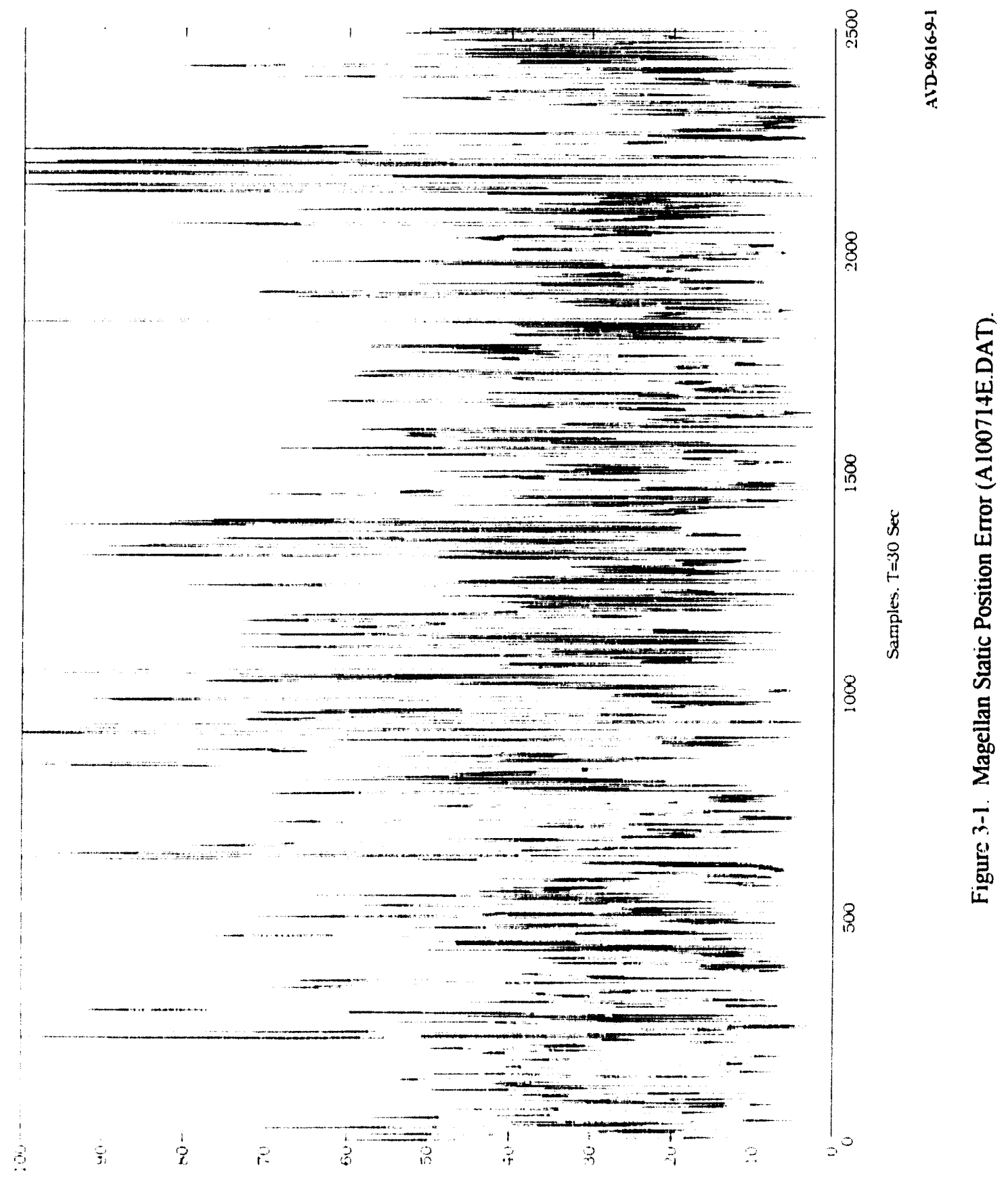




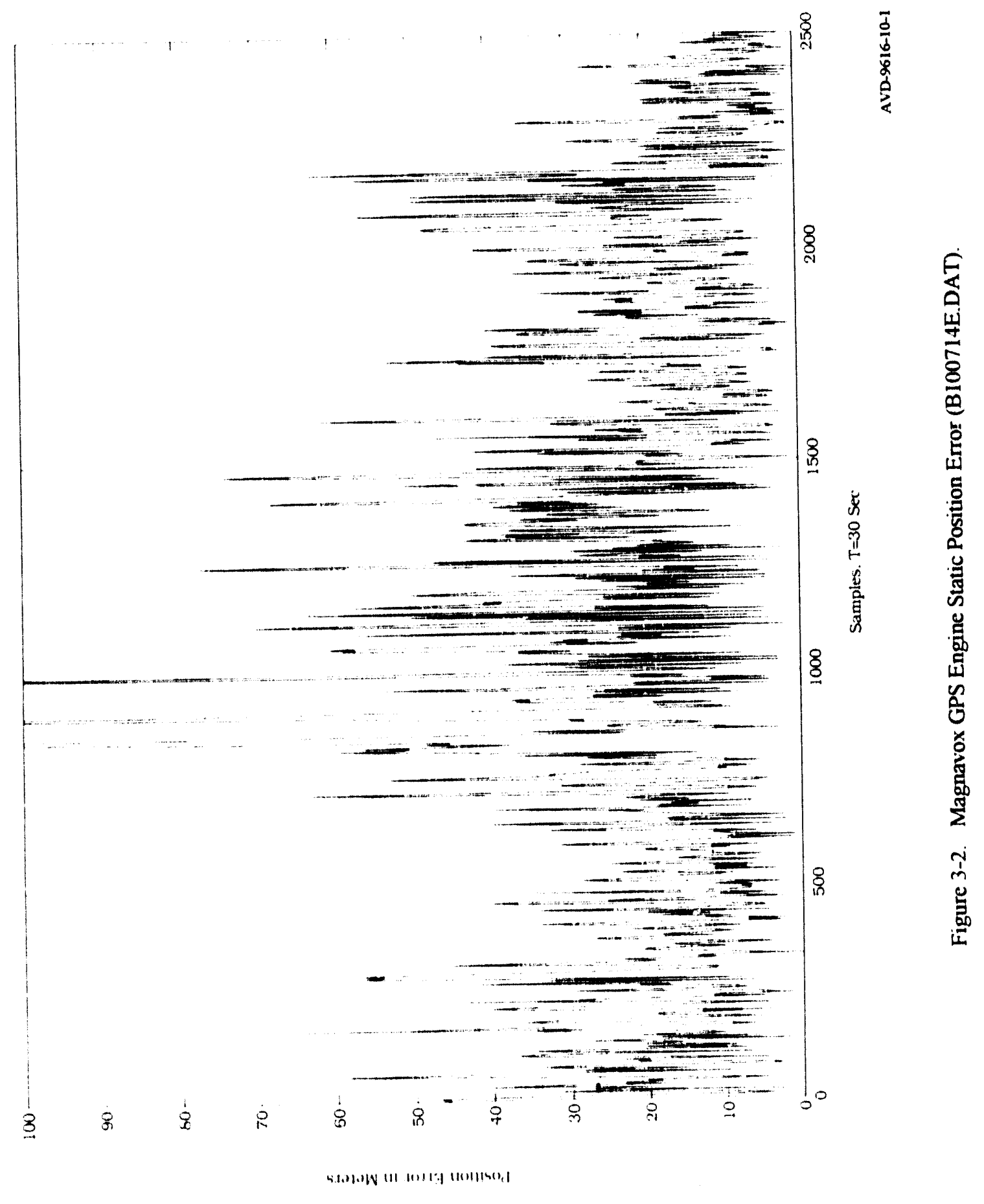




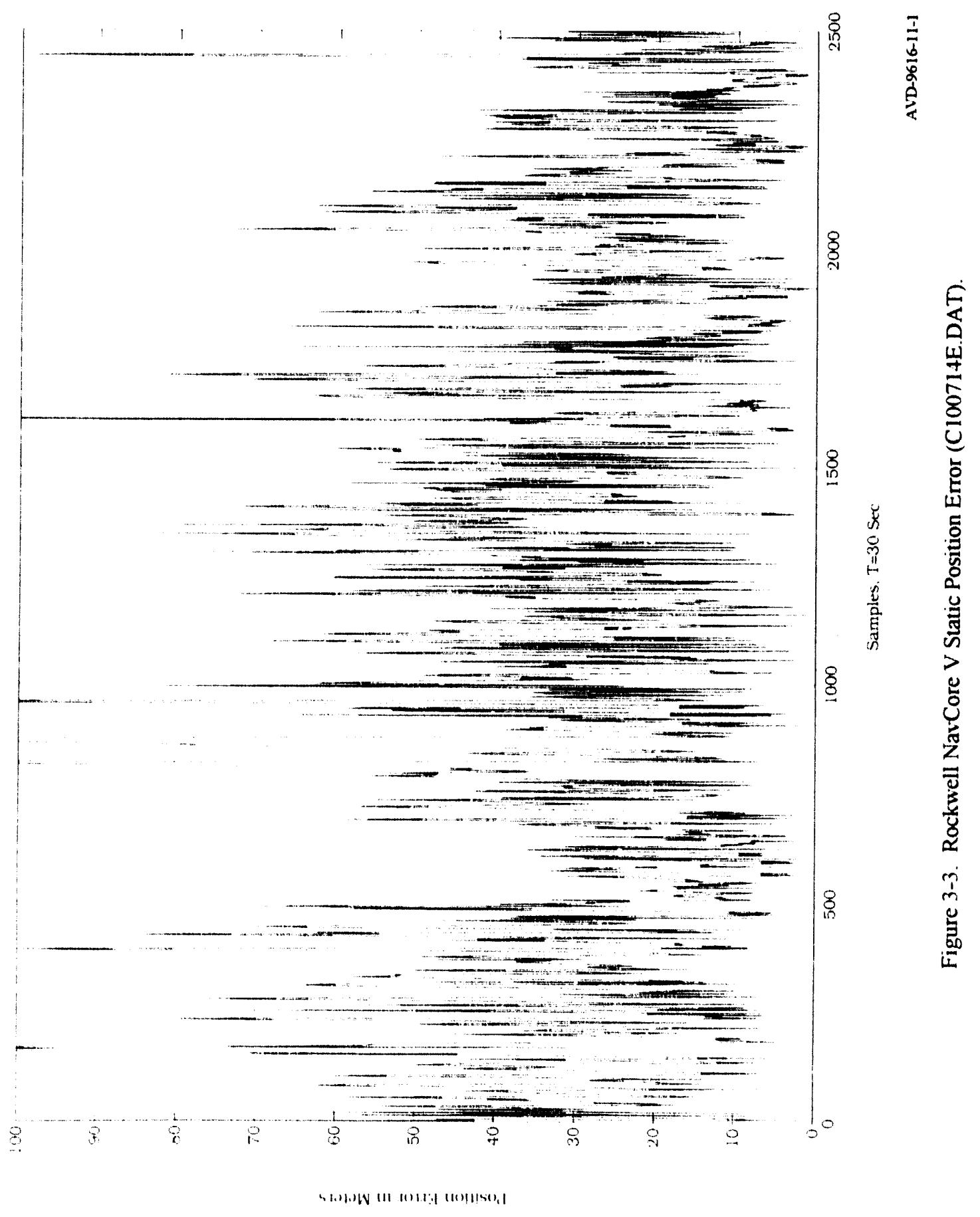




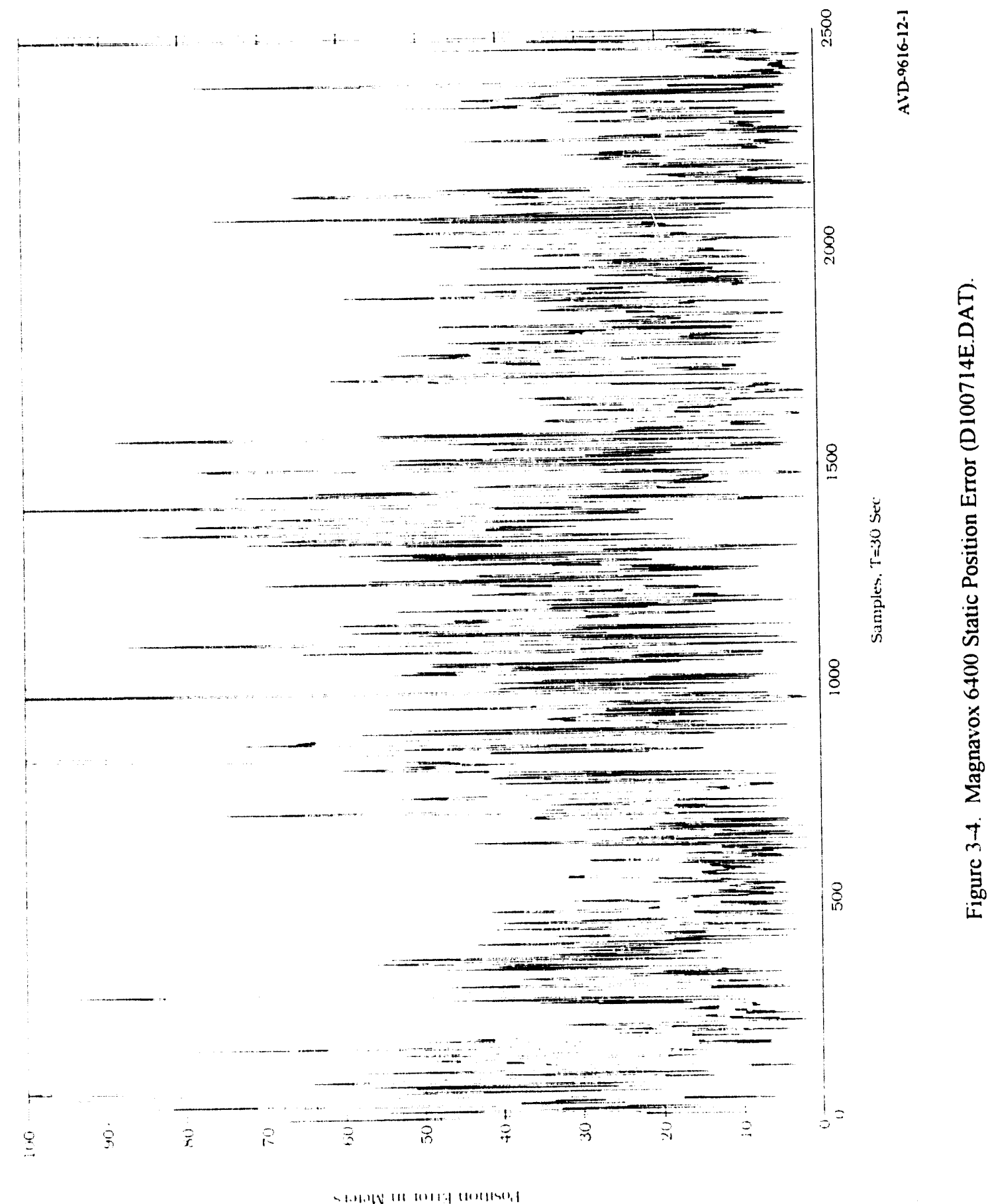

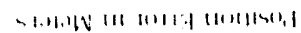




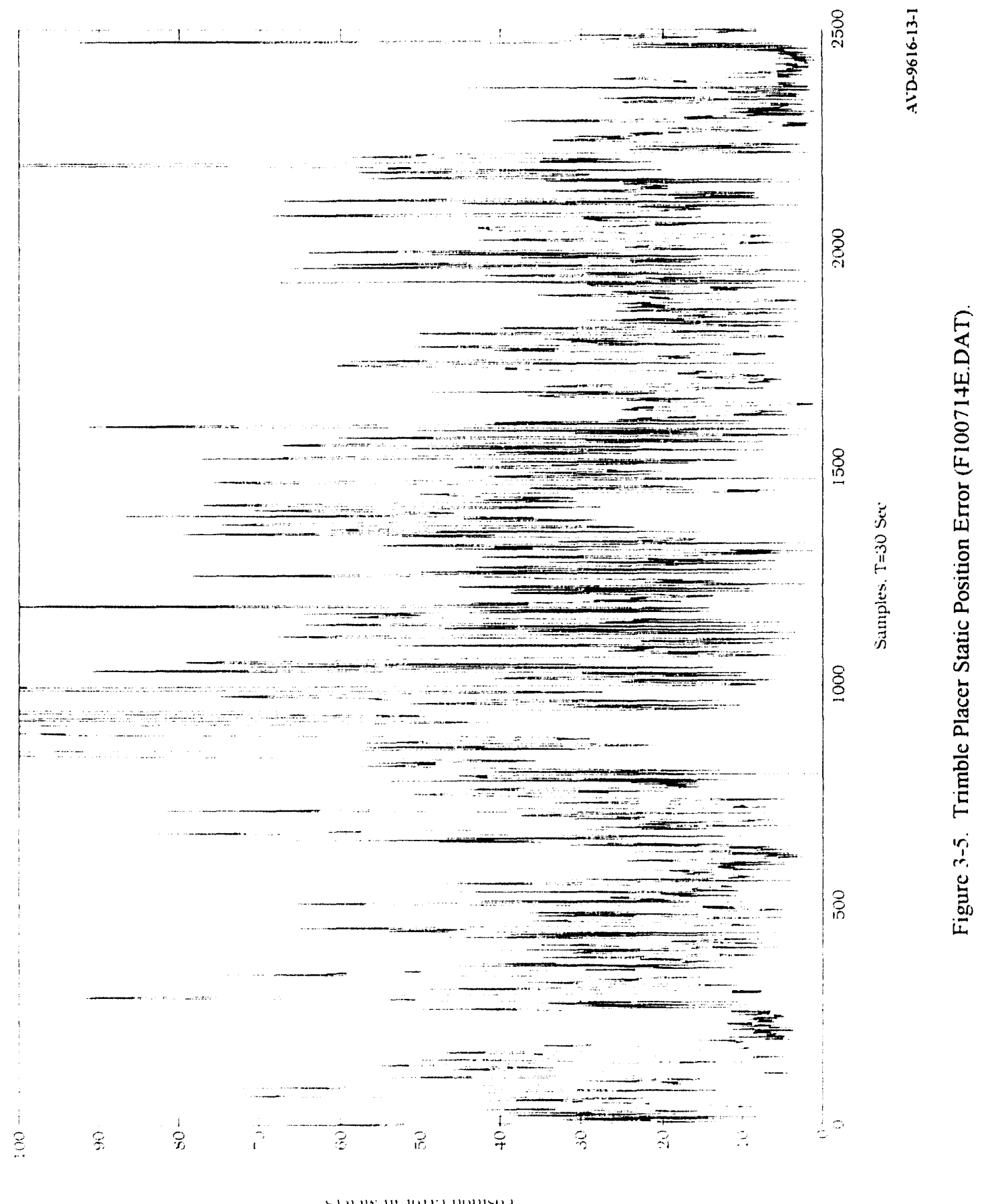

S1.31.14 $1143111+113114+1$ 


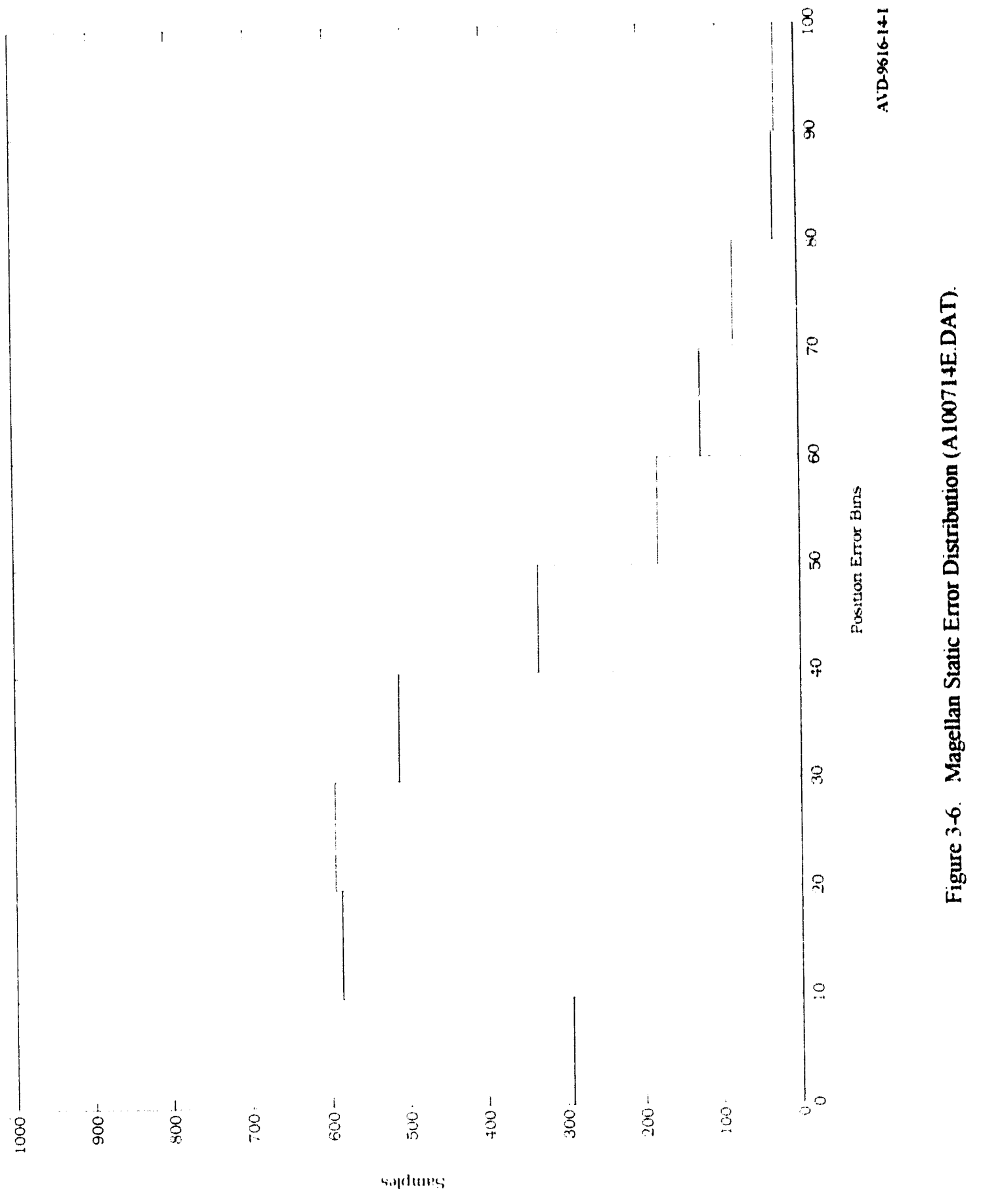




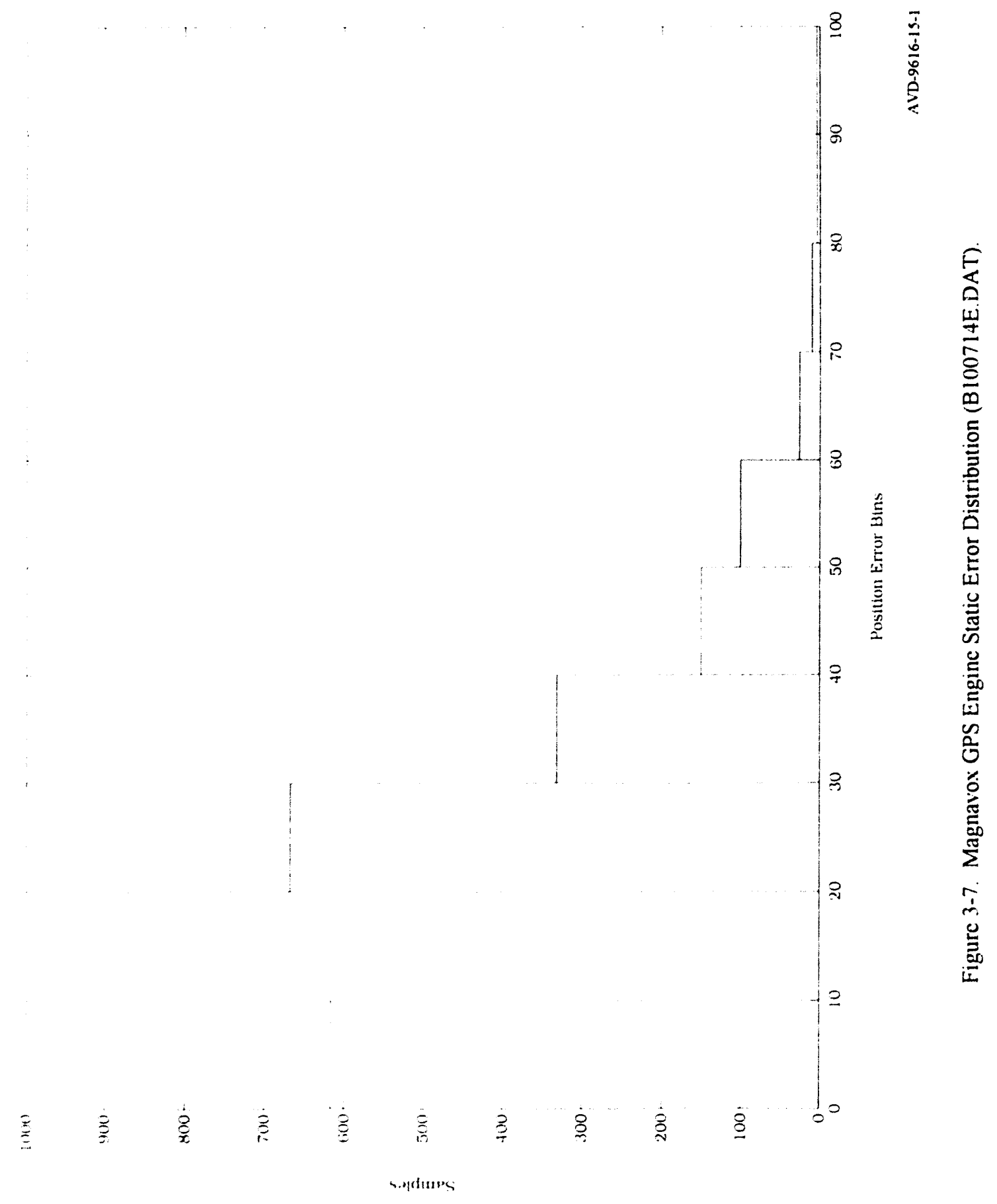




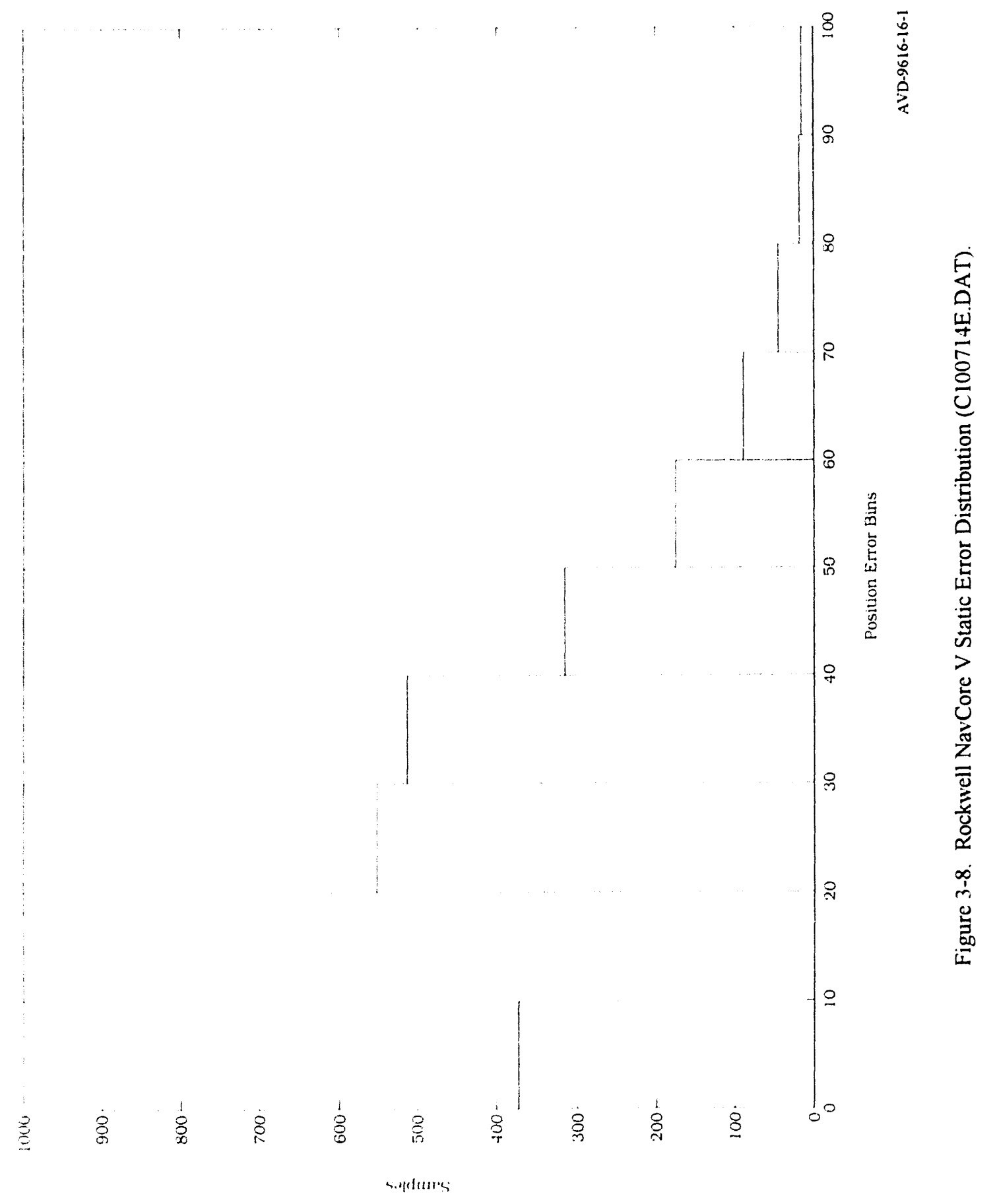




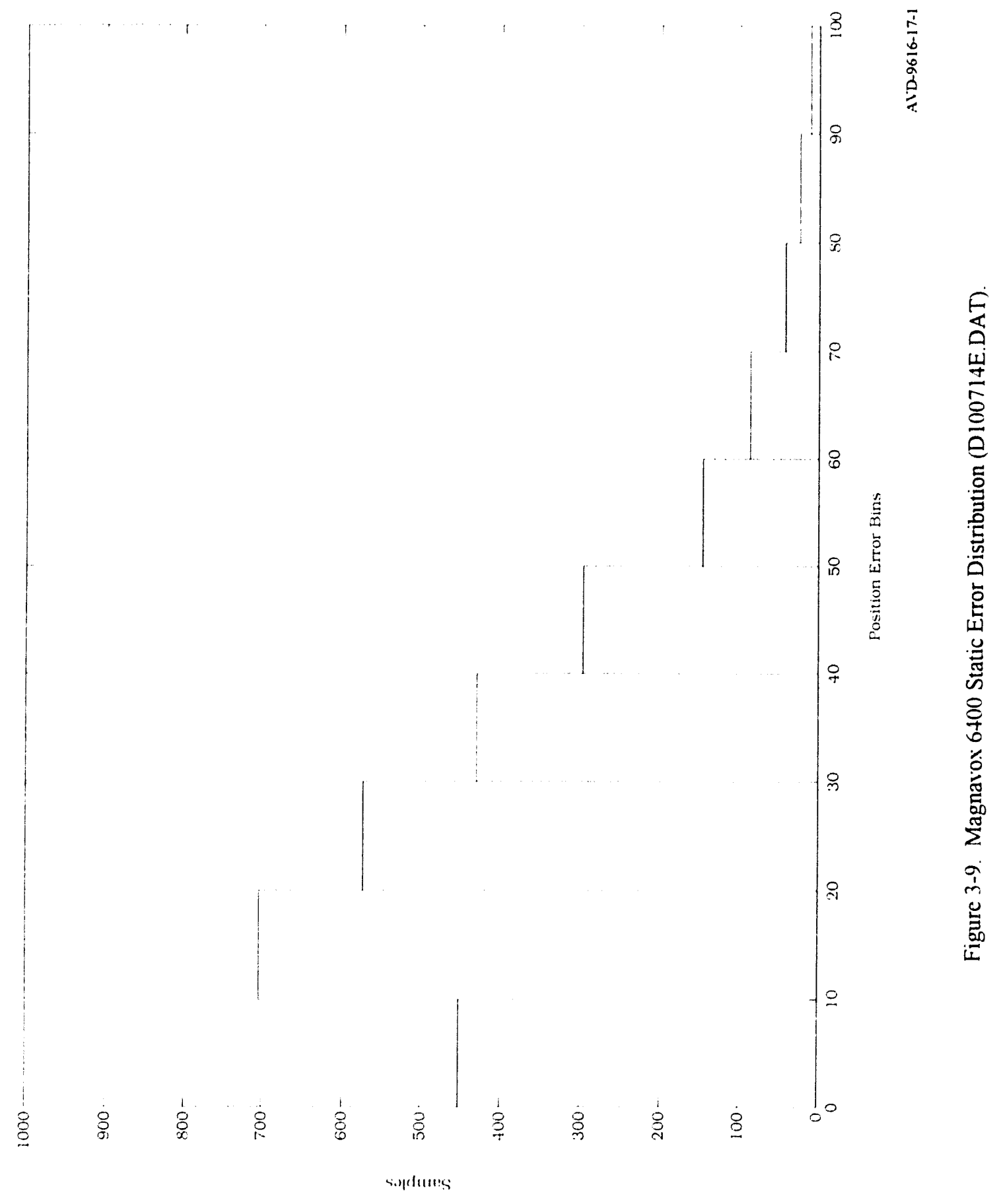




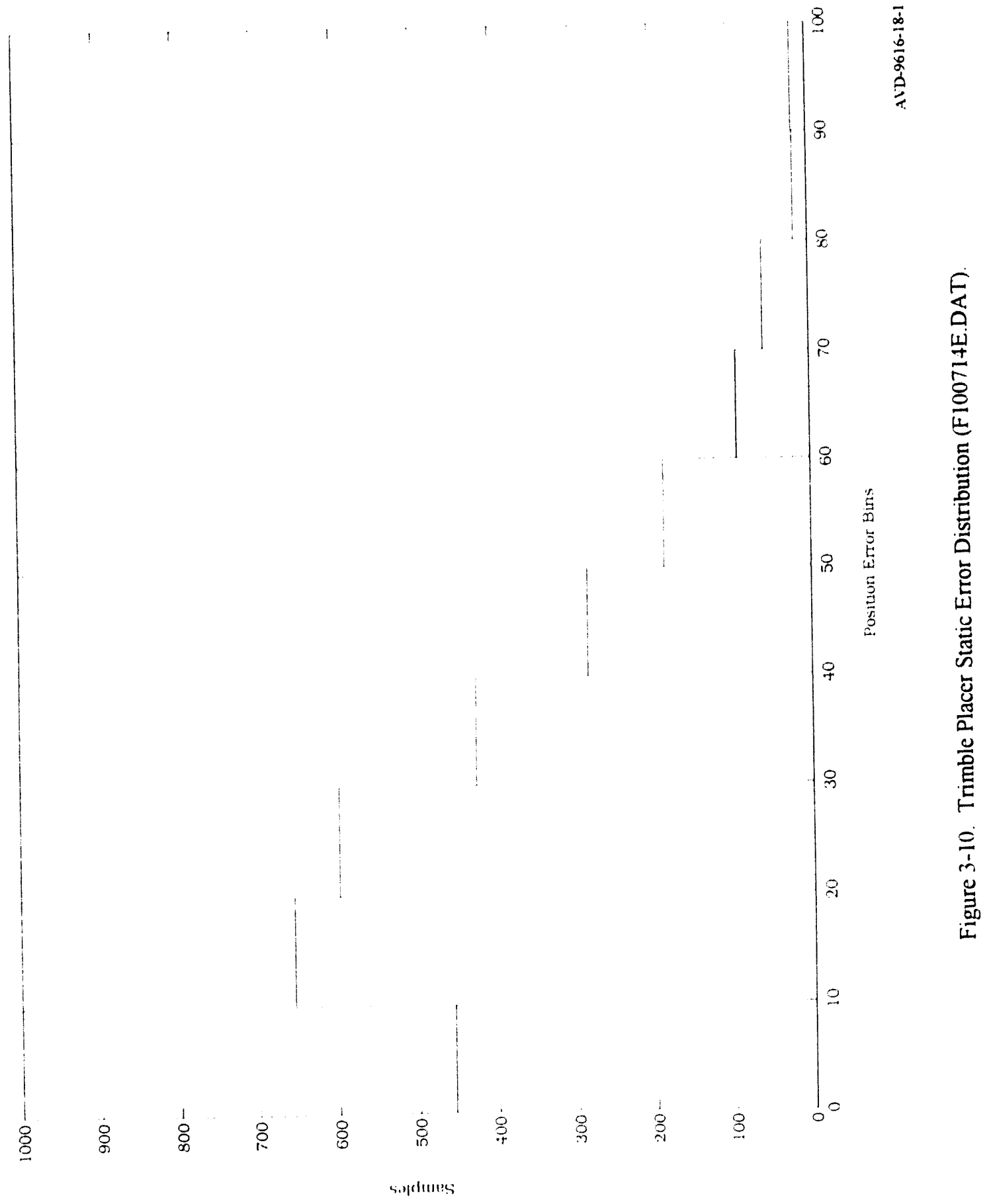


Navigation mode data for the different receivers is summarized in Table 3-3 for the static test. This data is also presented graphically in Figure $3-11$

Table 3-3. Summary of Navigation Mode Data for Static Test

\begin{tabular}{|c|c|c|c|}
\hline Receiver & $\%$ No Navigation & $1 \% 2-1)$ Navigation & $1 / 113-1)$ Navigation \\
\hline Magcllan & () & 17.78 & 82.22 \\
\hline Magnavox Engine & 0 & 2.35 & 97.6 .5 \\
\hline Rockucll Nancore & () & 2.66 & 97.34 \\
\hline Magnawox $64(1) 0$ & 1.55 & 2.22 & 96.23 \\
\hline Trimble Placer & 0 & 6.72 & 9) 28 \\
\hline
\end{tabular}

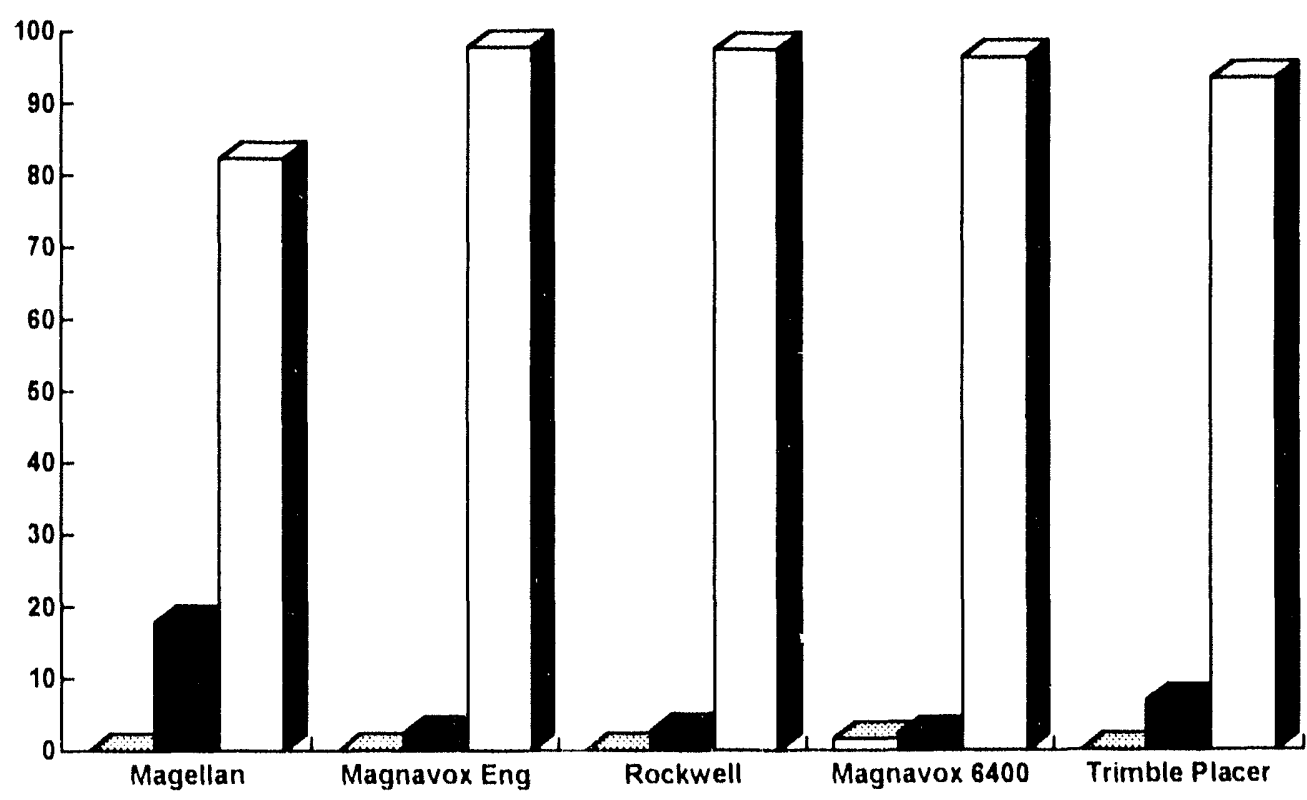

\section{$\square$ No Nav $\square$ 2D Nav $\square$ 3D Nav}

Figure 3-11. Navigation Mode Data for Static Test 
In order to analyge the data in Figure 3-11, one needs to take into account the DOP criterion for the different receivers. As mentioned previously. some receivers switch from 3-1) navigation (o 2-1) mavigation if four satcllites are visible but the DOP is above a predetermined threshold. The DOP switching criterion for the different receivers are outlined in Table 3-4. As seen in Table 3-4, the different receivers use different DOP criterion Howerer by taking advantage of Equations (3-1) and (3-2), the different DOP criterions can be compared.

$$
\begin{aligned}
& P D O P^{2}=V D O P^{2}+H D O P^{2} \\
& G D O P^{2}=P D O P^{2}+T D O P^{2}
\end{aligned}
$$

\begin{tabular}{|c|c|c|}
\hline Receiver & 2-D/3-D DOP Critcrion & PDOP Equivalent \\
\hline \multirow[t]{2}{*}{ Mangellan } & $\begin{array}{l}\text { If } 4 \text { satcllites visible and } V D O P>7 \text {, will } \\
\text { switch to } 2-D \text { navigation. }\end{array}$ & $P D O P \geq\left(I I D O P^{2}+7^{2}\right)^{1 / 2}$ \\
\hline & Enters 3-D navigation when VDOP $<5$. & PDOP $\leq\left(H D O P^{2}+5^{2}\right)^{12}$ \\
\hline \multirow[t]{2}{*}{ Magnavox GPS Engine } & $\begin{array}{l}\text { If } 4 \text { satcellites visible and } V D O P>10 \text {, } \\
\text { switches to } 2-D \text { navigation. }\end{array}$ & $P D O P \geq\left(H D O P^{2}+1()^{2}\right)^{12}$ \\
\hline & II IIDOP $>10$, suspends 2-D navigation & \\
\hline Rockwell NarCore $V$ & $\begin{array}{l}\text { If } 4 \text { satellites visible and (iDOP>13, } \\
\text { switches to } 2-1 \text { ) navigation. }\end{array}$ & $P D O P \geq\left(13^{2}-T D O P^{2}\right)^{12}$ \\
\hline Magnavox $(6400)$ & $\begin{array}{l}\text { Data Not Arailable in MX } 5400 \text { Manual } \\
\text { Provided }\end{array}$ & \\
\hline Trimble Placer & $\begin{array}{l}\text { If } 4 \text { satcllites visible and } P D O P=8, \\
\text { switches to } 2-D \text { navigation } \\
P D O P=12 \text {, receiver stops navigating }\end{array}$ & PIDOP $\geq 8$ \\
\hline
\end{tabular}

Table 3-4 Summary of DOP - Navigation Mode Switching Criterions

Table 3-t relates all of the different DOP criterions to the PDOP. Based on the information in Table 3-t. several comments can be made about the relative stringency of the various DOP criterions. First. the Magnavox GPS lingune VDOP criterion is much less stringent than the Magellan VDOP criterion (these wo can be compared directly). The Magellan unit also incorporates hysteresis, which makes the criterion eren more stringent Comparing the Rockwell to the Trimble Placer. the Rockwell criterion is much less stringent A 'T'DOP' of I0 2 would be required to make the two criterions equivalent. The Rockwell and Magnavox (iPS Engine have the least strungent DOP reguurements

Taking into account the DOP criterions of the different receivers. the significant amount of 2-1) navigatton exhibited by the Magellan receiver might be attributed to a more stringent DOP criterion. Ilowerer, this did not 


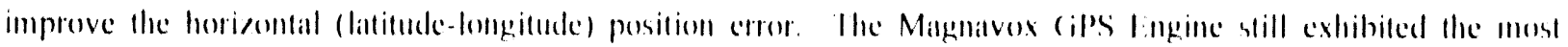

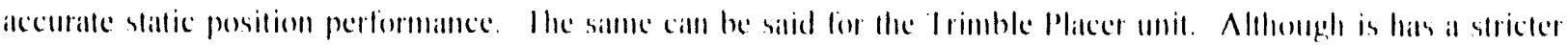

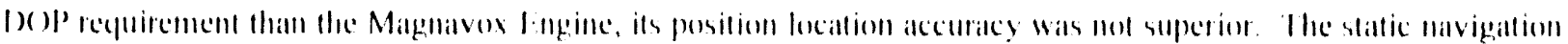
mode results dont conclusively show that any receiver has superior sensitivity. However, He static position error

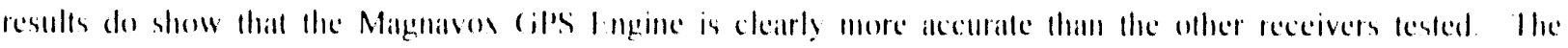
superior accuratey of the Magnavos receiver in the static tests might be attributed to more filtering in the receiver. It

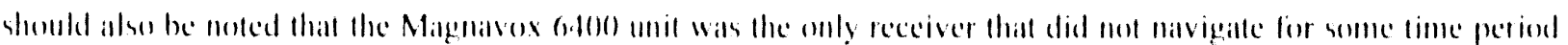
during the static test

\subsection{Dynamic Test Results}

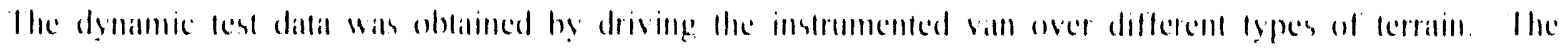

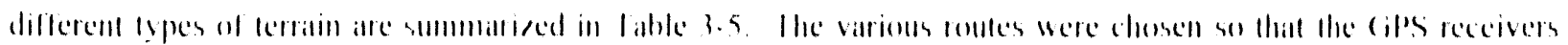

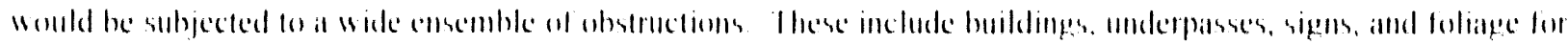

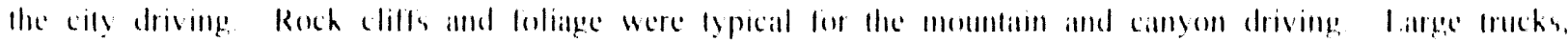

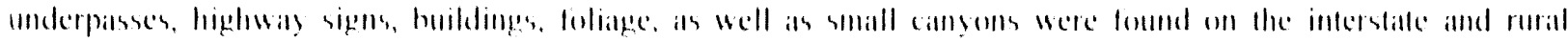
lightwaly droing! mules

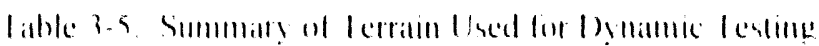

\begin{tabular}{|c|c|}
\hline Ierratim Iescription & Rond Sections, Ined for lestimg! \\
\hline (ii) Drivim! & 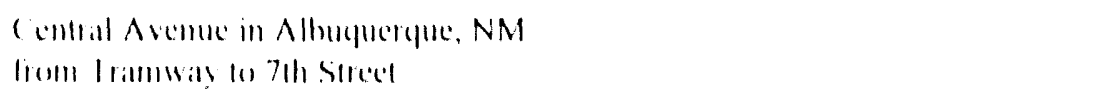 \\
\hline Monumain I movinge & 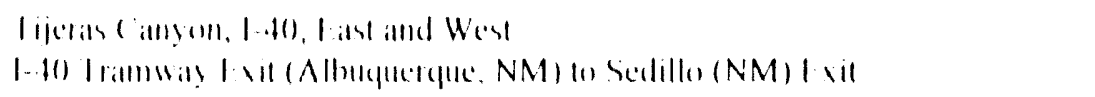 \\
\hline lnterstille llighmaly l)ris my! & 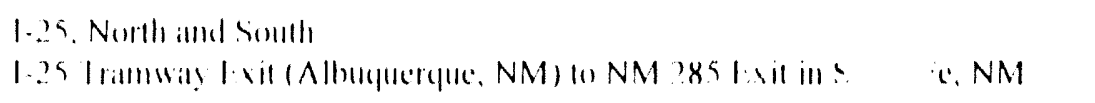 \\
\hline Rural Higlawaly Hrivin!! & 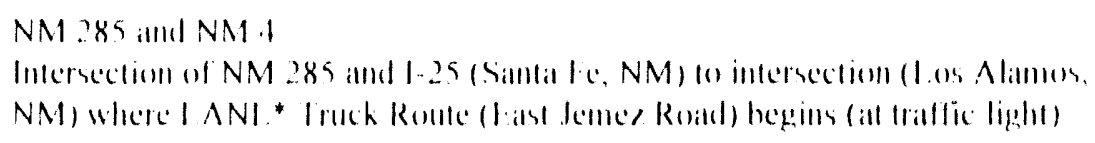 \\
\hline (amym I)riving & 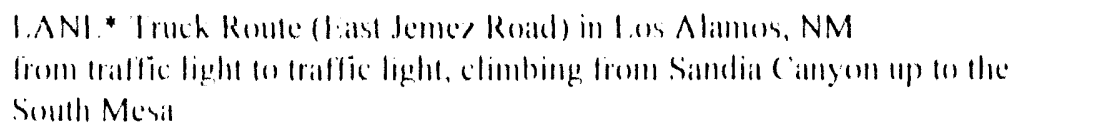 \\
\hline
\end{tabular}


The dymanic testing was carried out ower the course of several days the dalles of the different dymamic test roules are silmintarized in liable $3-6$

Table 3-6. Summanty of Dymamic Test Dilles

\begin{tabular}{|c|c|}
\hline Terrain Description & Dalles Testing Performed \\
\hline ('ily Drising & $10 / 22$ and $1(1 / 2.5 / 92$ \\
\hline Moumlain Drising & $1(1 / 2.5$ and $1(1 / 20 / 192$ \\
\hline Inlerstate Ilighwaly I)riving & $10 / 27$ and $10 / 28 / 92$ \\
\hline Rural Ilighway Drwing & $1(1 / 27$ and $1(1 / 28 / 4) 2$ \\
\hline (anỵon Driving & $1(1 / 27$ and $10 / 28 / 92$ \\
\hline
\end{tabular}

The results of the dymamic lesting are presented in wo formals first, a table is used to stmmmarize the percentage of 2-1) navigatıon, 3-1) navigation. and no navigation ('Tables 3-7 through 3-11) Then this information is presented graphically in the form of a bar graph (ligutres 3-12 through 3-16) The ratw dilla, including plots of the actual (ips position datia, appears in Appendix D) the dynamic test results as well als a discussion of the results appear on the following pages

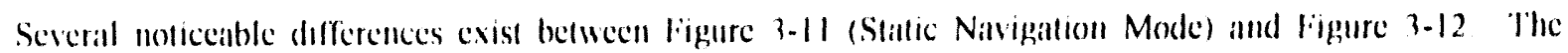

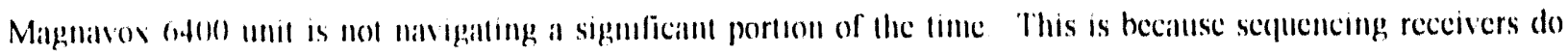
not perform as well in dynamic environments wilh periodic obstructions. The Magellan (ips receiver also masigated in 21) a larger percentage of the time compared with the other receivers The Rockwell unit wals able to

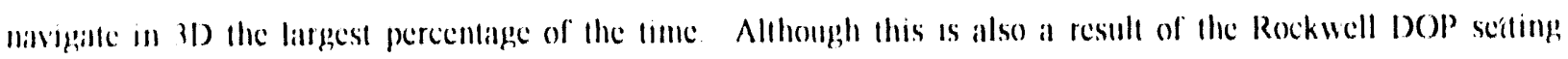
discussed in the previous section, it does seem to Indicite that the Rockwell receiver might hate slightly better sensitwity (Rockwell chams this is one of the recelver's sellimg points). The Magnitsox (ips limgme also did not mavifalle a small pereentage of the lame. This can be attribuled to the stmall period of time when the receiver was obstructed and the other receivers (which also were obstructed) might not have been oniputting, data (cillsed by asyuchronous silmpling)

The momntain driving actually yedded less obstructions than the cily driving. This might be a resull of better

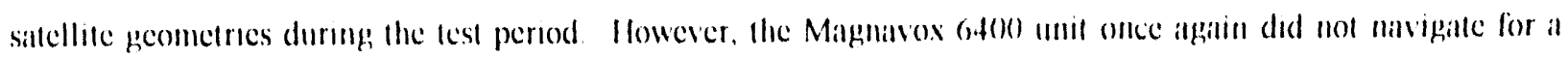
sigmeficant portion of the tume. The Magellan recester navigated in 21) a significint portion of the time, but this call be attributed to some degree to the stricte DOP limits The performance of the Rockwell Nat ('ore V. Trimble Placer, and Magnavox (ilds lingine are comparable 
liable 3-7 Summany of ('ity Driving Resulls

\begin{tabular}{|c|c|c|c|}
\hline Receiver & "/, No Nanigation & $11 / 2 \cdot 1$-1) Navigation & $1 / 3,3-1)$ Navigation \\
\hline Mappellill & () & 25.82 & 74.18 \\
\hline Magnialox lingine & 342 & 53.4 & ग) 2.4 \\
\hline Rockwell Nas V & 0 & 112 & $8 x 8$ \\
\hline Magnawox $(0+100)$ & 103.4 & 0.22 & 89.44 \\
\hline Trimble Placer & () & 5.18 & 94.82 \\
\hline
\end{tabular}

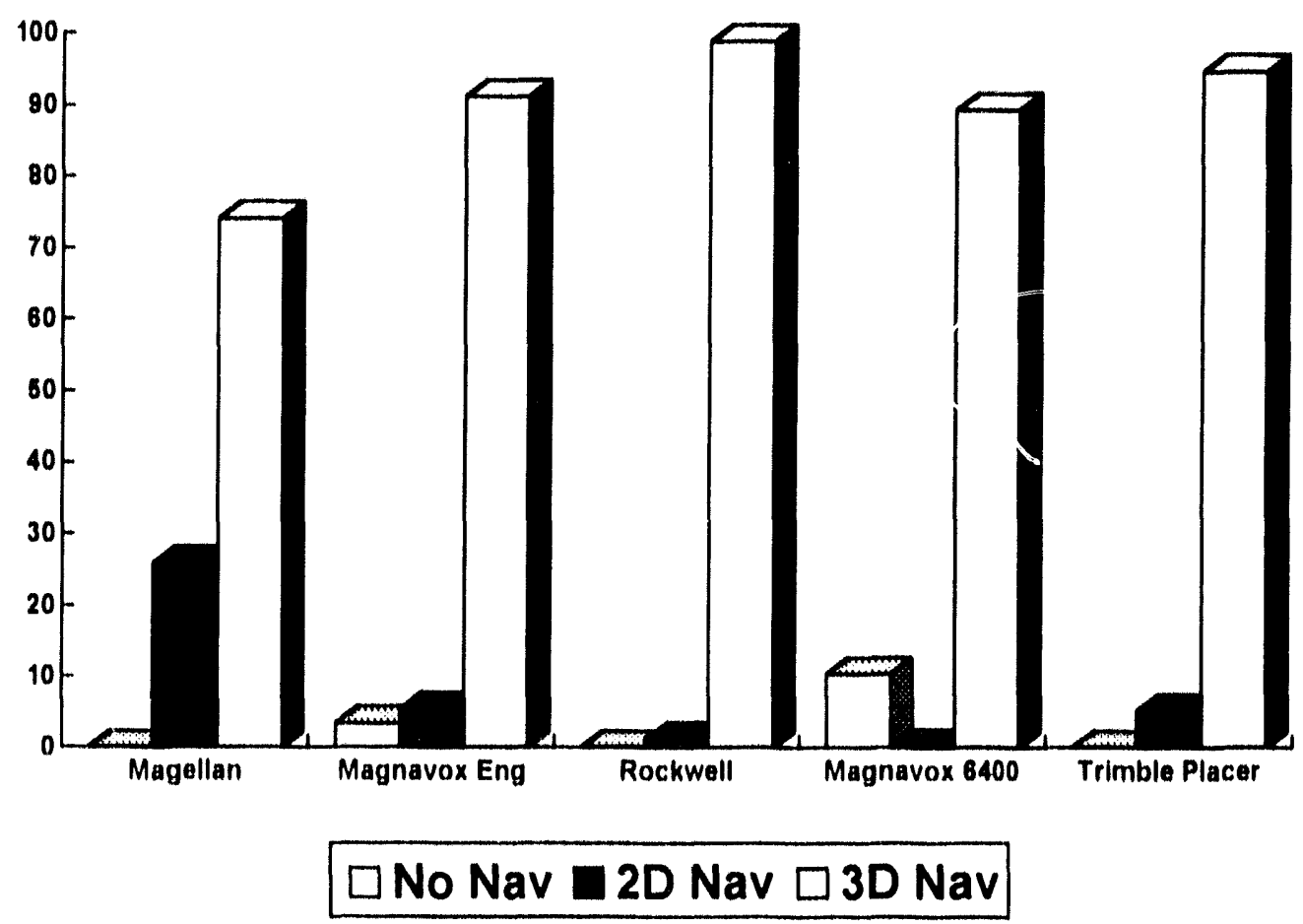

AVI) $)(6,201$

Figure 3-12. Summmary of (ity Driving Results 
Table 3.8. Summmary of Mountain Driving Results

\begin{tabular}{|c|c|c|c|}
\hline Receiver & "1/ No Navigation & $1 / 2-1$ Navigation & 1/3.D Navigation \\
\hline Maigellan & () & 12.29 & 87.71 \\
\hline Magnasox Engine & 0 & 0.97 & 99.03 \\
\hline Rockwell Nas V & () & () & 100 \\
\hline Magnasox $(04(0)$ & 4.55 & 0) & 95.45 \\
\hline Trimble Placer & () & 1.3 & 98.70 \\
\hline
\end{tabular}

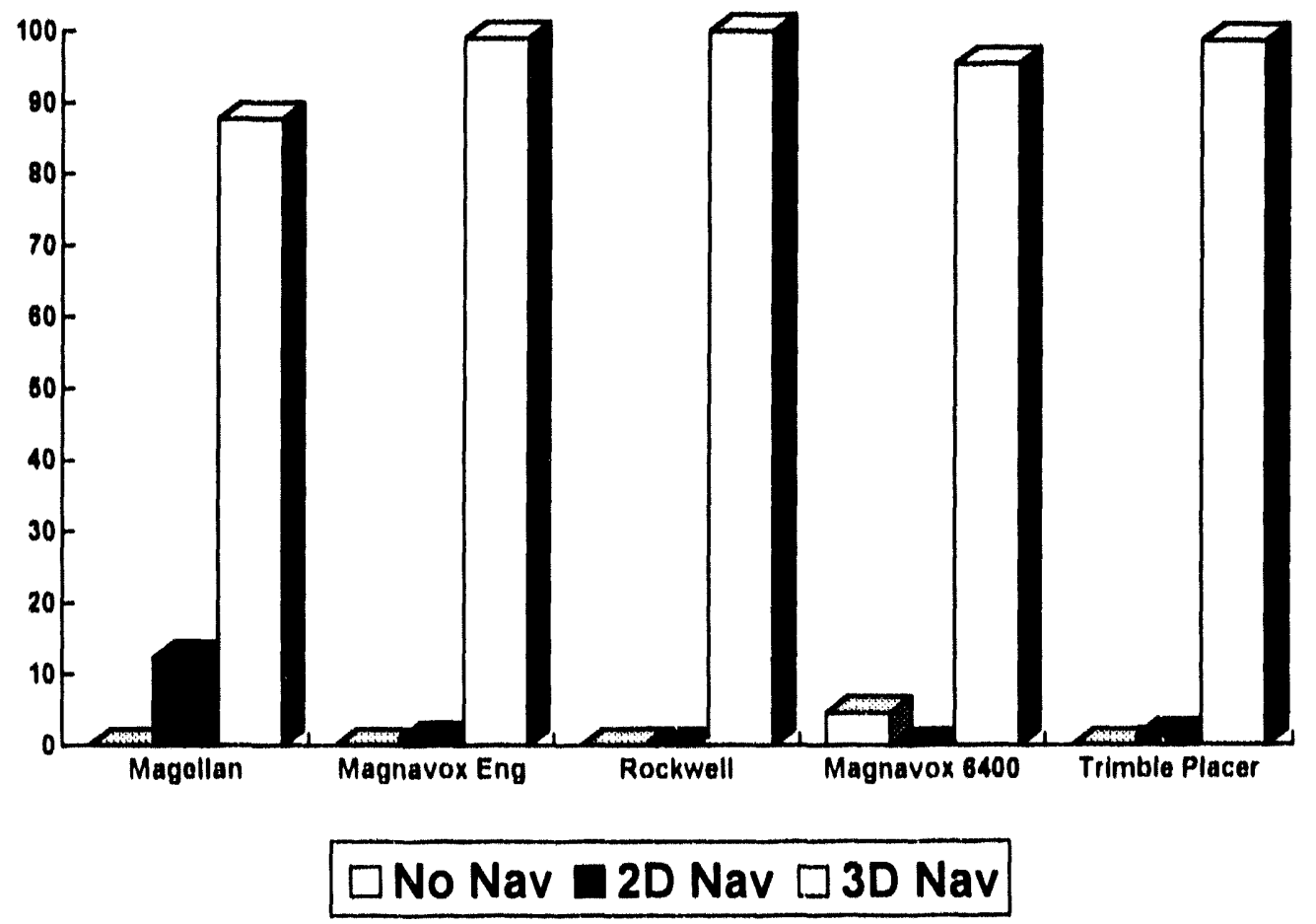

Avi) $9(6) 211$

Figure 3.13 Summary of Mountaun Driving Results 
Table 3-9). Summary of (anyon Driving Results

\begin{tabular}{|c|c|c|c|}
\hline Receiver & $1 \%$ No Navigation & $1 / 2-D$ Navigation & $\%$ 3-D Navigation \\
\hline Magcllan & () & 15.73 & 84.27 \\
\hline Magniwox Enginc & 1.114 & 4.35 & 94.57 \\
\hline Rockwcll Nav V & 1.18 & () & 98.82 \\
\hline Maghar ox 6400 & 30.17 & () & 69.83 \\
\hline Trimble Placer & () & () & 100 \\
\hline
\end{tabular}

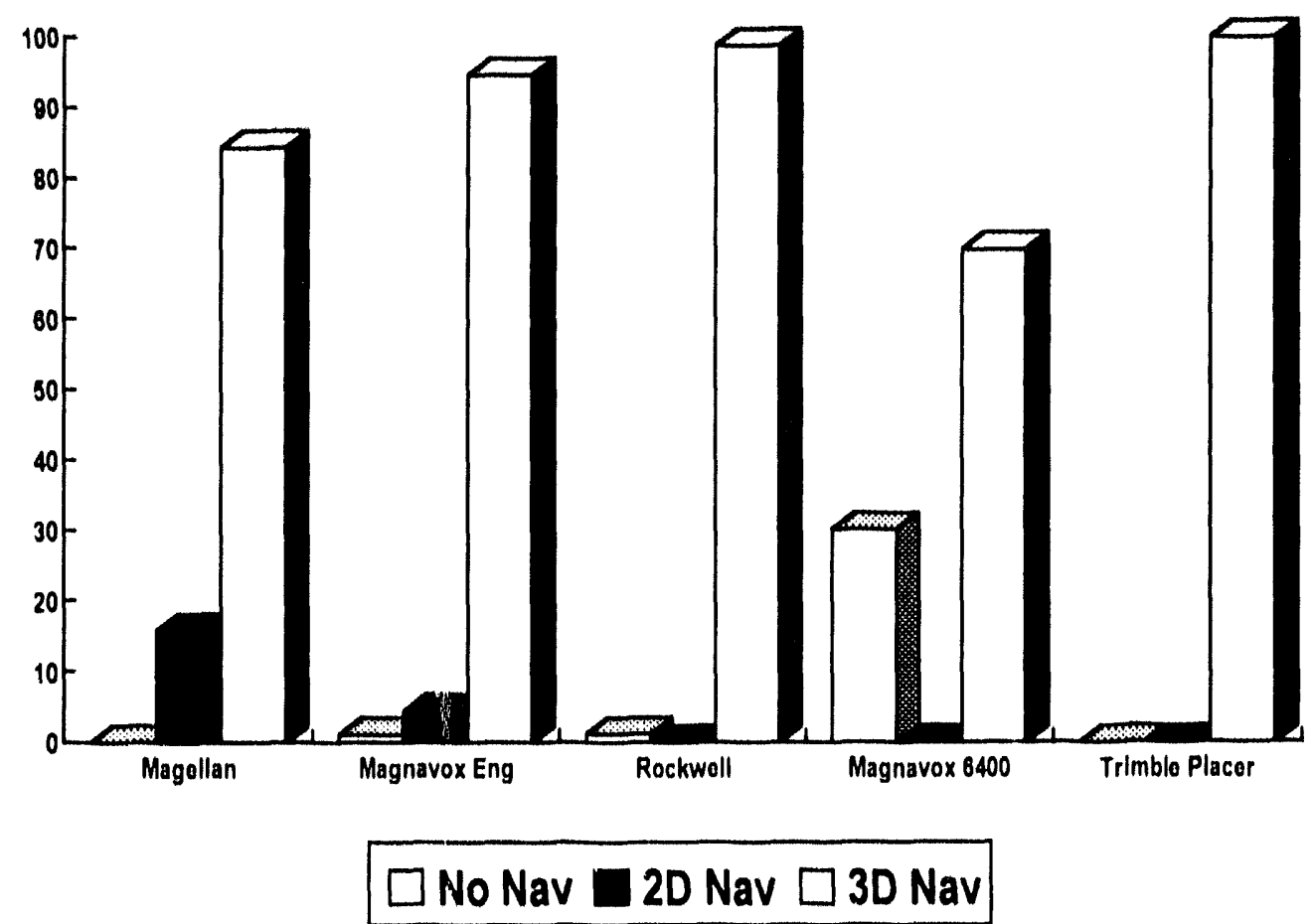

A 11961622

Figure 3-14. Summary of Canyon Driving Results. 
Table 3-10. Summary of Interstate Highway Results

\begin{tabular}{|c|c|c|c|}
\hline Recciver & $\%$ No Navigation & $\%$ 2-D Navigation & $\%$ 3-D Navigation \\
\hline Magcllan & 0) & 32.82 & 67.18 \\
\hline Magnavox Engine & 0.38 & 0.38 & 99.25 \\
\hline Rockwcll Nav V & 0.20 & 0.20 & 99.61 \\
\hline Magnavox 6400 & 20.08 & 0 & 79.92 \\
\hline Trimble Placer & () & 4.15 & 95.85 \\
\hline
\end{tabular}

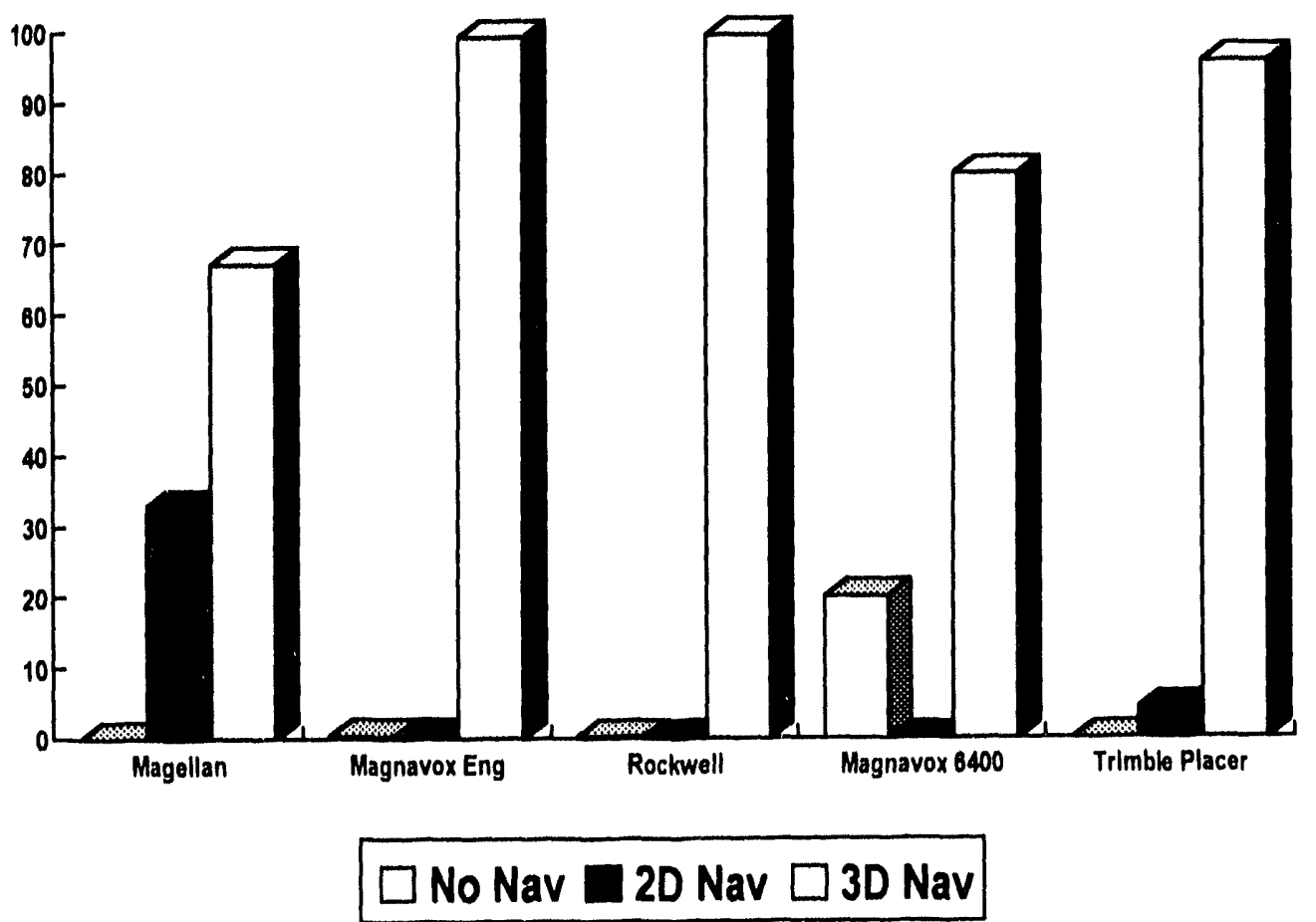

AVI) 9616.23 .1

Figure 3-15. Summary of Intcrstatc Highway Results. 
Table 3-11. Summary of Rural Highway Results

\begin{tabular}{|c|c|c|c|}
\hline Receiver & $\%$ No Navigation & $\% 2-\mathrm{D}$ Navigation & $1 \% 3-\mathrm{D}$ Navigation \\
\hline Magcllan & () & 7.35 & 92.65 \\
\hline Magnavox Enginc & 0.20 & 1.28 & 98.47 \\
\hline Rockwcll Nav V & 1.6 .3 & 0.54 & 97.83 \\
\hline Magnavox 6400 & 10.39 & 1.82 & 87.79 \\
\hline Trimble Placer & () & 3.89 & 96.11 \\
\hline
\end{tabular}

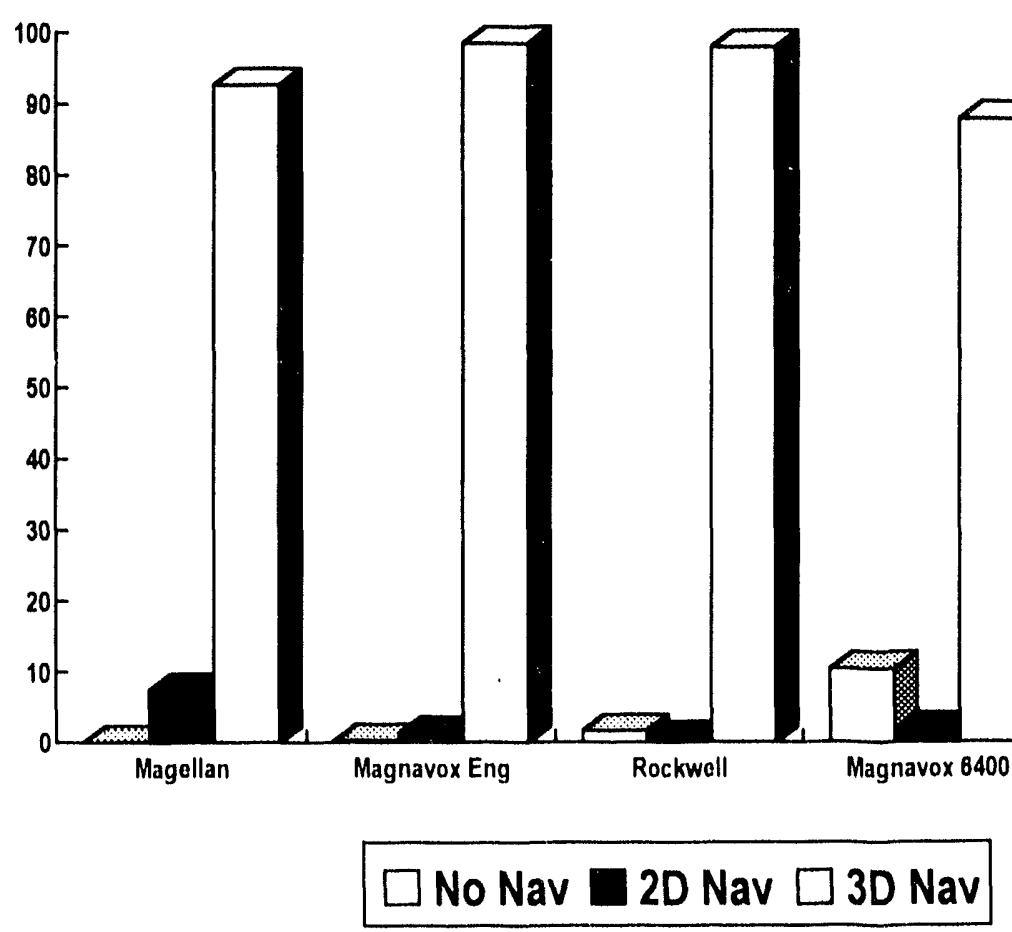

AVI) 9616 241

Figure 3-16. Summary of Rural Highway Results. 
The LANL. Truck Route Canyon testing exposed the CiPS receivers to the most obstructions. The stecp cillyon walls and abundant foliage stopped the current receiver from navigating over 30 percent of the time. The Magnavox GPS Engine and Rockwell receiver were also not navigating a small percentage of the time this particular test clearly shows the superiority of the newer receivers over the older sequencing receiver Beciuse the newer receivers are able to track cxtra satcllites and recover more quickly from obstructions, they are better sulted for opcration in dynamic environments with periodic obstructions. The Trimble Placer and Rockwell receiver performed the best in this particular test. followed closely by the Magnavox (iPS tingine

During the Interstate Highway driving tests. the Magnavos 6400 unit did not navigate over 20 pereent of the time. This is consistent with the sometimes poor performance exhibited by the current mavigation system. The other newer receivers did quite well, with the Trimble Placer, Magnavox (jPS Engine. and Rockwell Nar ('ore $V$ cxhibiting similar performance. Once again, the Magellan unit navigated in 2D) a significant portion of the time This can probably be attributed to the stricter DOP limits.

During the Rural Highway testing, the Magnavox $64(1)$ unit once agan did not navigate al significam portion of the time. All of the newer receivers had similar performance results The Magellan receiver nivigated in 21) considerably less in this test compared to the other dynamic tests.

\subsection{Summary of Test Results}

Both static and dynamic tests were used to compare the performance of the five different (ips receivers the static test results showed that the Magnavox (jPS Engine was the most accurate (for static situattons) The other four receivers were shightly less accurate and exhibited simular static position cror performance the stallic navigation mode results did not differentiate the sensitivity of the various receivers significantly The Magellan unit navigated in 2D much more frequently than the other receivers, but some of this can be altributed to stricter DOP limits. However, the stricter DOP limits of the Magellan receiver and Trimble Placer did not vield belter static position accuracies All four of the newer GPS receivers obtained a first fix under one mumute, which verifies the tume to first-fix specifications stated by the manufacturers.

The dynamic tests were used to differentiate receiver sensitivit! and the ability to recoser guickly from periodic obstructions. As expected. the Magnavox 6tofo until did not perform very well in the dinamic testing The Magnavox 64(0) was unable (o) navigate for some perod of each dynamic lest. This was most noticcable in the 1.ANI. Truck route canyon. where the receser did not havigate over 30 pereent of the tume the newer receivers performed much better in the dynamie testing. navigatung almost all of the tume the Magnatrox (ips bingine. Rockwell Nav Core $V$, and Trimble Placer exhibited comparable receiver/antenna sensitis lly during the dy namme testung based on the navigation mode data The Magellan unit navigated II 21) significantly more than the other receivers in the dynamic tests Most of this can probably be attributed to a more stringent DOPP refunrement 11 
should also be noted that the Magellan receiver was the only receiver to navigate (2D or 3D) 100 percent of the time in all of the dynamic tests

Orerall, the four newer receivers performed significantly better than the Magnavox 6400) unit in the dynamic tests In the static test. all of the receivers performed satisfactorily, but the Magnavox GPS Engine exhibited the most accurate position estimation. Recommendations on choosing a GPS recciver are outlined in the next section. 


\subsection{RECOMMENDATIONS}

The next two sections outline recommendations for choosing a GPS receiver as well as an integrated navigation system. Section 4.1 discusses the choice of a GPS receiver, while Section 4.2 discusses the requirements of the overall navigation system.

\subsection{GPS Receiver}

In order to discuss some of the integration issues involved with GPS receivers, a list of the problems encountered with the receivers tested is outlined in Table 4-1. The problems encountered with the Magnavox 6400 unit (there were several) are not listed because the Magnavox 6400 unit is not comparable to the newer receivers in performance.

Based on the problems experienced testing the GPS receivers as well as the requirements of the current application, a list of critical issues is outlined in Table 4-2.

One critical integration issue not mentioned in Table 4-2 is price. Almost any level of performance can be purchased, but at a significantly increased cost. This issue will be addressed further in the next section. Overall, the Magellan OEM Module, the Magnavox GPS Engine, Rockwell Nav Core V, and Trimble Placer are good receivers. The Magnavox GPS Engine exhibited superior static position accuracy. During dynamic testing, all of the receivers were able to navigate a large percentage of the time, even in hilly wooded terrain. Based on the experimental results, other integration issues such as price, software flexibility, technical support, size, power, and differential capability are probably the most important factors to consider when choosing a GPS receiver.

\subsection{Overall Navigation System}

The current navigation system uses dead reckoning (compass and odometry) and TRANSIT to supplement GPS. Because of the high value of the assets, a redundant navigation system is required. If the assumption is made that GPS is going to be operational 100 percent of the time for the long term, then the design of the navigation system is greatly simplificd. Assuming full GPS coverage, a redundant navigation system must be designed that can handle short periods of time when GPS is not available because of obstructions. The deadreckoning system only needs to be accurate for up to several minutes, which makes the design of the deadreckoning system much casier (and less expensive). 
4. Recommendations

Table 4-1. Summary of Problems Encountered with GPS Receivers Tested

\begin{tabular}{|c|c|}
\hline Recciver & Problems Encountered \\
\hline \multirow[t]{2}{*}{ Magcllan OEM Modulc } & $\begin{array}{l}\text { No problems, unit functioned correctly out of the box. However, the current } \\
\text { drain on the battery for the battery backed RAM scemed high. A I Amp- } \\
\text { Hour } 3.6 \text { volt Lithium battery only lasted a few months. }\end{array}$ \\
\hline & $\begin{array}{l}\text { The Binary position packet was used because of the increased position } \\
\text { resolution. Sometimes the receiver outputs a garbage binary packet (about } 1 \\
\text { percent of the time). }\end{array}$ \\
\hline \multirow[t]{2}{*}{ Magnavox GPS Enginc } & $\begin{array}{l}\text { The first unit received was a pre-production unit. It had a difficult time } \\
\text { tracking satellites. On one occasion it took over } 24 \text { hours to obtain a first } \\
\text { fix. This receiver was returned to Magnavox. Magnavox claimed that } \\
\text { upgrading the software fixed the problem. However, the EEPROM failed } \\
\text { when trying to load the oscillator parameters. A new production board was } \\
\text { shipped and it functioned flawlessly out of the box. }\end{array}$ \\
\hline & $\begin{array}{l}\text { The RF connector for the Magnavox GPS Engine was also difficult to obtain. } \\
\text { The suppliers recommended in the back of the GPS Engine Integration } \\
\text { Guide have large minimum orders. A sample connector was finally } \\
\text { requested. It never arrived and a sccond sample had to be requested. }\end{array}$ \\
\hline \multirow[t]{2}{*}{ Rockwcll Nar Core V } & $\begin{array}{l}\text { The first Rockwell receiver functioned for a while, and then began } \\
\text { outputting garbage at } 6(0) \text { baud }(960) \text { baud is the only sclectable baud rate). } \\
\text { Rockwell claims that a Gallium Arsenide IC that counts down a clock signal } \\
\text { was failing because of contamination from the plastic package of the IC } \\
\text { (suppliers fault). This Rockwell unit was returned for repair under warranty. }\end{array}$ \\
\hline & $\begin{array}{l}\text { The second Rockwell unit tested output data but did not navigate. Power } \\
\text { was applied to the unit with reverse polarity (Sandia's fault) and an internal } \\
\text { rectifier bridge allowed the unit to function, but not properly. Applying } \\
\text { power in the correct manner (positive on the outside contact) fixed the } \\
\text { problem. }\end{array}$ \\
\hline Trimble Placer & No problems, unit functioned correctly out of the box. \\
\hline
\end{tabular}


Table 4-2. Summary of Critical Integration Issues

Critical Issice

Flexible Software Interface

Differential ('apability

Time to first fix

Memory Back Up

Size, Power, and

Packaging

\section{Ralionalization}

Having the flexibility to control the dala output by the receiver is important. This includes serial data format (TTL. RS-2.32, RS-222), band rates, and packet data rates. It is desirable to have the receiver outpul position data at fixed data rate, that is user selectable. It is also desirable to be able to request other datia packets when needed All of the receivers with the exception of the Rockwell unit were fiarly flexible. The Rockwell unit on the otherhand outputs position data at a fixed 1-H1/ rate and fixed baud rate of 960) bilud.

The format of the data packets is also important. ASCII formats are casicr to work with because the raw data can be stored and then analyzed visually. The Rockwell unit uses an IEEE floating point format. Although Binary data formats and the Rockwell format might be more efficient, it is much easier to troubleshoot a problem when the data does not have to be post processed just to take a quick look.

The capability to receive differential corrections is important if increased accuracy is desired. Although a near-term ficlded system might not use differential corrections, the availability of subscriber networks that broadcast differential corrections in the future will probably make this a likely upgrade

A fast time-to-first-fix is important. However, all newer receivers usually advertise a first fix in under one minute when the receiver knows its approximate position. The difference between a 3()-second first fix and a onc-minute first fix is probably not that important. This parameter also affects how quickly the receiver can reacquire satellites after blockages.

Different manufacturers use different approaches for providing power to back up the static memory (which stores the last location, almanac, ephemeris, and receiver parameters) when the receiver is powered down. These include an internal lithium battery, an cxternal voltage supplied by the integrator, and a large capacitor. The large capacitor has the advantage of never needing replacement. This approach is taken on the Rockwell Nav Core V. However, the capacitor charge can only last for several wecks. An internal lithium battery can last for scveral years, but will eventually necd replacement. An external voltage supplied by the integrator can come from a number of sources, but must be taken into account when doing the system design.

Low power consumption and small size are advantagcous for vehicular applications. Some manufacturers also offer the antenna and receiver integrated into a single package. This has some advantages, but limits antenna choices 
Table 4-2. Summary of Critical Integration Issucs (continued)

\begin{tabular}{ll}
\hline \multicolumn{1}{c}{ Critical Issue } & \multicolumn{1}{c}{ Rationalization } \\
\hline Active/Passive Antenna & $\begin{array}{l}\text { Active antennas with built in amplificrs allow longer cable runs to the } \\
\text { receiver. Passive antennas require no power but can not be used with longer } \\
\text { cabling because of losses. }\end{array}$ \\
Cable length and & $\begin{array}{l}\text { The losses in the cabling and connectors must be taken into account when } \\
\text { number of connectors }\end{array}$ \\
Receiver/Antennang the cabling and choosing the appropriate antenna. \\
Sensitivity
\end{tabular}

The main integration issue is the level of coupling between the dead-reckoning system and the GPS receiver. A highly integrated system will be defined as a system where the dead reckoning and GPS are supplicd by a single manufacturer as a complete navigation system. The current navigation system supplied by Magnavox would be an cxample of a highly integrated system. A loosely integrated system will be defined as a system where the dead reckoning and GPS system are purchased or designed separatcly and then integrated by Sandia. The highly - itegrated system can actually be broken down further into two categories. Onc, a tightly coupled system, can be defined as a system where the dead-reckoning or inertial data is used in the same filter as the GPS data to estimate the current position. The other highly integrated system, a loosely coupled system, will refer to an integrated navigation system from a single manufacturer that does not include the inertial or dead-reckoning data in the GPS filter. These different configurations are depicted in Figures 4-1 and 4-2.

The tightly coupled configuration can use a centralized filter or cascade filter design, depending on the level of integration (Institute of Navigation, 1992). The loosely coupled system in Figure 4-2 results in a sub-optimal configuration because of the cascading of filters. However, it is often difficult to obtain raw GPS data. The loosely coupled system also has some advantages. These include casier fault detection and isolation as well as economy of operation (scveral reduced state filters rather than one large filter) (Institute of Navigation, 1992). 


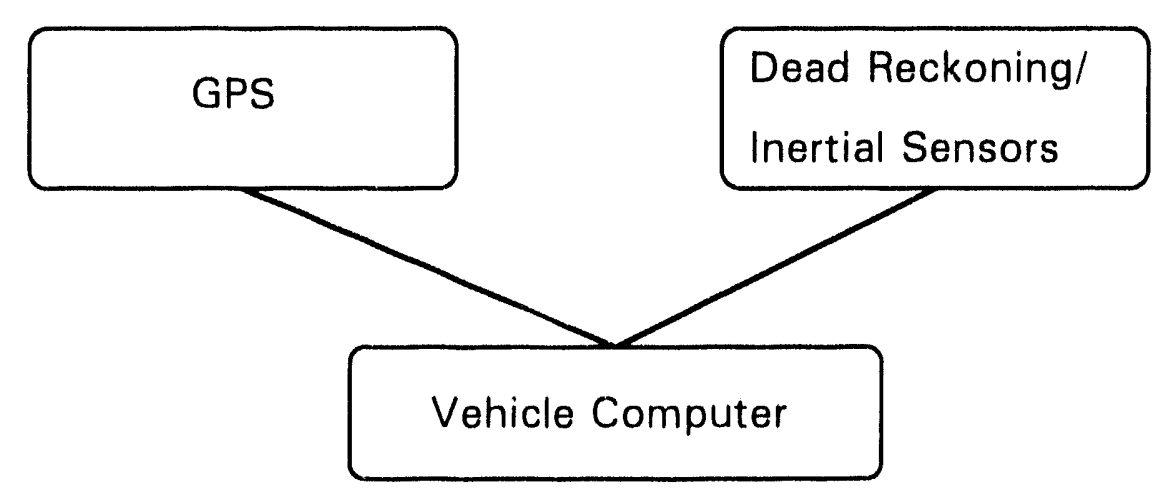

$\Delta V 1) .9616 .25 \cdot 1$

Figure 4-1. Looscly Integrated System.

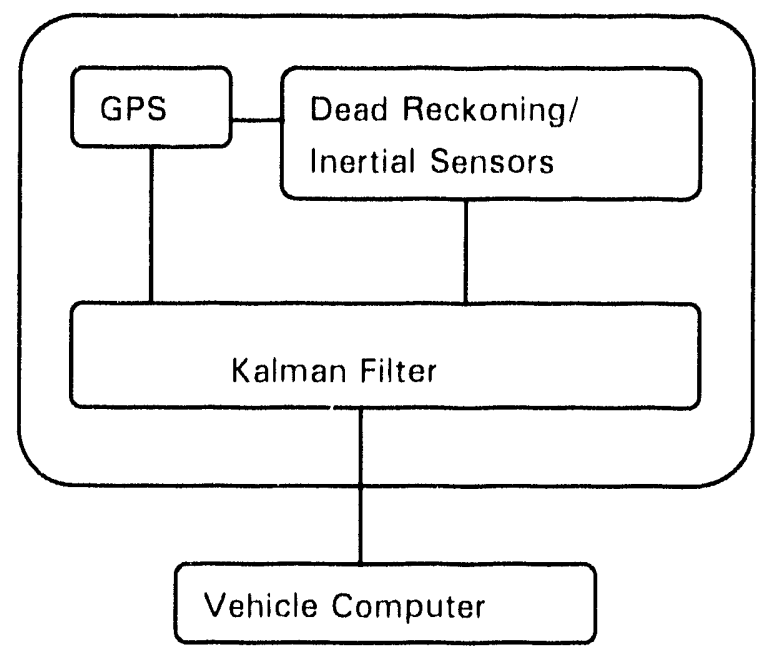

Tightly Coupled

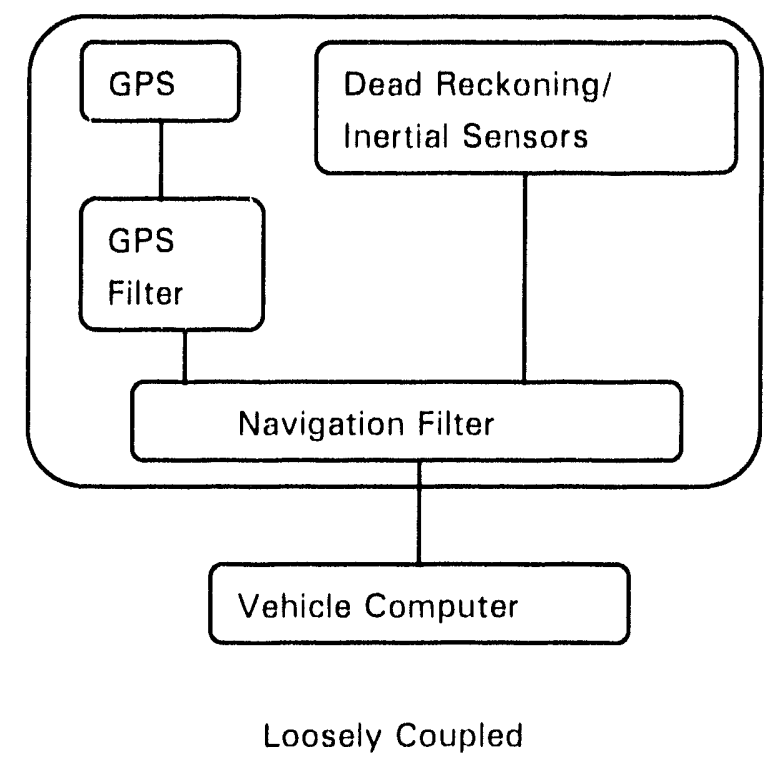

AVI) 9616.26 .1

Figurc 4-2. Highly Intcgrated Systems. 
The only difference between the loosely integrated system in Figure $4-1$ and the loosely coupled highly integrated system in Figure 4-2 is that the systems integration is already done for the highly integrated system. while Sandia (or a contractor) must do the integration for the looscly integrated system.

Tightly coupled GPS-Inertial Systems are being developed by several companies. However, no one has developed a tightiy coupled commercial system where dead-reckoning information, combincd with a vehicle model, is used with GPS in a single Kalman filter. Such a system is depicted in Figure 4-3. The advantages of this type of configuration include optimal position estimation. However, a considerable amoumt of time would have to be spent developing a vehicle model as well as characterizing the sensor noise. In addition. Imany of the functions already performed by a GPS receiver would not be utilized because the inputs to the filter would be the pseudo range estimates. Allhough this type of highly integrated position location system would provide an accurate and optimal position estimate. the time spent developing a good velicele model and characterising sensors would make the overall system very expensive

Because of the expense involved in developing the tighlly coupled position location system in Figure $4-3$, the most economical approach would be to purchase a loosely coupled highly integrated system or to integrate a loosely integrated system. There are advantages and disadvantages to both approaches. These are outlined in lable 4-3.

As secn in Table 4-3, the only real disadvantage of integrating a loosely integrated system is that Sandia must take the time to do the integration. The prices of several different systems are outlined in Table $4-4$ to compare the cost of the two options.

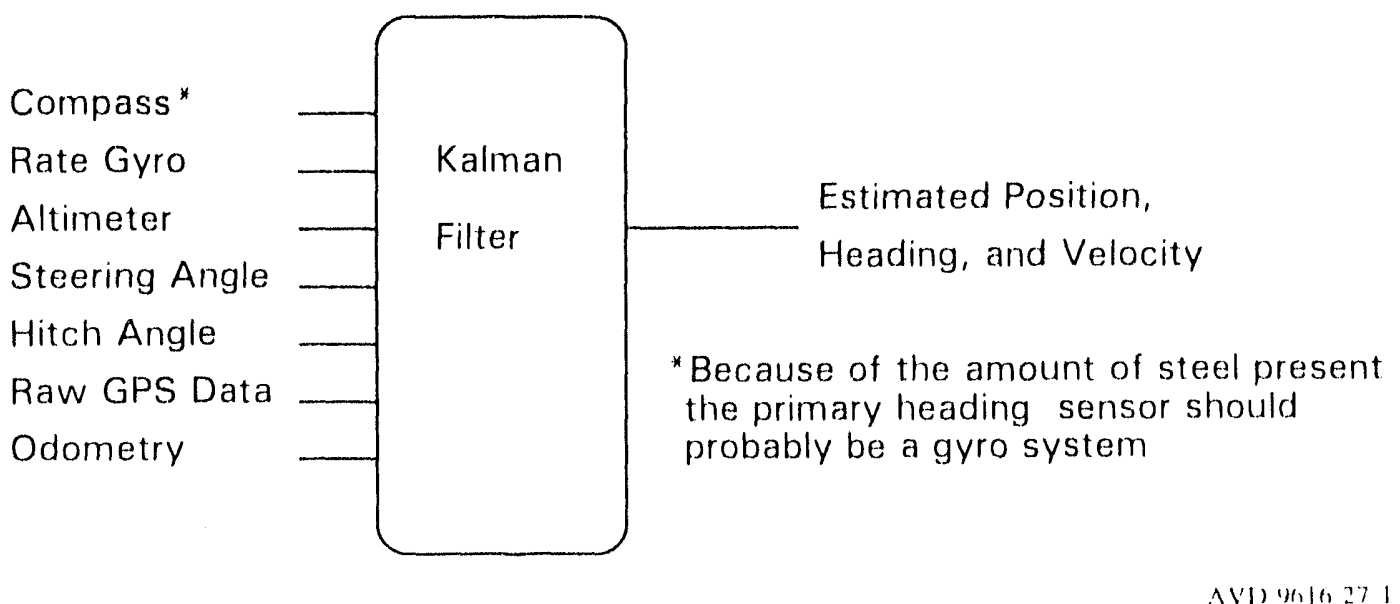

Figure 4-3. Tightly Coupled (jPS Navigation System. 
Table 4-3. Purchasing a llighly Integrated Navigation System vs. Performing the System Integration In-House

Purchase a Loosely (oupled
Ilighly lintegrated System

In order to compare purchasing a lonsely coupled highly integrated system to integrating a system in-housc, two different calses will be studied. Both cases assume that 200 systems will be purchased Case I describes the costs involved with a loosely coupled highly integrated system. while Case II covers the costs associated with integrating a sỵstem in-house.

\section{CASE I - Purchase a Loosely Coupled llighly Integrated System}

Assumc a Trimble Placer DR system is purchatsed. The Mangnavox integrated dead-reckoning (iPS system is not an off-the-shelf tem. Also, the Trimble system uses a rate gyro that should perform better than ant clectronic compass. The dead-reckoning accuracy of the Trimble Placer DR is specified as $3.5 \%$ of distance traveled up to 10 kilometers. The cost for 200 Trimble Placer systems is cillculated below.

$$
\begin{aligned}
& 200 \text { units } x \quad \$ 318.3 \text { per unIt }=\$ 6.36,6 \mathrm{~K} \\
& \text { Total Cost for } 200 \text { systems }=\$ 6.36 .6 \mathrm{~K}
\end{aligned}
$$


Trable 4-4. Summury of Pricing for Different Navigation Systems

\begin{tabular}{|c|c|}
\hline GPS/Navigation System & $\operatorname{Cost}(12 / 92)$ \\
\hline Trimble Placer DR - patch antcnma (Q)y $1-24)$ & $\$ 1.745$ \\
\hline Trimble Placer DR - patch antenna (Q1y 25-74) & $\$ 3,633$ \\
\hline Trimble Placer DR - patch antenna (Qty 75-149) & $\$ 3.44 .5$ \\
\hline Trimble Placer DR - patch antenna (Q)y 150-299) & $\$ 3.183$ \\
\hline Trimble Placer DR - patch antenna (Qty 3(1)(1-40)) & $\$ 2.121$ \\
\hline Trimble Placer DR - flange antenna (Q) $1-24)$ & $\$ 3,895$ \\
\hline Trimble Placer 30() w/differential (01y 1) & $\$ 1195$ \\
\hline Magellan OEM Module (Oty L-49) no antenna, w/differential & $\$ 44.5$ \\
\hline Magellan OEM Module $(Q t y+()()+)$ no antenna, w/differential & $\$ 3.4$ \\
\hline Antenna for Magcllan OEM Modulc (Avg Price) & $\$ 135$ \\
\hline Magnavox GPS Engine (Qty $1-24)$ no antenna, w/differential & $\$ 1.870$ \\
\hline Maignavox (iPS Engine (Qty 25-49) no antenna, w/differential & $\$ 1,360$ \\
\hline Magnavox (IPS Engine (Q1y. 5(1)-9)9) no antenna, w/differential & $\$ 1,1.50$ \\
\hline Magnavox (JPS Engine $(Q t y \mid()()-24$ ) no antenna, w/differential & $\$ 1,0(1)$ \\
\hline Magnavox (jPS Engine (Qty 25()-4ツ9) no antenna, w/differential & $\$ 050$ \\
\hline Antenna for Magnavox GPS Engine (Qty 1$)$ & $\$ 325-\$(10)$ \\
\hline Rockwell Nav Core V $($ Qty $I()(0)$ nol differential capable & $\$ 500$ \\
\hline
\end{tabular}

\section{CASE II - Integrate a Loosely Integrated System}

Assume, as calculated below, that the least expensive differential CPS system is purchased the Magellan OEM Modulc. Then determinc how much moncy would be available for development of the dead-reckoning system.

$\begin{array}{lll}\text { Receiver cost } & 200 \text { units } \times \$ 445 \text { per unit } & =\$ 89 \mathrm{~K} \\ \text { Antennal cost } & 200) \text { units } \times \$ 13.5 \mathrm{per} \text { unit } & =\$ 27 \mathrm{~K} \\ & & =\$ 116 \mathrm{~K}\end{array}$


Thus, the following are the funds len to develop dead-reckoning system:

$$
\$ 6.36 .6 \mathrm{~K}-\$ 116 \mathrm{~K}=\$ 520.6 \mathrm{~K}
$$

And then, assuming onc-man year of effort (0.5 for odometry, 0.5 for gyro system) at $\$ 150 \mathrm{~K}$, the following funds are len for hardware:

$$
\$ 520.6 \mathrm{~K}-\$ 150 \mathrm{~K}=\$ 370.6 \mathrm{~K}
$$

Thus, the cost per vehicle for gyro hardware is calculated below:

$$
\$ 370.6 \mathrm{~K} / 200 \text { units }=\$ 1,853
$$

These calculations assume that cxisting computing power could be used for the GPS dead-reckoning data fusion.

Although this is a rough cost comparison, because of the large number of systems involved, integrating the navigation system in-house might be justificd by the economics alone. Other reasons might include contributing to Sandia's Intclligent Vehicle Highway Systems (IVHS) tech basc as well as kecping sensitive information in-housc. In summary, a decision has to be made whether to purchase a fully integrated navigation system with a newer GPS receiver or to integrate a GPS receiver with a dend-reckoning system developed by Sandia or a contractor. The expertise for developing the dead-reckoning system is available at Sandia in Departments 9616 (odometry and vehicle modeling) and 2.334 (gyros and incrtial navigation). 


\subsection{SUMMARY AND CONCLUSIONS}

In summany, this report analyzes the performance of the current cipS receiver compared to newer, less expensive models and makes recommendations on possible options for upgriding the current system. The test fixture and lest melhodology used to perform both static and dymamic tests are documented. Static tests were used 10 determine the static position accuracy of the different receivers. Of the receivers tested, the Magnavox GPS Engine exhibited superior static position accuracy. All of the other receivers demonstrated similar. but less accurate static position accuracy Dynamic tests were used to determine how well the various receivers handle intermittent obstructions as well as to determine the receiver/antennil sensitivity. Because of different DOP limits, exict comparisons of the different receivers was difficult. Howerer. Laking into account DOP criterions and the navigation mode data. all of the newer receivers performed salisfictorily The performance of the newer receivers Was fitr superior to the current Magnawo 640() system being used. Based on the similar performance of the newer receivers in the dynimic tests, other integration issues like price, software llexibility, technical support. size. power. and differential capability are probably the most important factors 10 consider when choosing a GPS receiver.

The current navigation system uses dead reckoning (compass and odometry) and TRANSIT to supplement (ipS Becianse of the high value of the assets, a redundant nivigation system is required. If the assumption is made that (j)S is going to be operaltional 100 percent of the time for the long term. then the design of the current Inivigation system is grcinly simplified. Assuming full GPS coverage, a redundant navigation system must be designed that ciln handle short periods of time when GPS is not available because of obstructions. The deadreckoning system only needs to be atcurate for up to several minutes, which makes the design of the deadreckoning ș stem much easier (and less expensive).

The main integration issue is the level of coupling between the deald-reckoning system and the GPS receiver. A tightly coupled GPS navigation system that combines GPS data with incrtial and dead-reckoning sensors in a single Kalman filter would offer optimal perlormance. However, the cost of developing such a system would be fairly high (this approach should be taken if the 'best possible navigation system' is desired). A more economical approach would be to purchise a completely integrated GPS dead-reckoning sy'stem (like the Trimble Placer DR) or to develop the dead-reckoning sy'stem in-house and purchase a differential capable GPS receiver. Both options have advantages and disaldantages. These are summarized in Table 5-1.

A rough cost comparison of the two options in Table 5-1 was conducted in the previous section. The cost of integratung the system all Sandia might be justified on economics alone if cnough units are purchased. Other reasons for doing the dead-reckonng navigation in-house include keping the navigation tech base for IVHS related projects. Once a decision has been made whether 10 purchase an integrated system or to develop the dead- 
Table 5-1. Comparison of Integration Options

Purchase a Looscly Coupled

Highly Integrated System

Advantages

- Completc navigation system is an off-theshelf item.

- Simplificd maintenance because off-the-shelf system

\section{Disadvantages}

- The number of off-the-shelf integrated systems is limited. These include the Trimble Placer DR and a semi-custom Magnavox system.

- Sandia will be locked into a particular manufacturer for the complete navigation system
Integrate a Looscly Integrated System

Advantages

- Sandia is not locked into a particular manufacturer for the GPS system.

- GPS receivers can be updated as new technologies become available without affecting the dead-reckoning system.

- Sandia maintains vehicle navigation tech base that can be applicd to IVHS rescarch.

\section{Disadvantages}

- Sandia has to develop the dead-reckoning system (might not really be a disadvantage).

reckoning system in-housc, no major technical hurdles exist in implementing either system. Therefore, a decision has to be made, based on the data presented in this paper as well as the goals of the program, as to which option is most desirable. 


\subsection{REFERENCES}

Brown, R.G., and P.Y.C. Hwang. 1992. Introduction to Random Signals and Applied Kalman Filtering. 2nd cd. New York, NY: John Wilcy and Sons.

GPS Report. November 5, 1992. Potomac, MD: Phillips Busincss Information.

Institutc of Navigation. 1992. Class notes from "Introduction to GPS/INS Integration," Institute of Navigation GPS-92 Conference, Tutorials, Albuquerque, NM, September 14-15, 1992. Arlington, VA: Navtcch Seminars, Inc. 
APPENDIX A: TEST FIXTURE HARDWARE - CABLE PINOUTS

\author{
Developed by: \\ Raymond H. Byrne \\ Advanced Vehicle Development Department, 9616 \\ Sandia National Laboratories \\ Albuquerque, NM 87185
}




\section{APPENDIX A: TEST FIXTURE HARDWARE - CABLE PINOUTS}

\section{CABI.E PINOUTS}

\section{Connector Assignments}

Magellan $\quad$ ZT 890) J5(C()MI)

Magnavox Engine ZT 89()1 J4(COM2)

Rockwell NavCore V ZT $8841 \mathrm{JI}$

Magnavox 6400) ZT $8841 \mathrm{~J} 2$

Trimble Placer $\quad$ ZT $8841 \mathrm{~J} 4$

Magellan

\begin{tabular}{|lll|}
\hline Signal & DB-25 (Magellan) & 14 Pin (ZT 8901) \\
\hline TX & 3 & 3 \\
RX & 2 & 5 \\
GNI) & 7 & 13 \\
\hline
\end{tabular}

Rockwell Nav Core V

\begin{tabular}{|lll|}
\hline Signal & DB-9 (Rockwell Unit) & 14 Pin (ZT 8841) \\
\hline TX & 2 & 5 \\
RX & 3 & 3 \\
GNI) & 5 & 13 \\
\hline
\end{tabular}

Magnavox 6400

\begin{tabular}{|lll|}
\hline Signal & DB-25 (Magnavox 6400) & 10 Pin (ZT 8841) \\
\hline GNI) & 1 & 8 \\
GNI) & 7 & 7 \\
TX(A) & 14 & 14 \\
TX(B) & 2 & 13 \\
RX(A) & 15 & 1 \\
RX(B) & 3 & 2 \\
\hline
\end{tabular}

Trimble Placer

\begin{tabular}{|lll|}
\hline Signal & DB-25 (Trimble Placer) & 14 Pin (ZT 8841) \\
\hline TX & 3 & 5 \\
RX & 2 & 3 \\
RTS & 5 & 9 \\
CTS & 4 & 7 \\
GNI) & 22 & 13 \\
\hline
\end{tabular}

Magnavox GPS Engine Serial Interface

- TTL to RS-232 conversion done with a Maxim MAX235 chip

- A LM34()-5 chip was used to generate $+5 \mathrm{~V}$ from the battery supply

- A LM3 17 chip was used to generate $7 \mathrm{~V}$ from the battery supply 


\section{APPENDIX B.1: SERIAL DATA FORMATS - MAGELLAN OEM MODULE}

Excerpts (pages 3-1, 3-2, 4-1, and 4-2) from the 1992 User (inide for the Magellan OLM (GPS Module.

Reprinted with permission from

Magellan Systems Corporation

960 Overland Court

San Dimas, CA 91773 
B. 1-2

B. $1-2$ 


\title{
APPENDIX B.1: SERIAL DATA FORMATS - MAGELLAN OEM MODULE
}

\section{CHAPTER 3 OEM MESSAGE DEFINITIONS}

\section{PORT CONFIGURATIONS}

\author{
Baud Rate options: $1200,2400,4800,9600$ baud \\ Data Bits: $\quad 8$ \\ Parity: None \\ Stop Bits: $\quad 1$
}

The baud rate on the OEM is set by jumpers on the PCB. (See Delault PCB Configuration in Chapter 6.) Once in operation, firmware protocol will allow the baud rate to be changed. The change will be retained with memory backup, but if all power is removed the baud rate resets to the default as sel by the jumpers.

\section{MESSAGE FORMATS}

Both binary and ASCII formats are provided for most of the sentences. The exceptions are listed below:

$$
\begin{aligned}
& \text { Binary only: J00 - Differential corrections } \\
& \text { T01 - Almanac data } \\
& \text { T02 - Ephemeris data }
\end{aligned}
$$

ASCII only: PMGLI - Data flow contro

\section{BInary}

The BINARY sentence starts with "\$\$" (two HEX 24) followed by a one-byte sentence identifier (from $A$ to $Z$ in ASCII) and a one-byte binary subindex (00 to FF HEX), followed by the binary data field. All of the binary data are in integers with defined precision. The sentence is terminated with a line feed (HEXOA). The checksum of the sentence is one byte before the line feed, and is required in binary format. The checksum is calculated by XORing the 8 binary data bits of each byte in the sentence with each other, starting with the first byte after the "\$\$" and ending with the first byte before the checksum. For example:

\section{$\$ \$ R 100000000 \mathrm{CL}$ \\ $\times \times \% \times \times \% \times \% \times \%$}

(" $x$ " denotes data field to be XORed, "C" denotes checksum, "L" denotes line feed)

\section{ASCII}

The ASCII sentences conform to the NMEA (National Marine Electronics Association) 0183 software prolocol Two types of sentences are used. Where the 0183 protocol has a pre-defined sentence for specitic data, this sentence is used. This includes GPGGA, GPZDA, GPVTG, GPBOD GPBWC, GPHDM, GPHDT, GPAPA and so forth. For information that does not have a predefined sentence, we used the method defined in the protocol for designing our own proprietary sentences so they will be compatible with the standard sentences. The headers 
for proprietary sentences use ' $P$ ' for proprietary, 'MGL' for Magellan as manufacturer's identification, and a primary index of ' $A$ ' through ' $Z$ '. The first data field is a subindex, which has a range of from 00 to 99 . The checksum is the 2-byte hexadecimal ASCll of the binary byle, and is calculated by XORing each successive byte in the sentence, between the ' $\$$ ' and the '*'.

All data output sentences have the checksum calculated. The board's firmware does not require a checksum on ASCIl inpul, but withoul one the integrity of the data cannol be guaranteed. II you do not want to send the checksum, omit the "*. and the iwo following bytes

\section{Example with checksum:}

$$
\begin{aligned}
& \text { \$PMGLI, 00, U03, ],A, 02*CKRL } \\
& \times \times \times \times \times \times \times \times \times \times \times \times \% \times \times \times \times \times \%
\end{aligned}
$$

(' $x$ ' denoles data field to be XORed, 'CK' denotes 2 bytes checksum, ' $\mathrm{A}$ ' denotes carriage return - hex OD, ' $L$ ' denotes line teed - hex OA)

Example without checksum

$$
\text { SPMSL1, O0, U0\% } 3,1,2,02 \mathrm{~kL}
$$




\section{CHAPTER 4 OEM FIRMWARE PROTOCOL}

\section{OUTPUT MESSAGES}

Output messages are from the module to the host. Also, the ASCII reference included in each message title is the one used in the PMGLI (data flow control sentence) for that message.

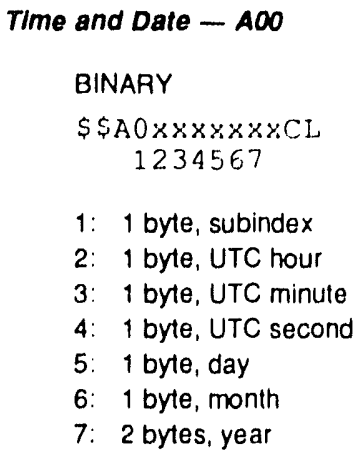

1: 6 bytes, UTC hhmmss

2: 2 bytes, day

3: 2 bytes, month

4: 4 bytes, year

Position and Alttude - BOO

BINARY

\$\$BOXXXXYXXYXXXXXXXXCL

$$
12.345
$$

1: 1 byte, subindex

2: 4 bytes, timetag in seconds, offset from the beginning of the GPS week (00:00 Sunday GMT)

3: 4 bytes, latitude in $10^{-7}$ degree (two's complement)

4: 4 bytes, longitude in $10^{.7}$ degree (two's complement)

5: 4 bytes, altitude in 0.01 meterffeet 
ASCII

\$GPGGA, $x \times x \times x x, x \times x x, x x, N, x \times x \times x, x x, w, x, x, x \times x, x \times x, M, x \times x x, M^{\star} C K R L$

$$
\begin{array}{lllllllllll}
1 & 2 & 34 & 5 & 6 & 7 & 8 & 9 & 10 & 11 & 12
\end{array}
$$

1: 6 bytes, UTC timetag of position fix (hhmmss)

2: 7 byles, GPS latifude (DDMM.HH where $D=$ degrees, $M=$ minutes, $H=$ hundredths of minutes)

3: 1 byte, latitude $\mathrm{N}$ or $\mathrm{S}$

4: 8 bytes, GPS longitude (DDDMM.HH)

5: 1 byte, longltude $E$ or $W$

6: 1 byte, GPS availability

$0=$ GPS nol avallable (last fix more than 10 seconds ago)

1 = GPS avallable

7: 1 byte, number of satellites being used (3 or 4)

8: 3 byles, HDOP (recalculated every 3 minutes or with every fix if PDOP $>8$; see message G00 tor a briel explanation of DOP's)

9-10: 3 bytes, antenna height, meters/teet (height above sea level)

11.12: 4 bytes, geoidal height, meters/eet (difference between antenna height and geoidal height in the WGS84 map datum)

Position Only - B01

BINARY

Same as $\$ \$ B O$

ASCII

$\$ G P G L L, x \times x \%, \times x, N, x \times \times x \times, \times x, W^{\star} C K R L$

$$
123 \quad 4
$$

1: 7 bytes, last fix latitude (DDMM.HH)

2. 1 byte, latitude $\mathrm{N}$ or $\mathrm{S}$

3: 8 bytes, last fix longitude (DDDMM.HH)

4: 1 byte, longitude $E$ or $W$

Extended Althude - B02

BINARY

$\$ \$ B 2 \times \times \times \times C L$

12

1: 1 byte, subindex

2: 4 bytes, altitude in 0.01 meters/feel 


\title{
APPENDIX B.2: SERIAL DATA FORMATS - MAGNOVOX GPS ENGINE
}

\author{
Excerpts (pages A-1 to A-4) from the 1991 \\ Magnovox (iPS Engine Integration Guide.
}

Reprinted with permission from:

Magnavox Advanced Products and Systems Company

2829 Maricopa Street

Torrance, CA 90503 
B. 2-2 


\section{APPENDIX B.2: SERIAL DATA FORMATS - MAGNAVOX GPS ENGINE}

\section{CONTROL PORT RECORDS}

NOTE

The structure of the control port records is based on the NMEA-0183 Standard for Interfacing Marine Eloctronics Navigation Devicos (Version 1.5). For details beyond those provided in this appendix, refer to the Standard document

Reserved characters are used to indicate the beginning and the end of records in the data stream, and to delimit data fiekds within a record. Only printable ASCll characters (Hex 20 ihrough $7 F$ ) may be used in the records. Table A.1 lists the reserved characters and delines their usage. Figure A-1 illustrates the general Magnavex proprietary NMEA record tormal

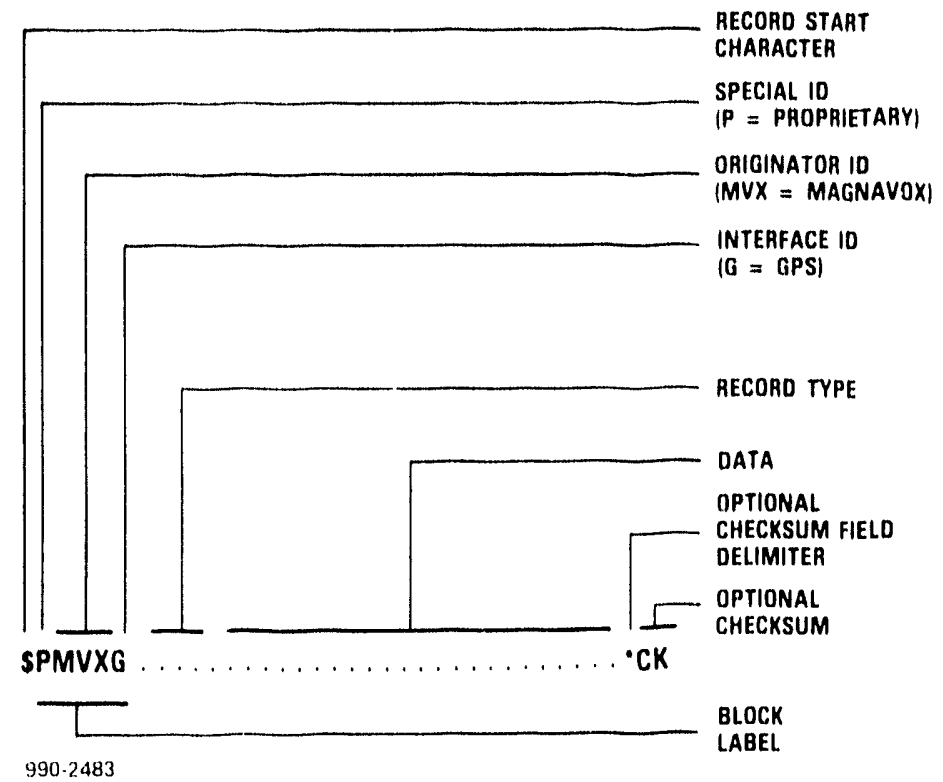

Figure A-1. Magnavox Proprietary NMEA Record Format 


\section{CONTROL PORT RECORDS}

Table A-1. NMEA Record Reserved Characters

\begin{tabular}{|l|l|l|}
\hline \multicolumn{1}{|c|}{ Character } & \multicolumn{1}{|c|}{ Hex Value } & \multicolumn{1}{c|}{ Usage } \\
\hline$\$$ & 24 & Start of Rocord Identifier \\
\hline$\{\mathrm{CR}\}\{\mathrm{LF}\}$ & OD OA & End of Record Identifier \\
\hline & $2 \mathrm{C}$ & Record Fiold Delimiter \\
\hline & $2 A$ & Optional Checksum Field Delimitor \\
\hline
\end{tabular}

Following the start character (\$), the first five characters constitute the block label of the record. For the Magnavox proprietary records, this label is always PMVXG. The next field after the block label is the record type consisting of the three decimal digits.

The data, delimited by commas, follows the record type. The data is defined for each record in Tables A.2 through A.37. Note that the GPS Engine ${ }^{\text {r* }}$ uses a free-format parsing algorithm so, you need not send the exact number of characters shown in the examples. You will need to use the commas to determine how many bytes of data need to be retrieved

The notation *CK shown in the tables symbolically indicates the optional checksum in the examples. The checksum is computed by exclusive-ORing all of the bytes between the $\$$ and the * characters. The $\$, *$ and the checksum are not included in the checksum computation. 


\section{CONTROL PORT INPUT RECORDS}

Table A-2. Record Type SPMVXG,000

Eunction: Initialization/Mode Control - Part A. Initializes the time, position and antenna height of the GPS Engine ${ }^{\text {tu }}$.

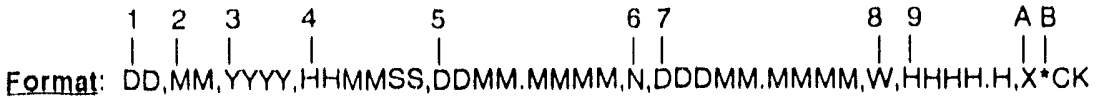

where:

Eield

Field Contents

Default Bange

1: DD

Day of month

$\begin{array}{ll}- & 1.31\end{array}$

2: MM

Month of year

$-$

$1 \cdot 12$

3: YYYY

Year

1992

$1991 \cdot 9999$

4: HHMMSS

GMT

5: DDMM.MMMM

Latitude (degrees, minutes)

$-$

235959

6: N

North $(S=$ south $)$

00.000

$0 \cdot 89.9999$

7: DDDMM.MMMM

Longitude (degrees, minutes)

N

$N$ or $S$

8: W

West $(E=$ east $)$

$E$

$E$ or W

9: HHHHH.H

Altitude (height above Mean

00.0

Sea Level) in meters
$A: X$
Not used
B: ${ }^{\star} \mathrm{CK}$
Delimiter and checksum

EXAMPLE MESSAGE:

\$PMVXG,000,04,04,1991,181115,3350.5287,N,11820.2131,W.42.7 , ${ }^{\star} 75$ 


\section{CONTROL PORT INPUT RECORDS}

Table A-3. Record Type \$PMVXG,001

Eunctlon: Initialization/Mode Control - Part B. Specifies various navigation parameters: Altitude aiding, acceleration, maximum DOP limits, and satellite elevation limits.

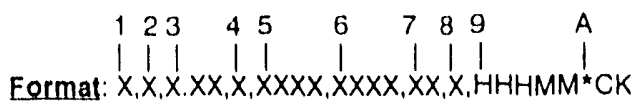

where:

Eield

$1: x$

2: $x$

3: $X . X X$

4: $X$

5: $x \times X X$

6: $x \times x X$

7: $X X$

8: $X$

9: HHHMM

$\mathrm{A}:{ }^{\star} \mathrm{CK}$
Eield Contents.

Constrain Altitude:

$0=$ Never constrained. 3.D nav only when 4 sats available. Determine lat, lon, time, altitude.

$1=$ Auto. 3-D nav when 4 sats available, and determines lat, lon, lime, altitude. Switches to 2.D nav when only 3 sats available, and deter. mines lat, lon, time using manually entered altitude.

2 = Always constrained. $2 \cdot D$ nav when 3 sats available. Determine lat, lon, time, using manually entered altitude.

$3=$ Coast. $3 \cdot D$ nav when 4 sats available, and determines lat, lon, ime, altitude. Switches to 2-D nav when only 3 sats available, and determines lat, lon, time using last calculated GPS altitude.

Not used

Horizontal acceleration factor $\left(\mathrm{m} / \mathrm{sec}^{\star \star 2}\right)$

Not used

VDOP limit (3-D nav suspended when limit is exceeded)

HDOP limit (2.D nav suspended when limit is exceeded)

Elevation limit (degrees) (sat not used if elevation angle is below limit)

Time output mode:

$$
\begin{aligned}
& U=\text { UTC } \\
& L=\text { Local time }
\end{aligned}
$$

Local time offset $( \pm$ ) from GMT

Delimiter and checksum
Delault

Range

3

$0 \cdot 3$

(1) 


\section{APPENDIX B.3: SERIAL DATA FORMATS - ROCKWELL NAVCORE V}

Excerpts (pages 4-1 to 4-15 and 4-21 to 4-23) from the March 1992

NavCore ${ }^{\circledR} V$ - Rockwell Global Positioning System

Receiver Engine Designer's Guide.

Reprinted with permission from:

Rockwell International

3200 East Renner Road

Richardson, TX 75082 


\section{B. 3-2}




\title{
APPENDIX B.3: SERIAL DATA FORMATS - ROCKWELL NAVCORE V
}

\author{
NavCore ${ }^{\circledR} V$ \\ Designer's Guide
}

4. SERIAL DATA INTERFACE

\subsection{Serlal Data Protocol}

\subsubsection{Data Bit Rate}

The serial data bit rate is determined by the state of pin J2.14 of the NavCore ${ }^{\circledR} V$ at application of "Prime" power. If the pin is held high, the data will be transmitted and received at $9600 \mathrm{bps}$. If the pin is held low, the NavCore $V$ will receive data at 19,200 bps and will transmit data at 76,800 bps. Once the data rate has been established, it will remain unchanged throughout the current power cycle. (Normal operation is 9600 bps.)

\subsubsection{Data Encoding and Format}

Each byte of information is transmitted through the serial port as a sequence of 11 bits. The serial data port will be configured for odd parity, so that each byte of serial data is encoded into 11 bits for serial transmission - one start bit, eight data bits, one odd parity bit, and one stop bit (Figure 4-1). The data bits are ordered from least significant bit to most significant bit. For each data word, the least significant byte is transmitted first, followed by the most significant byte. Integer and floating point data types consisting of more than one word are transmitted from the lowest numbered word to the highest numbered word as indicated in the data type format descriptions below.

\section{DATAFORMATS}

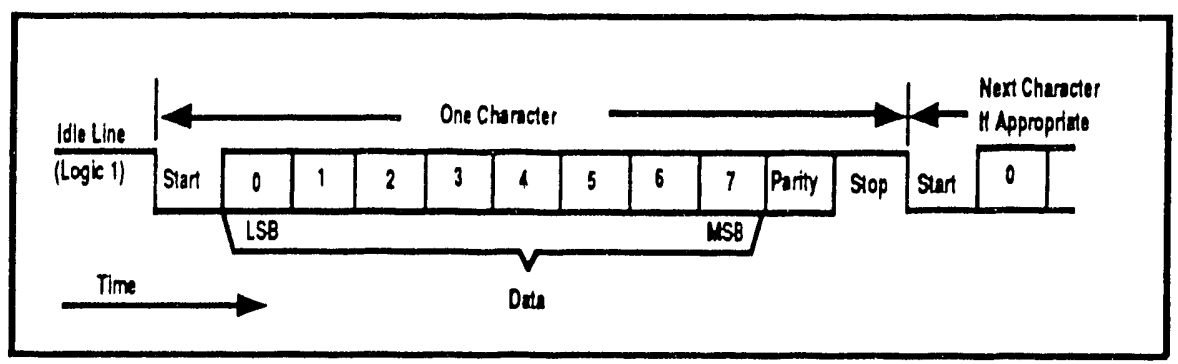

Figure 4-1. Serlal Data Timing Diagram. 


\section{Single Precision Integer Format}

Single precision integer data types are allocated one 16-bit word. The most significant bit is the sign bit. Negative numbers are represented in two's complement form, where the sign bit is one (Figure 4-2).

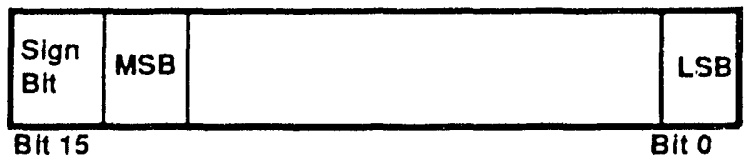

Figure 4-2. Single Precision Integer Format.

\section{Double Precision Integer Format}

Double precision integer data types are allocated two 16-bit words. The most significant bit is the sign bit. Negative numbers are represented in two's complement form, where the sign bit is one (Figure 4-3).

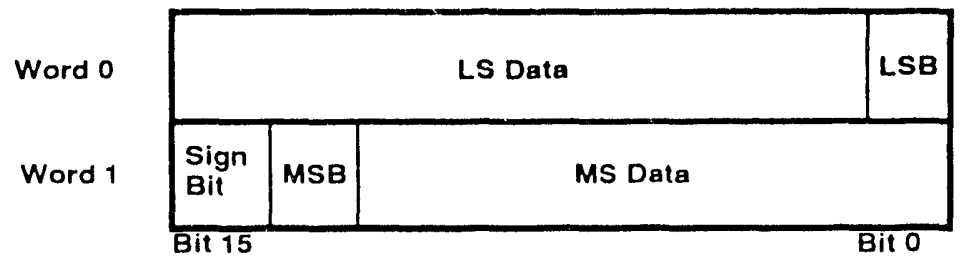

Figure 4-3. Double Precision Integer Format.

\section{Floating Point Format}

Floating point data types are allocated two 16-bit words (Figure 4-4). The floating point representation consists of a mantissa, exponent, and sign bit, where the absolute value of the floating point number equals the mantissa multiplied by 2 Exponent, and where a sign bit of 0 indicates a positive number.

The mantissa is normalized so that its most significant bit (the $2^{-1}$ place) is a 1 , with the exception of the value 0.0 , in which case all bits in the words are 0 . Thus, the most significant bit is hidden, and the mantissa has one extra bit of precision more than its actual number of allocated bits. The mantissa field width is 23 bits for floating point data types, which allows 24 bits of precision. For all floating point types, the exponent field is eight bits wide. Exponents are represented in excess 128 notation. Since all bits are 0 for the value 0.0 , floating point representations with a zero exponent and a non-zero mantissa or sign bit are not allowed.

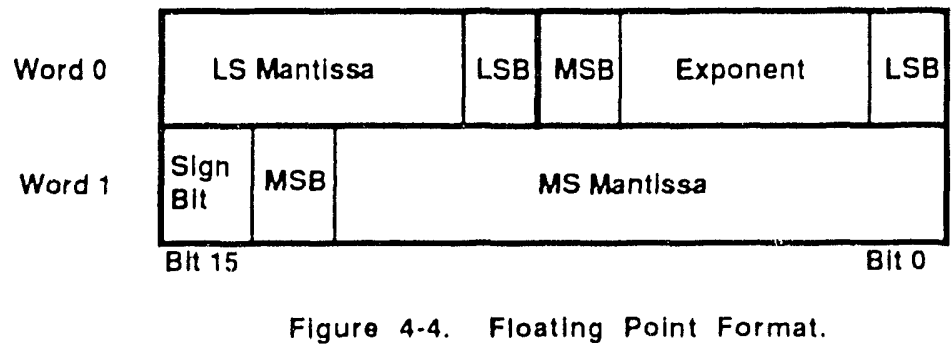

Rev. F 


\section{Extended Floating Point Format}

Extended floating point data types are allocated three 16-bit words (Figure 4-5). The extended floating point representation consists of a mantissa, exponent, and sign bit, where the absolute value of the extended floating point number equals the mantissa multiplied by 2 Exponent, and where a sign bit of 0 indicates a positive number.

The mantissa is normalized so that its most significant bit (the $2^{-1}$ place) is a 1 , with the exception of the value 0.0 , in which case all bits in the words are 0 . Thus, the most significant bit is hidden, and the mantissa has one extra bit of precision more than its actual number of allocated bits. The mantissa field width is 39 bits for extended floating point, which allows 40 bits of precision. For all floating point types, the exponent field is eight bits wide. Exponents are represented in excess 128 notation. Since all bits are 0 for the value 0.0 , extended floating point representations with a zero exponent and a non-zero mantissa or sign bit are not allowed.

\begin{tabular}{|c|c|c|c|c|c|c|}
\hline \multirow{2}{*}{$\begin{array}{l}\text { Word } 0 \\
\text { Word } 1\end{array}$} & \multicolumn{2}{|c|}{ LS Mantlssa } & LSB & MSB & Exponent & LSB \\
\hline & \multicolumn{6}{|c|}{ Middle Mantissa } \\
\hline \multirow[t]{2}{*}{ Word 2} & $\begin{array}{l}\text { Sign } \\
\text { Bit }\end{array}$ & MSB & \multicolumn{3}{|c|}{ MS Mantissa } & \\
\hline & BHt 15 & & & & & Bit 0 \\
\hline
\end{tabular}

Further discussion of the conversion routines "from" and "to" the NavCore $V$ formats in IEEE 754 format is included in Section 11.1 . 


\subsubsection{Message Structure}

Each message will consist of a message header, which identifies the message, and message data. A Checksum word will accompany each component for error defection. Figure 4-6 shows a simplified message structure illustrating where the components are placed to form a message.

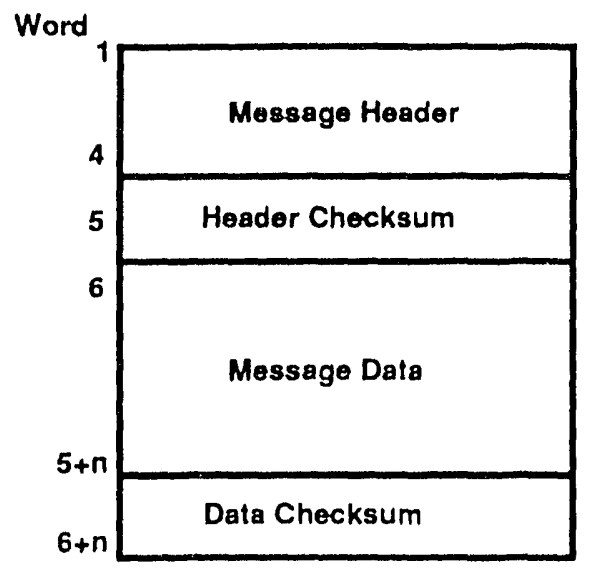

Figure 4-6. Message Structure. 
The message will consist of two parts: a header and a data portion. The organization for a word will be such that the least significant byte arrives first. The header portion will have a fixed length of five 16-bit words, consisting of a DEL-SOH byte pair, message ID, Word Count, flags, and the Header Checksum. The length of the data portion will be defined in the header and, if present, will consist of $n$ data words and a Data Checksum, where $n$ will be less than or equal to 100 (Figure 4-7).

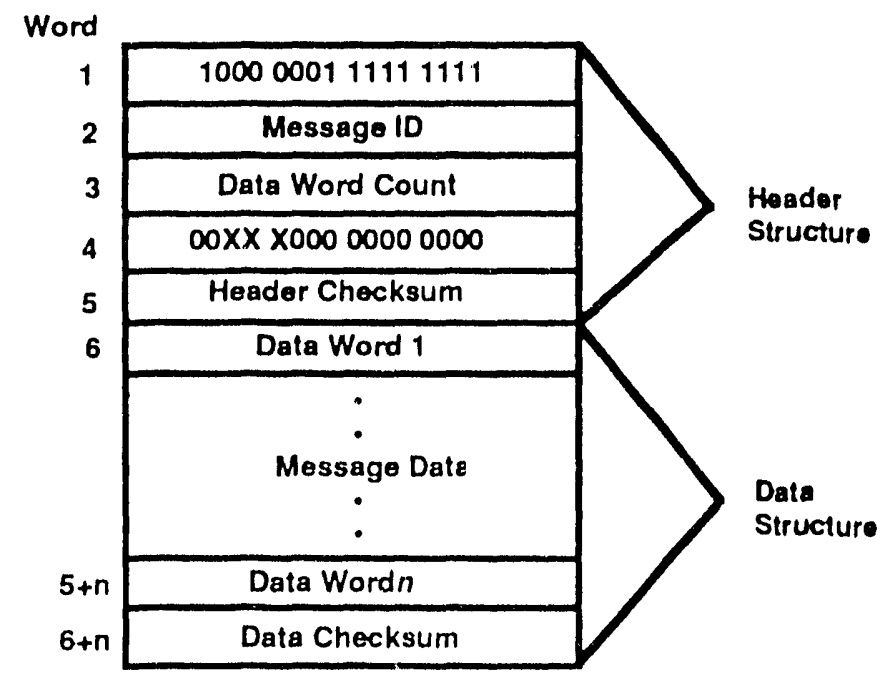

Figure 4-7. Complete Message Structure. 


\subsubsection{Header Structure}

All messages have a message header that consists of five words as follows: a word indicating the start of the message, equal to 129 decimal in the high order byte and 255 decimal in the low order byte; an integer value equal to the message ID; an integer value specifying the number of words of data in the message; and a word containing protocol related flags. Examples are given for headers "to" NavCore $V$ (Figure 4-8) and "Yrom" NavCore V (Figure 4-9).

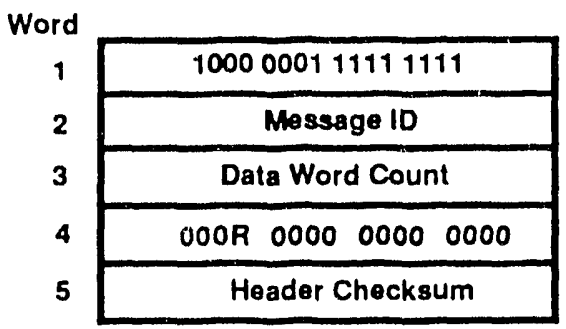

Figure 4-8, Header for Message "To" NavCore V.

$(R)=$ Acknowledge Request

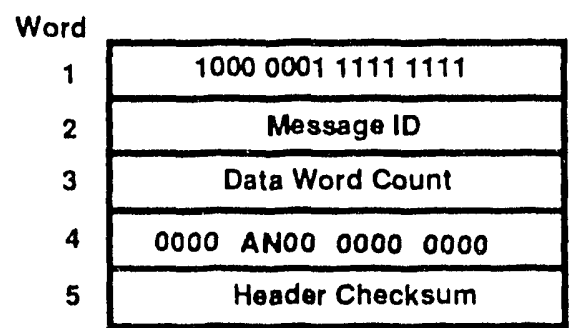

Figure 4.9. Header for Message "From" NavCore V.

$(A)=$ Acknowledgment Flag

$(\mathrm{N})=$ Negative Acknowledgment Flag

\subsection{Header Format Word 1 of 5 (Stant of Message)}

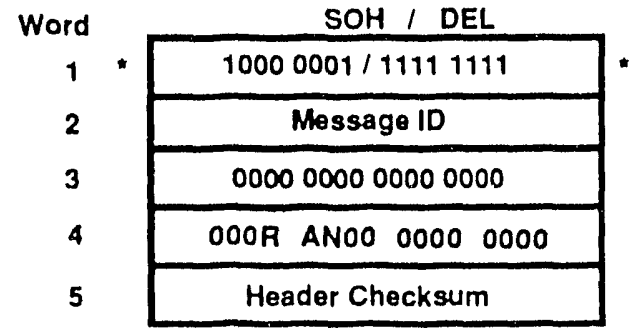

Figure 4-10. Word 1 Start of Message.

The first word of any header indicates the start of a message (Figure 4-10). This word is divided into two bytes. The higher order byte $(\mathrm{SOH})$ is equal to 129 decimal. The lower order byte (DEL) is equal to 255 decimal.

$D E L=A$ constant byte valued at 255 decimal (all ones). DEL forms the first eight bits of Word 1 of the header.

$\mathrm{SOH}=\mathrm{A}$ constant byte valued at 129 decimal. $\mathrm{SOH}$ forms the second eight bits of Word 1 of the header.

Rev. F 
4.1.3.1.2 Header Format Word 2 of 5 (Message ID)

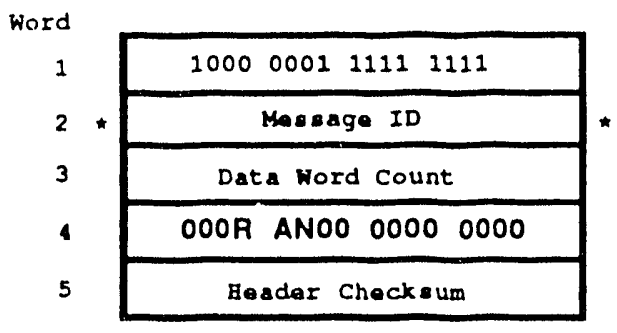

Figure 4-11. Word 2 Message ID.

The message ID (Figure 4-11) is a binary representation of the "Message ID Number" located in Figures 412 and 4-13.

For example, ID \#203 is "0000 000011001011 ." 
MESSAGE ID = A 16-bit field which uniquely defines the message type and origin. This field coriprises Word 2 of the header and is a right justified integer.

\begin{tabular}{|c|l|c|c|}
\hline Message ID & \multicolumn{1}{|c|}{ Message Descriptlon } & Rate & Source \\
\hline 101 & Bullt-In Test Results & On request & GPSRE \\
\hline 102 & $\begin{array}{l}\text { Vlsihle Satellite Azlmuth(s) } \\
\text { and Elevation(s) }\end{array}$ & $\begin{array}{l}2 \text { mlnute } \\
\text { Intervals }\end{array}$ & GPSRE \\
\hline 103 & $\begin{array}{l}\text { NavCore V Navigatlon Solution and } \\
\text { Status (Time Mark Solutlon) }\end{array}$ & $1 \mathrm{~Hz}$ & GPSRE \\
\hline 104 & Almanac Data & $\begin{array}{l}\text { On roquest } \\
\text { (max. 1 Hz) }\end{array}$ & GPSRE \\
\hline 105 & Age of Almanac & On request & GPSRE \\
\hline
\end{tabular}

Figure 4-12. Status (Output) Blocks to the Application Processor (AP). "GPSRE = GPS Recelver Englne.

\begin{tabular}{|c|c|c|c|}
\hline Message ID & Message Descriptlon & Rate & Source \\
\hline 201 & $\begin{array}{l}\text { Position, Veloclty, and } \\
\text { Time Inttlallzation }\end{array}$ & $\begin{array}{l}\text { As requilred } \\
(\max .0 .1 \mathrm{~Hz})\end{array}$ & AP \\
\hline 202 & Bullt-In Test Command & $\begin{array}{l}\text { As required } \\
(\max .0 .1 \mathrm{~Hz})\end{array}$ & AP \\
\hline 203 & $\begin{array}{l}\text { Altitude Hold Enable } \\
\text { Command }\end{array}$ & $\begin{array}{l}\text { As required } \\
(\max .1 \mathrm{~Hz})\end{array}$ & AP \\
\hline 204 & $\begin{array}{l}\text { Amended Altifude Hold } \\
\text { Command }\end{array}$ & $\begin{array}{l}\text { As requlred } \\
(\max .1 \mathrm{~Hz})\end{array}$ & AP \\
\hline 205 & $\begin{array}{l}\text { Externally Supplied } \\
\text { Almanac Data }\end{array}$ & $\begin{array}{l}\text { As requlred } \\
\text { (max. } 1 \mathrm{~Hz} \text { ) }\end{array}$ & AP \\
\hline 206 & Almanac Data Request & $\begin{array}{l}\text { As required } \\
\text { (max. } 1 \mathrm{~Hz})\end{array}$ & AP \\
\hline 207 & Age of Almanac Request & $\begin{array}{l}\text { As requlred } \\
(\max , 1 \mathrm{~Hz})\end{array}$ & $A P$ \\
\hline 208 & Manual Satellite Selection & $\begin{array}{l}\text { As requlred } \\
(\max .0 .1 \mathrm{~Hz})\end{array}$ & $A P$ \\
\hline
\end{tabular}

Figure 4-13. Command (Input) Blocks from the Appllcation Processor (AP).

Figures 4-12 and 4.13 are described in more delail in Sections 4.2 and 4.3 . 


\subsection{Header Format Word 3 of 4 (Data Word Count)}

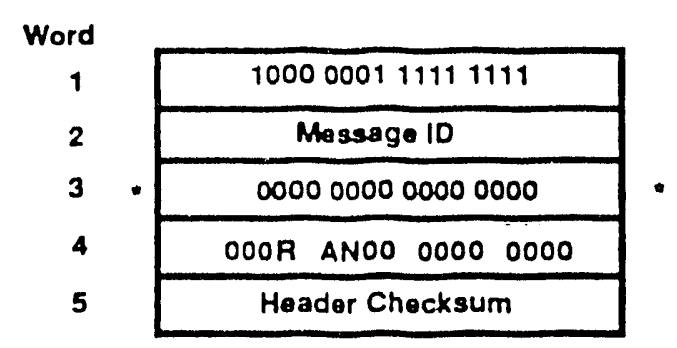

Figure 4-14. Word 3 Data Word Count.

WORD COUNT $=$ A 16-bit field which specifies the number of words contained in the data field (Figure 4 . 14). The Word Count does not include the Data Checksum word. The value zero is used to indicate a message comtaining no data, in which case the message is a header-only message and will terminate with the header Checksum word. The word is a right justitied integer.

\subsection{Header Format Word 4 of 5 (Flags)}

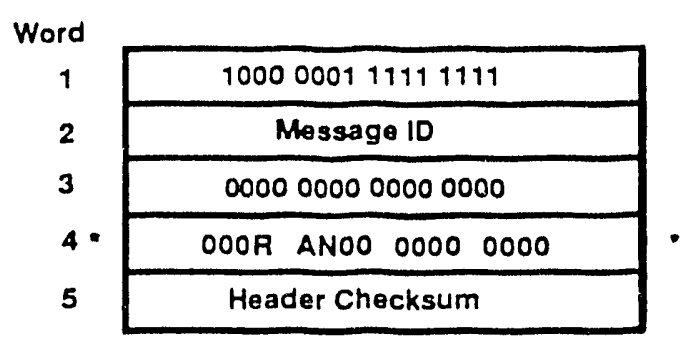

Figure 4-15. Flag Blts.

FLAGS $=$ A 16-bit field allocated to protocol and message related flags (Figure 4-15). These flag bits provide for the control of the protocol operation. The NavCore $V$ only requires bits $10,11,12$ for message acknowledgement. These messages are described in more detail in the following sections.

\subsection{Header Format Word 5 of 5 (Header Checksum)}

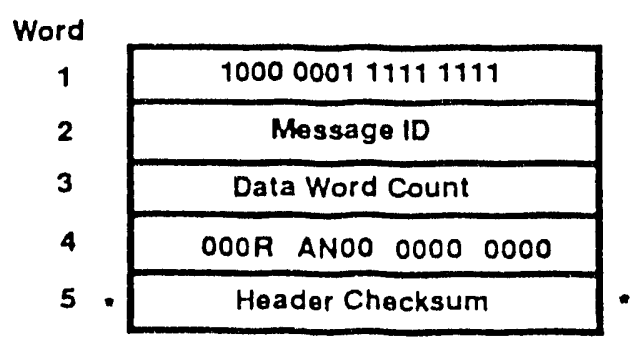

Figure 4-16. Word 5 Header Checksum. 
HEADER CHECKSUM $=A 16$ bit Checksum is used to validate the header portion of the message (Figure 4-16). It is computed by summing (modulo $2^{* 16}$ ) all words (including the word containing DEL and SOH) contained in the header and then complementing that sum. The computation of Header Checksum may be expressed mathematically as:

$$
\text { Header Checksum }=\cdot \operatorname{Mod} 2^{16} \sum_{l=1}^{4} \operatorname{Word}(1)
$$

where:

(a) Unary negation is computed as the two's complement of some 16-bit data word.

(b) Mod $2^{16}$ indicates the least 16 bits of an arithmetic process. That is, carry bits from the bit position 16 are ignored.

(c) The summation is the algebraic binary sum of the words indicated by the subscript (i).

\subsubsection{Data Structure}

The data structure (Figure 4-17) consists of formatted message data followed by a data Checksum. Data formats are unique for each message, and are shown in Section 4.2 for status messages and Section 4.3 for command messages. Once the message data is formatted, a Data Checksum is calculated as described in Section 4.1.3.2.2.

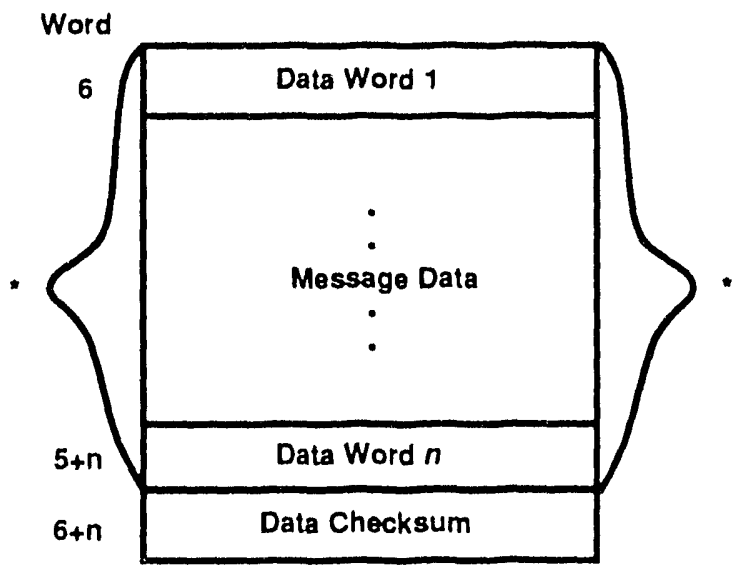

Figure 4-17. Data Structure.

\subsection{Data Word Format (Words 6 through $5+n$ )}

DATA = The message data field. This field is totally transparent to the protocol and has no restrictions on bit patterns or character groupings. The field will contain the number of words specified in the Word Count field. When the Word Count field is zero, the data field does not exist. Data fields are formatted as shown in Figure 4-17. Messages transmitted and received by the NavCore $V$ have a maximum length of 106 words, so that up to 100 words of data, plus the header and Checksums, can be transmitted in a single message. 


\subsection{Data Checksum Format (Word $6+n$ )}

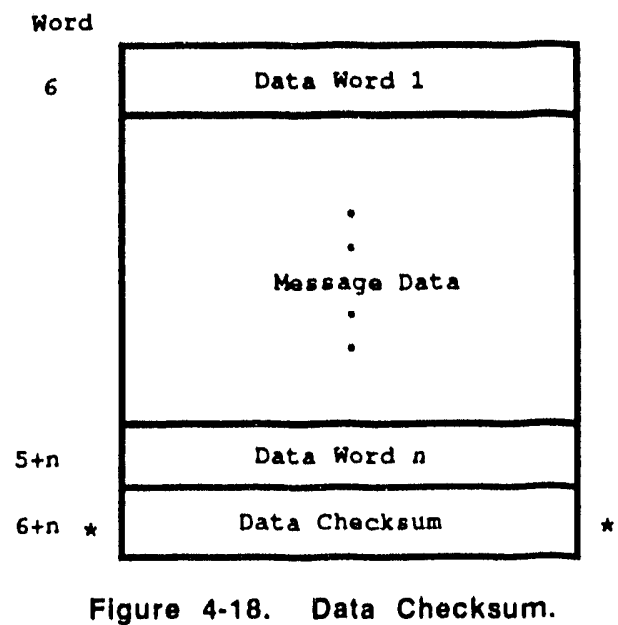

DATA CHECKSUM = A 16-bit Checksum is used to validate the data portion of the message. It is transmitted as the last word of any message containing data (Figure 4-18). When the Word Count field is zero, the Data Checksum does not exist. It is computed by summing (modulo $2^{* * 16}$ ) all words in the data portion of the message and then complementing that sum. The mathematical expression for the Data Checksum is:

$$
\text { Data Checksum }=\cdot \operatorname{Mod} 2^{16} \sum_{i=6}^{5+N} \operatorname{Word}(i)
$$

where:

(a) Unary negation is computed as the two's complement of some 16-bit data word.

(b) Mod $2^{16}$ indicates the least 16 bits of an arithmetic process. That is, carry bits from the bit position 16 are ignored.

(c) The summation is the algebraic binary sum of the words indicated by the subscript (i).

\subsubsection{Message Acknowledgment}

The NavCore $V$ software will respond to requests from the OEM Application Processor to acknowledge received messages. A request for message acknowledgment will only be recognized if the Acknowledge Request flag (Figure 4.19) is asserted in the header of the received message, and the header was received without errors. Upon receiving an Acknowledge Request, an Acknowledgment Message (Figure 4-20) or Negative Acknowledgment Message (Figure 4-21) will be transmitted back to the OEM Application Processor within 250 milliseconds." Serial data messages transmitted to the OEM Application Processor will not require acknowledgment.

-400 milliseconds at the lower, 9600 bps serlal rate. 
II an Acknowledge Request was sent and neither an Acknowledgment message nor Negative Acknowledgment message was received after $250 \mathrm{~ms}^{*}$, then the OEM Application Processor must assume that a transmission error occurred. And, since messages received in error by the NavCore $V$ are discarded, the Application Processor must resend the message if it is still desired that the message take effect.

A new message with Acknowledge Request should not be sent until either an Acknowledgment Message or Negative Acknowledgment Message has been received in response to the previous message with Acknowledge Request, or until $250 \mathrm{mS}^{*}$ have elapsed.

The Application Processor must be prepared to receive a periodic message (such as Message 102 or 103) before receiving the Acknowledgment or Negative Acknowledgment to a message with Acknowledge Request.

" 400 milliseconds at the lower, 9600 bps serlal rate. 


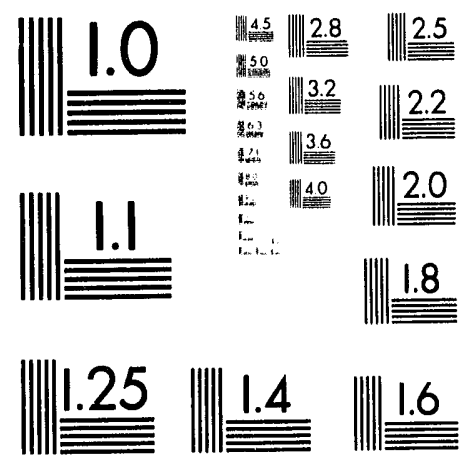



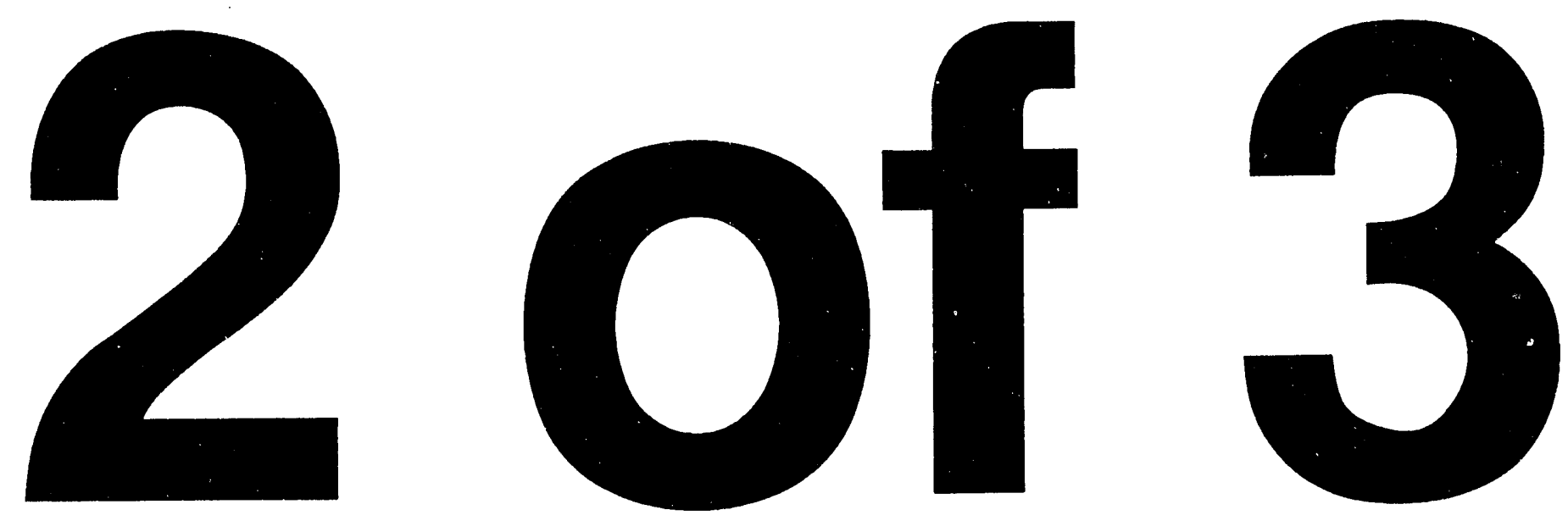


\subsubsection{Acknowledge Request ("To" NavCore V)}

\begin{tabular}{|c|}
\hline 10000001 1111 1111 \\
\hline Message ID \\
\hline Data Word Count \\
\hline O00R 0000 0000 0000 \\
\hline Header Chocksum \\
\hline Data Word 1 \\
\hline \\
Message Data \\
- \\
\hline Data Word $n$ \\
\hline Data Checksum \\
\hline
\end{tabular}

Figure 4-19. Acknowledge Request Flag.

$(R)=$ ACKNOWLEDGE REQUEST FLAG (BIT 12) (Figure 4-19). Indicates that the message block bein transmitted requires acknowledgment by the NavCore $V$. This bit (BIT 12) is set to a logical 1 for a request

\subsubsection{Acknowledge Message Description ("From" NavCore V)}

\begin{tabular}{|c|}
\hline 1000000111111111 \\
\hline Message ID \\
\hline 0000000000000000 \\
\hline 0000 A000 0000 0000 \\
\hline Header Checksum \\
\hline
\end{tabular}

Figure 4-20. Bit 11 Acknowledge/Flag.

$(A)=A C K N O W L E D G E(B i t$ 11) (Figure 4-20).

Acknowledge (ACK) is transmitted only in response to a message, requiring acknowledgment, which wa received without parity or Checksum errors.

The ACK message is constructed in the following manner:

(a) Set Flag bit 12100.

(b) Set Flag bit 11 (ACKNOWLEDGE FLAG) to 1.

(c) Set Word Count (Word 3) 100

(d) Recompute the Header Checksum.

(e) Transmit the new header (No data words are transmitted for an ACK.) 


\subsubsection{Negatlve Acknowledge Message Descrlptlons ("From" NavCore V)}

\begin{tabular}{|c|}
\hline 1000000111111111 \\
\hline Message ID \\
\hline Data Word Count \\
\hline 0000 ONO0 0000 0000 \\
\hline Header Checksum \\
\hline
\end{tabular}

Figure 4-21. Bit 10 Negative Acknowledgment Flag.

$(N)=$ NEGATIVE ACKNOWLEDGE (Bit 10) (Figure 4-21).

Negative Acknowledge (NAK) is transmitted only in response to a message requiring acknowledgment whose header was received correctly, but whose data portion was received with a parity or Checksum error. A NAK message also indicates that none of the data in the message requiring acknowledgment was accepted by the NavCore $V$. Header-only messages requiring acknowledgment that are received with errors cannot be negatively acknowledged with a Negative Acknowledge Message. The absence of an ACK message serves as Negative Acknowledgment for header-only messages.

The message is constructed in the following manner:

(a) Set Flag bit 12 10 0.

(b) Set Flag bit 10 (NEGATIVE ACKNOWLEDGE FLAG) 101.

(c) Set Word Count (Word 3) to 0.

(d) Recompute the Header Checksum.

(e) Transmit the new header (No data words are transmitted with a NAK.)

\subsubsection{Error Handling}

Serial data messages received by the NavCore $V$ are validated by detecting parity and framing errors in received serial data byte transmissions, detecting erroneous data bit transitions, and verifying the Header and Data Checksum words according to the Checksum calculations of the message protocol. Received messages that contain errors, as well as messages with unassigned message IDs, are discarded. Received messages that have errors in the data portion, but whose headers were received correctly, may be negatively acknowledged. 


\subsection{NavCore V io OEM Appllcation Processor Messages}

In the following paragraphs, abbreviations for data types are as follows:

$\begin{array}{ll}\text { I } & \text { Integer } \\ \text { D } & \text { Double Precision Integer } \\ \text { FP } & \text { Floating Point } \\ \text { EFP } & \text { Extended Floating Point } \\ \text { B } & \text { Boolean }\end{array}$

Boolean data types are represented as integers, where a value of zero indicates false and a value of one indicates true. All bits that are designated as spare or reserved within the bit descriptions of binary data will be set to logic zero by the NavCore $V$. These may be used in the future so the OEM is advised NOT to rely on their being zero, but should mask these unused bits prior to processing the defined data bits. 


\subsubsection{NavCore V Series Position, Velocity, TIme Solutions and Status (TIme Mark Message) (Message ID 103)}

This message contains time, position, and velocity data that is valid for the current Time Mark pulse. II also contains status information valid for the current Time Mark pulse, including error information, channel tracking status, signal-to-noise ratios, Altitude Hold status and Receiver Engine Mode information.

Message ID: 103

Rate: $\quad 1 \mathrm{~Hz}$

Word Length: 64

Word

Ne

Name

Ixpe Units

Bange

Besolution

1-4 Message Header

5 Header Checksum

6.8 GPS Time of Week

9 GPS Week Number

EF

10 UTC Validity

11-13 UTC Time of Day

14 UTC Day

15 UTC Month

16 UTC Year

17-18 Set Time

19-21 Position $X$

22-24 Position $Y$

25-27 Position $Z$

28-29 Velocity East

30-31 Velocity North

32-33 Velocity Up

34-36 Latitude

37-39 Longitude

40-41 Altitude

42 Horizontal Dilution of Precision

43 Ventical Dilution of Precision

44 Position Dilution of Precision

45 Time Dilution of Precision

Rev. F 


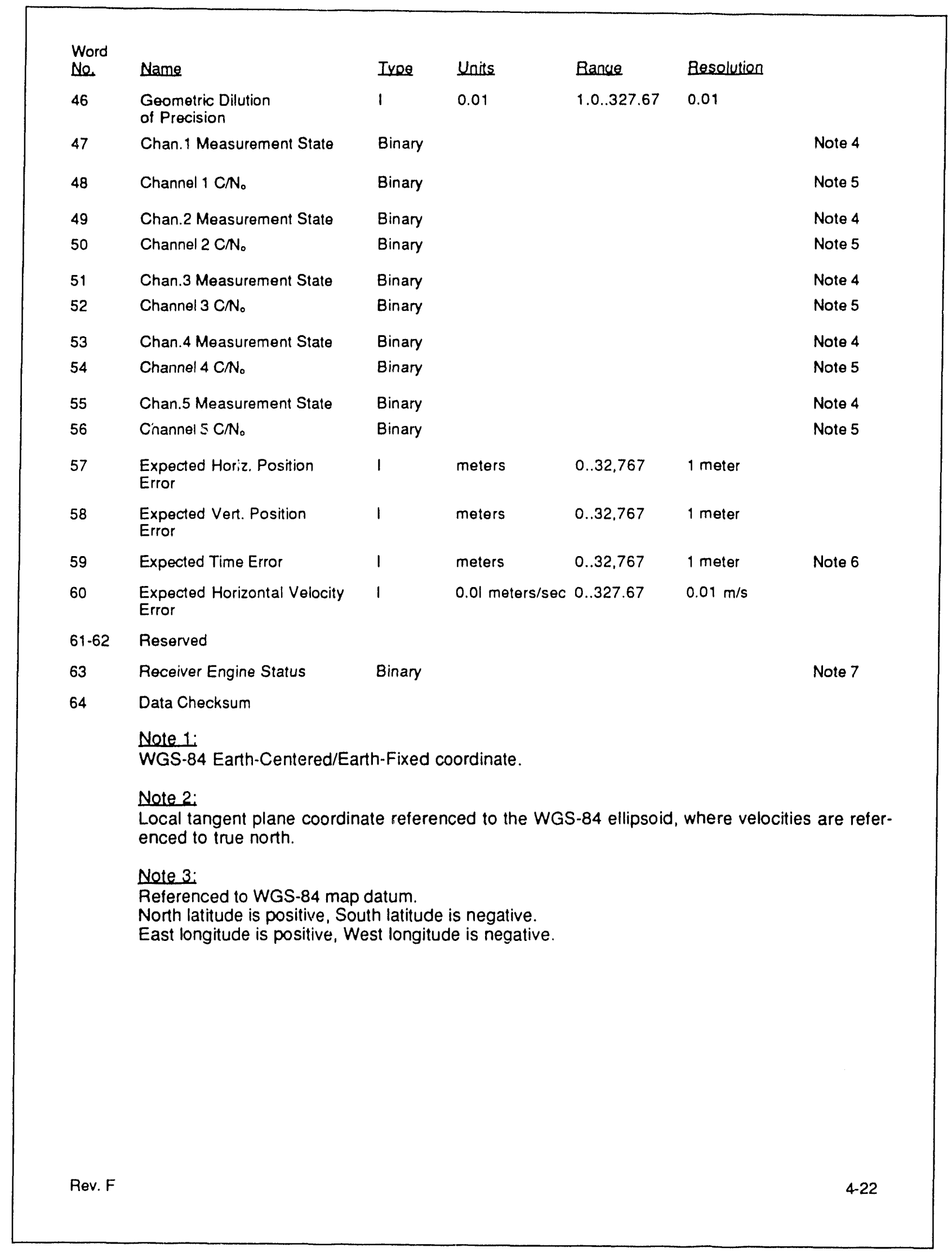


Note 4:

Channel Measurement State Words are formatted as follows:

bits 0-5 Satellite PRN Code, integer range 1-32. A value of 0 indicates that no satellite is assigned to this channel.

bits 9-11 Channel Activity

000 - Idle

001 - C/A code search

bit $15 \quad$ Spare

Note 5:

Signal-to-noise values are formatted as follows:

$\begin{array}{ll}\text { bits } 0-7 & \text { Spare } \\ \text { bits } 8-13 & \text { Integer value of } \mathrm{C} / \mathrm{N}_{0}, \text { range } 0-63 \text {, in units of } \mathrm{dBHz} \\ \text { bits } 14-15 & \text { Spare }\end{array}$

Note 6:

The expected time error can be converted to units of seconds by dividing by the speed of light.

Nole 7:

The Receiver Engine Status word contains Boolean indicators and integer data fields formatted as follows:

bit $0 \quad$ Altitude Accept - Logic 1 indicates entered or automatic Altitude Hold measurements will be accepted (if Altitude Hold is enabled) to produce a navigation solution.

bit 1 Altitude Used - Logic 1 indicates Altitude Hold measurements were used in the navigation solution.

bit 2 Altitude Hold Enabled.

bit 3 Navigation Mode Logic 1 indicates that the Receiver Engine is in Navigation Mode. Logic 0 indicates that the Engine is in Acquisition Mode.

bits 4-6 Integer value, range 0 to 5 , indicating the number of satellite measurements being incorporated.

bit $7 \quad$ Spare

bits 8-11 An integer value indicating the Figure of Merit, which is the estimated position error, where:

$$
\begin{aligned}
1 & \Rightarrow>\text { less than } 26 \text { meters } \\
2 & \Rightarrow 26 \text { to } 50 \text { meters } \\
3 & \Rightarrow 51 \text { to } 75 \text { meters } \\
4 & \Rightarrow>6 \text { to } 100 \text { meters } \\
5 & \Rightarrow>101 \text { to } 200 \text { meters } \\
6 & \Rightarrow>201 \text { to } 500 \text { meters } \\
7 & \Rightarrow 501 \text { to } 1000 \text { meters } \\
8 & \Rightarrow>1001 \text { to } 5000 \text { meters } \\
9 & \Rightarrow>\text { Greater than } 5000 \text { meters }
\end{aligned}
$$

bits 12.14 Integer value, range 0 to 5 , indicating the channel designated as the utility channel, which is used to acquire and track secondary satellites and to collect satellite data while in Navigation Mode. A value of 0 indicates that no utility

bit 15 channel is currently assigned.

Spare. 


\title{
APPENDIX B.4: SERIAL DATA FORMATS - MAGNAVOX 6400
}

\author{
Excerpts (pages D-1 and D-3) from the 1988 \\ MX 5400 (JPS Satellite Navigation System - Technical Reference Manual \\ Reprinted with permission from: \\ Magnavox Advanced Products and Systems Company \\ 2829 Maricopa Street \\ Torrance, CA 90503
}


B. $4-2$ 


\section{APPENDIX B.4: SERIAL DATA FORMATS - MAGNAVOX 6400}

EXT INTEC CONNECTOR PORT A (COMMUNICATION CHAMNEL 1) RAW DATA FORMATS

This appendix describes the available format optlons for the raw data transferred from the MX 5400 to a user-supplied data device via port A. Data communtcation is asynchronous, with the format and transfer rate selectable with KYBD function 3 (IO-PORT A), as described in Chapter 3 . The modes selectable with KYBD function 3 relate to the data in this appendix as follows:

KEYBOARD FUNCTION

PORT A OUTPUT OPTION

NAV 1

NAV

NAV+

ALL

DBUG

RAW

NONE.

NMEA

\section{APPENDIX REFERENCE}

Data record 29 only

Data records 21 and 31

Data records $21,31,903,904$ and a $11400-$ series

All data records

All data records plus test messages

Data blocks $Q, P$, and $V$

No data output

Selectable records in NMEA-0183 format

The data records, as listed in table D-l, are in ASCIT format. The RAW output data blocks, as listed in table $\mathrm{D}-2$, are in binary format. The three raw data blocks are quality, position, and velocity. The quality data block is always transmitted once per second. The position and velocity blocks are also transmitted once per second, but only if the MX 5400 is in the navigation mode. A typical output from port $A$ is shown in figure $\mathrm{D}-1$. The NMEA record formats are described in Appendix $\mathrm{E}$. 
Table D-1. Data Record Formats (Continued)

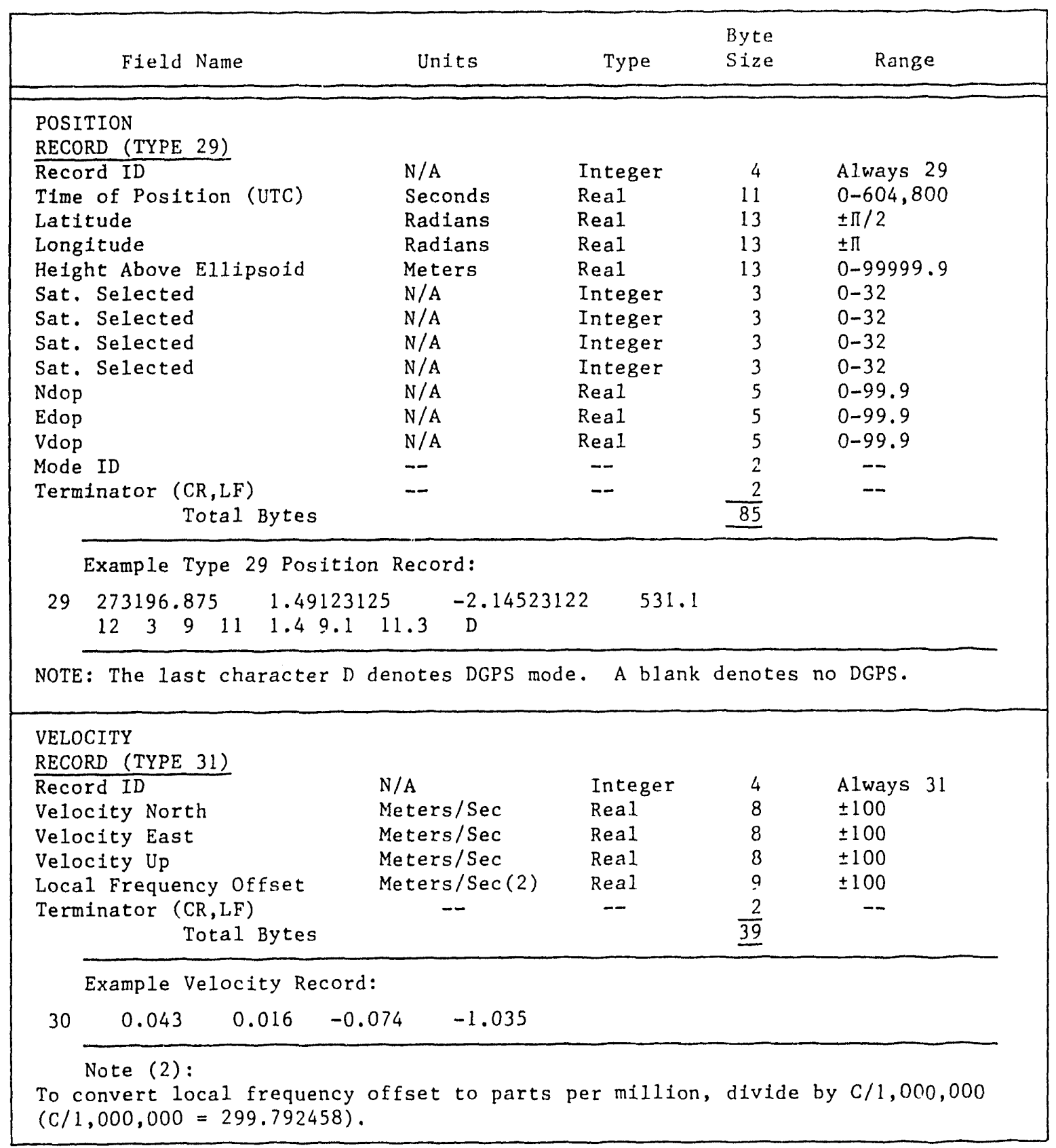




\section{APPENDIX B.5: SERIAL DATA FORMATS -}

\section{TRIMBLE PLACER}

Excerpts (pages 1 to 4 of Appendix A,

Trimble ASC.II Interface Protocol /TAIP' / Version 1.01) from the 1991

Placer TM GPS Intallation and Operator's Mamual

Reprinted with permission from:

Trimble Navigation

645 North Mary Avenue

Sunnyvale, CA 94088-3642 
B. 5-2 


\title{
APPENDIX B.5: SERIAL DATA FORMATS - TRIMBLE PLACER
}

\author{
Trimble ASCII Interface Protocol (TAIP) \\ Version 1.01
}

\subsection{General}

Trimble ASCII Interface Protocol is a Trimble-specified digital communication interface, based on printable ASCII characters over a serial data link. It supports scheduled and polled responses. Messages may be scheduled for output at a user specified rate starting on a given epoch from top of the hour. For communication robustness, the protocol optionally supports checksum on all messages. It also provides the user with the option of tagging all messages with the unit's previously specified id. This greatly enhances the functional capability of the unit in a network environment. Additionally, given the printable ASCII format of all communication, TAIP is ideal for use with mobile data terminals, seven bit modems and portable computers. Although, sensors incorporating this protocol are shipped from the factory with a specific serial port setting, the port characteristics are fully programmable through TAIP messages.

\subsection{Message Format}

All communication is done using printable ASCII characters. The interface provides the means to configure the unit to output various sentences in response to query or on a scheduled basis. Each sentence has the following general format:

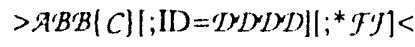

where

$>\quad$ start of new message,

A message qualifier,

$B B$ a two character message ID,

$C$ data string,

DPDDID Optional 4 character vehicle ID,

yf optional 2 character checksum,

$<\quad$ the delimiting character.

Notation:

$\{x\} \quad$ signifies that $x$ can occur any number of times.

$|x| \quad$ signifies that $x$ may optionally occur once.

Start of new message

$A$ ' $>$ ' is used to specify the start of at new sentence. 


\section{Message Qualifier}

A one character message qualifier is used to describe the action to be taken on the message. The following table lists the valid qualifiers:

$\begin{array}{ll}\text { Qualifier } & \text { Action } \\ \mathrm{Q} & \text { Query for a single sentence. } \\ \mathrm{R} & \text { Response to a query or scheduled report } \\ \mathrm{F} & \text { Scheduled reporting frequency interval in seconds } \\ \mathrm{S} & \text { Set command }\end{array}$

Message ID

A unique two character message ID consisting of letters of alphabet is used to identify different type messages. Valid message IDs are presented in the tables of section 3.

\section{Data String}

The format and length of the data string are dictated by the message qualifier and the message ID. It can consist of any printable ASCII character with the exception of $('>$ ', '<', and ' $; '$ '). See section 3 for detailed descriptions of message formats. Most messages are length sensitive and unless otherwise specified, field separators including space are not used.

\section{Vehicle II)}

A vehicle ID may optionally be used in all the communications with the unit. Each vehicle may be assigned a four digit ID and be forced to use that in all correspondence. The default vehicle ID is '(OOO)' and the default mode of operation is noi to use vehicle ID.

\section{CheckSum}

The checksum field provides for an optional two digit hex checkst!n value, which is computed as XOR of all characters from the beginning of the sentence up to and including the '*'. If provided, the checksum is always the last element of the sentence before the message delimiter. The default mode of operation is to include checksum in sentences.

\section{Message Delimiter}

$\Lambda$ '<' signifies end of a sentence ard is used as message delimiter.

\subsection{Message Formats}

The following table lists all the messages currently supported: 


\begin{tabular}{ll} 
Message ID & Message Name \\
CP & Compact Position Solution \\
DC & Differential Corrections \\
DD & Delta Differential Corrections \\
ID & Vehicle ID \\
PT & Port characteristic \\
PV & Position/Velocity Solution \\
RM & Reporting Mode \\
VR & Version Number \\
CP & \\
\hline
\end{tabular}

Data String Format:

AAAAABBBCCCDDDDDEEEEFG

\begin{tabular}{|c|c|c|c|}
\hline$\underline{\text { Item }}$ & \# of Char & UNITS & Format \\
\hline GPS Time of day & 5 & $\mathrm{Sec}$ & АAЯAЯ \\
\hline Latitude & 7 & Deg & $B B B . C C C C$ \\
\hline Longitude & 8 & Deg & $\mathcal{D D D D . E E E E}$ \\
\hline Source & 1 & $\mathrm{n} / \mathrm{a}$ & $\mathcal{F}$ \\
\hline \multicolumn{4}{|l|}{ Possible Values: } \\
\hline GPS 2D & 0 & & \\
\hline GPS 3D & 1 & & \\
\hline DGPS 2D & 2 & & \\
\hline DGPS 3D & 3 & & \\
\hline Age of Data Indicator & 1 & $\mathrm{n} / \mathrm{a}$ & $G$ \\
\hline \multicolumn{4}{|l|}{ Possible Values: } \\
\hline Fresh $(<10 \mathrm{sec})$ & 2 & & \\
\hline Old $(>=10 \mathrm{sec})$ & 1 & & \\
\hline Unknown & 0 & & \\
\hline
\end{tabular}

Position is in latitude (positive north) and longitude (positive east) WGS-84. The GPS time of day is the time of fix rounded to the nearest second.

PV

Position/Velocity Solution

Data String Format:

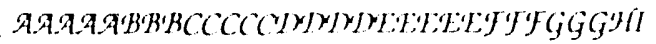

TAIP.DOC: I Aas mod: $9 / 17 / 91$ 


\begin{tabular}{|c|c|c|c|}
\hline Item & \# of Char & UNITS & Format \\
\hline GPS Time of day & 5 & $\mathrm{Sec}$ & ARARA \\
\hline Latitude & 8 & Deg & BBBB.CCCCC \\
\hline Longitude & 9 & Deg & $\mathcal{D D D D D . E T E E E}$ \\
\hline Speed & 3 & $\mathrm{MPH}$ & $\mathcal{F} \mathcal{F} \mathcal{F}$ \\
\hline Heading & 3 & Deg & $G G G$ \\
\hline Source & 1 & $\mathrm{n} / \mathrm{a}$ & $\mathscr{H}$ \\
\hline \multicolumn{4}{|l|}{ Possible Values: } \\
\hline GPS 2D & 0 & & \\
\hline GPS 3D & 1 & & \\
\hline DGPS 2D & 2 & & \\
\hline DGPS 3D & 3 & & \\
\hline Age of Data Indicator & 1 & $\mathrm{n} / \mathrm{a}$ & $I$ \\
\hline \multicolumn{4}{|l|}{ Possible Values: } \\
\hline Fresh $(<10 \mathrm{sec})$ & 2 & & \\
\hline Old $(>=10 \mathrm{sec})$ & 1 & & \\
\hline Unknown & 0 & & \\
\hline Total & 30 & & \\
\hline
\end{tabular}

Position is in latitude (positive north) and longitude (positive east) WGS-84. Heading is in degrees from True North increasing eastwardly. The GPS time of day is the time of fix rounded to the nearest second.

ID $\quad$ Vehicle ID

Data String Format:

AAAA

Item \# of Char UNITS Format

Numeric vehicle ID $4 \quad$ n/a $\quad \mathcal{A A A A}$

Vehicles unique four digit ID. The default at start-up is ' 0000 '.

RM Reporting Mode

Data String Format:

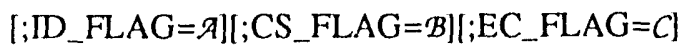




\title{
APPENDIX C.1: SOFTWARE LISTING - GPS CONVERSION PROGRAM
}

\author{
Developed by: \\ Frank Wunderlin* \\ Technadyne Engineering Consultants, Inc. \\ P.O. Box 1328 \\ Albuquerque, NM 87192
}

* Work performed under Contract No. 87-2050 for the Advanced Vehicle Development Department (9616), Sandia National Laboratories. 
C. $1-2$ 


\section{APPENDIX C.1: SOFTWARE LISTING - GPS CONVERSION PROGRAM}

Converts raw GPS data into latitude, longitude, and navigation mode columns.

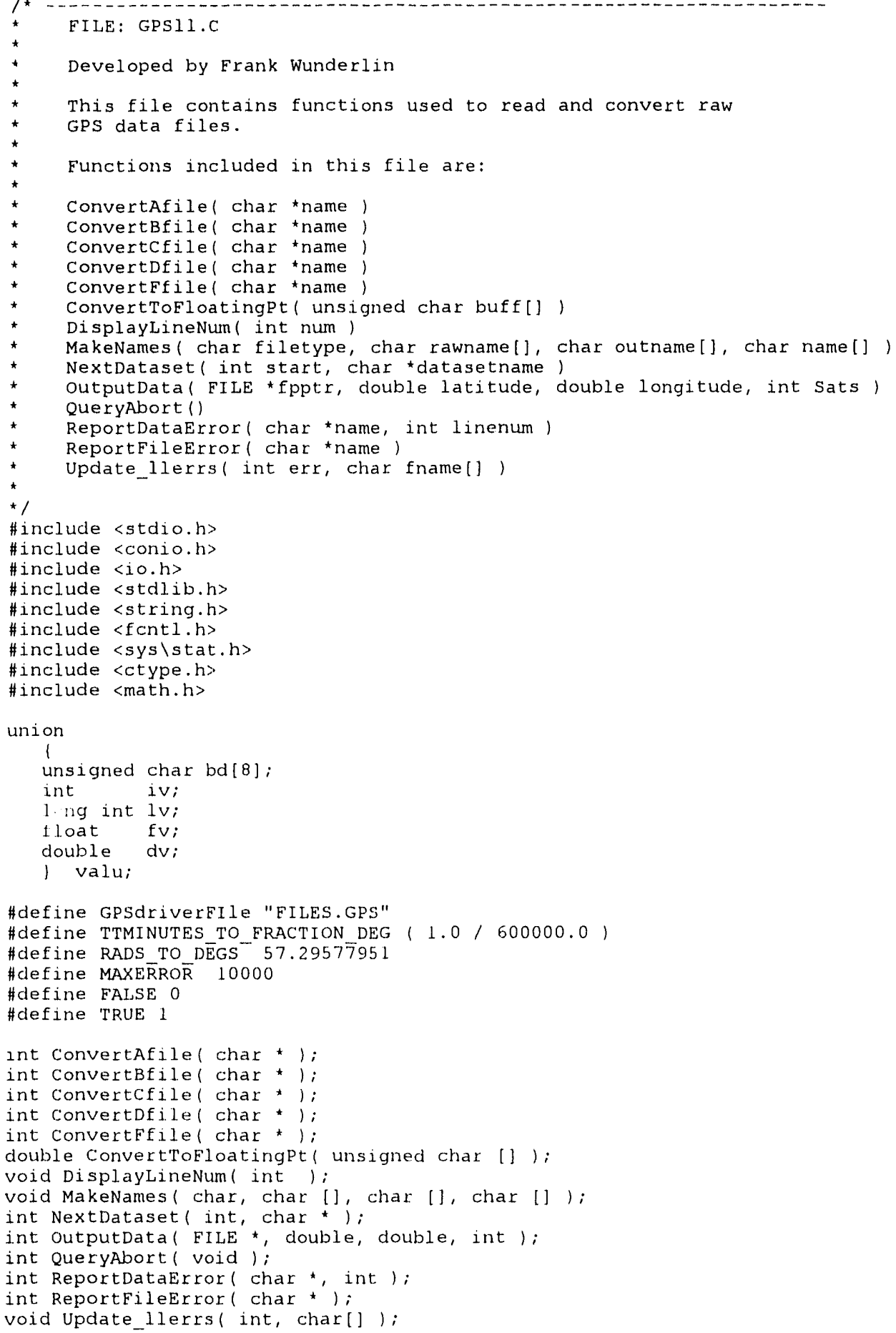




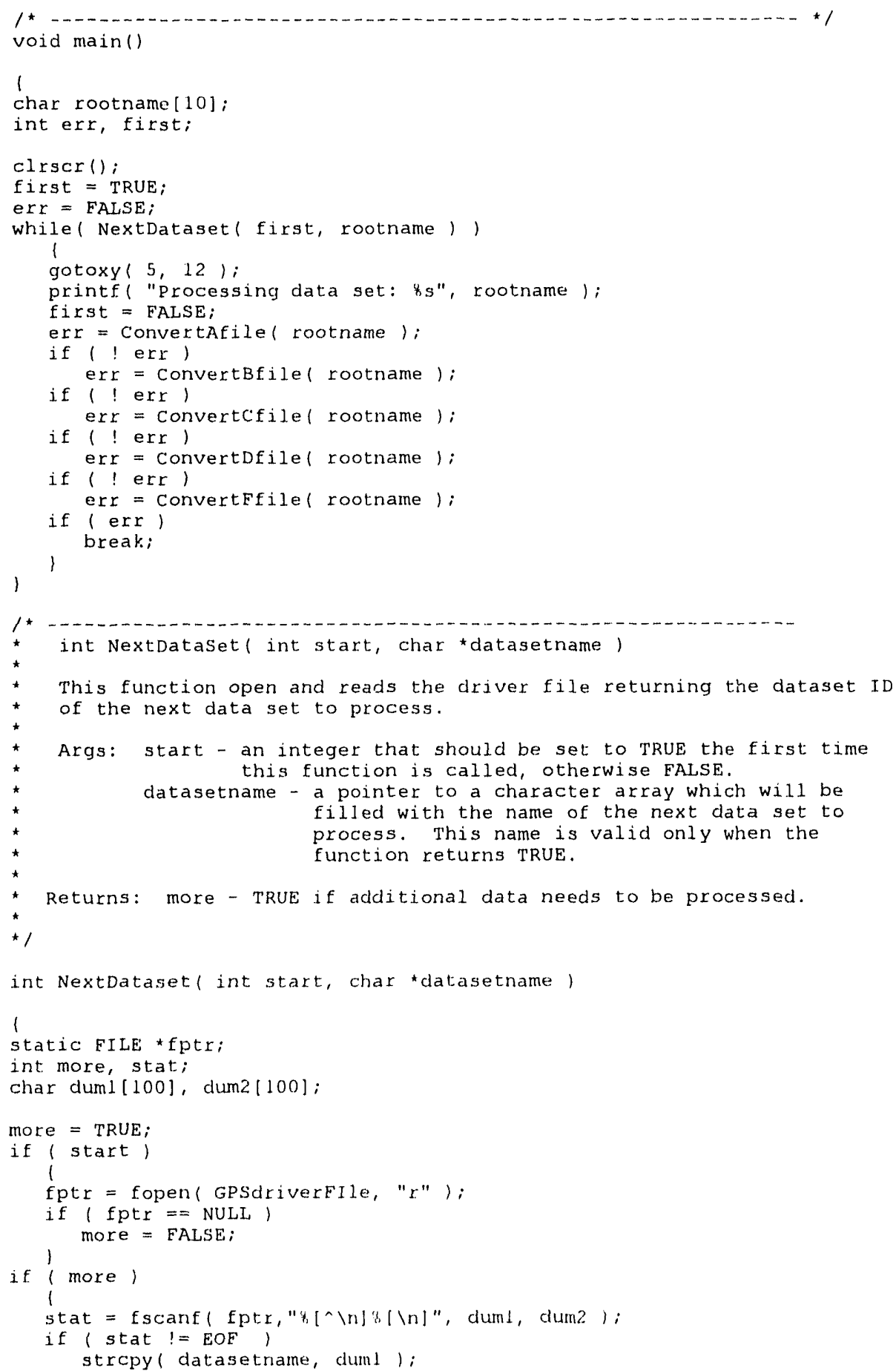




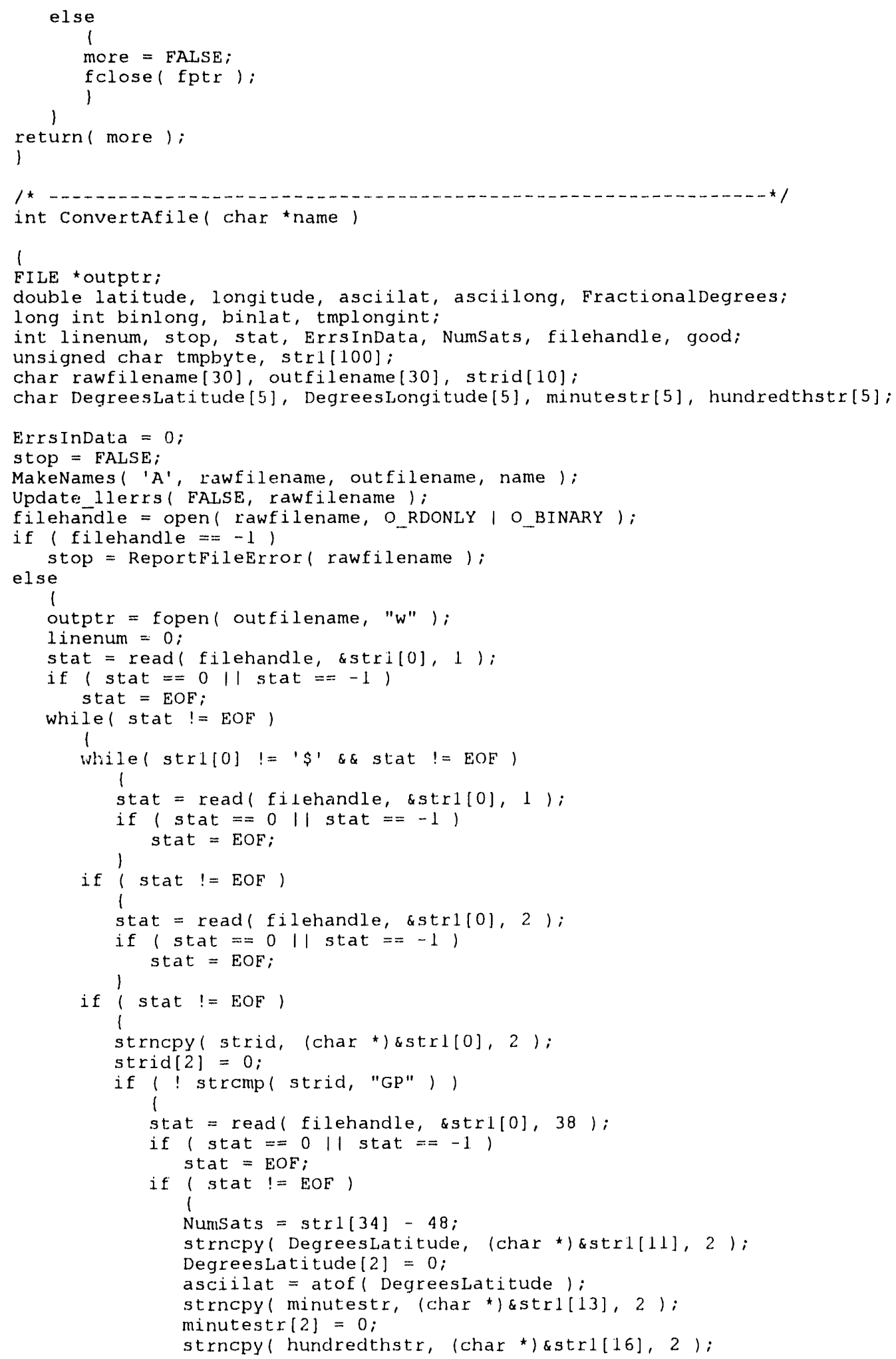




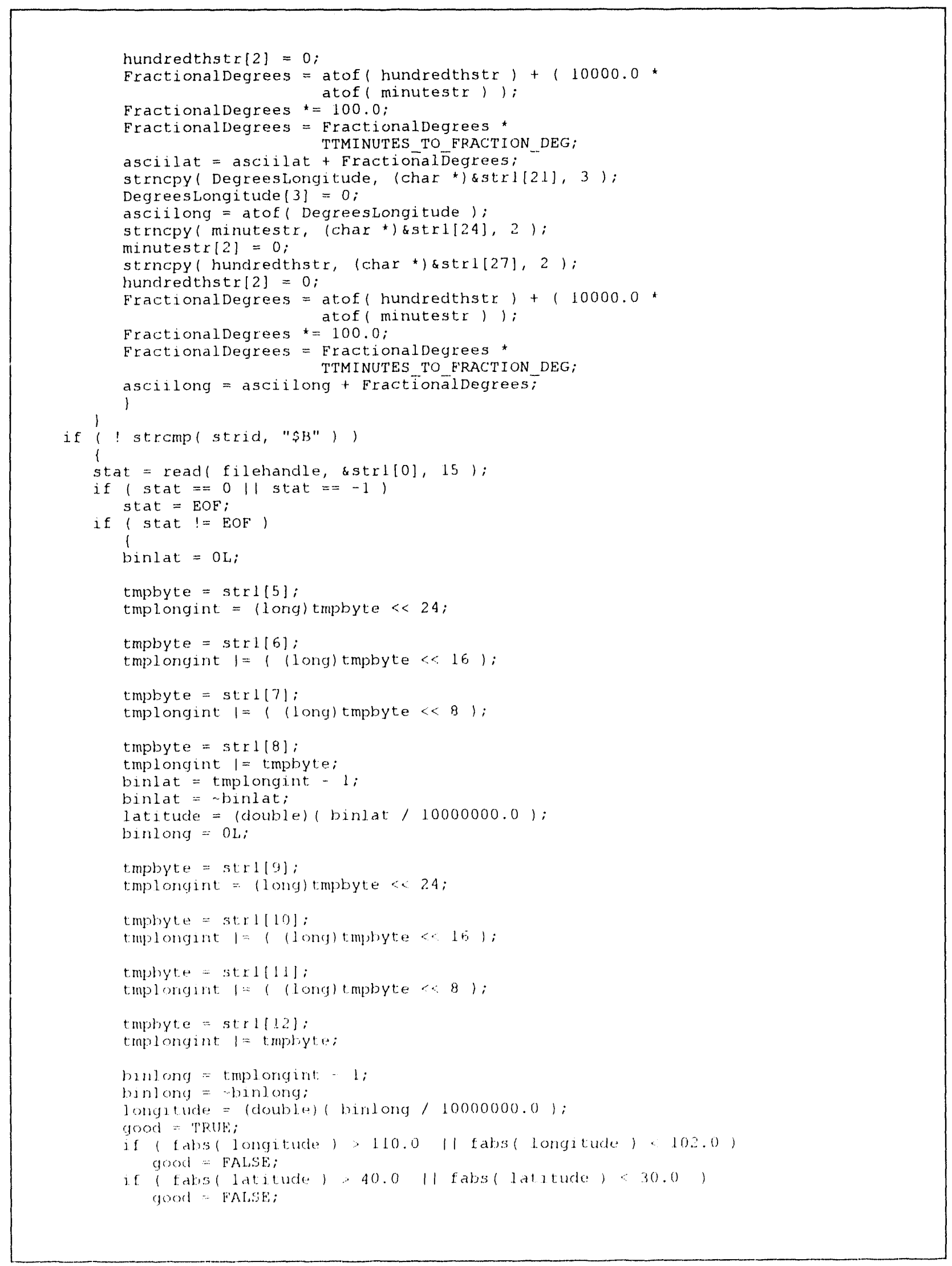




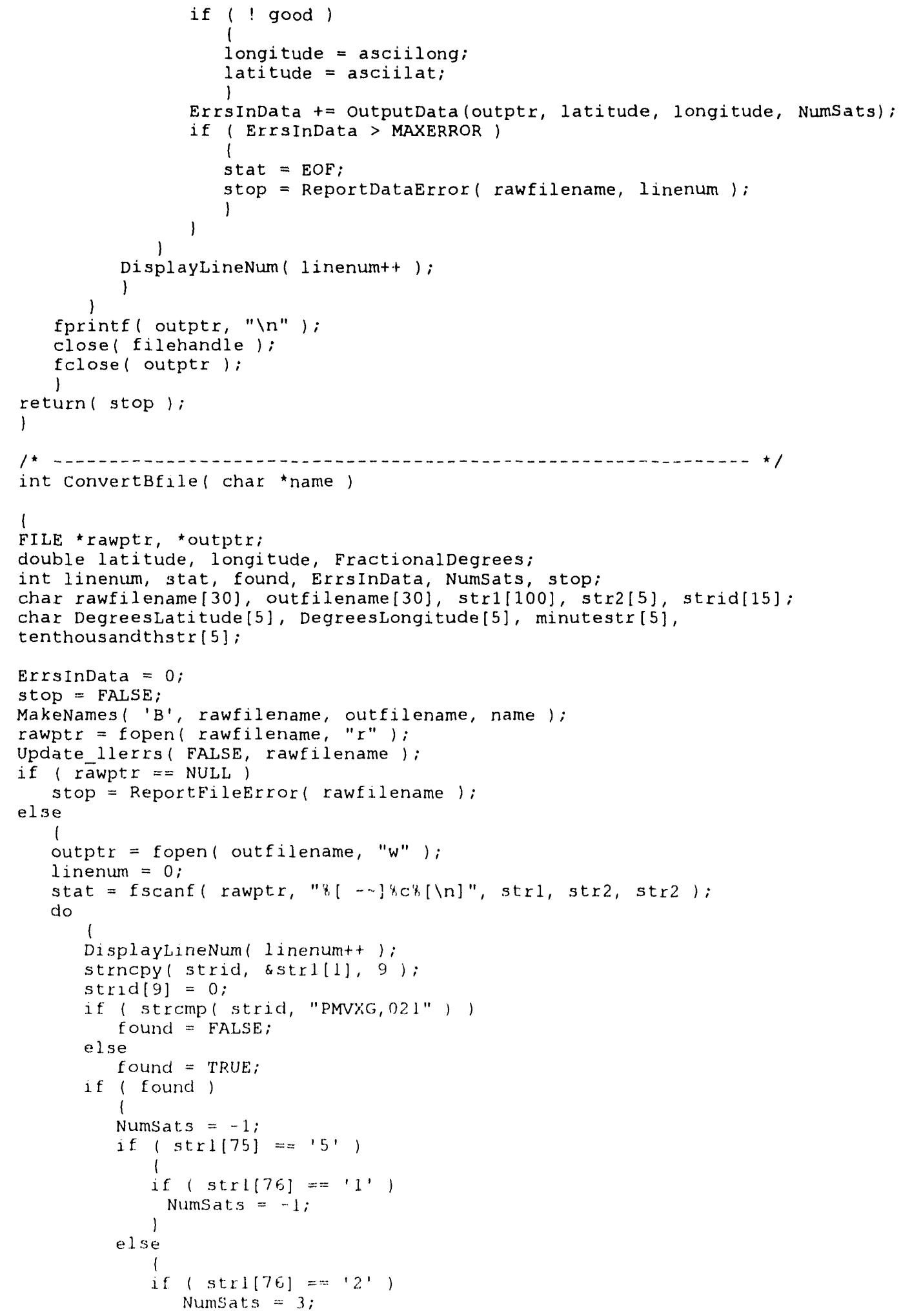




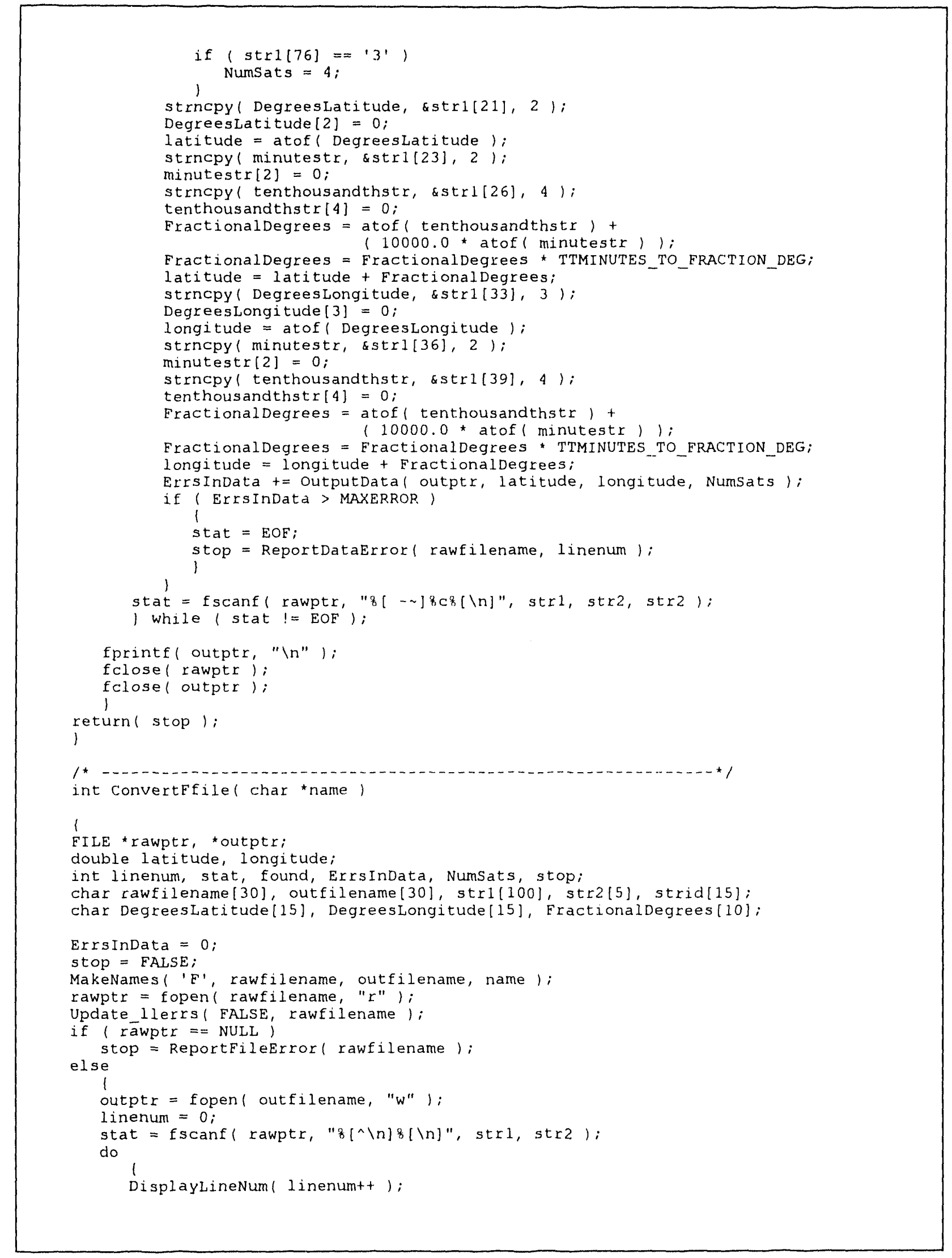




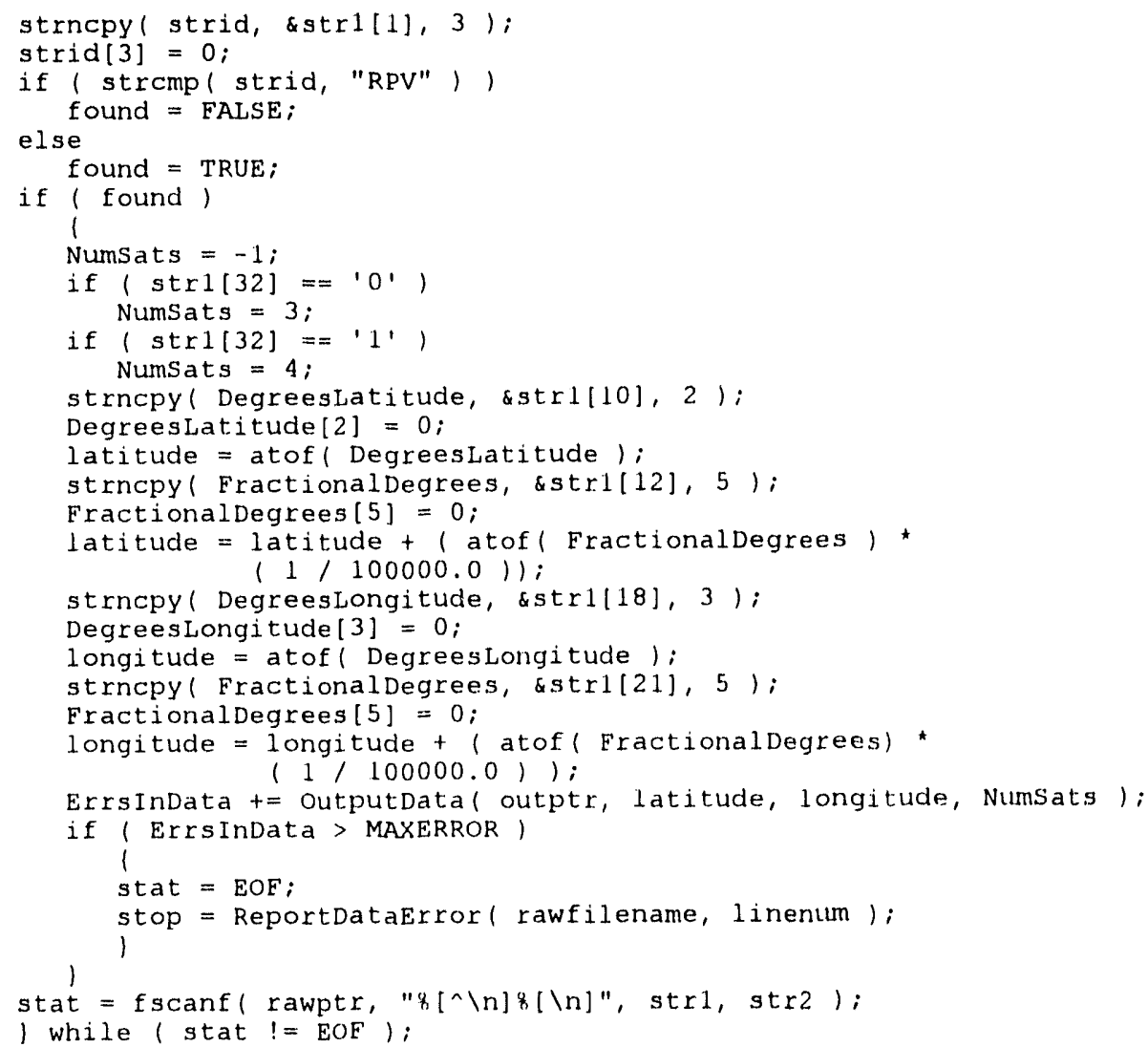




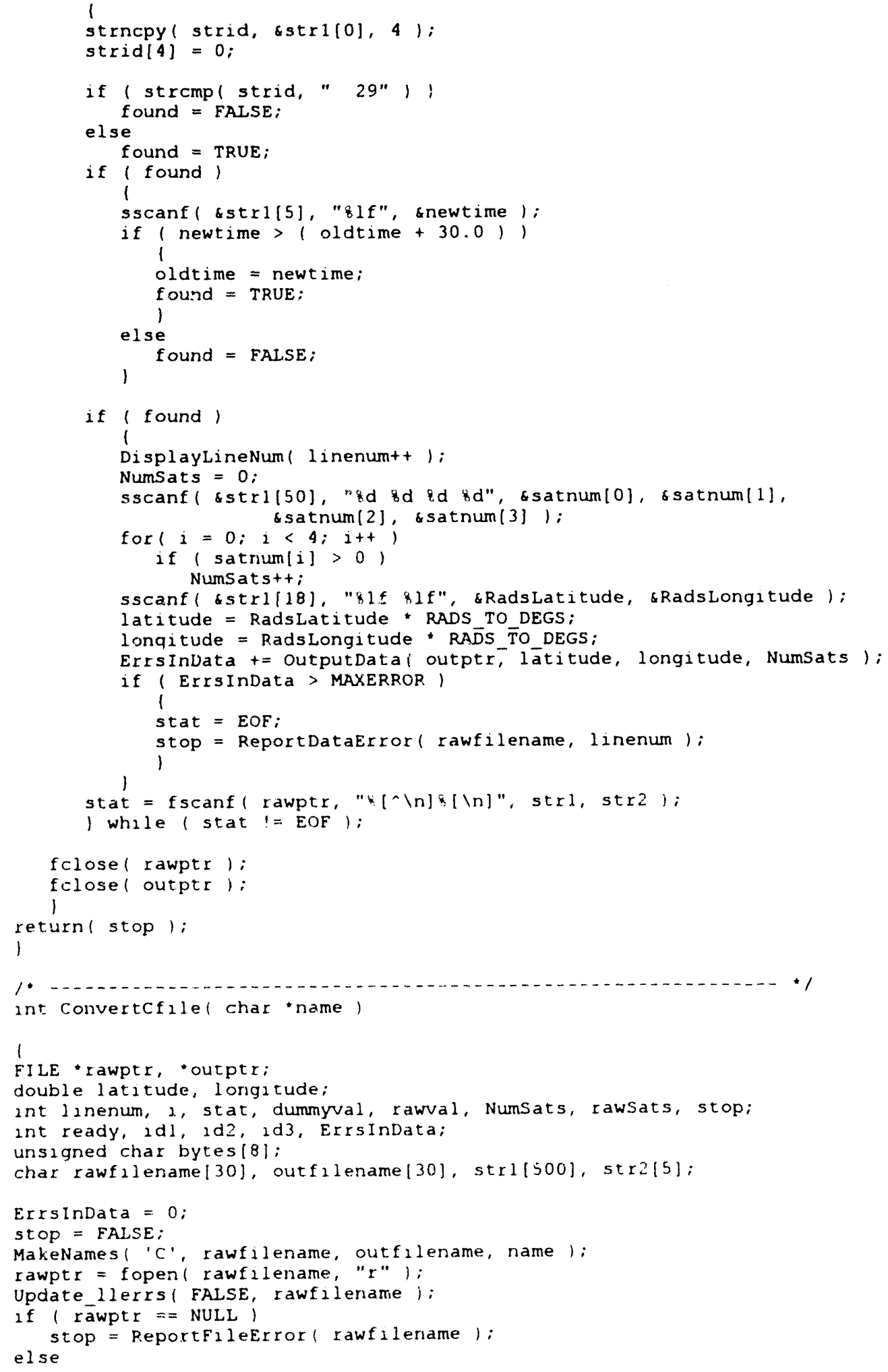




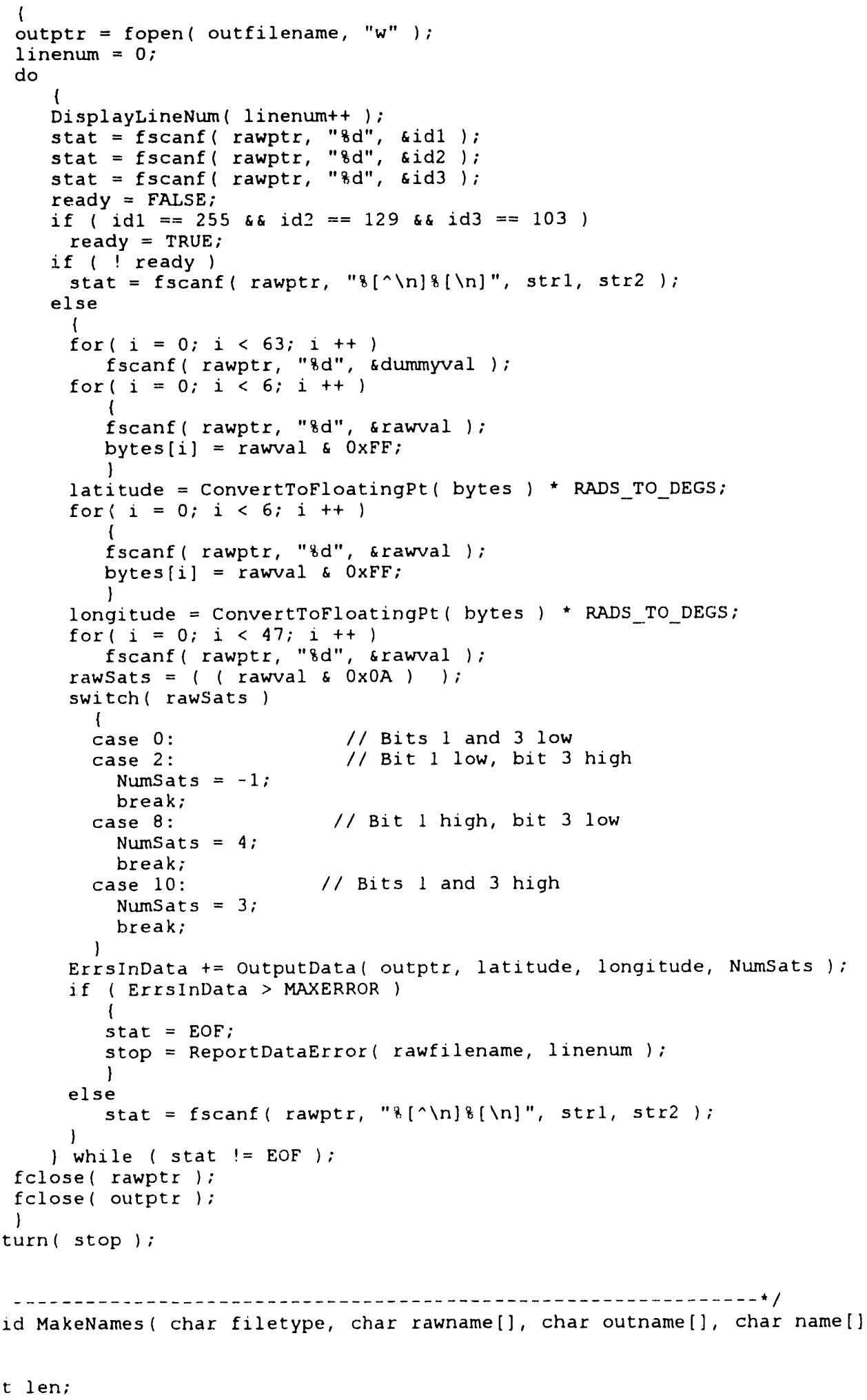




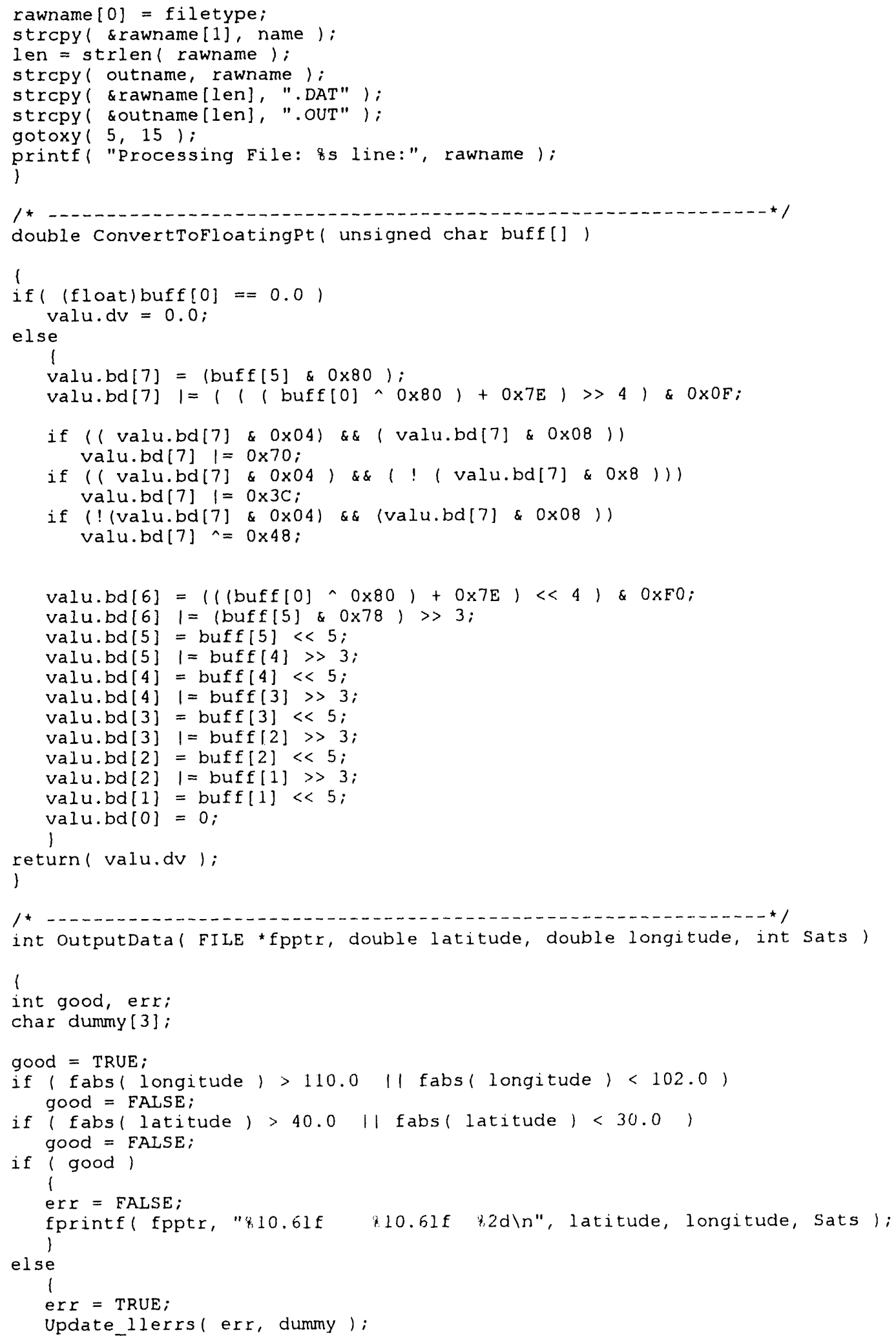




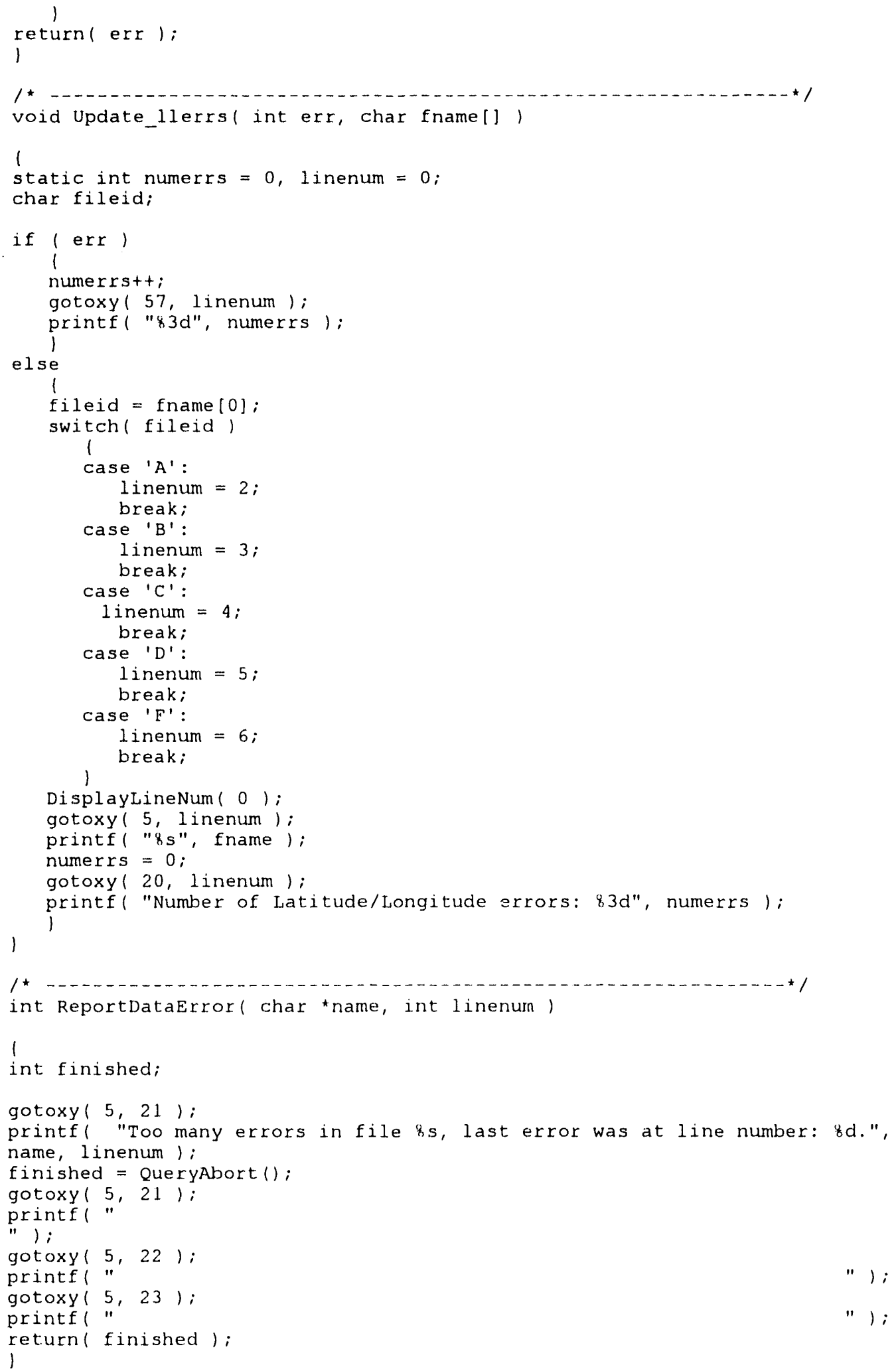




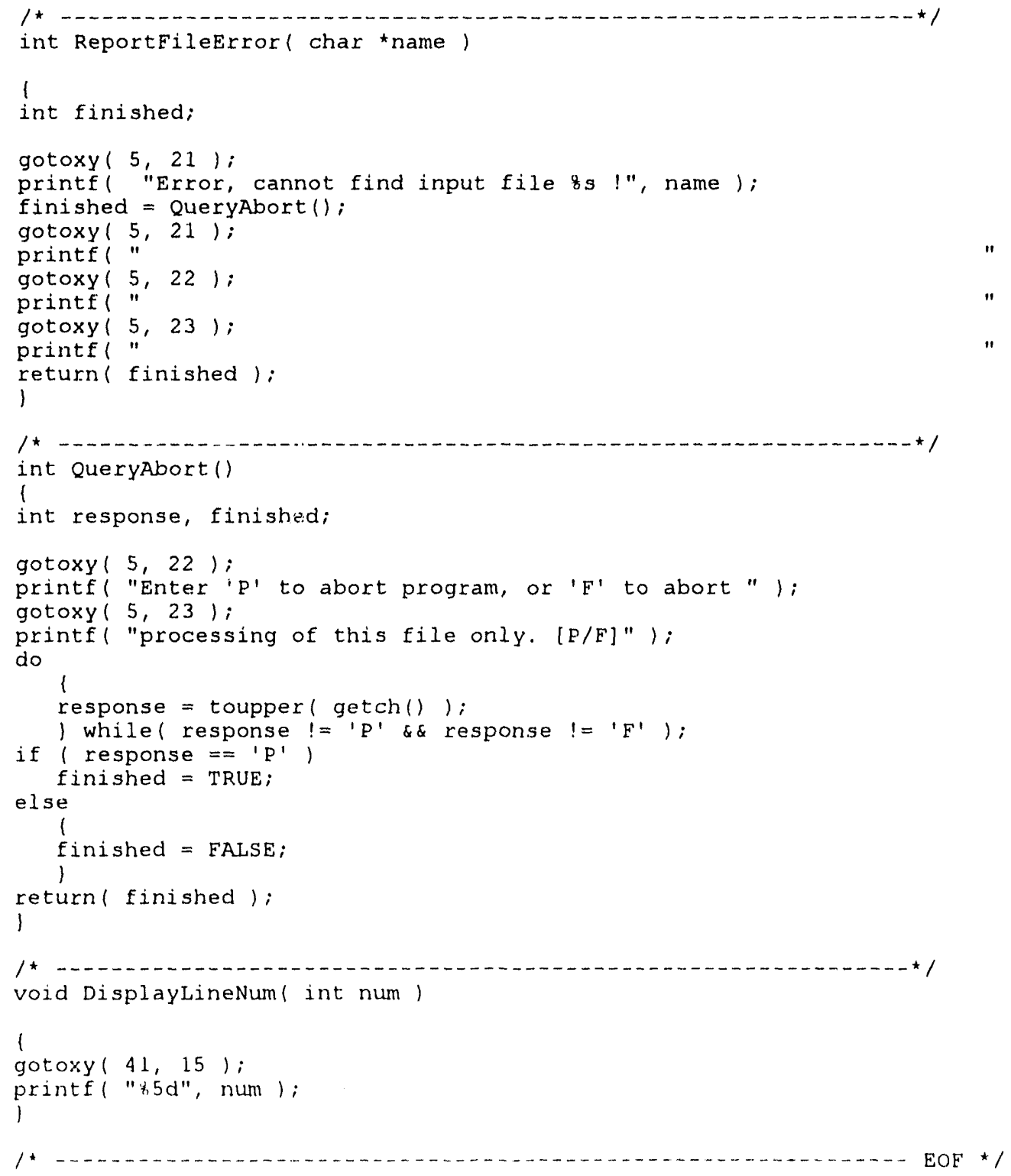




\title{
APPENDIX C.2: SOFTWARE LISTING - GPS DATA ACQUISITION PROGRAM
}

\author{
Developed by: \\ Raymond Byrne \\ Advanced Vehicle Development Department, 9616 \\ Sandia National Laboratories \\ Albuquerque, NM 87185
}


C. $2-2$ 


\section{APPENDIX C.2: SOFTWARE LISTING - GPS DATA ACQUISITION PROGRAM}

Gathers serial GPS data and logs data to a file. Uses the two serial ports on the ZT 8901 processor card as well as the four serial ports on the ZT88CT41 Quad Serial Card.

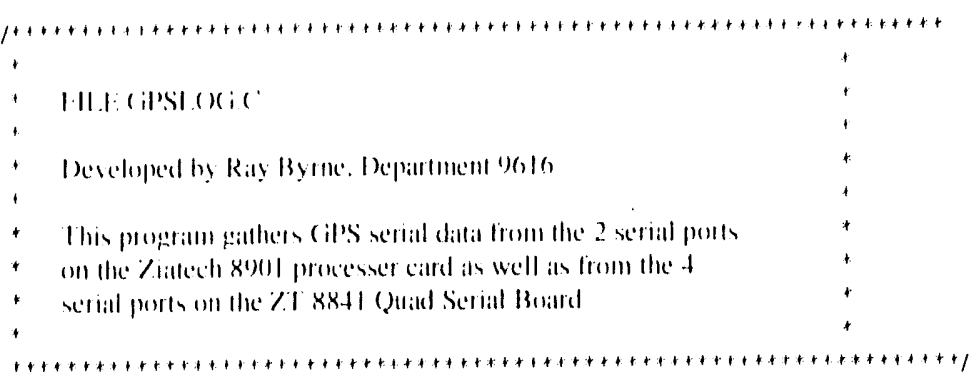

Hincturle alush:

Hincluele andion.

Hinclude coldions

Hinclude estringh.

Hinclude eddph he

Hinclute anchs

Honclude esel8250 ha

\begin{tabular}{|c|c|}
\hline Hedeline & hulfer \\
\hline Haldime: & liall liill \\
\hline Helime & trmerinul \\
\hline Holetinc & (fill) \\
\hline Heline & (n) I \\
\hline Hollime & ch : \\
\hline Heletinc & (h) 1 \\
\hline Helime & (h) $t$ \\
\hline Haline & ih 5 \\
\hline Halime & ch 6 \\
\hline
\end{tabular}

Hestine IRI: I

Halime HASS:

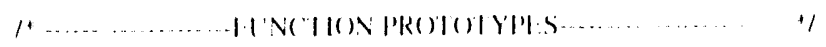

\begin{tabular}{|c|c|c|}
\hline ind & 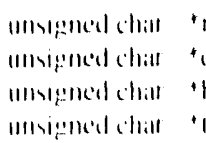 & 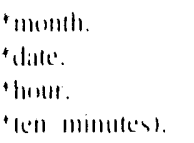 \\
\hline 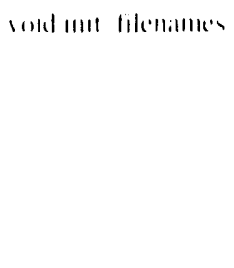 & 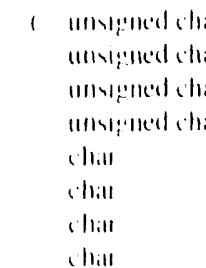 & 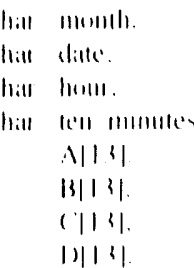 \\
\hline
\end{tabular}




$\begin{array}{ll}\text { chatr } & \text { E }|13| . \\ \text { chair } & |1| 3 \mid 1:\end{array}$

void crealte_files (char $\quad \wedge|1.3|$.

chill B|I.3|.

chat $\quad(\mid 131$.

char D|1.31.

char E|1.31.

chilt F|1.3|):

void Init_PIC (void):

void closecfiles (void):

void Init_Serial_Ports (void):

void Save_A (void):

void Silve_B (void):

void Save_C (void):

void Salve_1) (void):

void Save_l: (void):

void Salve_F( void):

isid Set_l'p_Rec (void):

void Req Magellan (void):

I* .................-VARIABI.I: DI:('I.ARAIIONS

I:Il, *I:A, *IB, *I:( *I:I), *I:1: *I:I:

unsigned chat eom_value $=(1 \times$ (hat:

unsigned char Rockwell_count $=0$.

Record Rockwell = I:AI SI : :

unsigned chatr month.

dille.

hour.

kn_minutes:

chat $A|1.31 .13| 1.31 .(1|3|, 1)|131,13| 1.31 .191131$ :

unsigned chall huffer $\Lambda / 2 *$ bufter sicel.

butier $B \mid 2 *$ burfer sizel.

hulfer $(12 *$ hulfer sizel.

hulfier (1)/2 bufter sizel.

huffer $1: 12 *$ butfer sine 
butfer_1 $12 *$ buffer_sizel:

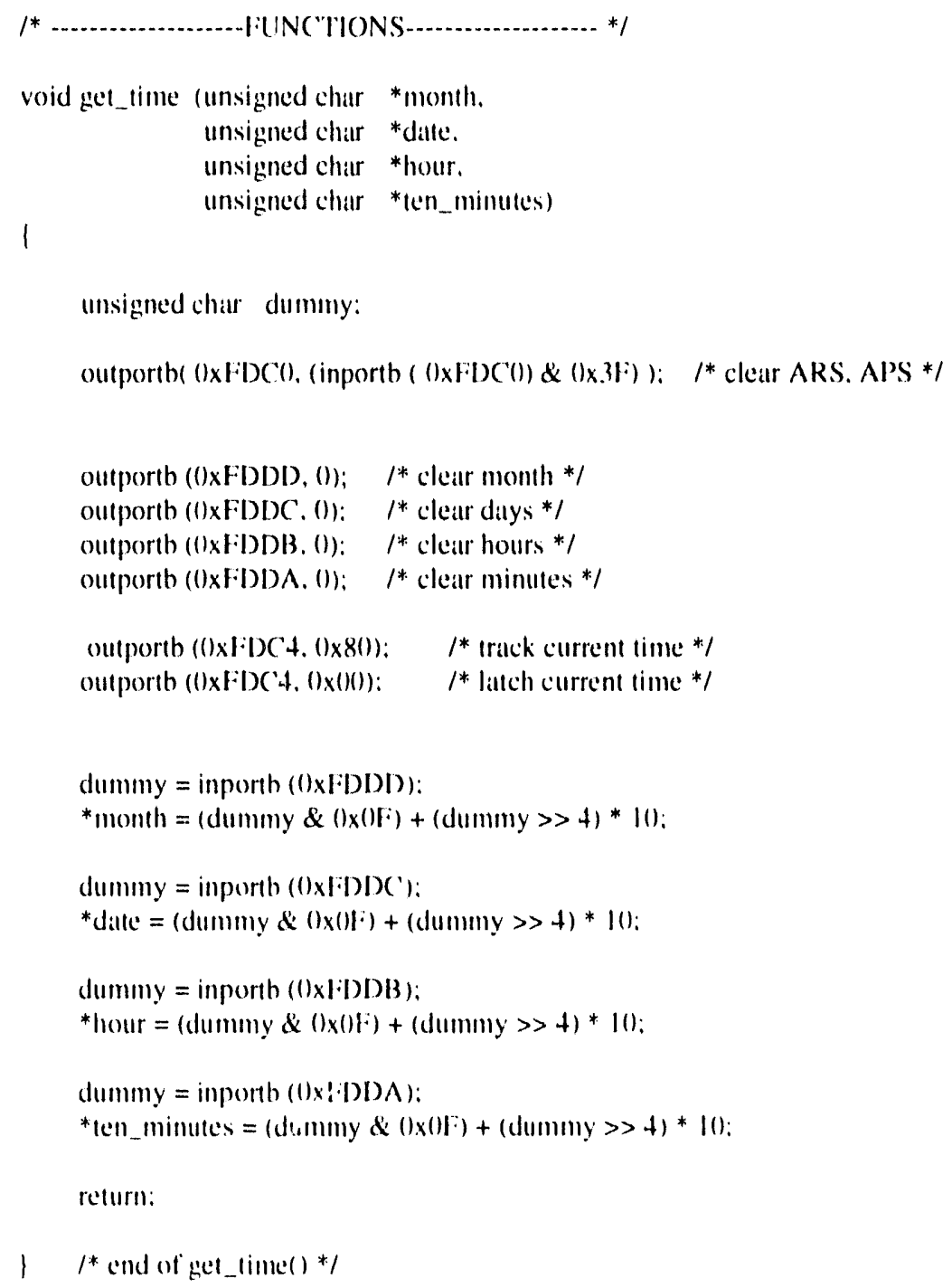




\section{char $\quad|1| 3 \mid 1$}

1

ansigned int

$$
\begin{aligned}
& \text { month_lens. } \\
& \text { month_ones. } \\
& \text { dalle_tens. } \\
& \text { dale_ones. } \\
& \text { hour_tens. } \\
& \text { hour_ones: }
\end{aligned}
$$

month_tens $=$ month $/(1):$

month_ones $=$ month $\%(1)$ :

date_tens = date / I ):

date_ones $=$ date $\% 10$;

hour_lens = hour $/ 10$;

hour_ones $=$ hour $\% 10$ :

sprintf (A. "A\%d\%d\%d\%d\%d\%d\%c.DAT".month_kens, month_ones.

date_tens. date_ones. hour_tens. hour_ones, ten_minutes +48 ):

sprintf (B, "B\%d\%d\%d\%d\%d\%d\%c.DAT",month_lens. month_ones.

date_tens. date_ones. hour_tens. hour_ones. ten_minutes + 48).

sprinti (C. "C\%d\%d\%d\%d\%d\%d\%c.DAT".month_tens. month_ones.

date_tens. dalte_ones. hour_tens. hour_ones. ten_minutes +48 ):

sprintf (D). "D\%d\%d\%d\%d\%d\%d d c.DAT".month_lens, month_ones.

date_tens. date_ones. hour_lens. hour_ones, ten_minutes + 48 ):

sprimi (E. "lE\%d\%d\%d\%d\%d\%d\%s.DAT". month_lens. month_ones.

date_tens. date_ones. hour_lens. hour_ones. ten_minutes +48$)$ :

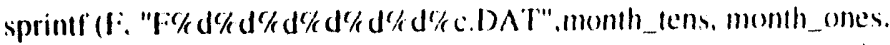

dalte_tells. date_ones. hour_tens. hour_ones, ten_minutes + 48 ):

return:

1 * end of init fillenames( $* 1$

void create files

1

char

A|1.3|.

char $B|1,3|$.

char ('|1.31.

char D.1131.

char $\quad$ E.131.

char 1.11311

1

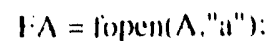

$1: B=$ (o) 
$F(C=$ fopen $(C . " a ") ;$

$F \mathrm{D}=$ fopen $(\mathrm{D}) . " \mathrm{a} "):$

$\mathrm{FE}=$ fopen(E:"a"):

$\mathrm{IF}=$ fopen(F." a"):

return:

$1 \quad$ * end of create_files() *I

void Init_PIC (void)

1

unsigned int ercode.

version.

$C p u_{-}\left(y p e=0 D P_{-} Z T_{-} 89(1)\right.$.

salve_matsk = DDP_TRUL.

addr ()$=() \times A B$

addr $1=() \times A 9$.

base_vector $=(1) \times 80$.

master_ir_level $=2$ :

ercode $=$ Piclnitsw $($ \&version $):$

if (ercode) printf ("Lrror intializing PIC Soltwareln"):

ercole $=$ Piclnilllw (cpu_lype, save_mask):

if (ercode) printt ("Error initializing PIC Hardwareln");

ercode $=$ PiclnitSlave (addr). addrl. base_vector. master_ir_level):

if (ercode) printl" ("Error initializing Slave PIC $\left(n^{1}\right)$ :

return:

1 $\quad I^{*}$ end of Init_PIC*

void close_files (void)

1

ficlose (FA):

folose (FB):

liclose (FC):

filose (IF)):

ficlose (FE):

liclose (FIF):

return:

$1 \quad$ /* end of close_files() */ 
void Init_Serial_Ports (void)
unsigned int ercode,
version:

ercode $=$ Ser825()InitSw(\&version):

if (ercode) printf("Error initializing Serial Softwareln"):

I* initialize COM1, 960) Batud, 8 bit, 1 stop, no parity */

$1 *$ Magellan OEM GPS Module on J5. ZT8901 */

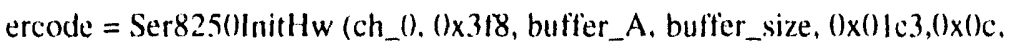
DDP_ZT_89()1, eom_value);

if (ercode) printf("Error initializing COMl portln"):

1* initiallize COM2, 480)( Batud, 8 bit, I stop. no parity */

/* Magnavox GPS Engine on J4, ZT890)! */

ercode $=$ Ser825()InitHw (ch_1.0 () 2f'8, buffer_B, buffer_size, ()x()183, ()x()b. DDP_ZT_89()1. com_value):

if (ercode) printf("Error initializing COM2 porthn"):

1* initialize 88+1-COM1.960) Baud. 8 bit, I stop. odd parity */

$1 *$ Rockwell CiPS Unil on J1, ZT8841*/

ercode $=$ Ser8250)InitHw (ch_2. ()x.3e(), buffer_C. buffer_size, $0 \times(0) 1 \mathrm{cb} .0 \times 84$, DDP_ZT_8901, eom_value):

if (ercode) printf ("Error initializing ch_2ln"):

I* initialize 8841-COM2. $24(1)$ Batud, 7 bit, 1 stop. odd parity */

1* Magnavox SST CiPS System */

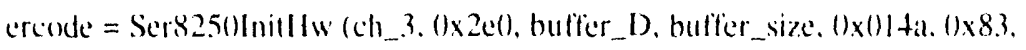
DDP_ZT_89(1). eom_value):

if (crcode) printf ("Latror initializing ch_3\n"):

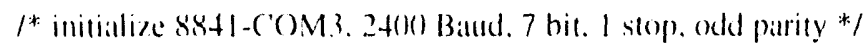

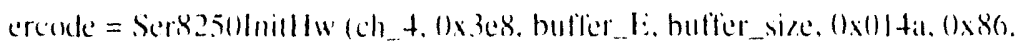
DI)P \% Y Y $8(1)$. com_ralue):

if (crode) printe ("Iror initialisin: (h. +lu"): 
I* initialize 8841-COM4, 9600) Batud. 8 bit. I stop. odd parity */

/* Trimble Placer Cips on J4. \%.T884I */

ercode $=$ Ser825()Inithw (ch_5. $0 \times 2 e 8$, bulfer_li, butfer_size. $(1) \times() / c h .() \times 8.5$, DDP_Z'I_89()I, ecom_value):

if (ercode) printf ("Error initializing ch_5 5 "s"):

$1 \quad I^{*}$ and of Init_Serial_Ports()*I

void Silve_A (void)

1 $\begin{aligned} & \text { unsigned int } \text { inchar. } \\ & \text { stattus. } \\ & \text { ercode: }\end{aligned}$

ercode $=$ Ser8250)Reev (ch_0. \&inchar. timeout):

if (ercode)

1

printe ("Lirror \% i on (hannel ()n". ercode): ercode $=$ Ser8250)Status (ch_(). \&status):

1

fprintt (FA. "C//c". inchar):

$1 \quad 1 *$ end of Salve_A( $) * /$

void Silve_B (void)

1

unsigned int inchar.

stattus.

ercode:

ercode $=$ Ser8250)Reev (ch_1, \&inchar, timeout): if (ercode)

I printf ("Irror \% i on (hamnel IIn". ercode): ercode $=$ Ser8250Status (ch_1. destallus):

1

iprintf (I:B. "\%(c". inchar):

\} $\quad l^{*}$ end of Save_B( $) * /$

roid Sille ( ( void)

1 


$$
\begin{aligned}
\text { unsiensed int } & \text { inchar. } \\
& \text { valtus. } \\
& \text { ercode: }
\end{aligned}
$$

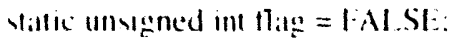

ercode $=$ Serk2501Reer reh_2. deinchar. timeour):

if lercode)

1

primil "lerror ch on ("hannel 2 In". ercode)

ercode $=\operatorname{Ser} 2501$ Stalus reh_2. devtatust:

1

witch (inchar)

1

$$
\text { case 255: flagl }=\text { TRI } \begin{aligned}
\text { hreak. }
\end{aligned}
$$

(a) 129: If $117 \mathrm{ag}==\operatorname{TR}(t)$

1

Rockwell_count+t:

if (Roch well _ount $==$. $(1)$

fprintf (1.C. "Incif if". 255.129):

Hag = FAl.St:

Record Rockwell = TRI : :

1

$\|$ Rocowell coumt $>301$

1

Record Rochwell = I Al St:

Rochucll coumt $=0$.

1

1 i* end of if *i

we

1

If Record Roshwell $==|R| 1 \mid$

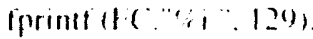

1

hreal.

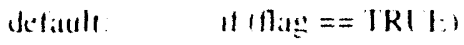

i

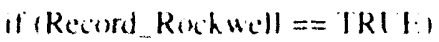

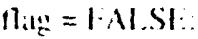

fprintelle." "21". 2551.

1

$\|$ Record Rockwell $==|R| 1$,

hreith.

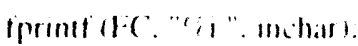

1 $\quad$ and of wnth * 
$1 \quad l^{*}$ end of Salve_C( $* 1$

void Salve_D (void)

1

unsigrd int inchar,

stallus,

ercode:

ercode $=$ Ser8250Recv (ch_3. deinchar, timeoul) $)$

if (ercode)

1

printf ("Error \% $\%$ i on (hannel 3\n". ercode):

ercode $=$ Ser8250)Status (ch_3. \&stattus):

\}

fprintf (FD, "\%c". inchar):

$1 \quad I^{*}$ end of Save_D(1*/

void Save E (void)

1

$\begin{array}{ll}\text { unsigned int } & \text { inchar. } \\ & \text { status. } \\ & \text { ercode: }\end{array}$

ercode $=$ Ser8250Recv (ch__. \& inchar. timeour):

if (ercode)

1

printf ("Frror / $i$ on (hannel 4 "n". ercode):

ercode $=$ Ser8250)Status (ch... 4. \&status):

1

fprinte (1:L: "c//c". inchar):

$1 \quad I^{*}$ end of Save_f $(1 * 1$

void Save fl (void)

1

1* Salver data to file f:******. DAT from Trimble (BPS unit */

$$
\begin{array}{ll}
\text { unsigned int } & \text { inchar. } \\
& \text { status. } \\
& \text { ercode: }
\end{array}
$$

crocke $=$ Ser8250Reev (ch_.5. dinchar. timesur):

if (ercide)

1 


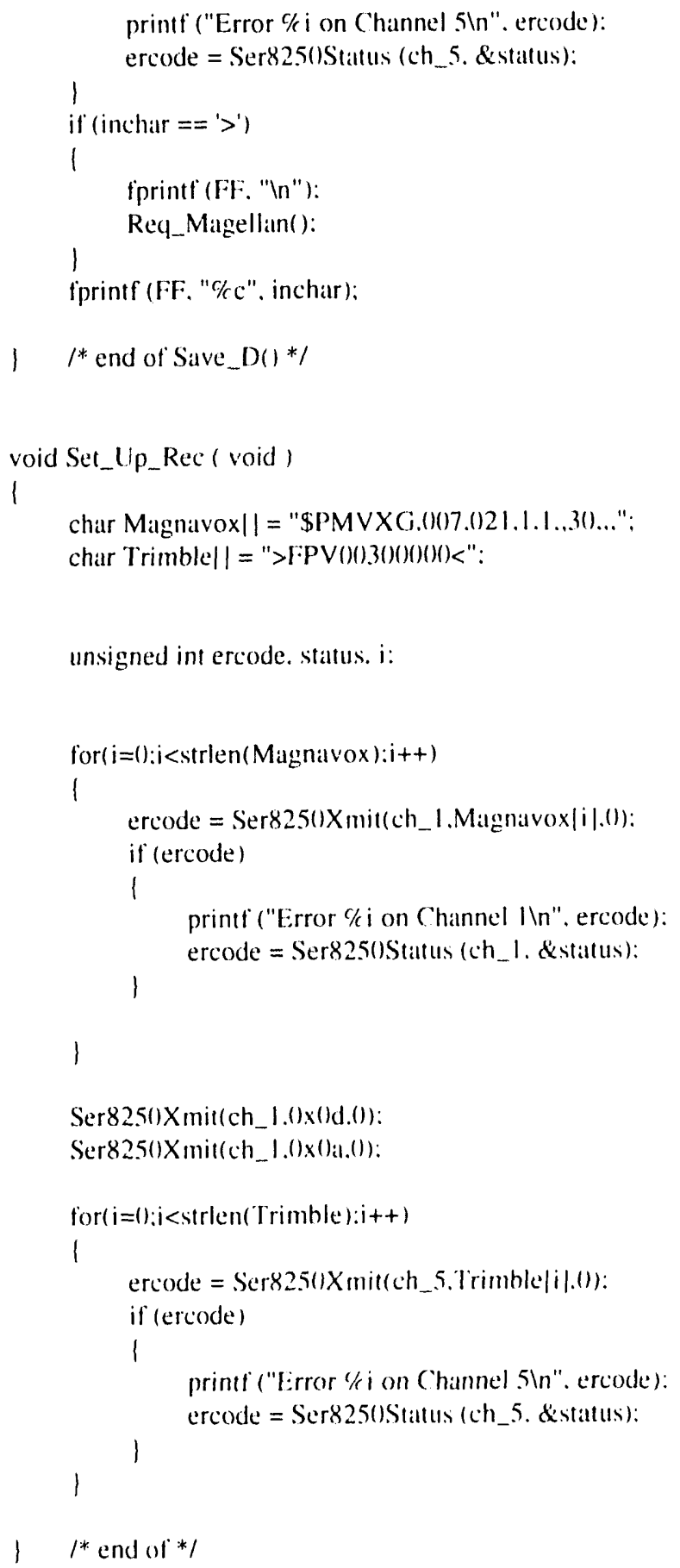


char Magellan III = "\$PM(iI.I.10(1.B()0.1.A.":

unsigned int i, ercode, stallus:

for( $i=(): i<$ strlen(Magellam) $i++$

1

ercode $=$ Ser82501) Xmitlch (1),Magellan|il,(1):

if (ercode)

1

printf ("Itrror "/ri on ("hannel (Nn". ereode):

ercode = Ser8250)Status (ch_. (). destillus):

1

\}

Ser8250)

Ser82.50)Xmit(ch_(1).(1) ()a.(1)):

for(i=1):i<strlen(Magellann 1):i++)

1

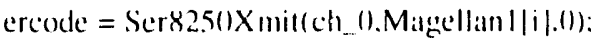

if (ercode)

1

printe ("Error \% i on ('hannel (No". ercode):

ercode = Ser8250Stalus (ch_(), destatus):

1

1

Ser82.50) Xmit(ch (1).(1)x(1).(1)):

Ser8250xmit(ch_(1).(1) (1)a.(1)):

$1 \quad$ * end of Recy_Magellan */

main()

1

unsigned ins

ercode.

count.

stattus.

com_count:

unsigned int ch:

unsigned int inchar:

get_time (demonth. dedate. dehour. delen minutes):

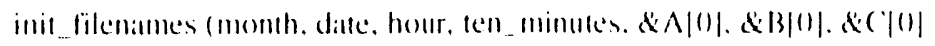




\section{$. \& 1)|(1) . \& F|(1) . \&|i|(1):$}

Init PI ():

Init_Serial__Ports():

create files(A. B. (C. D. F., fi):

Set_(Ip_Rec():

while (!khhil())

I

ercode = Ser8250)Recv(hk (ch_o), \&count):

if (ercode) printf ("Error: (hannel () Buffer"):

if (coumt $>=1$ ) Save_A $A$ ):

ercode $=$ Ser82501Recv (hk (ch_l. decount):

if (ercode) printf "Frror: (hannel I Buffer"):

if (count $>=1$ ) Save B( ):

ercode $=$ Ser8250Recv( hk (ch_2. decount):

if (ercode) printl" ("I.rror: ( hannel 2 Buffer"):

if (count $>=1$ ) Silve ('):

ercode $=$ Ser8251)Recv( he (ch.3. decount):

if (ercode) printl ("Etror: (hannel 3 Buffer"):

if (count $>=1$ ) Silve_ i) ():

ercode $=\operatorname{Ser} 82.5()$ Reco $($ hk $(c h)+$ decoume):

if (ercode) printl ("lirror: ("hammel + Buffer"):

if loount $>=1$ ) Salve f $(1)$ :

ercode $=$ Ser8250Reco ( hk (ch_.5. \&ecount):

if fercode) printf ("I:rror: (hannel 5 Buffer"):

ifleoum $>=1$, Sille_lit):

1 I* and of while (!kbhill) */

ercode $=$ Ser825()!: $\mathrm{xin}():$

if (ercode) printe ("I:ror closinge sertal pertsin"):

close filks): 
1 | ${ }^{*}$ end of main */ 


\title{
APPENDIX C.3: SOFTWARE LISTING - ASCII TO BINARY CONVERSION PROGRAM
}

\author{
Developed by: \\ Frank Wunderlin* \\ Technadyne Engineering Consultants, Inc. \\ P.O. Box 1328 \\ Albuquerque, NM 87192
}

* Work performed under Contract No. 87-2050 for the Advanced Vehicle Development Department (9616), Sandia National Laboratorics. 


\section{C. $3-2$}




\section{APPENDIX C.3: SOFTWARE LISTING - ASCII TO BINARY CONVERSION PROGRAM}

This program converts the raw Rockwell GPS data, stored in ASCII, to a binary file so that the Rockwell provided programs can be used to analyze the Rockwell data.

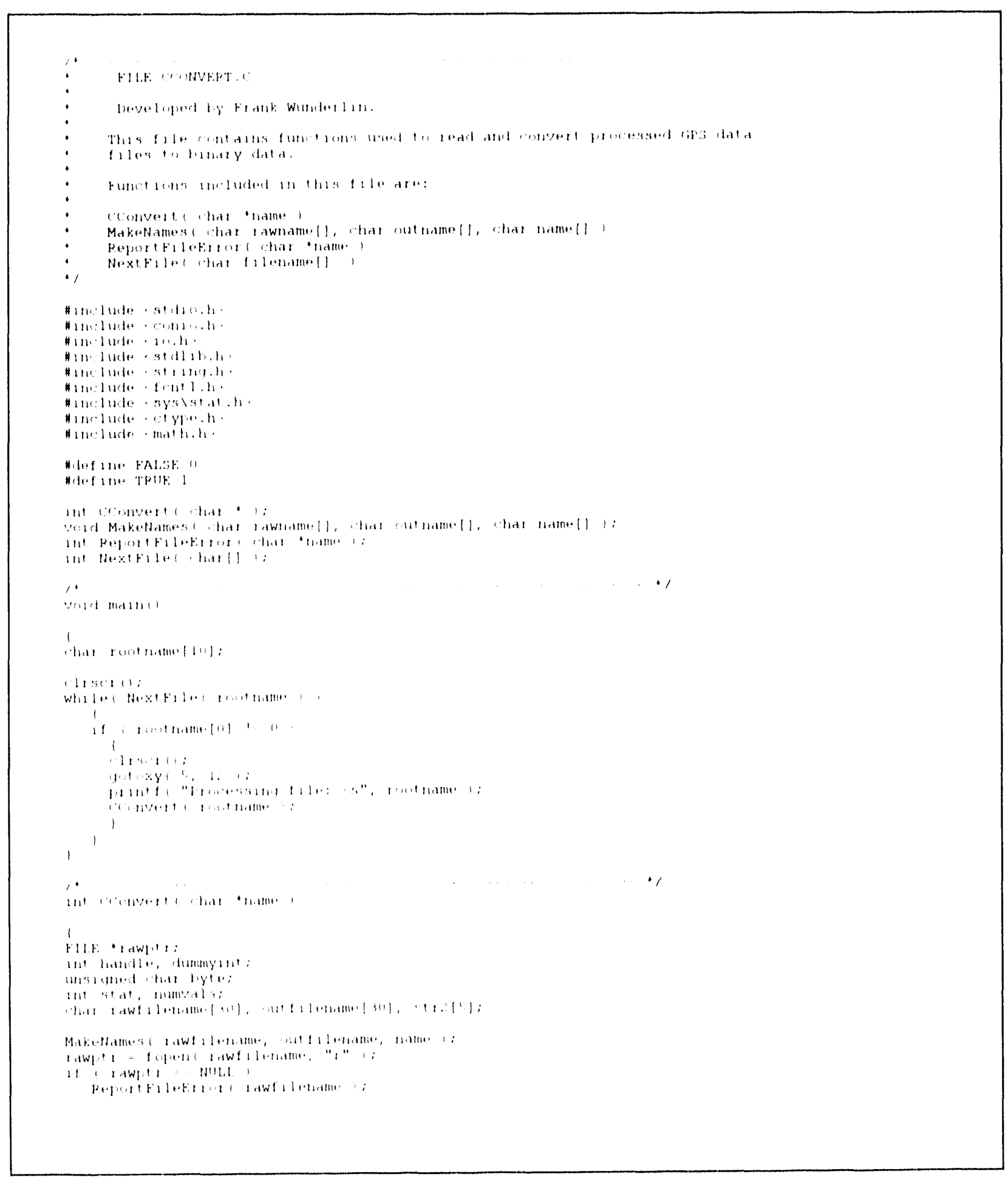




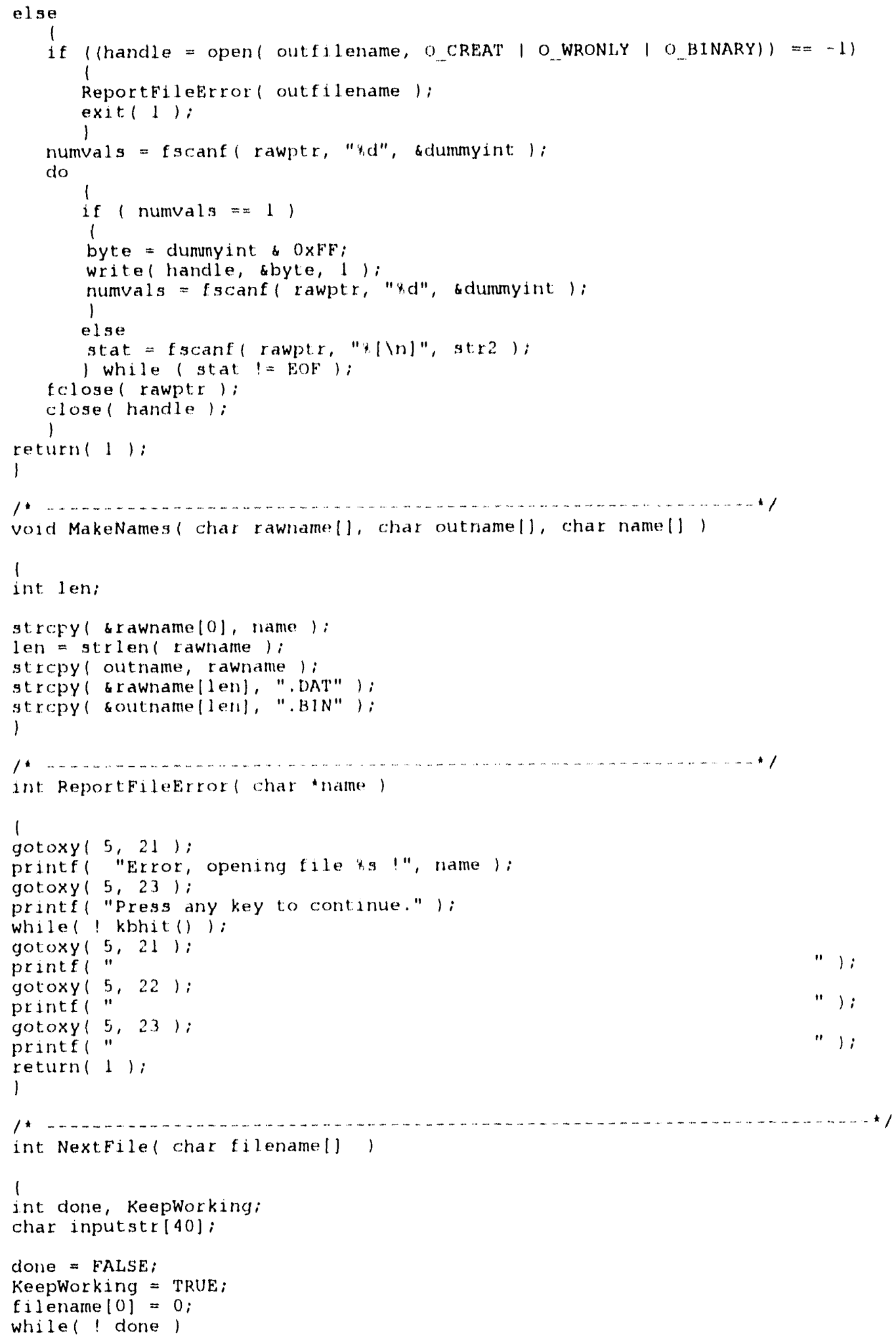


1

cleser();

gotoxy $(5,5)$ i

printf( "Extension of file to convert to binary ig assumed to be '.DAT" "): gotoxy $(5,6) ;$

printf ( converted file will have extension '.BIN'." );

gotoxy $(5,10)$;

printf ("Input name of tile ( do not enter extension) to convert to binary"

gotoxy $(5,11)$;

printfo "followed by a CR or enter 'Q' to quit: " ):

scanf( "as", inputstr);

if ( strlen( inputstr) $=1$ )

1

if ( toupper (inputst: $[0])={ }^{\prime} Q^{\prime}$ )

KeepWorking = FAlsti;

done $=$ T'RUF:

1

e]se

1

stropy( filename, inputats);

done = TP.UE:

1 1

return( KeepWorking)

$/$

EOF 
Reprinted with permission from:

Ziatech Corporation

3433 Roberto Court

San Luis Obispo, CA 93401 


$$
\text { C. 4-2 }
$$




\section{APPENDIX C.4: SOFTWARE LISTING - DESCRIPTION OF ZIATECH SOFTWARE ROUTINES}

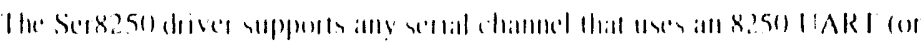

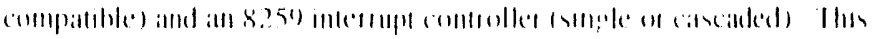

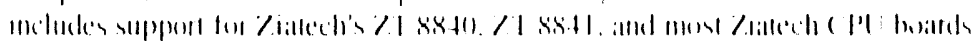

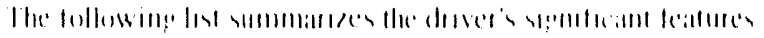

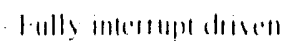

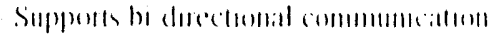

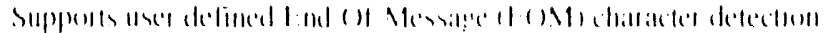

|-

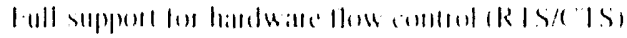

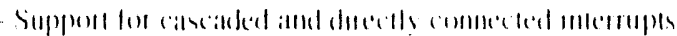

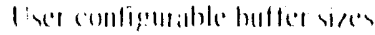

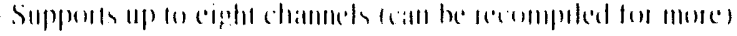

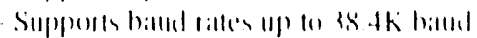

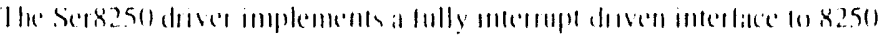

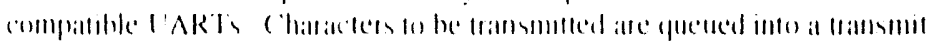

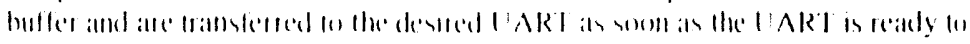

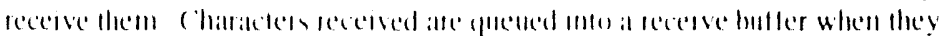

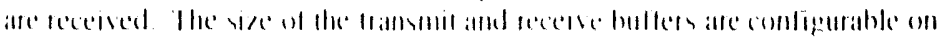
a) (hitmencl biaste

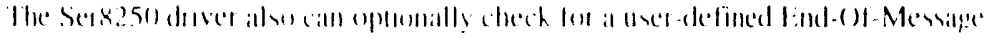

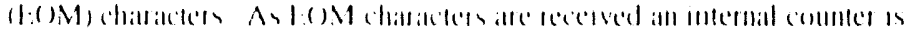

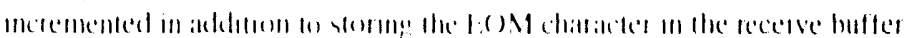

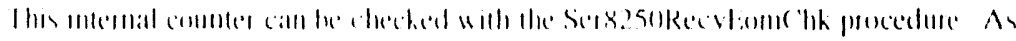

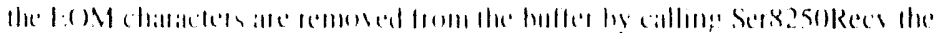

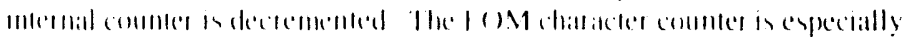

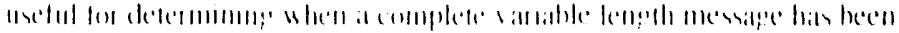
maming

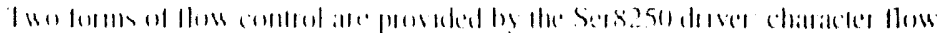

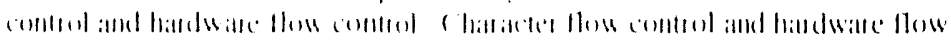

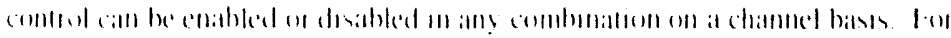

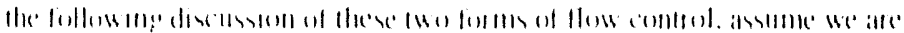

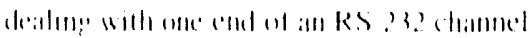

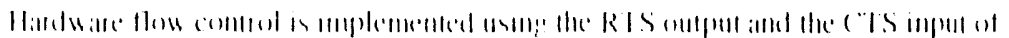

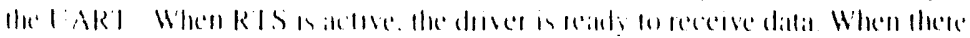

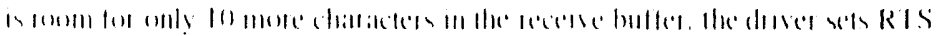

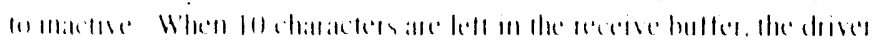

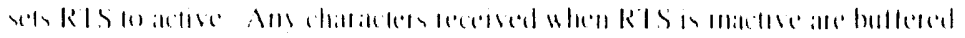

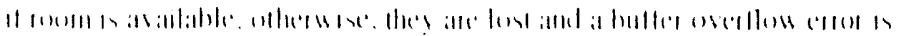

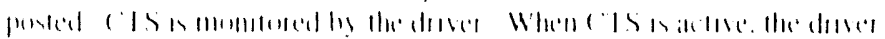

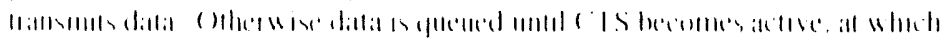

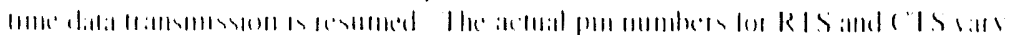

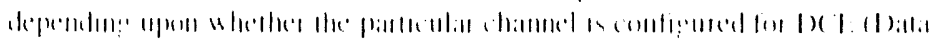

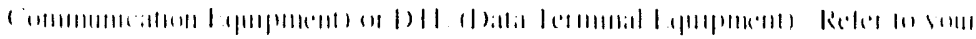

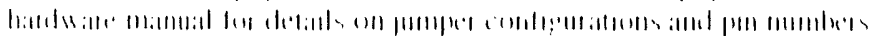

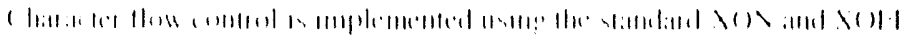




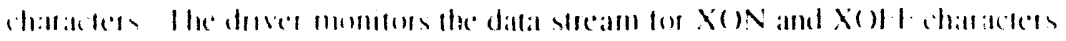

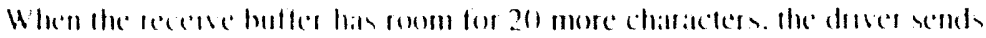

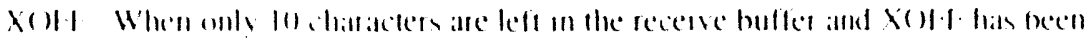

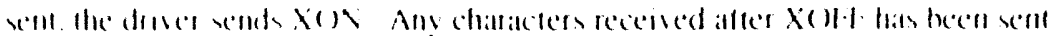

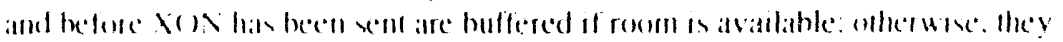

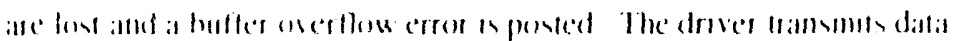

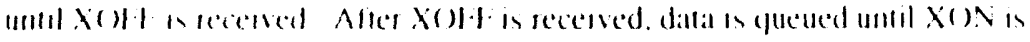

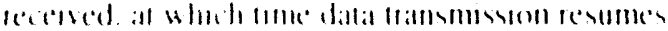

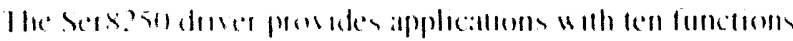

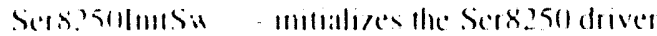

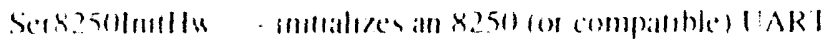

$$
\begin{aligned}
& \text { Sestestsimn - tamsmul a character on a channel } \\
& \text { Sers? } 50 \text { Red Hecene a characker on a channel }
\end{aligned}
$$

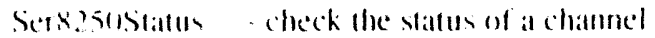

$$
\begin{aligned}
& \text { Sersesukecush - check the number of characies in the recerve }
\end{aligned}
$$

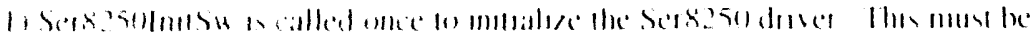

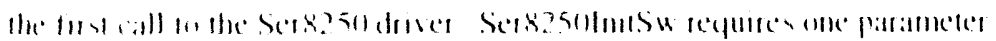
111) (1)แ1!u!t

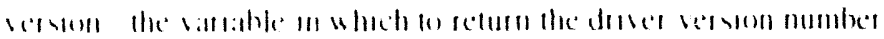

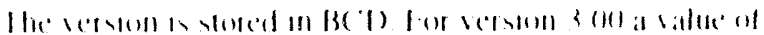

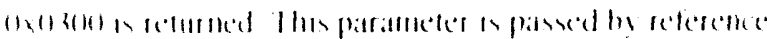

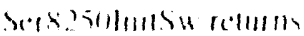

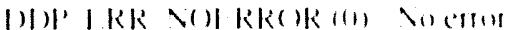

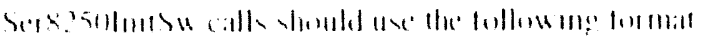

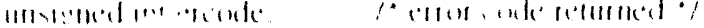

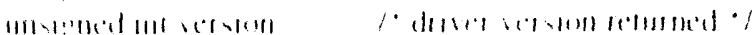


ercode $=$ Serk250) nitswidverstom).

2) Ser8250)/nitlwe inttalizes one sertal $/ /()$ channel. This procedure must be called once for each serial chanmed on be used the buffers are imstalized. the interruph handler is installed. and the $I \triangle \mathrm{R} T$ is configured. Picinitsw and Piclnulla mus be called prior to Ser8250llnitllw. light paramelers are recpuired for inpul

chan - the chamnel number to imitialiac (1)-7). The number is used lo reference a particular serial channel. This parameler is passed by value

lant - the hatse adderess of the UAR' for this channel. This parameter is passed hy value

hulfer - the atderess of the data buffer. This is a pointer to a character array that is to be doveded evenly into two huffers. This parameler is passed by value

but size - The sige of each buffer. The character array pointed to by 'huffer' must be 'huf size' 2 characters !ong. This parameter is passed hy value

mode - specifices the operational chanacteristics for thes channel. The bable helow dereribe the hit defimations for this parameter. This parameter a passed by value

hul(s) descriptun

15.12 Reserved lleate as zeron

11 lecho inpul.

11- disithled

1- enabled

lo Hardware flow commol rets/e "IS)

11- disibled

1. enabled

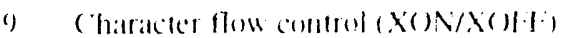

1)- disithled

1 - enabled

X-6) Batud rate

876

-....

() () () $-19.2 K$ batud

() $01-38+4 \mathrm{~K}$ halld

(1) $10-30$ ba batud

(1) 1 - 600) halud

1 $010-1200$ batud

101- 24013 hatud

$110-48001$ batud

$111-96(1)$ halud

5.3 Parrly

$5+3$

$x x 0$ - Noparaty

(1) 1 - (hold parlly

(1) I liven partl! 
I) I - Mark (High) parily

1 11 - Space (low) parily

2 Sisp bits:

() - one stop bit

1 - two stop bits ( 1.5 for 5 dalta bils)

1.(1 Data bits:

11

-..

() () - 5 data bits

() 1 - 6 data bits

10.7 dala bits

$11-8$ data bits

vector - the interrupt vector number to use for this channel. This number must correspond to the interrupt vecerer enenerated by the 8259 interrupt controller for this LARTs interrupt level. This parameter is passed by value.

cpu type - the ('Pllype as defined in "DDP.II." This parameter is passied by value.

eom value - the End-Of-Message (EOM) character value. Values of o thru 255 are supported as valid EOM characters. To disahle this leature, use a value greater than 25.5. This parameter is pasised by value.

Ser825(1) nitllw returns:

I)IDP IERR_NOERROR (()) - No error

DDP IRR_BADARCiI (II) - Invalid value for chan

I)I IRR_BAI)AR(i) (14)-Invalid value for buf size

Ser8250) nilllw calls should use the following formall

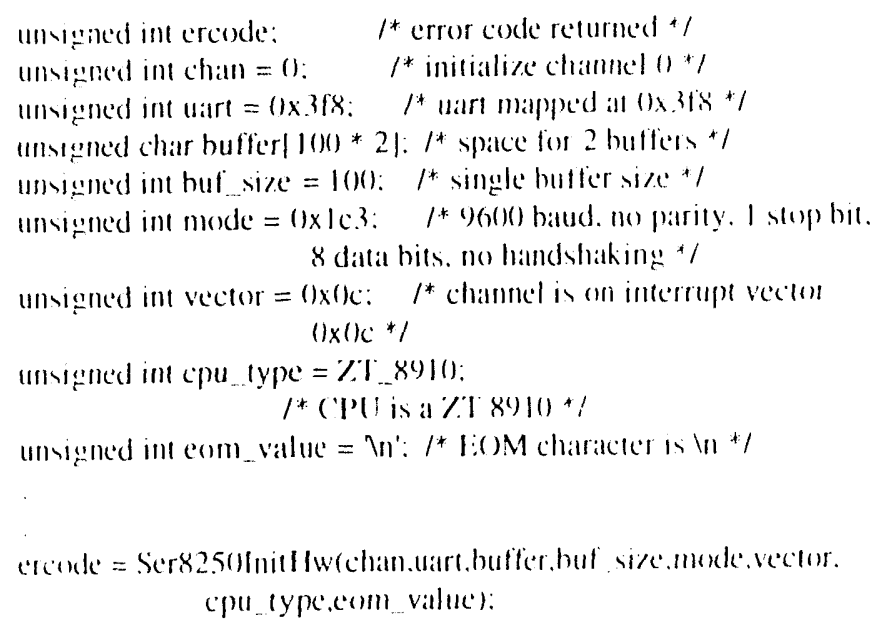

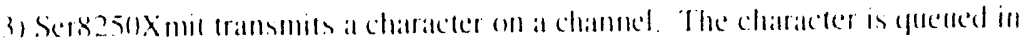

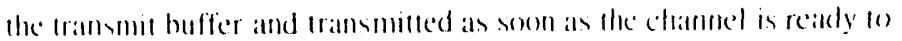
Iramsun data. Three parameters are requined for impun 
chan - the channel number used to transmit (0-7). This parameter is passed by value.

ch - the character to transmit. This parameter is passed by value.

timeout - the value lo use for a timeout if the transmit buffer is full. If zero, this procedure waits indefinitely until room is available in the transmit buffer. Non-zero values are used as a maximum time fo wail for room in the transmit buffer. This value depends on CPl speed. This parameter is passed by vallue

Ser8250xmit returns:

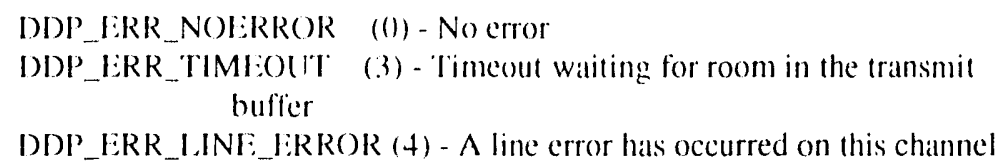

Ser8250Xmit calls should use the following format:

unsigned int ercode: $\quad / *$ error code returned */

unsigned int chan $=0 ; \quad / *$ transmit to channel $0 * /$

unsigned int ch $={ }^{\prime} A$ ': $\quad l^{*}$ transmil a ' $A$ '*l

unsigned int timeout $=0:\left.\quad\right|^{*}$ no timeout */

ercode $=$ Ser825()Xmiltchan.ch,timeout $):$

4) Ser8250Recr receives a chatacter from a channel. The chanacter is taken from the receive huffer. There paramelers are required - two for inpul echatn and timeoull) and onc for output (ch):

chan - the chamnel number from which you receive (1)-7). This parameter is passed by value

ch - the variable in which to return the received character. This parameder is patsised hy reference.

timeout - the value to use for a timeout if the receive buffer is empty. If acro. this precedure wats indefinitely until a character is available. Non-gero values are used as a maximum time on wait for a character on be available. This value depends on chll speed. This parameter is palssed by value

Ser8250Rece relurns:

DI)I IIRR NOI:RR()R ((1)- No error

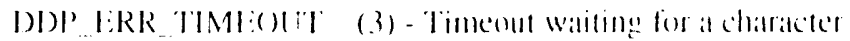

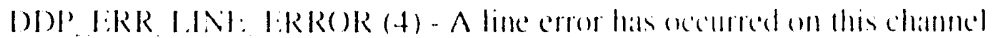

Sers250Reere calls shombl use the following formall: 


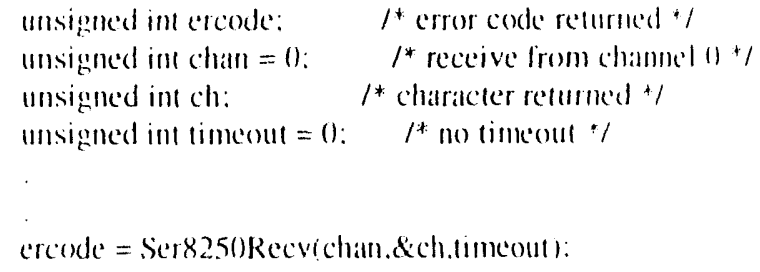

5) Ser8250 Status checks a channel's line status. Two parameters are requiredone for imput (chan) and one for output (status):

chatn - the channel number whose status you are checking (1)-7). This parameter is passed by value.

status - the variable in which to return the chammel slatus. The lathe below describes the bit definitions for this paramerer. This parameter is passed by reference.

bit(s) description

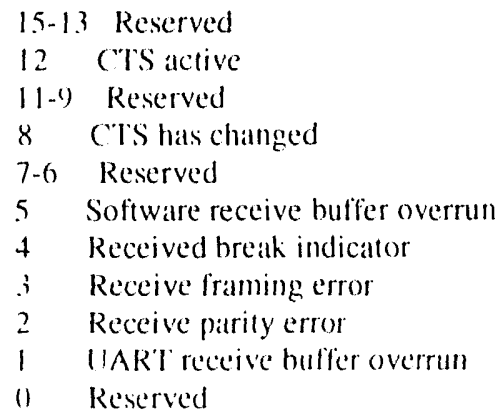

Sier8250) Siatus relurns:

1)I)P IERR NOERROR (1I) - NO error

Ser82501status calls should use the following format

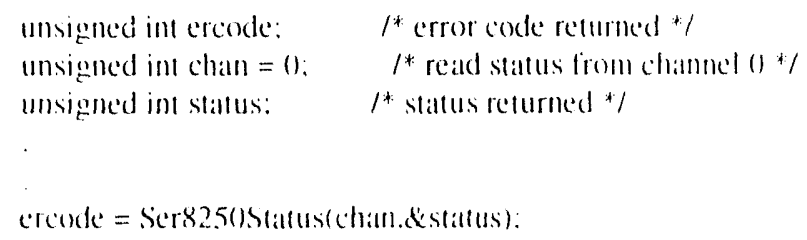

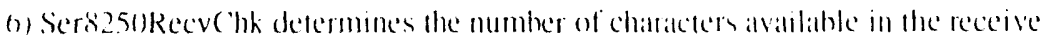
buffer for a chamel. Two parameters are recpuired - one for input (cham) and one for output corment:

chan - the number of the chamel whose receive buller is a be chected (0)-7). This parameter is passicel hy value. 
count - the vartiable in which fo retum the mumber of characters available in the receive buffer. This parameter is passed by reference

Ser8250Recov'lik returms:

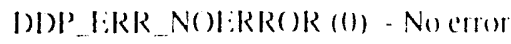

Ser8250Recer hik calls should use the followinge formall:

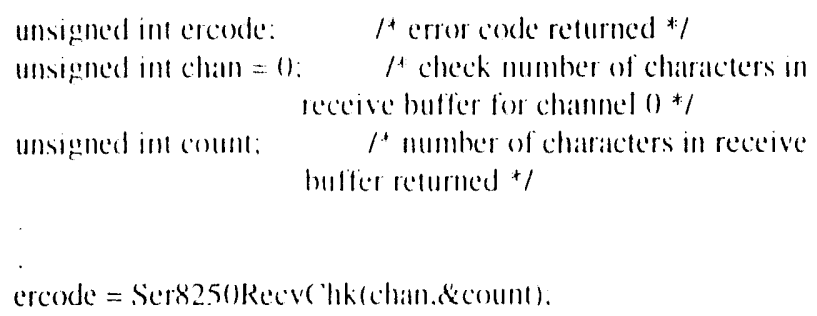

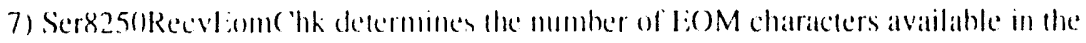
receive buffer for a chanmel. Two parameters are reguised - one for input (chan) and one for output fcount):

chan - the mumber of the channel whose receive huffer is to be checked (0)-7). This parameter is passed by value.

count - the vartable: in which to return the number of I:( ) M characters avaiblable in the receive huffer This parameler is passed by reference

Ser8250Recutome hik returms.

I)I) IERK N()I:RR()R(1) - No (Tror

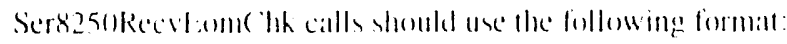

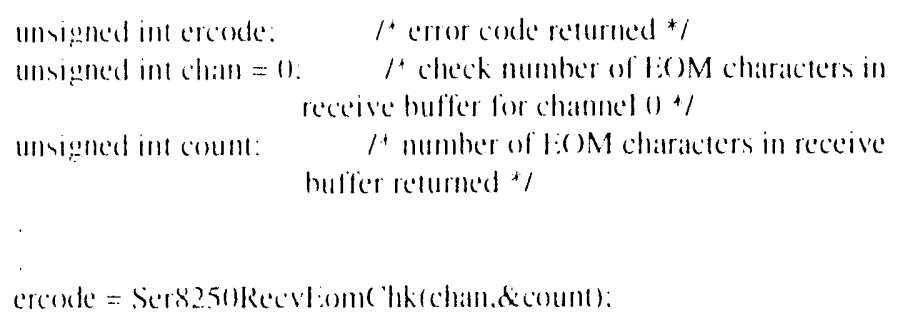

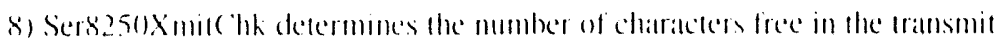

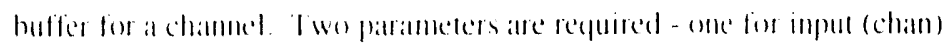
and onc for sutput (comml)

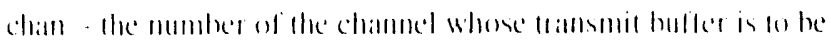
checked (0)-7). Thes partameder in parsed by vallue 
count - the varuble in which to return the number of characters fre. in the transmit buffer. This parameter is passed by reference.

Ser8250Xmilchk returns

DI)P_ERR_NOERROR (0) - No error

Ser8250Xmitchk calls should use the following format:

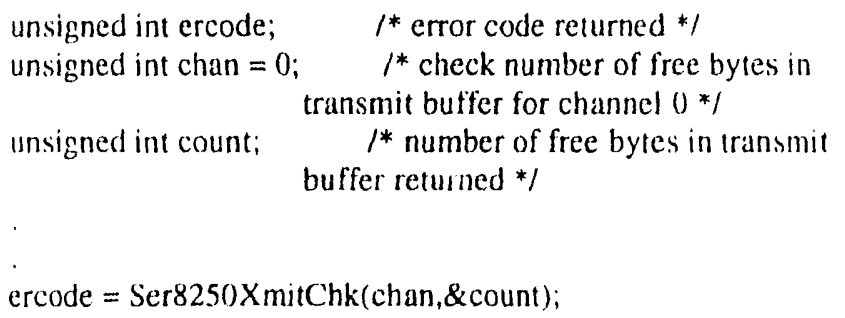

9) Ser8250BuffFlush flushes the transmit and/or receive buffers for a channel. Three parameters are required for input:

chan - the channel number to flush for buffers (0-7). This parameter is passed by value.

in - specifies whether or not to flush the receive buffer. A non-zero value causes the receive buffer to be flushed. This parameter is passed by value.

out - specinies whether or not to flush the transmit buffer. A non-zero value causes the transmit buffer to be flushed. This parameter is passed by value.

Ser8250BuffFlush returns:

DDP_ERR_NOERROR (0) - No error

Ser825()Buffrlush calls should use the following format:

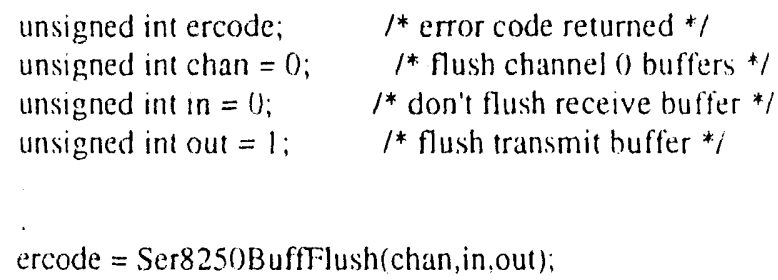

i1) Ser8250Exit disables all channels. No parameters are used

Ser825(j) Exit returns:

DDP_ERR_NOERROR (O) - No erTOr 
Ser8250):xit should use the following format:

unsigned int ercode: $\quad 1 *$ croror conde refurned *I

ercode $=\operatorname{Sic} 825011: x i 11):$

\section{USIN( I TIII: SIER8250 DRIVI:R WITH MICROSOFI'}

The / is compiler option MUSI be specitied for DOS systems. Otherwise, stack overflows can occur during inlerrupt service routines.

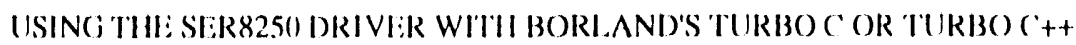

The -N compiler option MUSI NOT be specified for DOS systems. Oherwise, statck overtlows can occur during interrupt service routines.

\section{USING THIE SER8250 DRIVI:R WITH MICROSOFT'S QUICK BASIC}

The Ser8250 driver is not compatable with the Quick BASIC environment. It is, however, compatable with stand-alone Quick BASIC programs provided that the buffer is allocilled using the SirATle metacommand. For example:

rem sinclude: 'Ser8250).bas'

rem \$static

dim buffer\%(1)(0)

ercode $\%=$ Ser8250) nitSw(version\%)

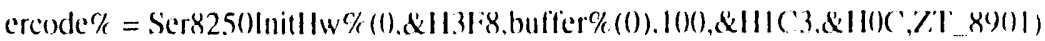

\section{THIE SER8250 SOUR( IE (O)II IIILS}

The Ser8250 driver uses a generic interrupt driven serial handler (SIERIAI.( ). This generic hander relie's on a collection of IIAR'l specilic macro definitions. These macro definitions are located in STIR8250.C. 
APPENDIX D.1: GPS DATA -

MAPS MADE DURING DYNAMIC TESTING

Dynamic Testing Performed

from October 22 - 28, 1992 


\section{APPENDIX D.1: GPS DATA . MAPS MADE DURING DYNAMIC TESTING}

The following tables summarize the te st dates (Table D. I-1) and the terrain (Table D. I-2) used for the dynamic testing of the GPS systems. Figures D.1-1 through D.1-25 present the mapping of the GPS data taken during the dynamic testing.

Table D.1-2. Summary of Dynamic Test Dates

\begin{tabular}{lc}
\hline \multicolumn{1}{c}{ Terrain Description } & Dates Testing Performed \\
City Driving & $10 / 22$ and $10 / 2.5 / 92$ \\
Mountain Driving & $10 / 25$ and $10 / 26 / 92$ \\
Interstatc Highway Driving & $10 / 27$ and $10 / 28 / 92$ \\
Rural Ilighway Driving & $1(1) / 27$ and $10 / 28 / 92$ \\
Canyon Driving & $10 / 27$ and $10 / 28 / 92$ \\
\hline
\end{tabular}

Table D.1-2. Summary of Terrain Used for Dynamic Testing

Terrain Description

City Driving

Mountain Driving

Interstatc Highway Driving

Rural Highway Driving

Canyon Driving
Rond Sections Used for Testing

Centrill Avenue in Albuquerque. NM

from Tramway io 7 th Street

Tijcras Canyon, 1-4(), East and West -..

I-40) Tramway Exit (Albuquerquc, NM) to Sedillo (NM) Exit

1-25, North and South

1-25 Tramway Exil (Albuquerque, NM) 10 NM 28.5 Exit in Santa Fc, NM

NM 28.5 and NM 4

Intersection of NM 285 and 1-25 (Santa Fe, NM) to intersection (Los Alamos, NM) where LANL* Truck Roule (East Jeme Road) begins (at traffic light)

LANL* Truck Route (East Jemer Road) in Los Alamos, NM -... from traffic light to traflic light, climbing from Sandia Canyon up to the South Mesa

* Los Alamos National Laboratory 
Appendix D.1: GPS Data - GPS Maps Made During Dynamic Testing

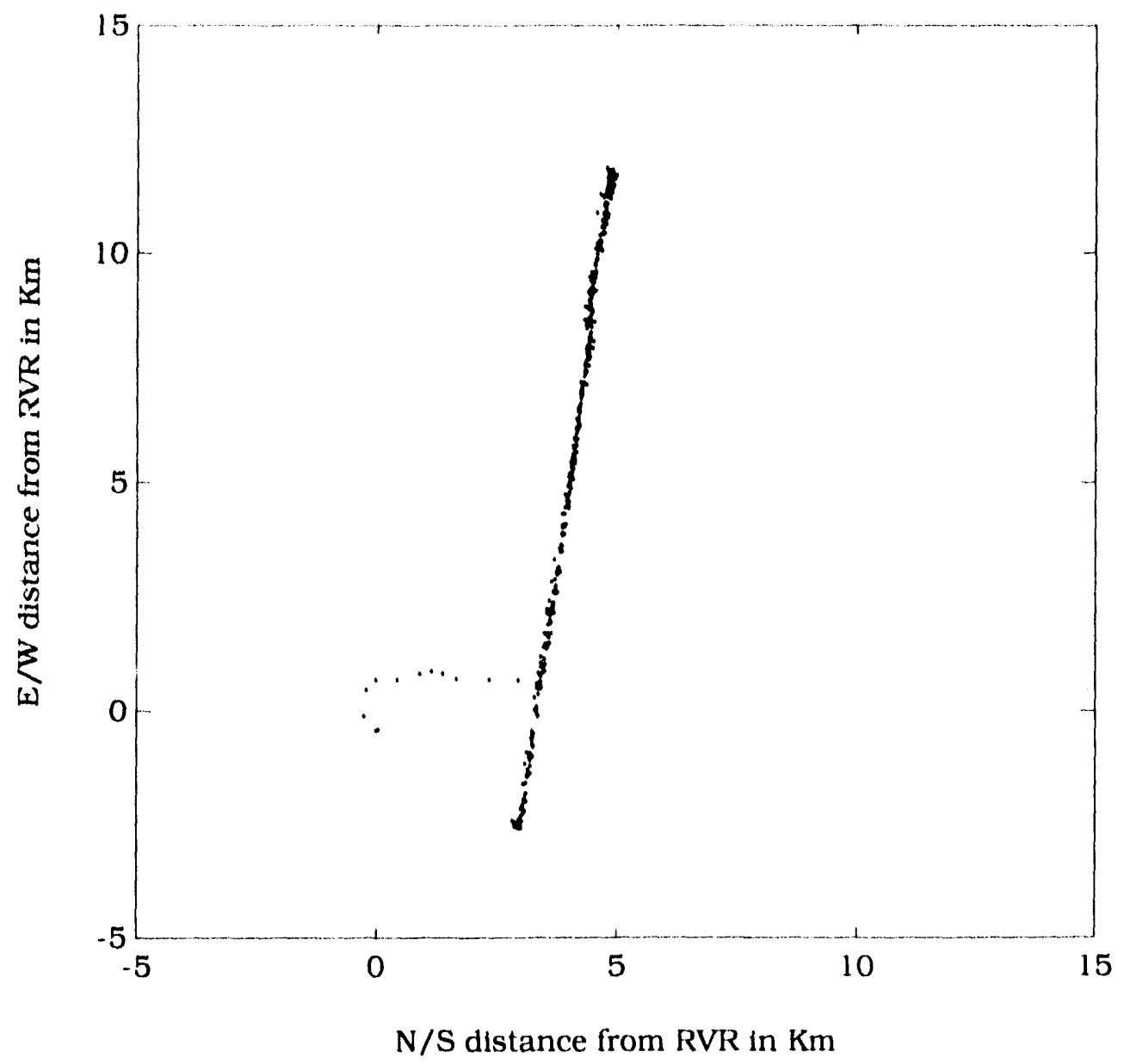

AVD-9616-28-1

Figure D.1-1. City Driving Data, Magcllan. 
Appendix D.1

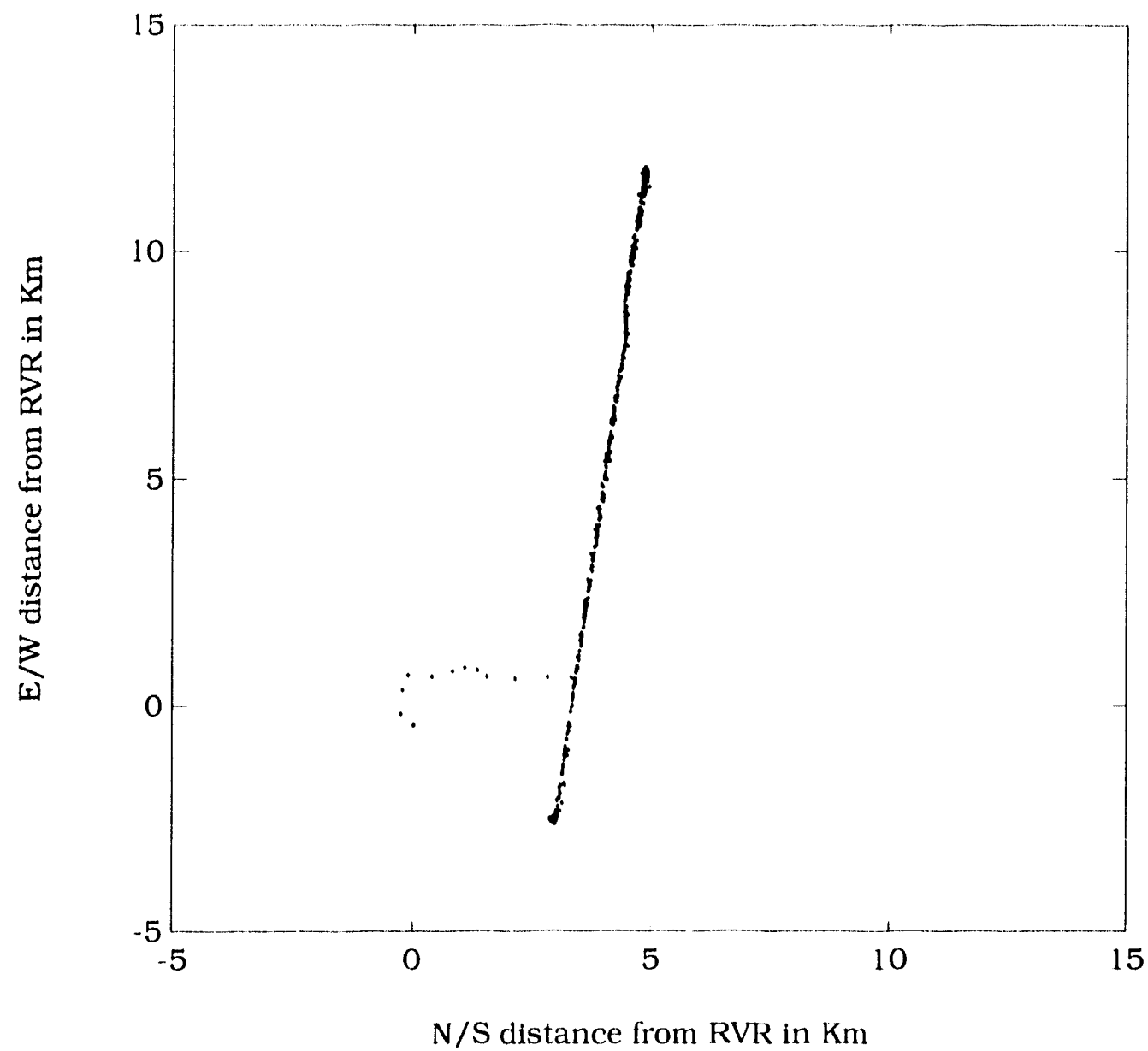

AVD.9616.29.1

Figure D.1-2. City Driving Data, Magnavox GPS Engine. 


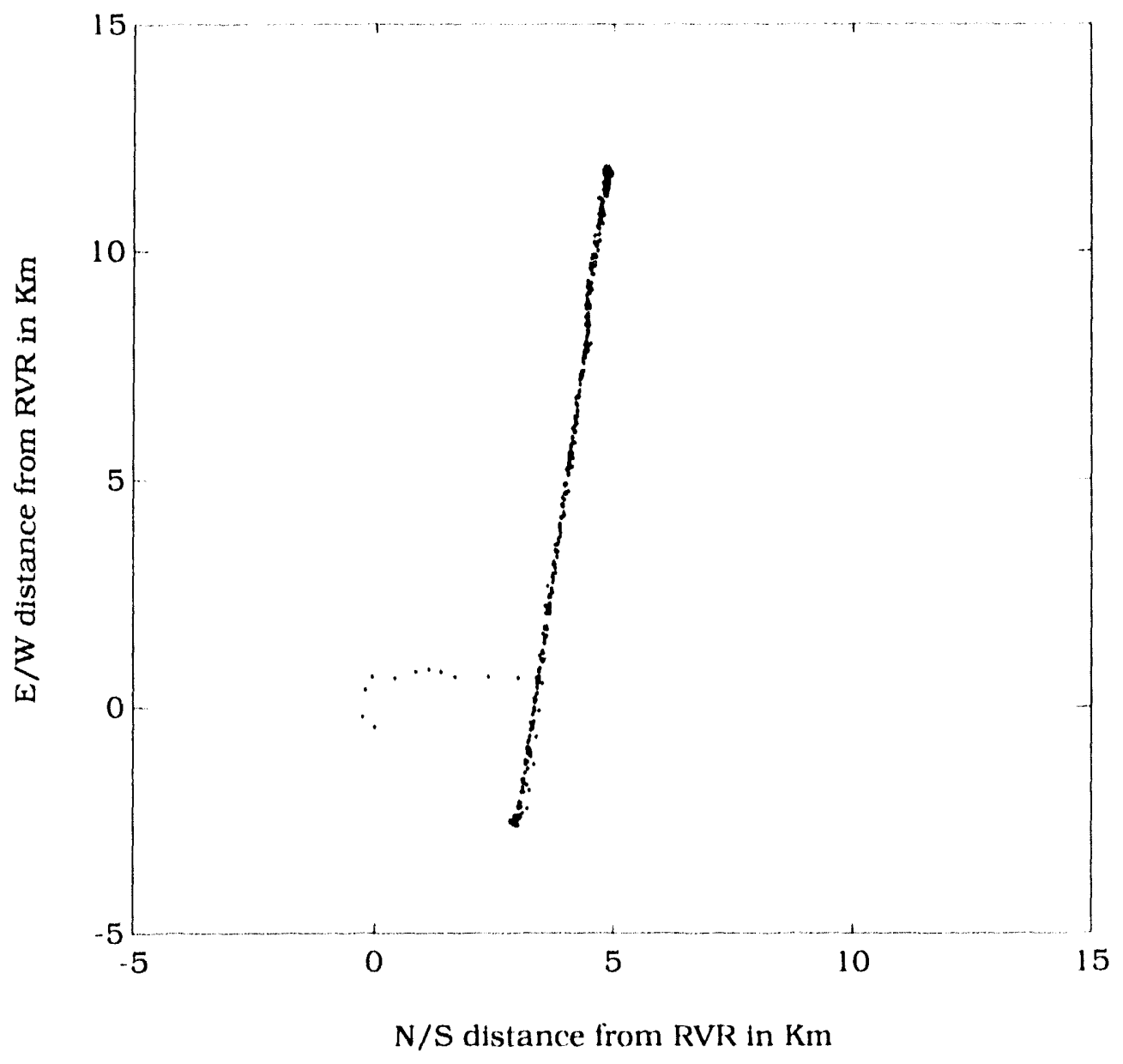

AVD-9616-30-1

Figure D.1-3. City Driving Data, Rockwell NavCore V. 


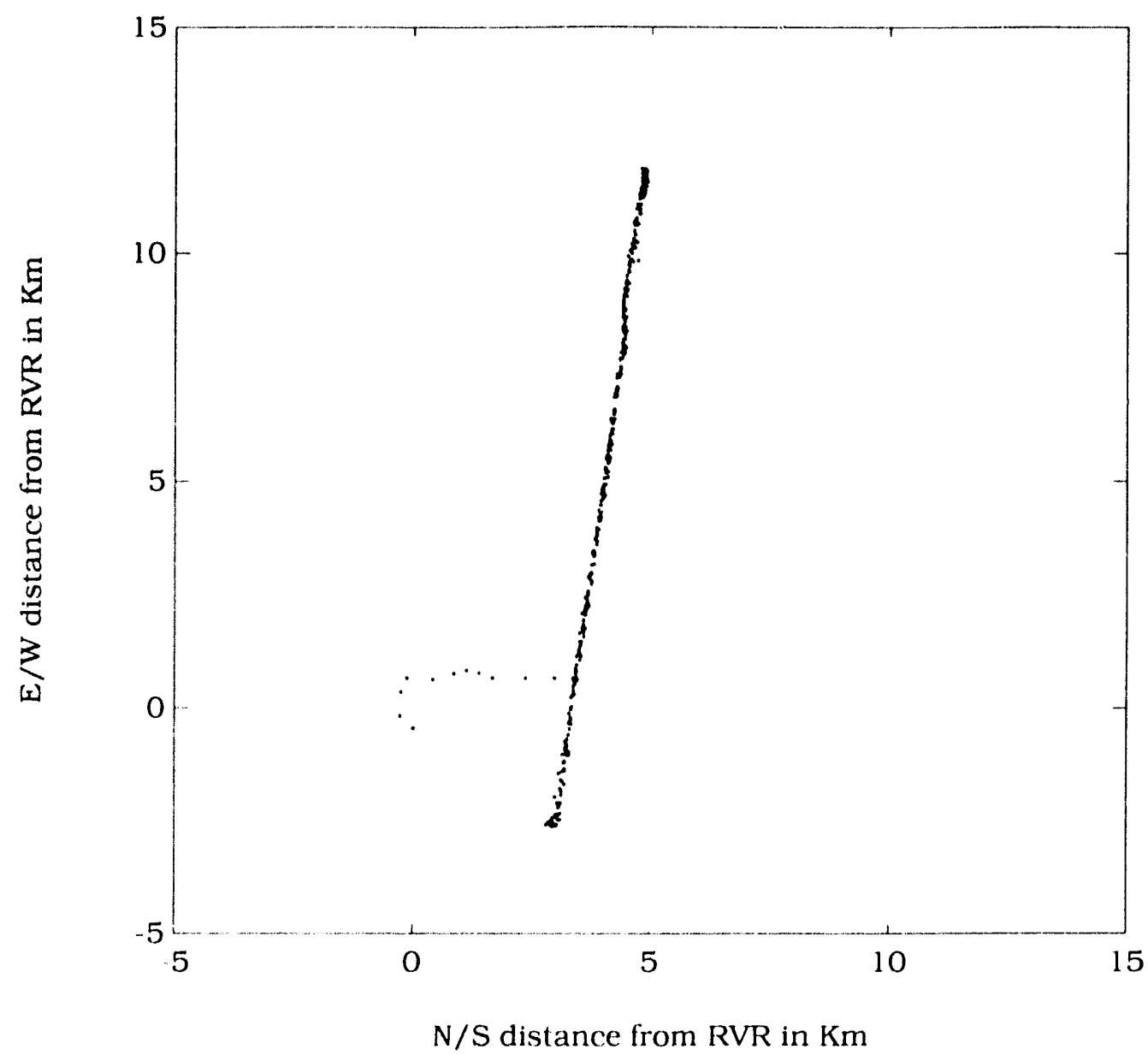

AVD-9616-31-1

Figurc D.1-4. City Driving Data, Magnavox 6400. 


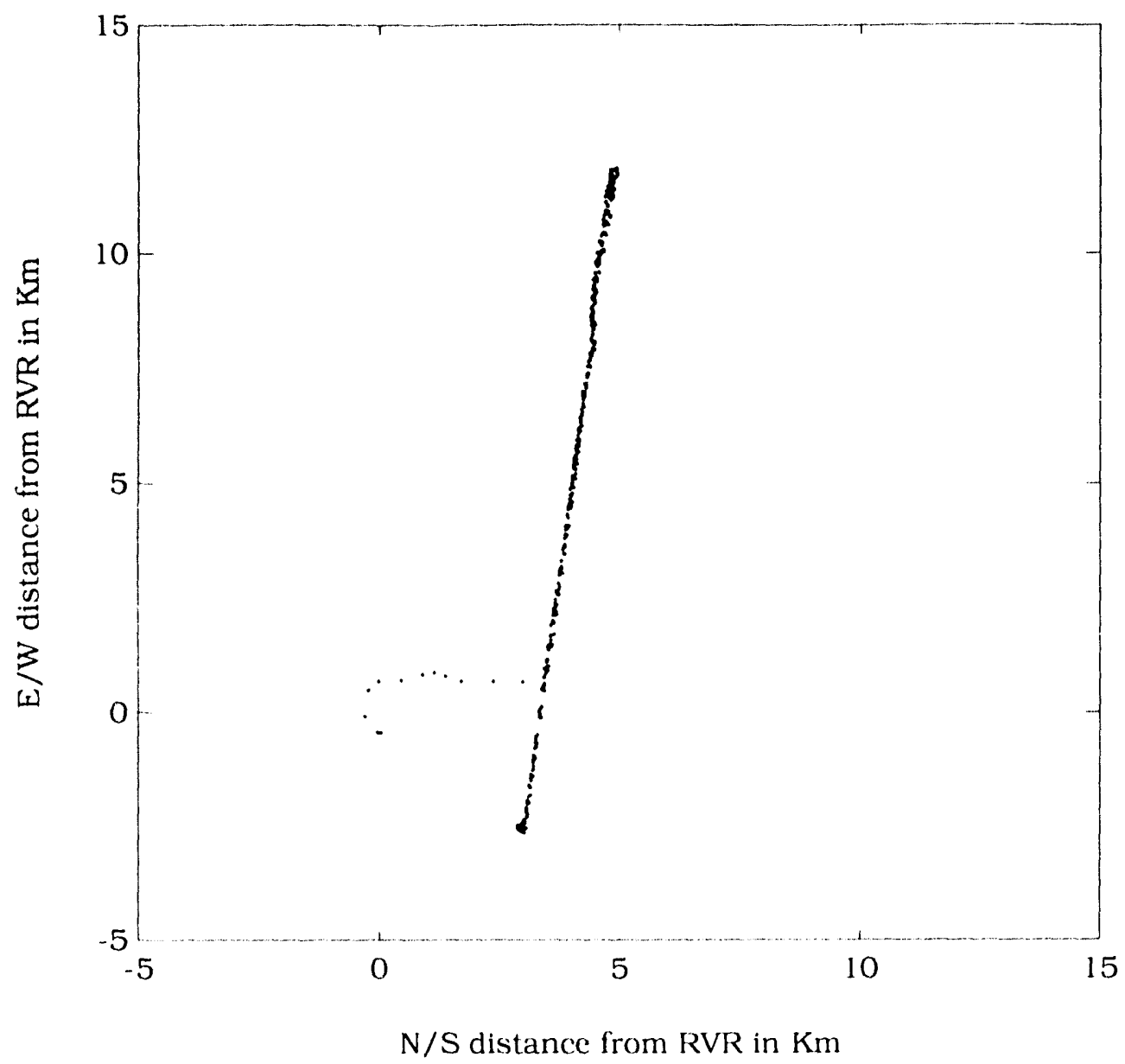

AVD-9616-32-1

Figurc D.1-5. City Driving Data, Trimble Placer. 


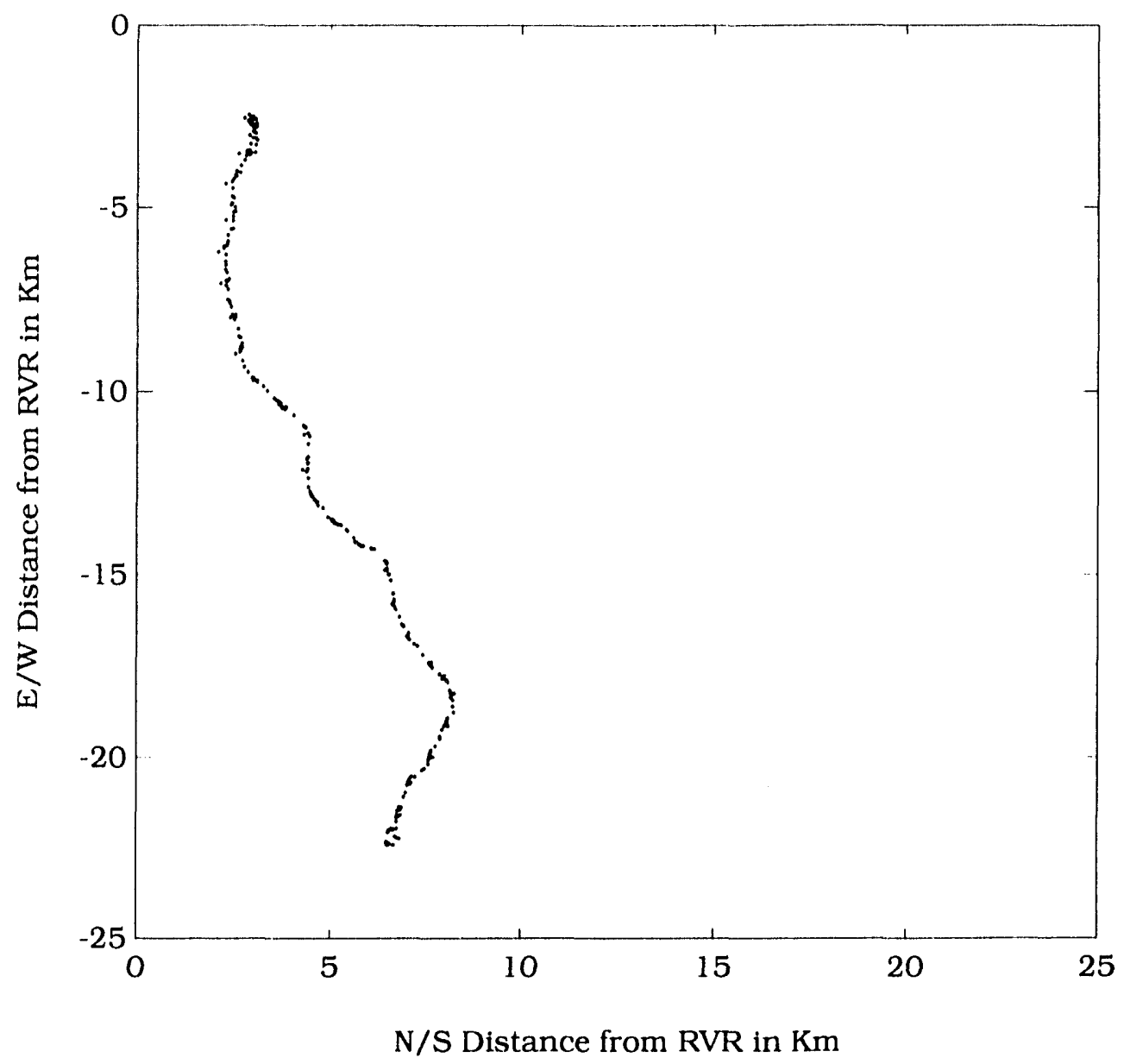

AVD-9616-33-1

Figure D.1-6. Tijeras Canyon Data, Magellan. 
Appendix D.1: GPS Data - GPS Maps Made During Dynamic Testing

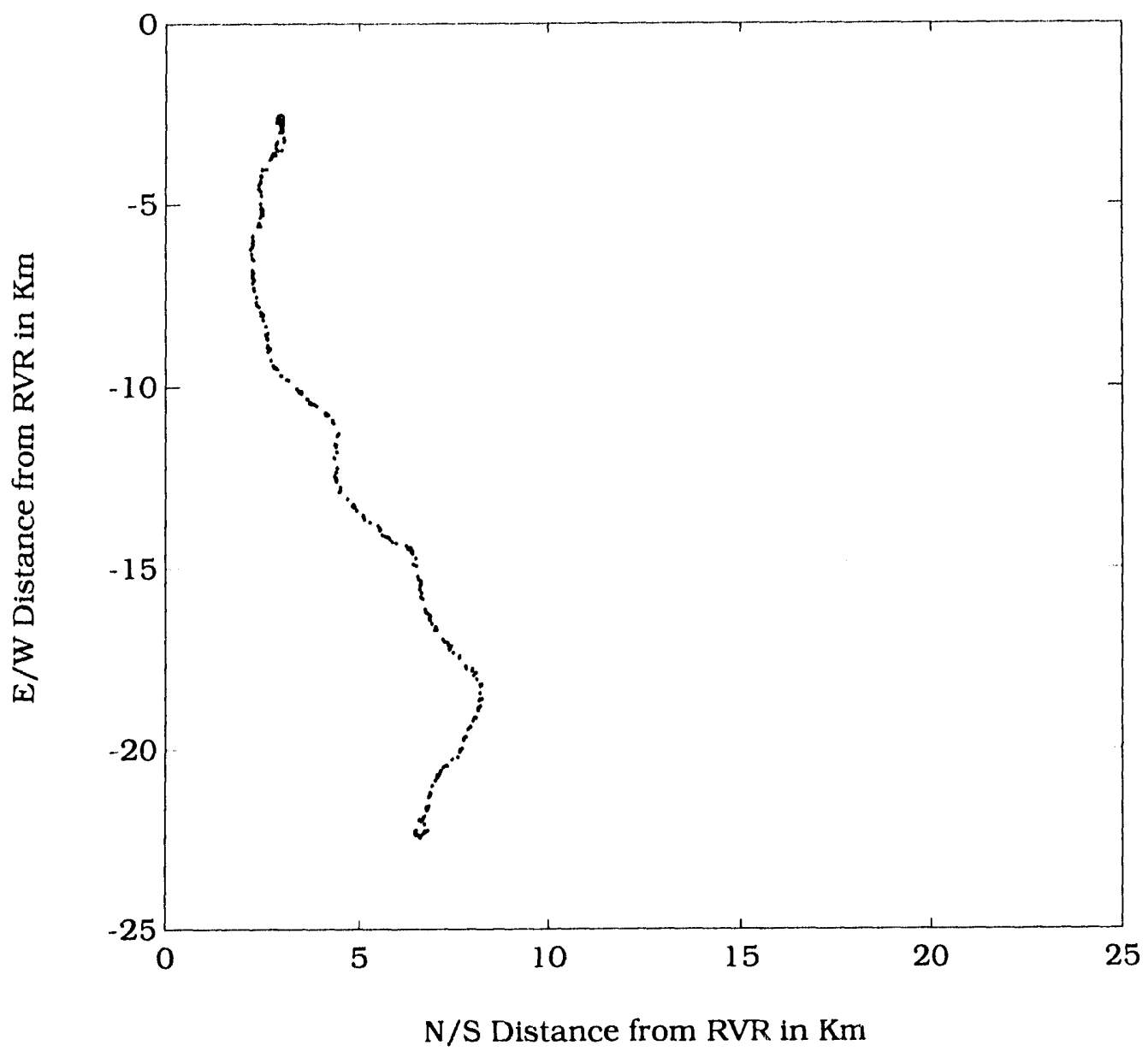

AVD-9616-34-1

Figure D.1-7. Tijeras Canyon Data, Magnavox GPS Engine. 


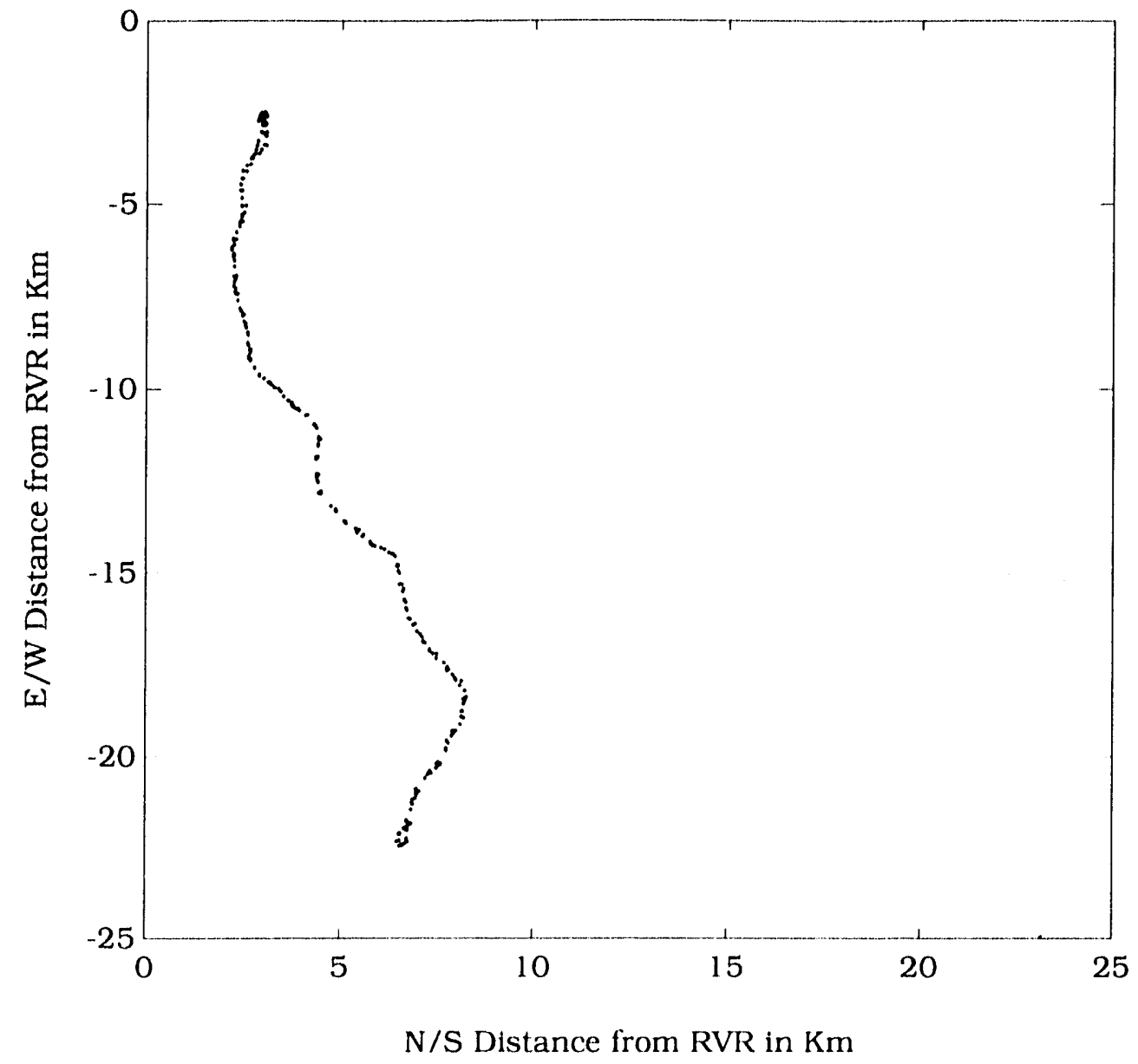

AVD-9616-35-1

Figurc D.1-8. Tijcras Canyon Data, Rockwcll NavCorc V. 


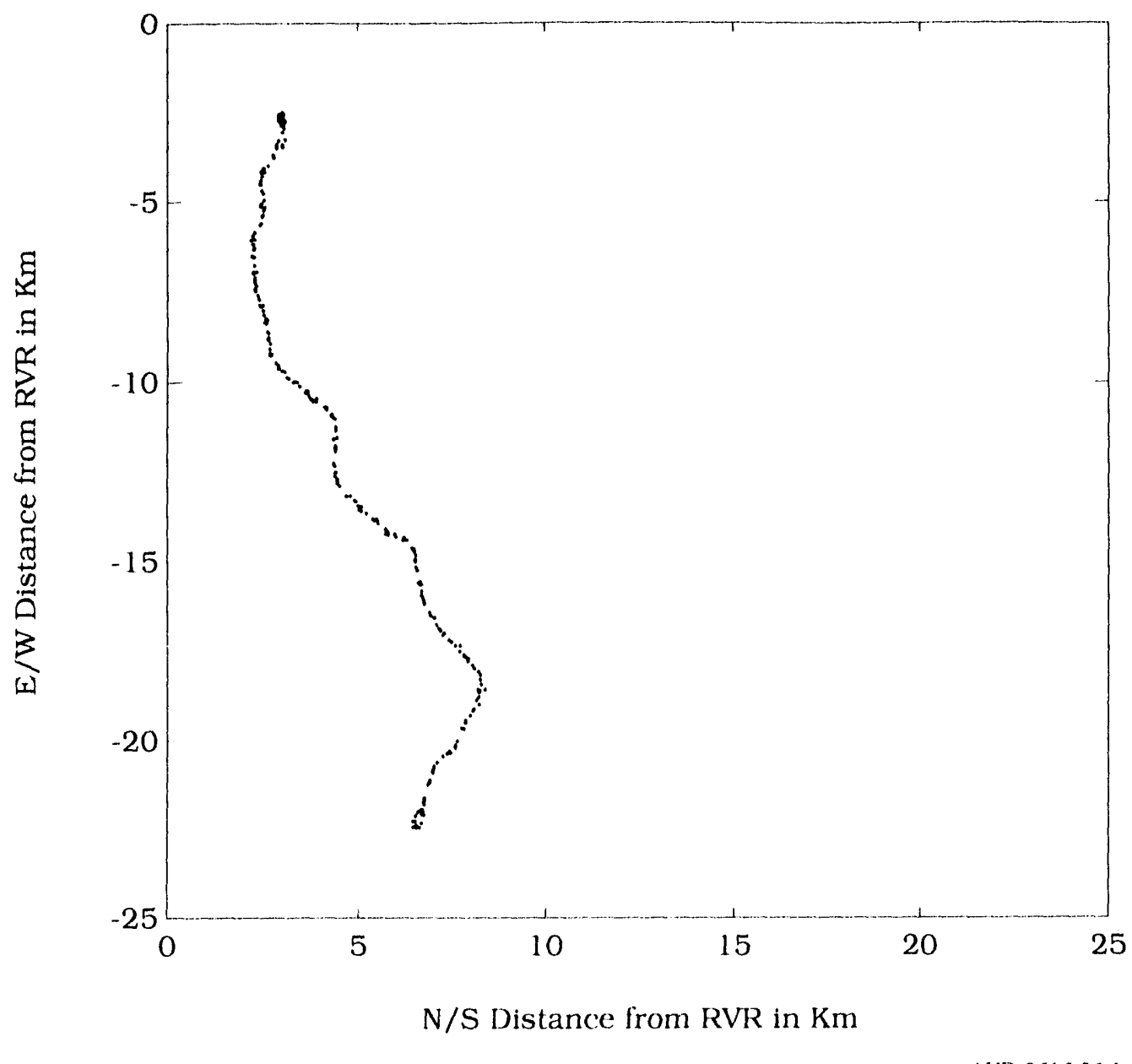

Figure D.1-9. Tijeras Canyon Data, Magnavox 64()(). 


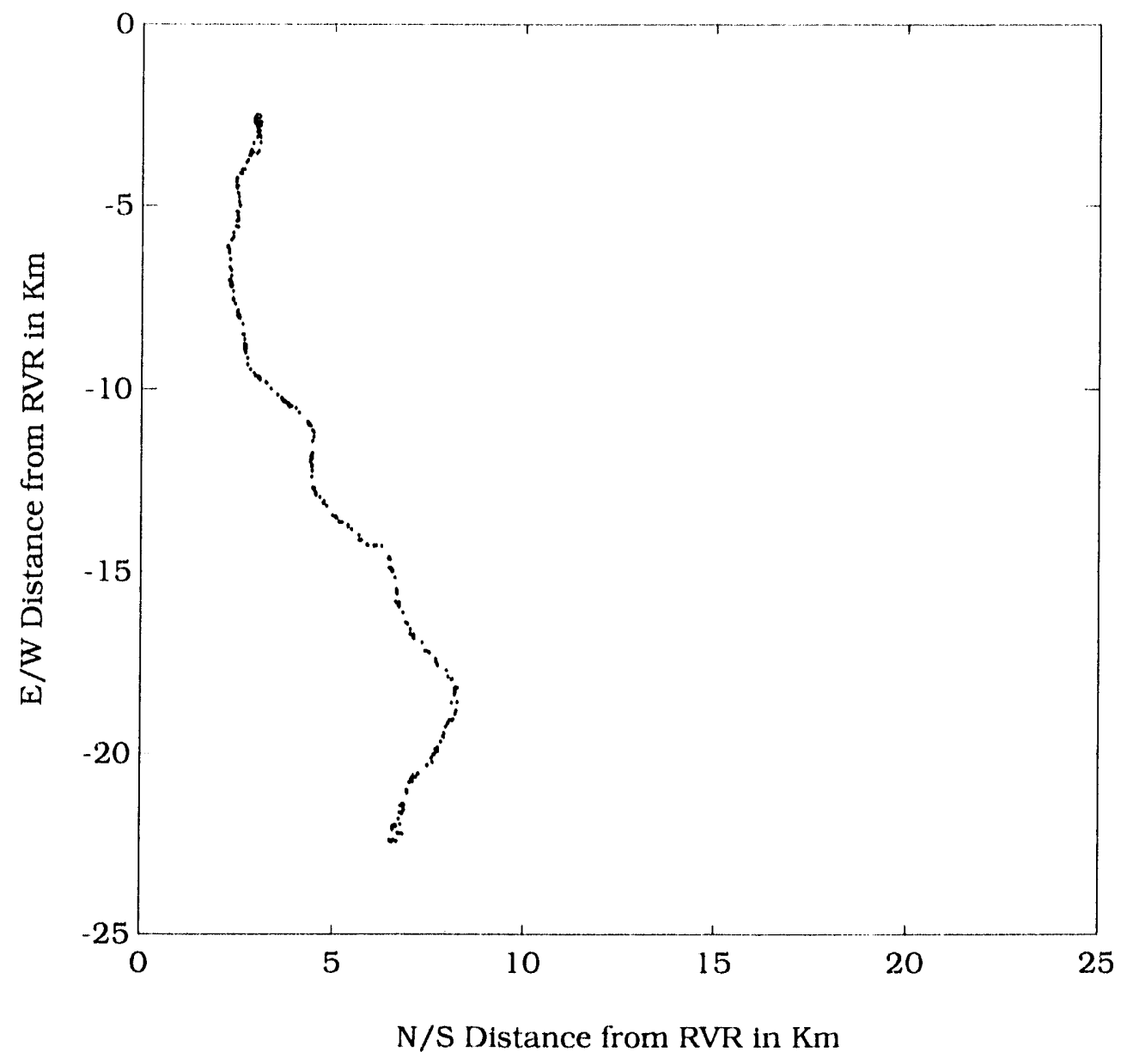

AVD-9616-37-1

Figure D.1-10. Tijeras Canyon Data, Trimblc Placer. 
Appendix D.1: GPS Data - GPS Maps Made During Dynamic Testing

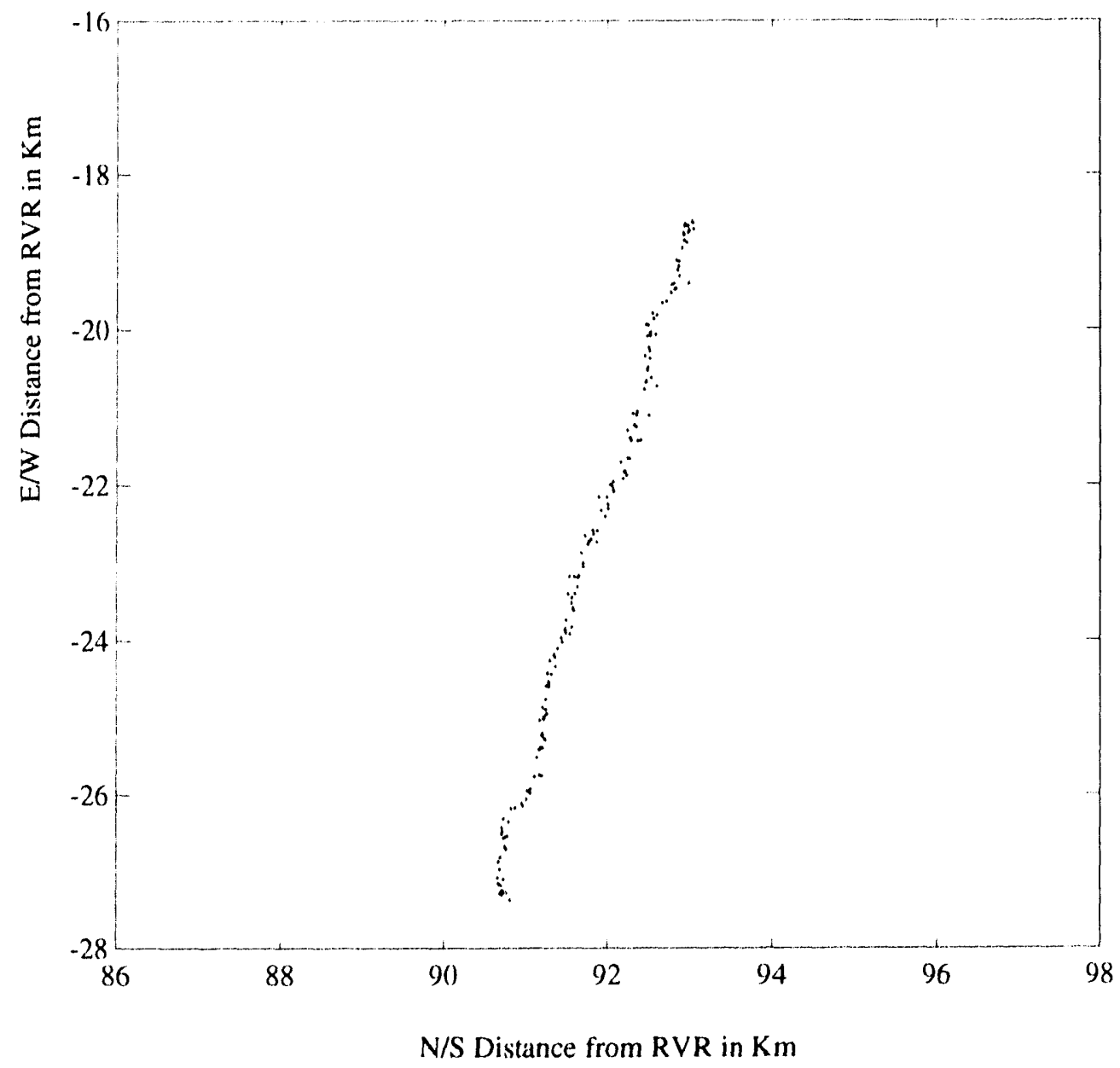

AVD-9616-38-1

Figurc D.1-11. LANL Truck Routc Canyon Data, Magellan. 


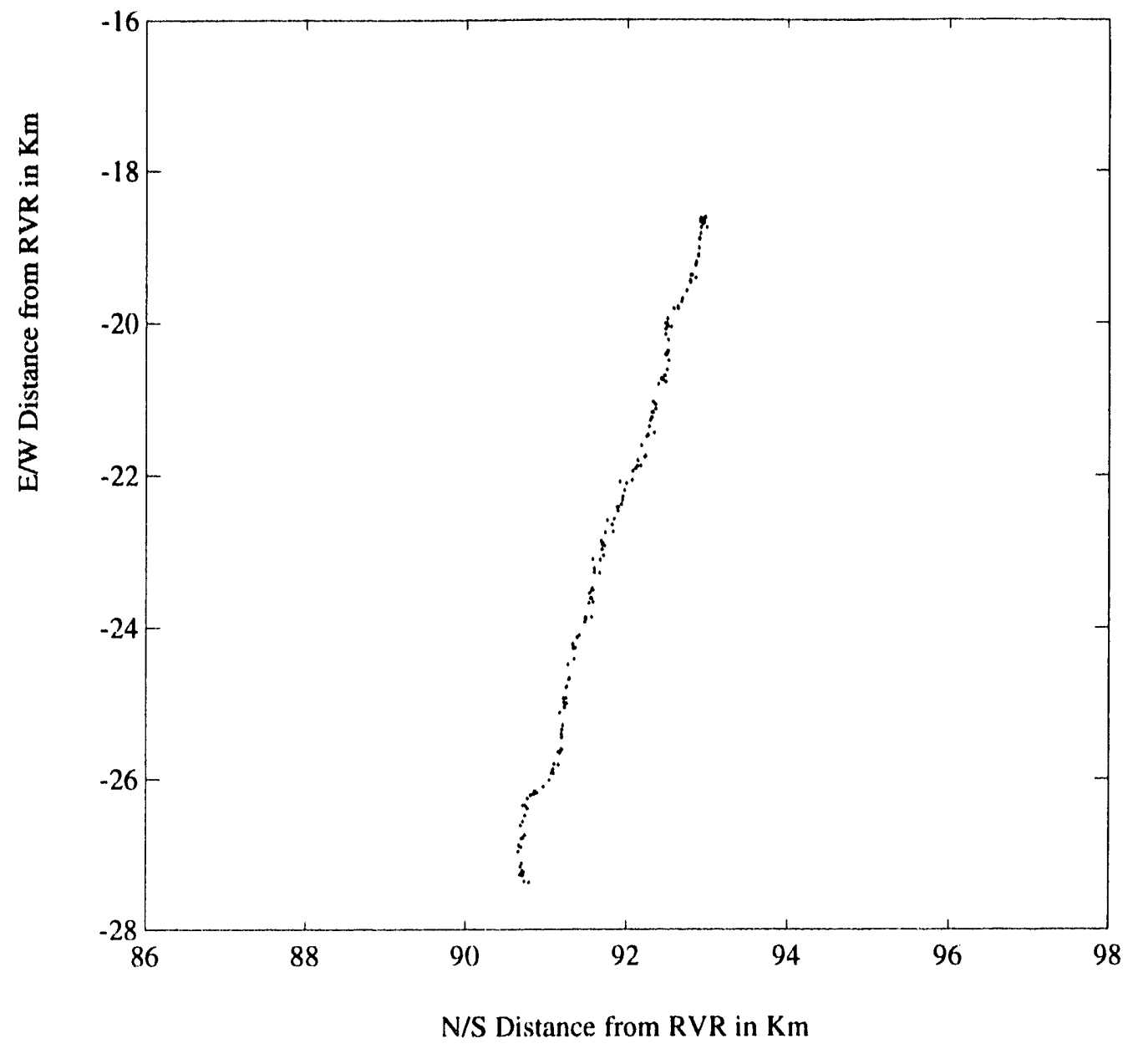

Figure D.1-12. LANL Truck Route Canyon Data, Magnavox GPS Enginc. 


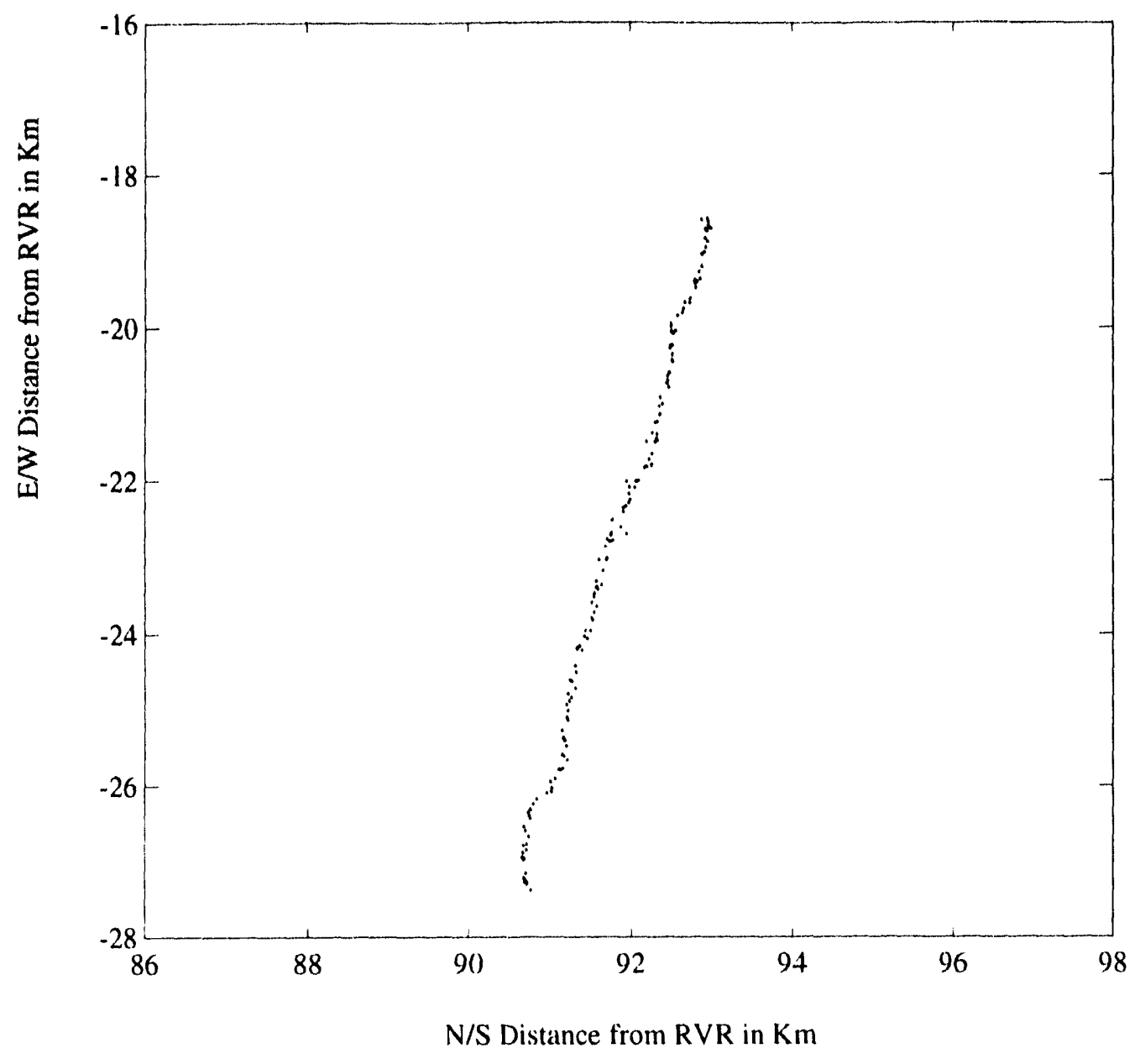

AVD-9616-40-1

Figure D.1-13. LANL Truck Routc Canyon Data, Rockwell NavCorc V. 


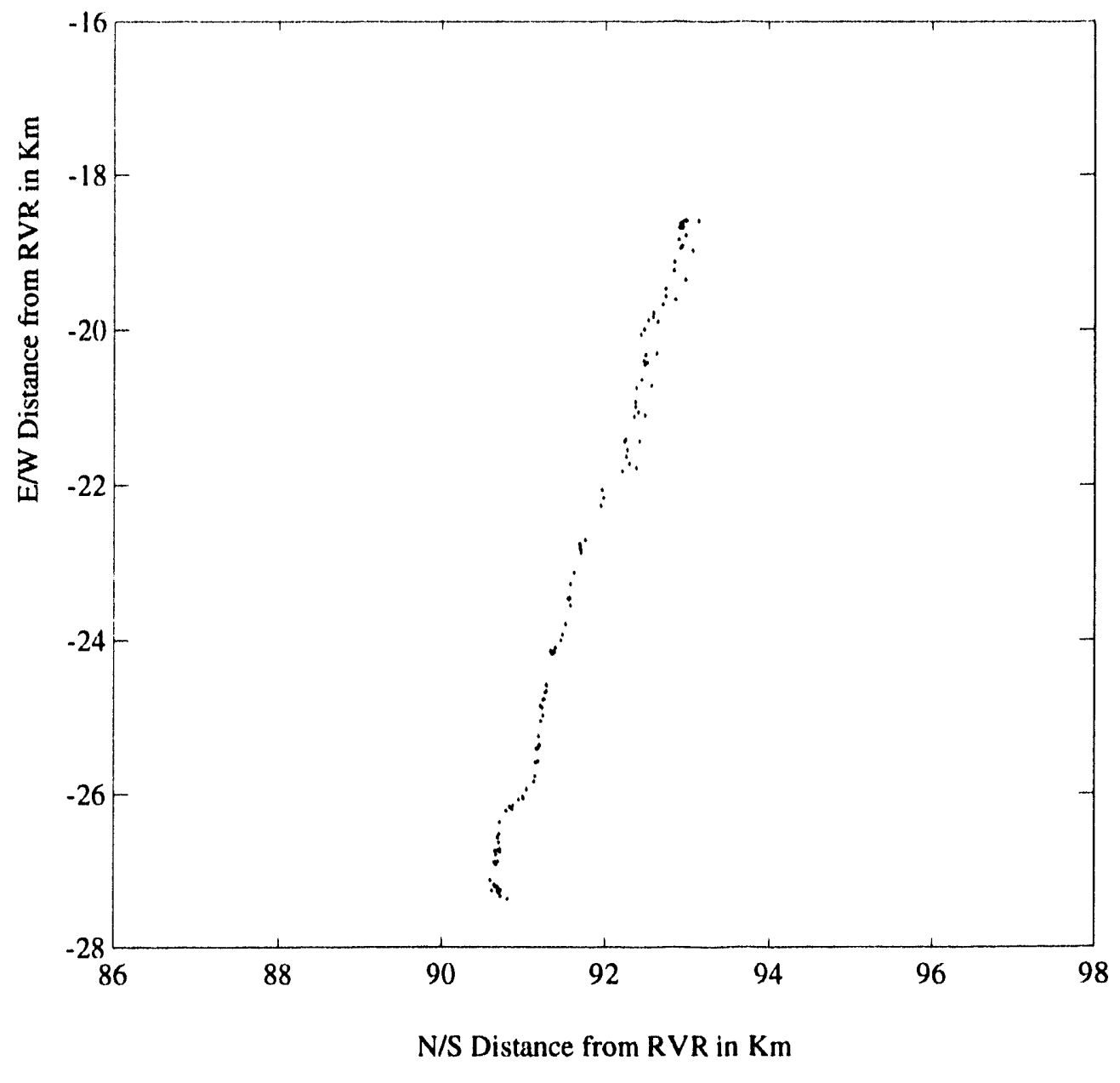

AVD-9616-41-1

Figure D.1-14. LANL Truck Routc Canyon Data, Magnavox 6400. 


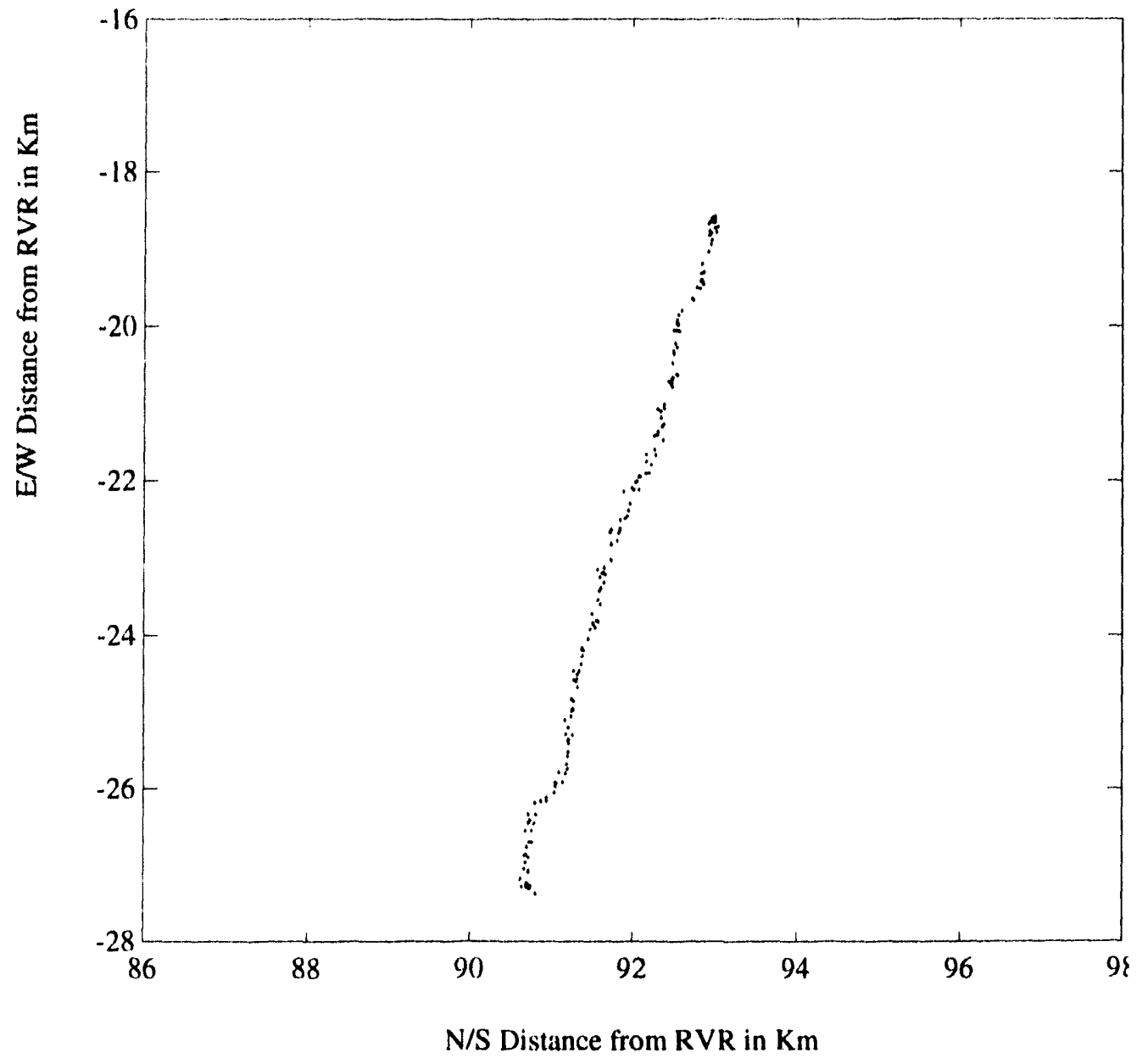

AVD-9616-42-1

Figure D.1-15. LANL Truck Route Canyon Data, Trimble Placer. 


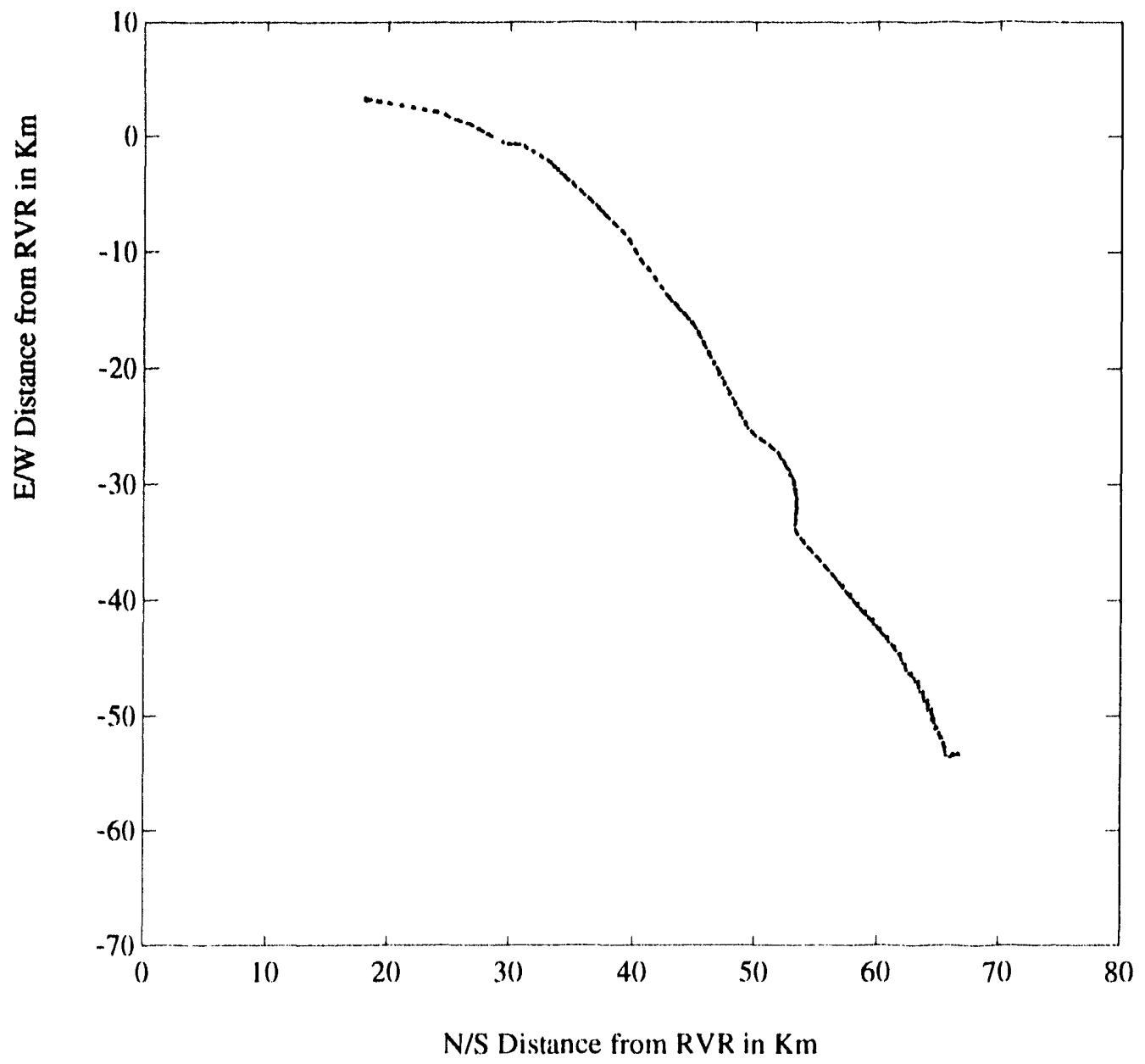

VD-9616.43-1

Figure D.1-16. I-25 Data, Magcllan. 
Appendix D.1: GPS Data - GPS Maps Made During Dynamic Testing

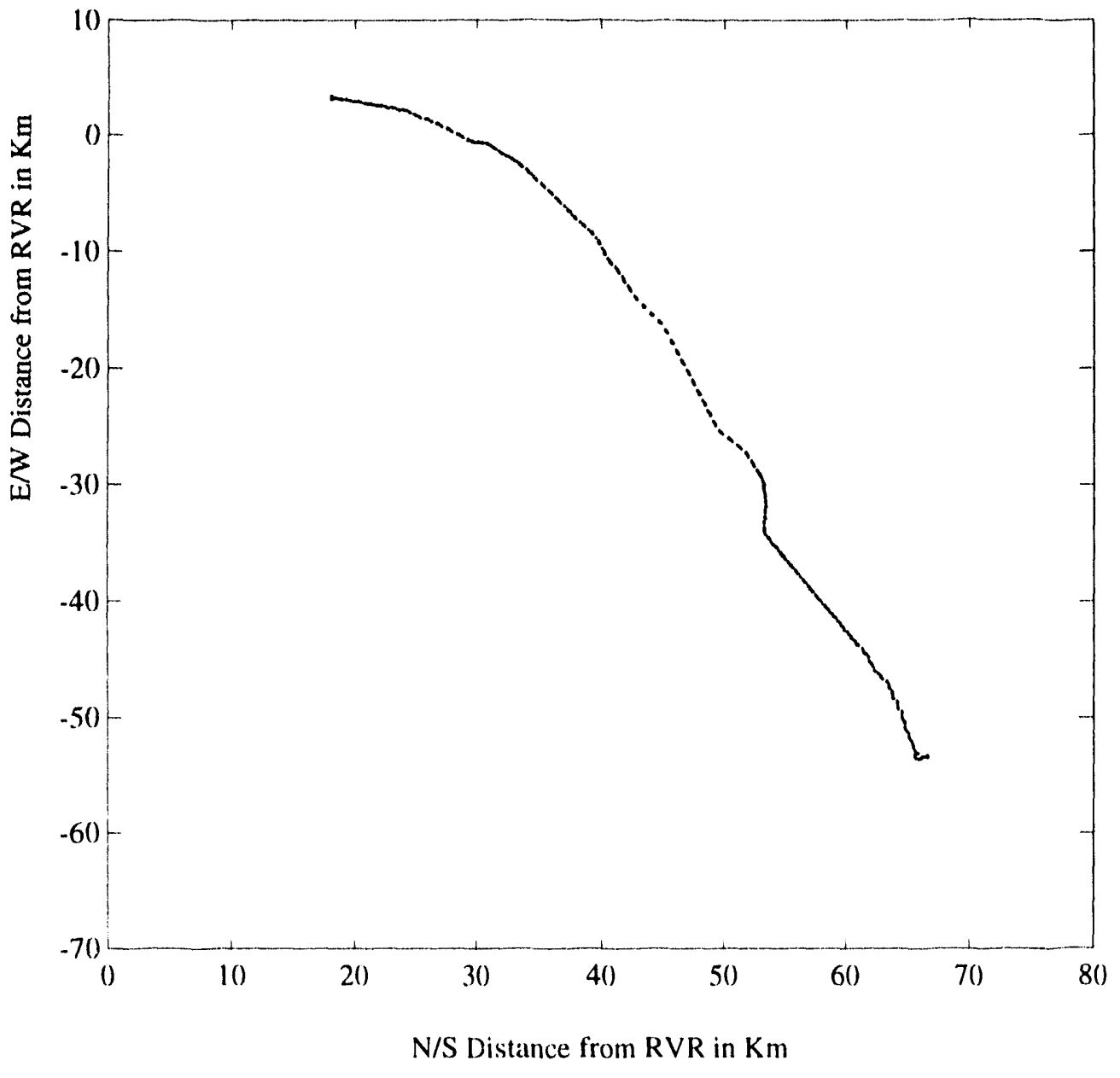

AVD-9616-44-1

Figure D.1-17. I-25 Data, Magnavox GPS Enginc. 


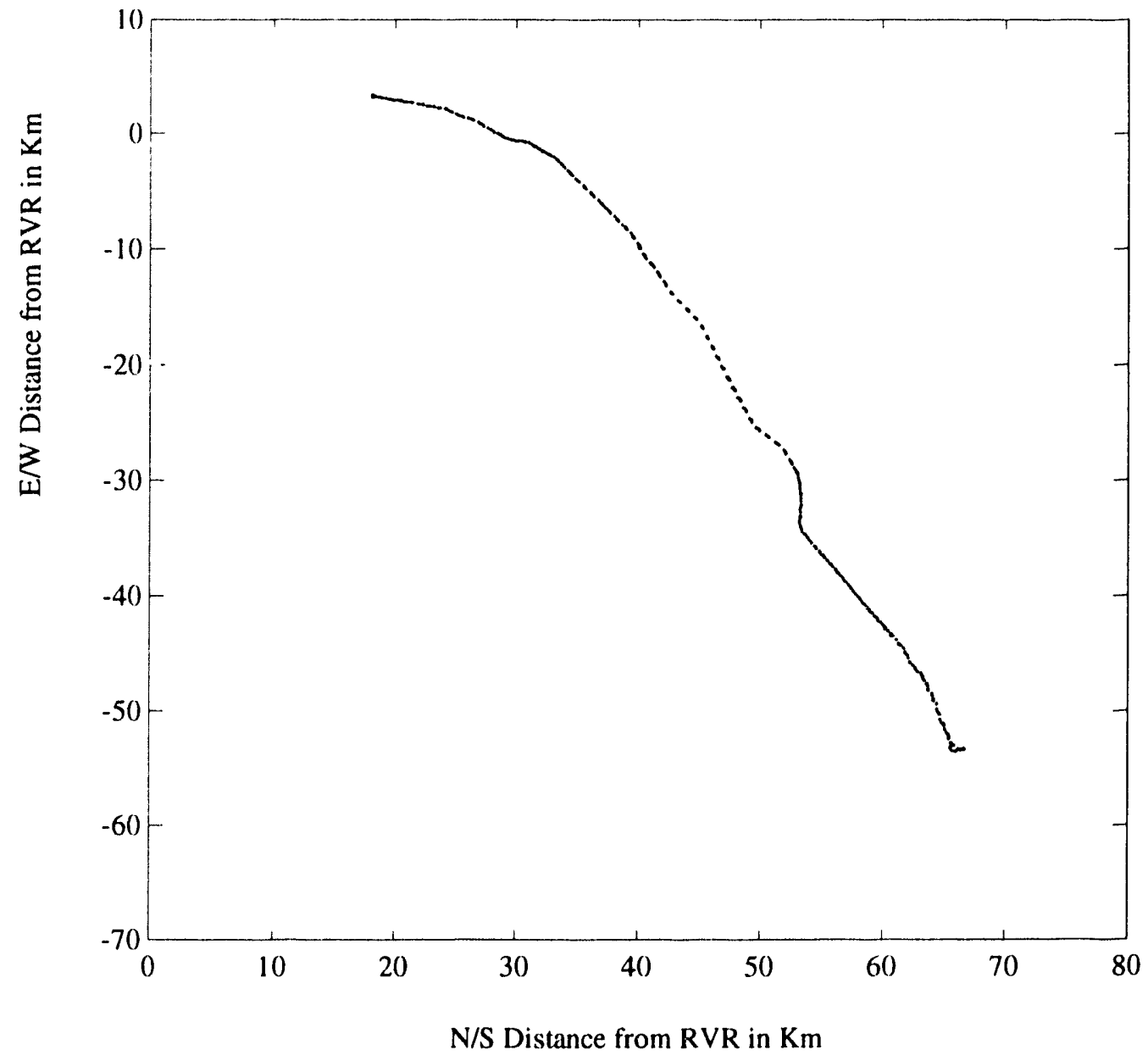

AVD-9616-45-1

Figure D.1-18, I-25 Data, Rockwell NavCore V. 
Appendix D.1: GPS Data - GPS Maps Made During Dynamic Testing

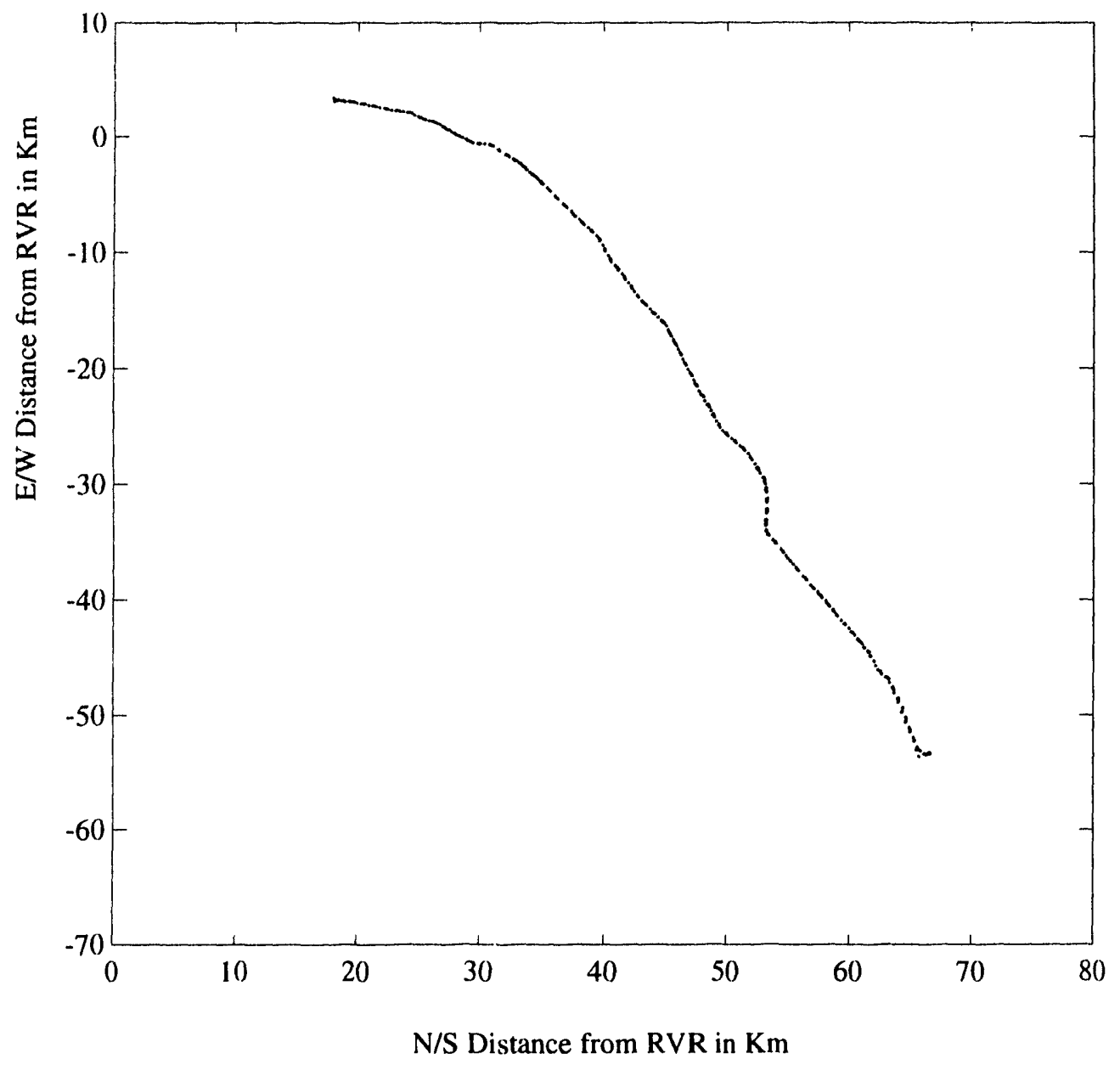

AVD-9616-46-1

Figure D.1-19. I-25 Data, Magnavox 6400. 


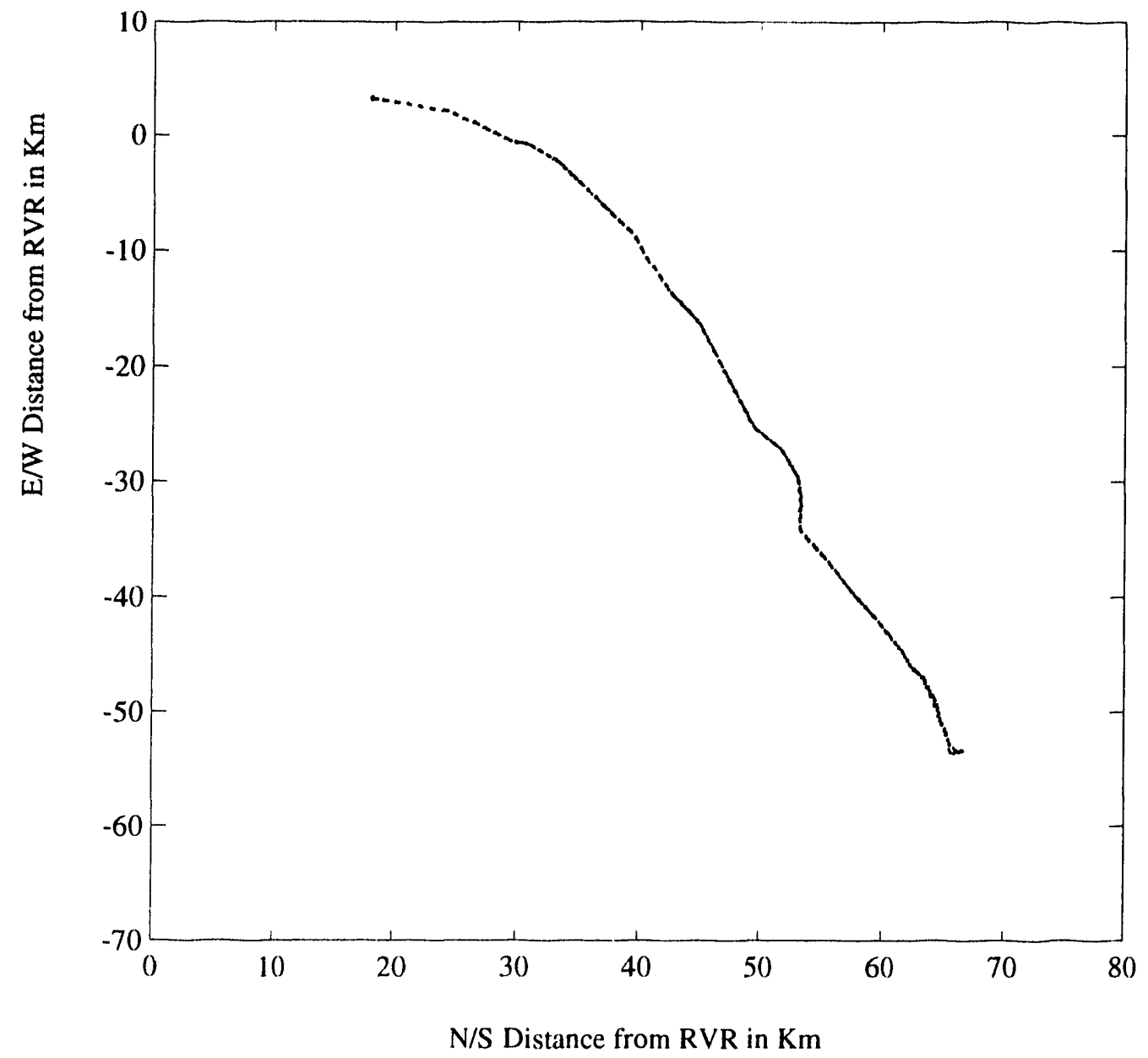

AVD-9616-47-1

Figure D.1-20. I-25 Data, Trimble Placer. 
Appendix D.1: GPS Data - GPS Maps Made During Dynamic Testing

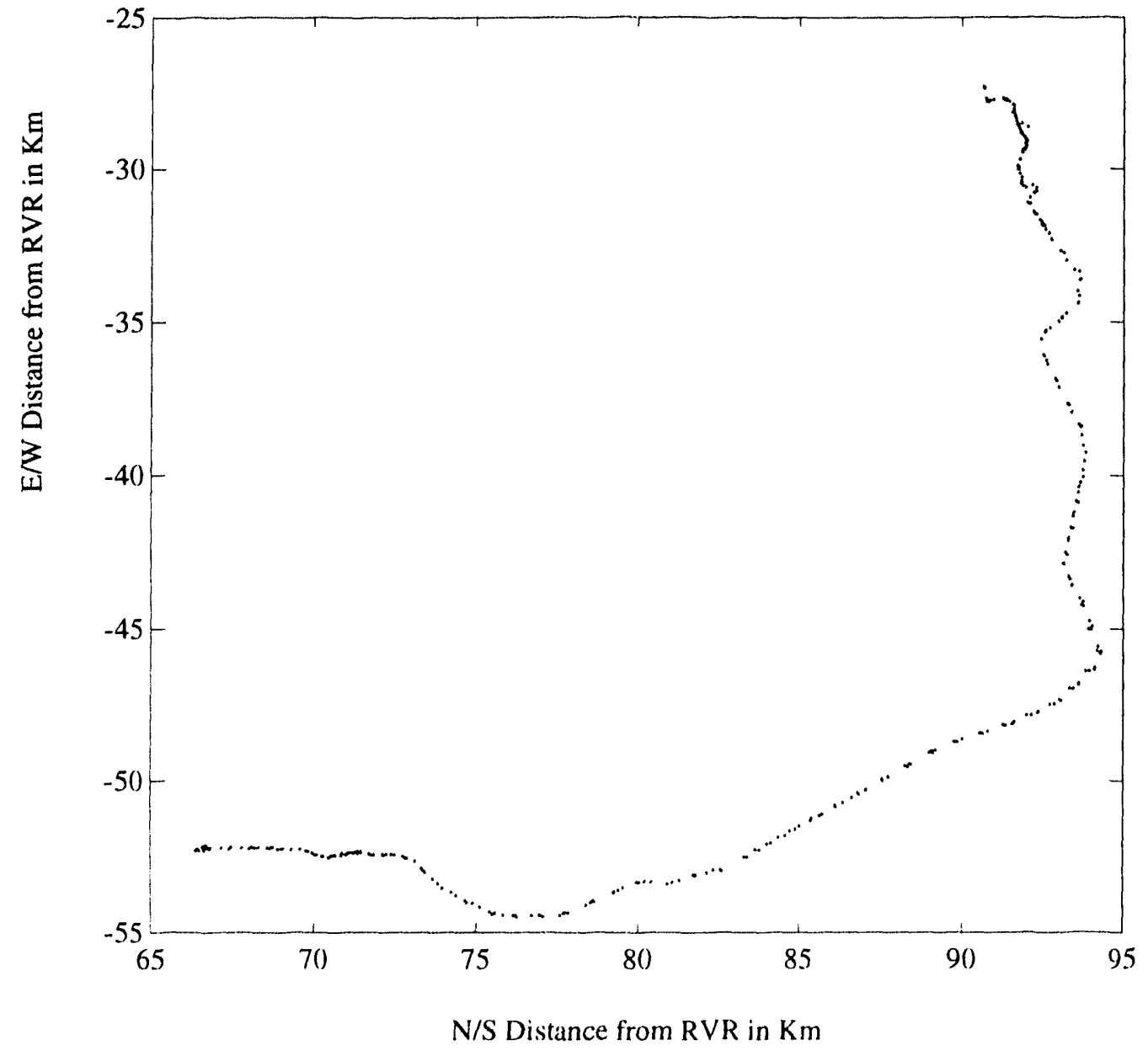

AVD-9616-48-1

Figure D.1-21. Santa Fe to LANL Data, Magellan. 


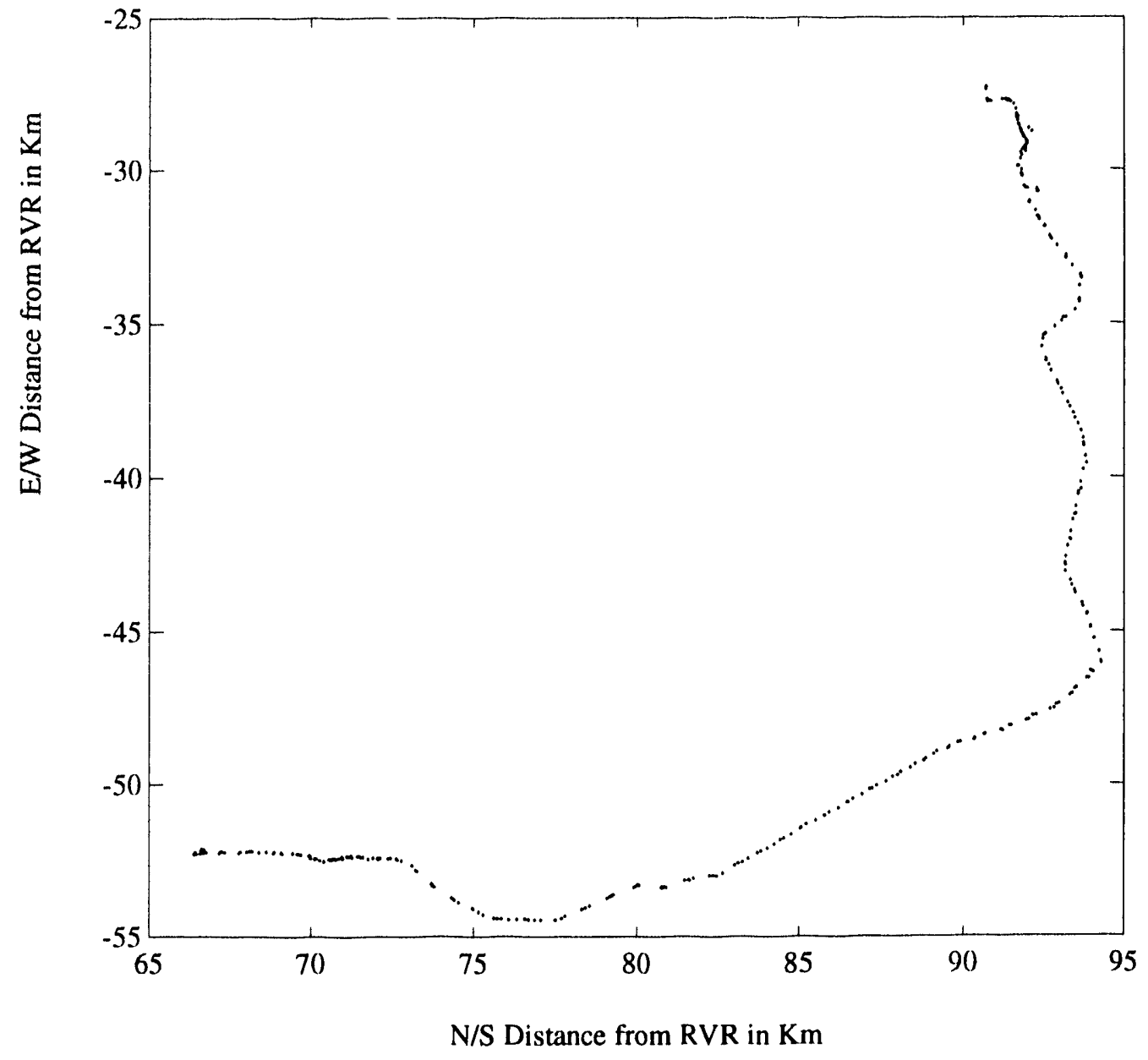

AVD-9616-49-1

Figure D.1-22. Santa Fe to LANL Data, Magnavox GPS Engin:. 


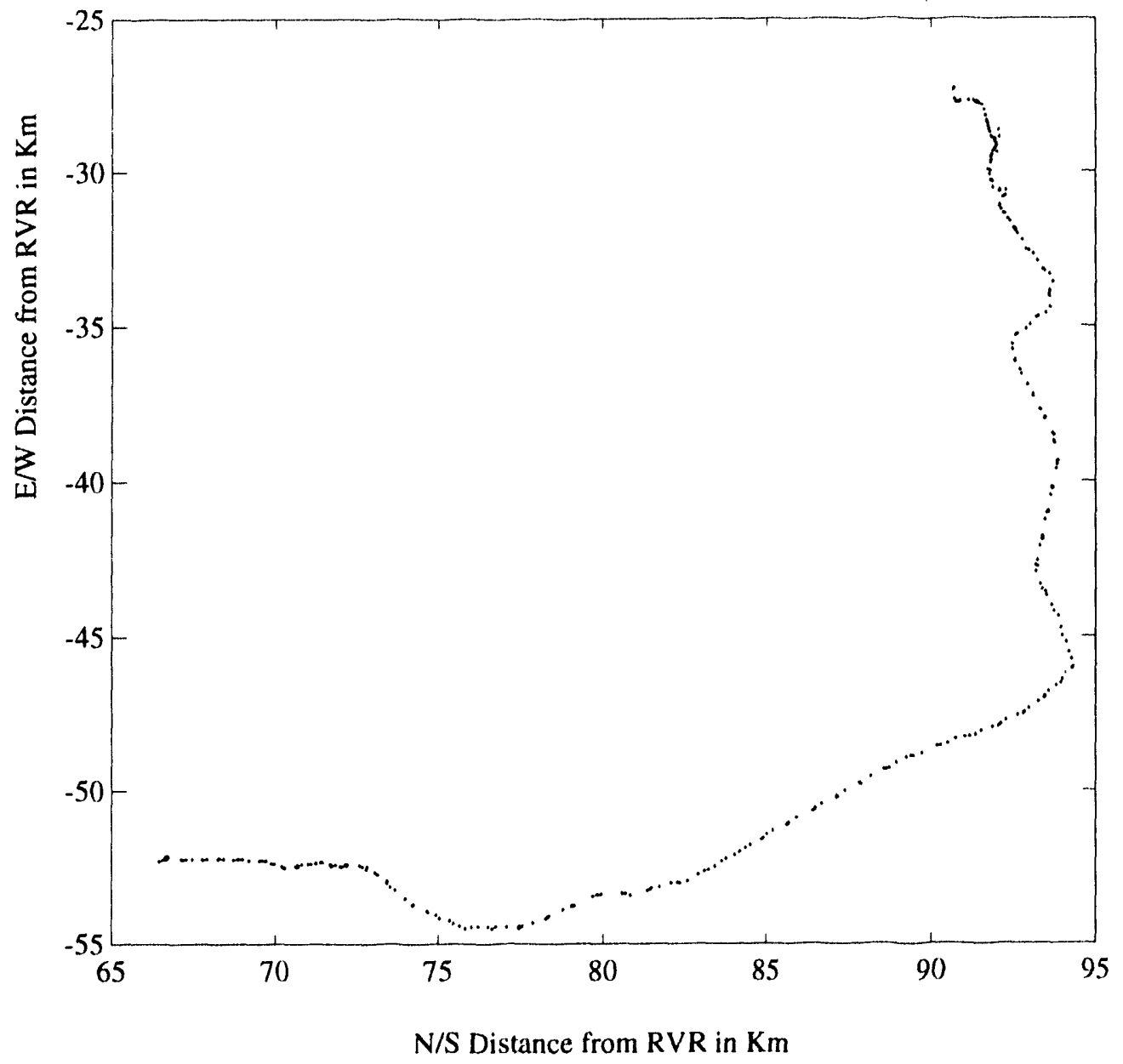

AVD-9616-50-1

Figure D.1-23. Santa Fe to LANL Data, Rockwell NavCore V. 


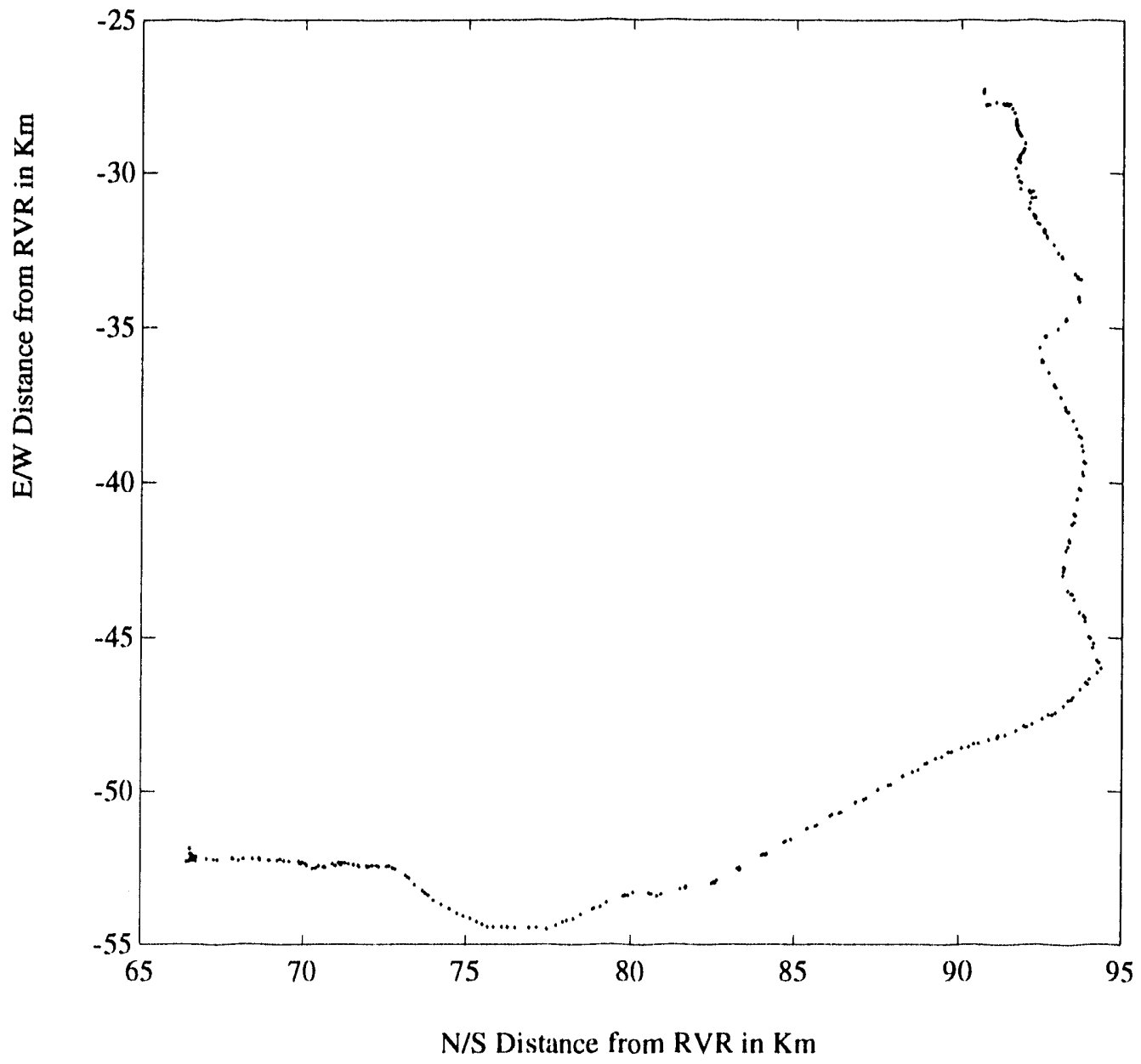

AVD-9616-51-1

Figure D.1-24. Santa Fe to LANL Data, Magnavox 640(). 
Appendix D.1: GPS Data - GPS Maps Made During Dynamic Testing

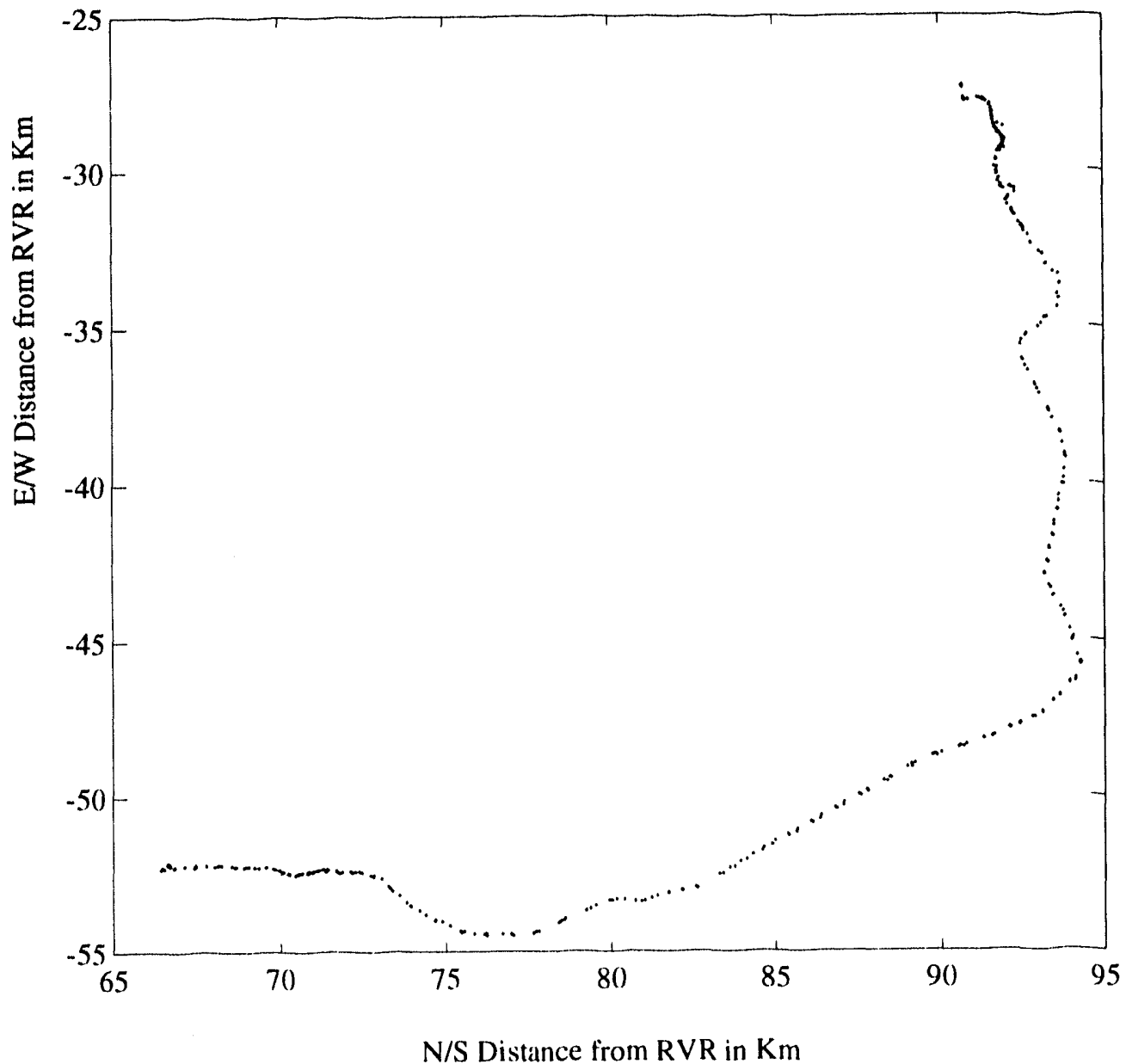

AVD-9616-52-1

Figure D.1-25. Santa Fe to LANL Data, Trimble Placer. 
APPENDIX D.2: GPS DATA -

STATIC TEST NAVIGATION MODE

AS A FUNCTION OF TIME

D. 2-1 
D. 2-2 


\section{APPENDIX D.2: GPS DATA - STATIC TEST NAVIGATION MODE AS A FUNCTION OF TIME}

The following pages show static data in graph form. 


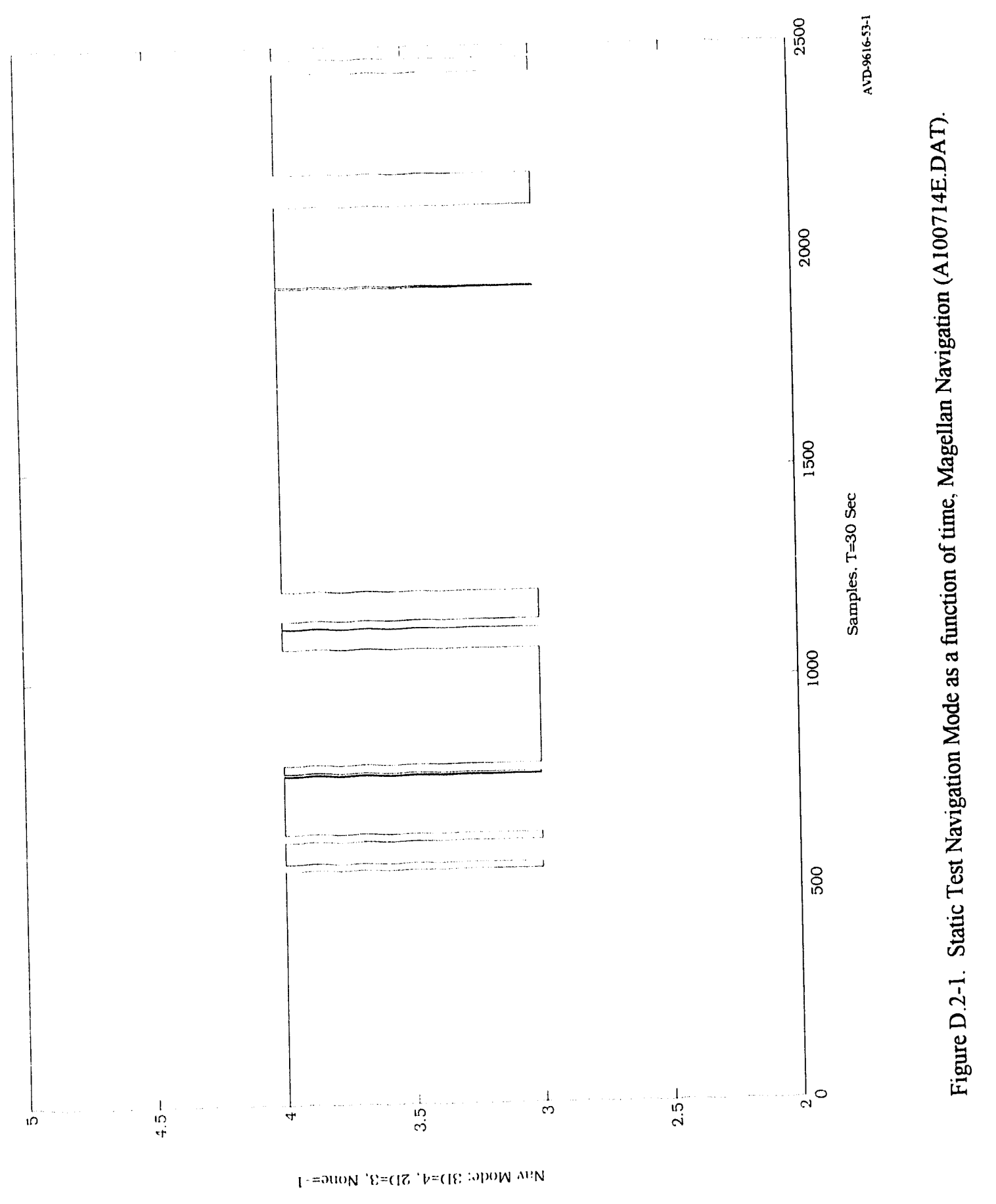

D. $2-4$ 


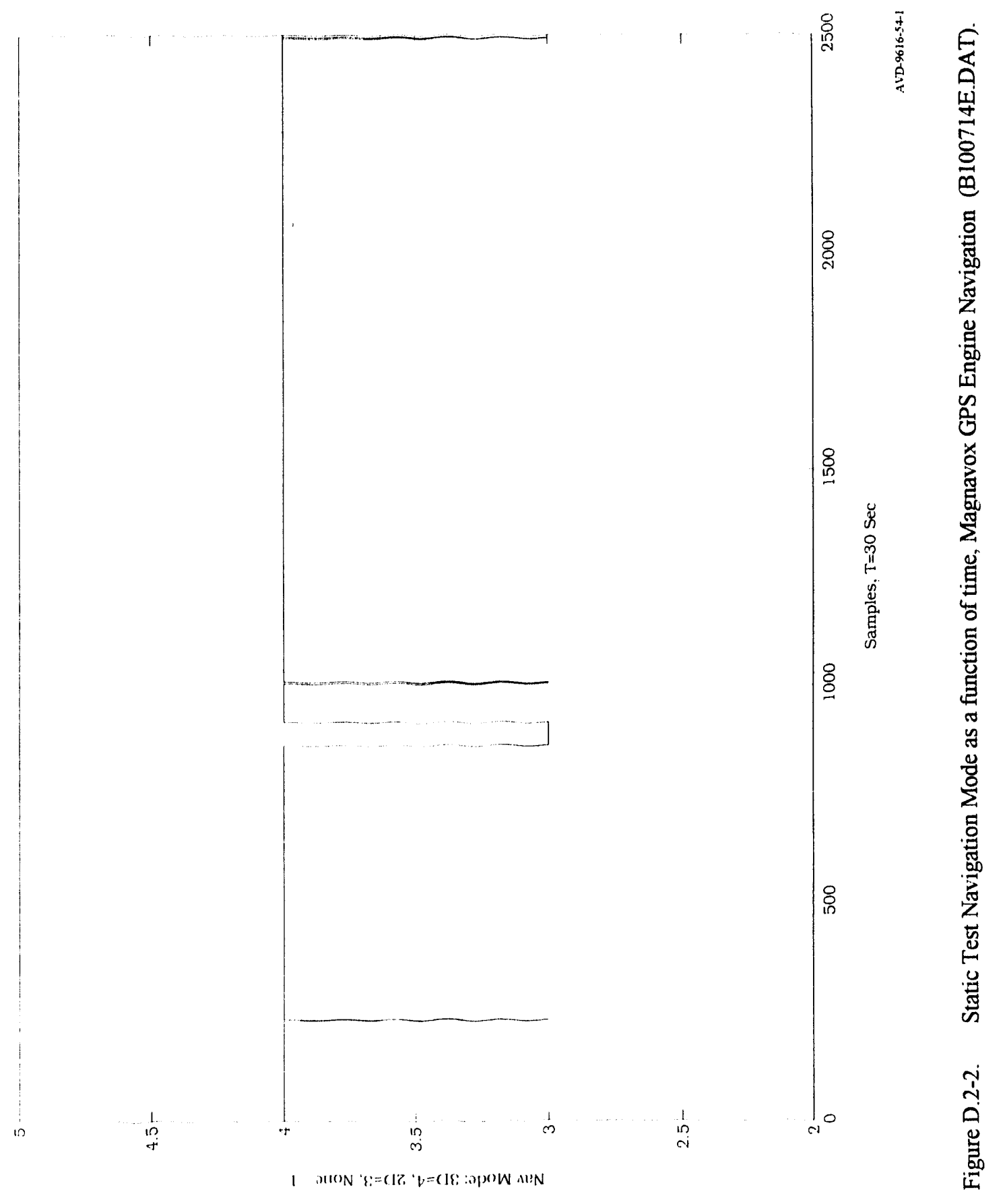

D. 2-5 

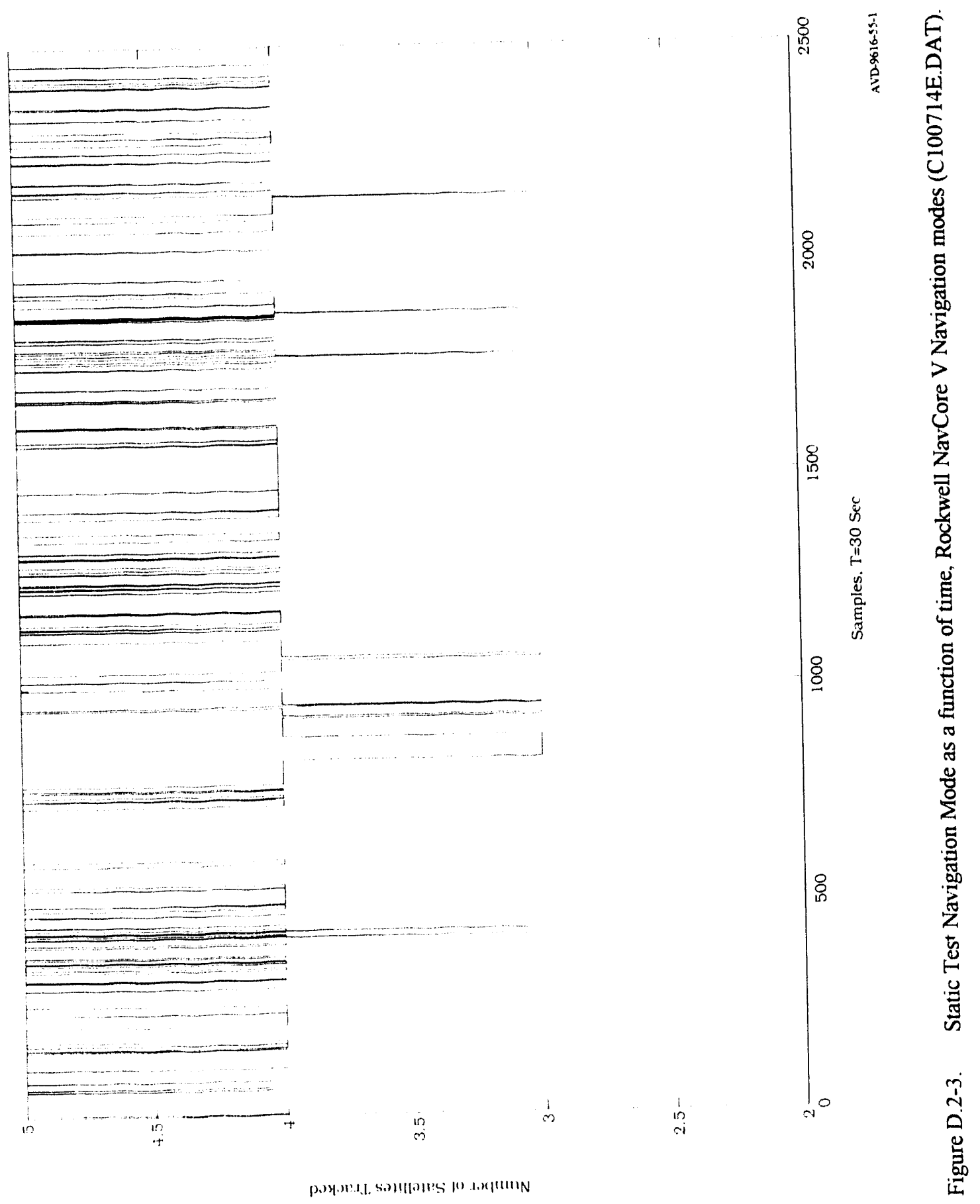

D. 2-6 


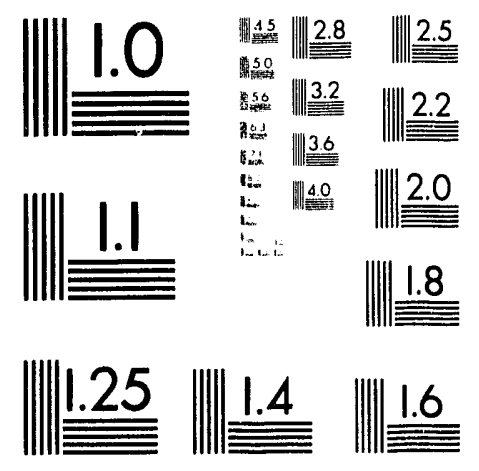



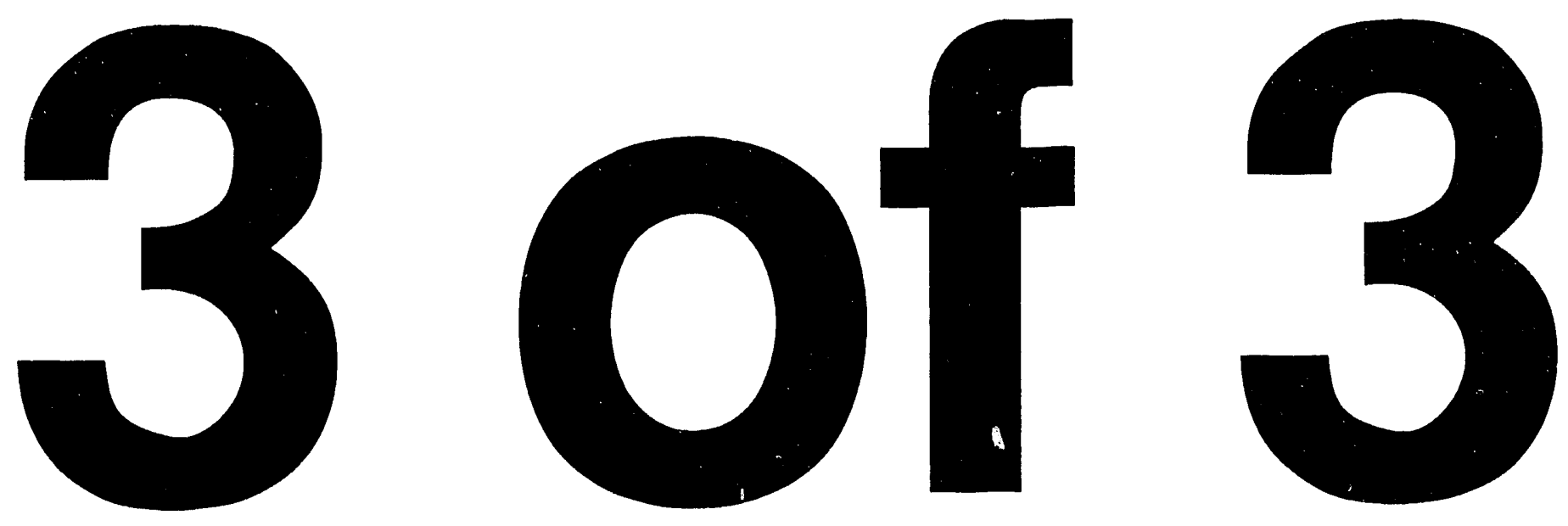


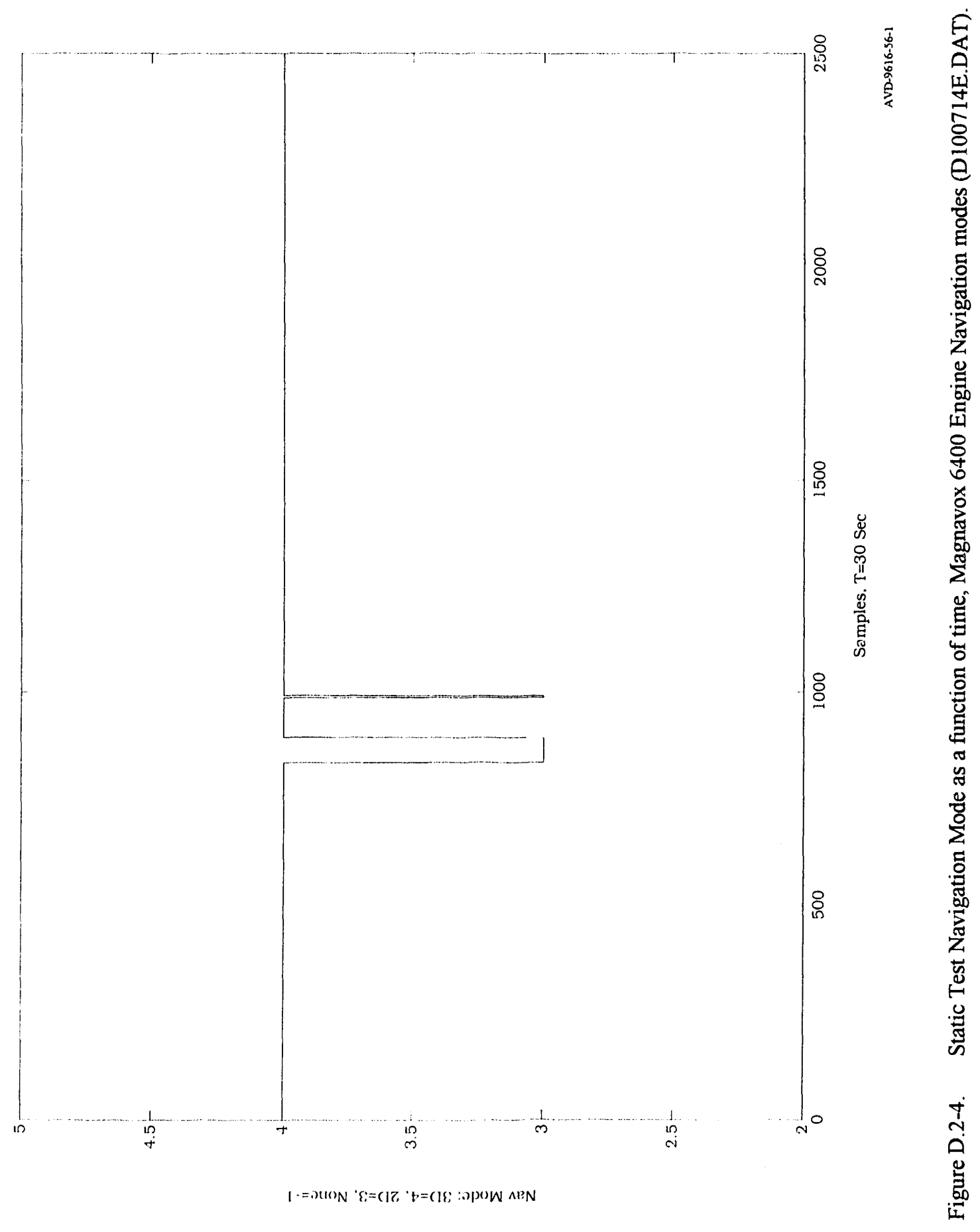

D. $2-7$ 


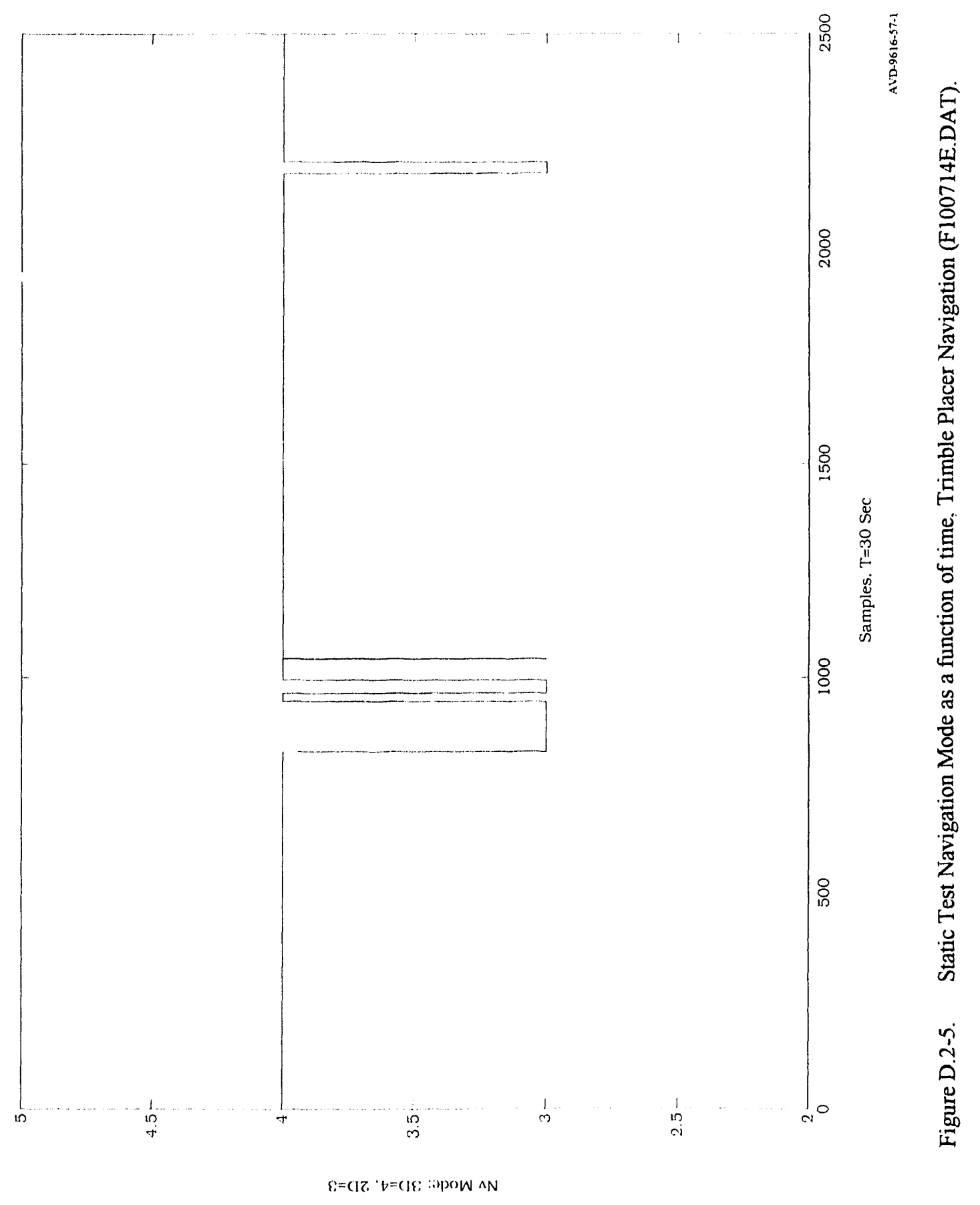


APPENDIX E: SAMPLES OF RAW DATA

Samples of Test Data taken during the GPS receiver experimental period

(July to October 1992) 
E-2 


\title{
APPENDIX E: SAMPLES OF RAW DATA
}

\author{
Magellan \\ \$GPGGA,201920,3502.43,N,10631.29,W,1,4,002,999,M,-023,M*68 \\ \$\$BPGÂA, पY̛ं\% \\ \$GPGGA,201950,3502.43,N, 10631.28,W,1,4,002,999,M,-023,M*6E

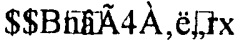

\section{Magnavox GPS Engine \\ \$PMVXG,021,332333.00,3502.4450,N, 10631.2908,W,01642.8,-023.0,0000.1,-000.1,03*71 \\ \$PMVXG,021,332363.00,3502.4423, N, 10631.2873,W,01627.9,-023.0,0000.3,-000.2,03*7E \\ \$PMVXG,021,332393.00,3502.4394,N,10631.2815,W,01615.2,-023.0,0000.3,-000.2,03*70 \\ \$PMVXG,021,332423.00,3502.4371,N, 10631.2751,W,01607.3,-023.0,0000.3,-000.1,03*79}

\section{Rockwell NavCore V}

25512910305800096125147351801297434153210145140208623014701002007147101790 149166209421341811511721138425415215014015820881941242382174412312037175127220 862001282462122521432812921521515924823713925138762330441124122301841326034 21420411758039267404328820050402053200007681155147

25512910305800096125147213179977834153210145842071342451470100200716110779 01491872041941331811516123716625415215031081008194127251263125146155612869151 128221231401432812971812124823713911225772330441124122301841326028214204117 580422674042289003150402053200007681193134

25512910305800096125147136179658234153210145322066515701002007175113790149 229101071331811518515425325315215018631708194127118222971272685154126172156160 1281481284914428129114200142248237139121129701880251057118101061282603121420 411758042267404139002750402052200007681250181

25512910305800096125147621791863415321014524820462015701002007139119790149 12833184132181151223342492531521503923112281941279315571238022651254932211128 126207361442812921104109248237139752016819100163118501131282603121420411758 0) 4226740413900285040205220000928142199

\section{Magnavox 6400}

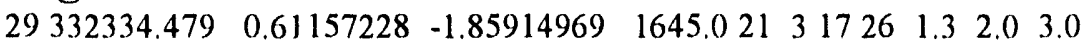

:O11911DB018EAEEB4405E000000000000006840005C000E9800290041

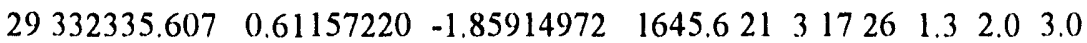

$\begin{array}{llllllllllll}29 & 332336.728 & 0.61157210 & -1.85914977 & 1645.8 & 21 & 3 & 17 & 26 & 1.3 & 2.0 & 3.0\end{array}$

\section{Trimble Placer}

$>$ RPV73170+3504044-1065214900003912;*78< $>$ RPV73200+3504046-1065213900003912;*79< $>$ RPV73230+3504052-1065213100003912;*77< $>$ RPV73260+3504058-1065211700103912;*7D< $>$ RPV73290+3504069-1065211200103912;*75< 


\section{APPENDIX F: GPS COMPANY CONTACTS}

List of the individual contacts,

who provide technical support and pricing information for the GPS receivers tested. 


\title{
APPENDIX F: GPS COMPANY CONTACTS
}

The following is a list of the individual contacts, who provide technical support and pricing information for the GPS receivers tested.

\author{
Magellan \\ Emile Yakoup \\ Magellan Systems Corp. \\ 960 Overland Court \\ San Dimas, CA 91773 \\ 909-394-6062
}

Magnavox Advanced Products and Systems

Eric Furlong

Magnavox Advanced Products and Systems

2829 Maricopa Street

Torrance, CA 90503

310-618-1200, Ext. 3056

\section{Rockwell International}

Larry Creech

Rockwell International

3200 East Renner Road

MS 461-235

Richardson, TX 75082

214-705-1704

\section{Trimble Navigation}

Jeff Jacobs (Qty Pricing)

408-481-2865

Joel Avey (Tech Support)

408-481-8927

Trimble Navigation

645 North Mary Avenue

Building 5

Sunnyvale, CA $94088-3642$ 


\section{DISTRIBUTION}

\section{Company Contacts}

1 Magellan Systems Corp. Attn: Emile Yakoup 960 Overland Court San Dimas, CA 91773

3 Magnavox Advanced Products and Systems Attn: Eric Furlong (3) 2829 Maricopa Street Torrance, CA 90503

1 Rockwell International Attn: Larry Creech 3200 East Renner Road MS 461-235

Richardson, TX 75082

1 Rockwell International Attn: Bob Knott Commercial GPS Business 3200 East Renner Road Richardson, TX 75082

1 Trimble Navigation Attn: Joel Avey 645 North Mary Avenue

Building 5

Sunnyvale, CA $94088-3642$

1 Ziatech Corporation

Attn: Dave Rennie

3433 Roberto Court

San Luis Obispo, CA 93401

\section{Additional Distribution}

1 Lt. Col. Mark Swinson

USMC

UGV/JPO

U.S. Army Missile Command (MICOM)

Attn: AMSMI-RD-UG (AMC-PM-UG)

Redstone Arsenal, Bldg. 5410

Huntsville, Alabama 35898
1 Russell Garnsworthy

Australian Associated Technologies Ptg Limited

Level 32

600 Bourke St.

Melbourne, Australia 3000

2 Tech Reps, Inc.

Attn: M. Minahan

B. Grant

5000 Marble NE, Suite 222

Albuquerque, NM 87110

\section{Sandia Internal}

$\begin{array}{lll}1 & 1602 & \text { R.W. Harrigan } \\ 1 & 2346 & \text { A.L. Schauer } \\ 1 & 9600 & \text { J.R. Kelsey } \\ 1 & 9602 & \text { D.L. Caskey } \\ 1 & 9603 & \text { E.R. Hoover } \\ 1 & 9604 & \text { S.C. Roehrig } \\ 1 & 9613 & \text { R.C. Wahlberg } \\ 1 & 9615 & \text { R.C. Ghormley } \\ 5 & 9615 & \text { K.T. Malone } \\ 1 & 9615 & \text { L. Scott } \\ 1 & 9615 & \text { L. Riblett } \\ 1 & 9616 & \text { B.C. Caskey } \\ 20 & 9616 & \text { R.H. Byrne } \\ 1 & 9616 & \text { J.B. Pletta } \\ 1 & 9616 & \text { R.K. Cover } \\ 1 & 9616 & \text { F.K. Wunderlin } \\ 3 & 8523-2 & \text { Central Technical Files } \\ 3 & 7151 & \text { Technical Publications } \\ 10 & 7613-2 & \text { Document Processing } \\ & & \text { for DOE/OSTI } \\ 5 & 7141 & \text { Technical Library }\end{array}$



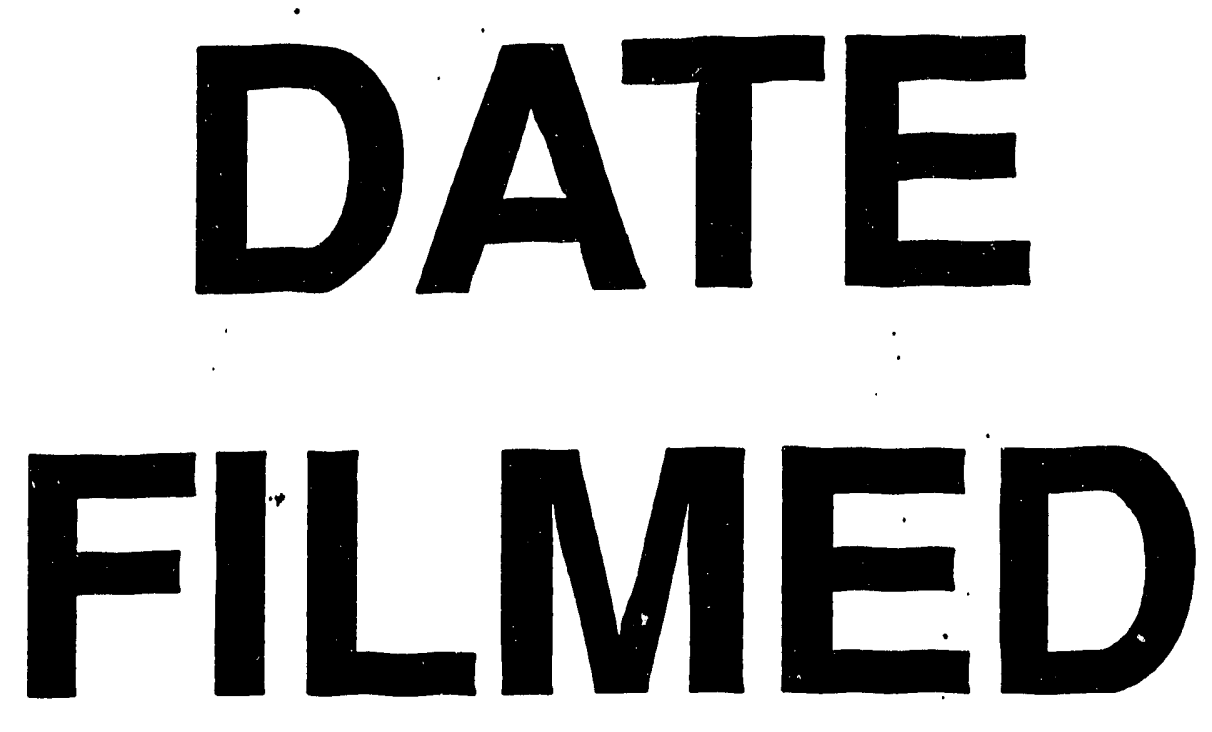

$12 / 27 / 93$
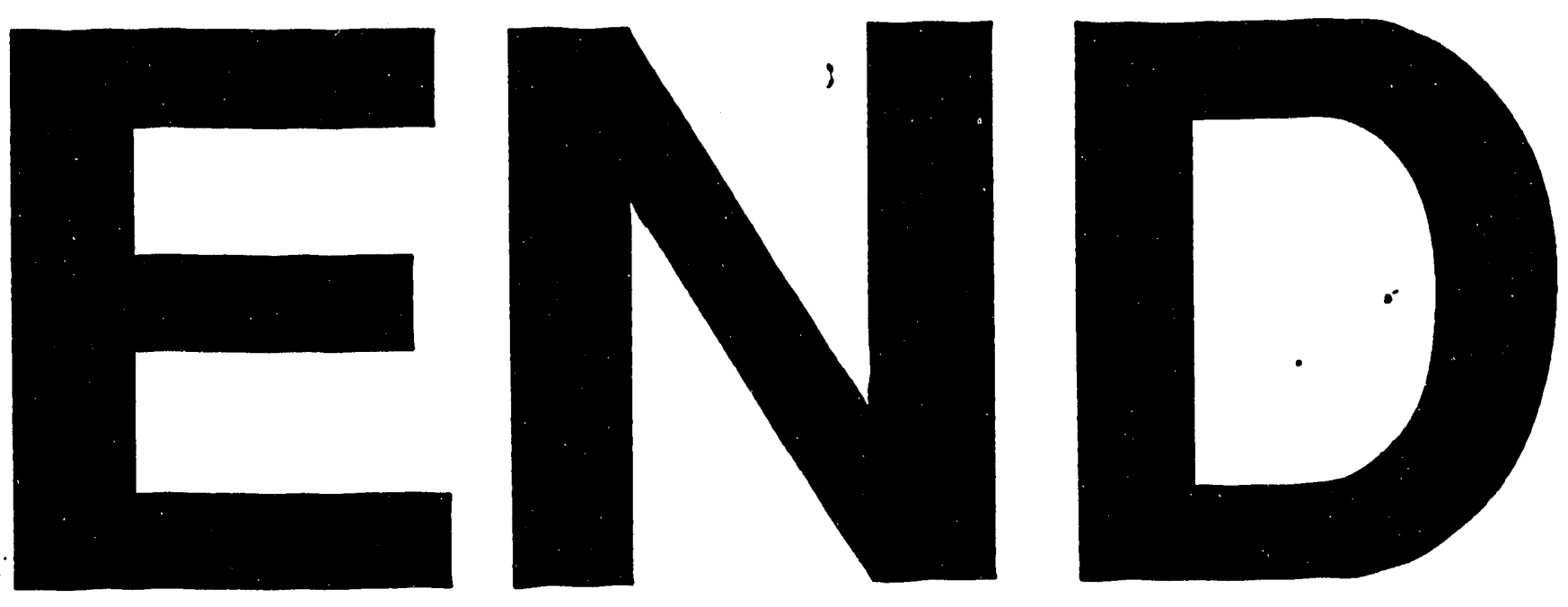


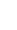

